\title{
Talent Identification and Development in Sport
}

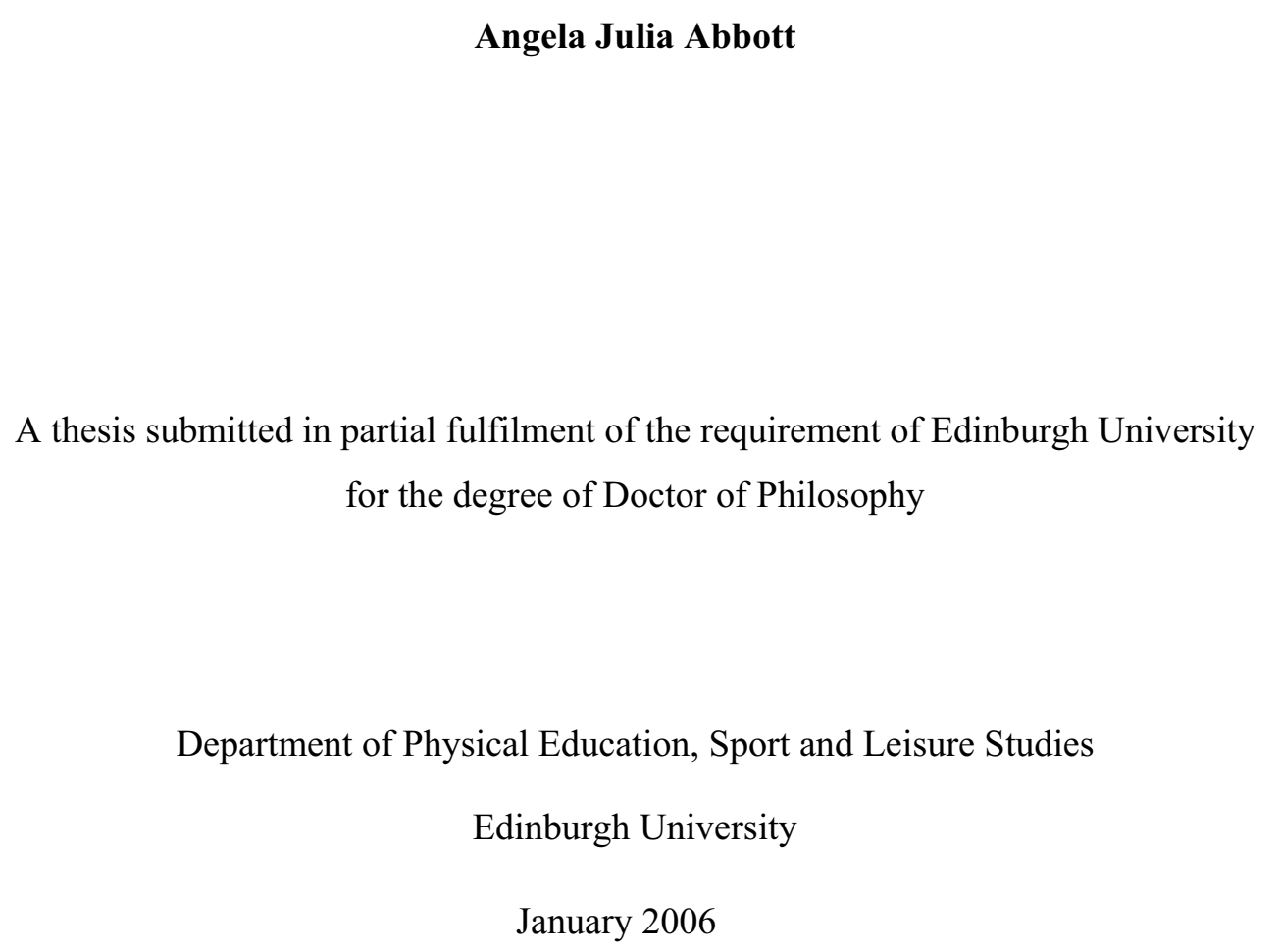

Doctor of Philosophy - The University of Edinburgh - 2006 
NAME OF STUDENT: Angela Julia Abbott

THESIS TITLE: Talent Identification and Development in Sport

DEGREE: $\mathrm{PhD}$

LENGTH OF THESIS: 65,871 words

This thesis is my own original work and has not been accepted in substance for any degree or award, and is not being submitted concurrently in candidature for any other degree or award.

Signed:

Date:. 


\section{TABLE OF CONTENTS}

ACKNOWLEDGEMENTS...................................................................................

CHAPTER 1 INTRODUCTION _....................................................... 1

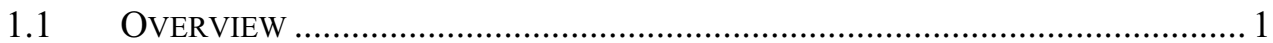

1.2 Characteristics of DeVElopment AND ExCELlence (Chapter 2) ........ 7

1.3 The Current Context: Conceptual and Practical Models of

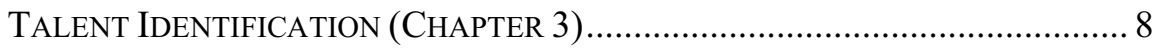

1.4 How do Traditional TI Processes EMPLOYED IN SPORT DO IN

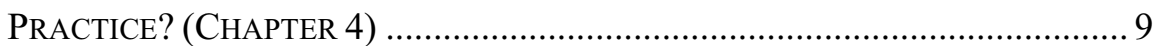

1.5 How SHould TALENT Be IDENTIFIED AND DEVELoped: THEORETICAL AND DeVElopMental CONSIDERATIONS (CHAPTER 5)

1.6 Developing a Multi-Dimensional and Dynamic TID Model (Chapter 6)

1.7 Translating Theory to Practice: Systems AND Resources (CHAPTER 7). 10

1.8 Evaluation of the Multi-Dimensional and Dynamic TiD Model (CHAPTER 8) 10

1.9 CONCLUSIONS AND Future DiReCTIONS (CHAPTER 9) 10

CHAPTER 2 CHARACTERISTICS OF DEVELOPMENT AND

EXCELLENCE 11

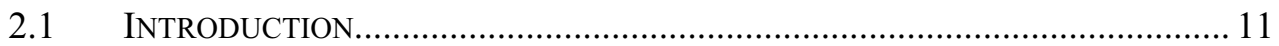

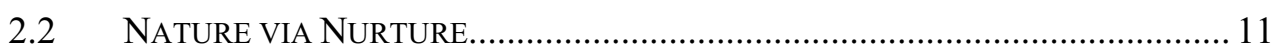

2.3 ChARACTERISTICS OF ELITE ATHLETES ……........................................... 17

2.3.1 Physiological and anthropometric correlates of success ................. 17

2.3.2 Fundamental movement skills ..................................................... 28

2.3.3 Psychological determinants of excellence ........................................ 33

2.4 SUMMARY OF RESEARCH ON DETERMINANTS OF EXCELLENCE ................... 44

CHAPTER 3 THE CURRENT CONTEXT: CONCEPTUAL AND PRACTICAL MODELS OF TALENT IDENTIFICATION ..................................45 


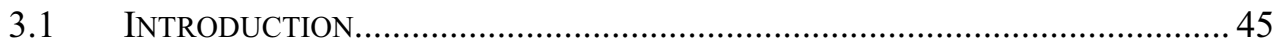

3.2 A REVIEW of CONCEPTUAL MOdELS OF TALENT IDENTIFICATION.............. 45

3.2.1 Traditional models of identifying talent ............................................. 45

3.2.2 An Alternative model for identifying and developing talent .............. 49

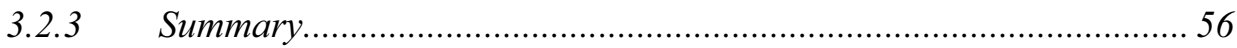

3.3 A Review of Talent Identification Processes Employed in Practice

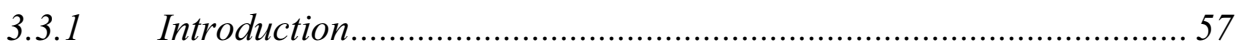

3.3.2 The problem with natural selection processes ................................... 58

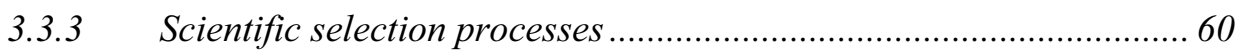

3.3.4 The empirical basis of Talent Search …................................................ 67

3.3.5 The role of Talent Search in the sporting success of Australia ......... 69

CHAPTER 4 TALENT SEARCH: AN EMPIRICAL ANALYSIS OF A TRADITIONAL APPROACH TO IDENTIFYING THE TALENTED ........ 75

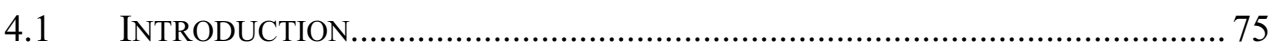

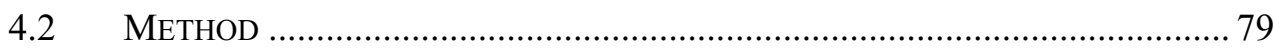

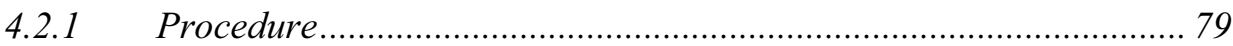

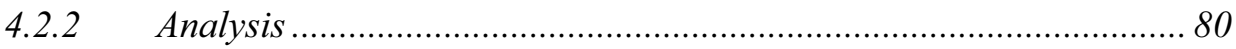

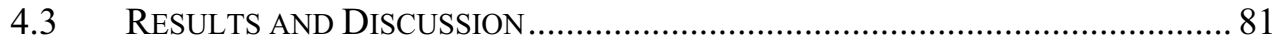

4.3.1 Criterion one: ability to discriminate between performances on tasks .

4.3.2 Criterion two: interpretation of scores by comparison with a

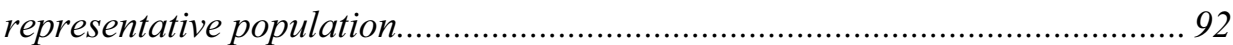

4.3.3 Criterion three: appropriateness of the algorithms employed to direct children towards different sports .................................................................. 98

4.3.4 Criterion four: relative stability ……………................................. 99

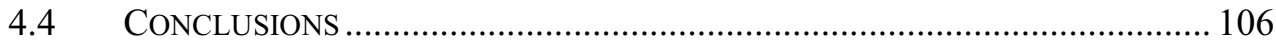

CHAPTER 5 HOW SHOULD TALENT BE IDENTIFIED AND

DEVELOPED? EXPERIENCES OF WORLD-CLASS ATHLETES ..............107

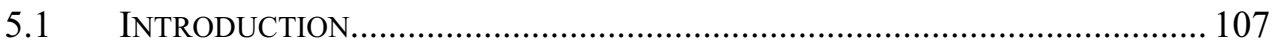

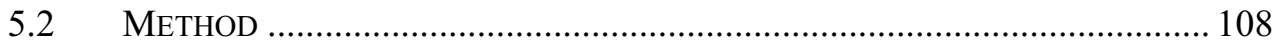




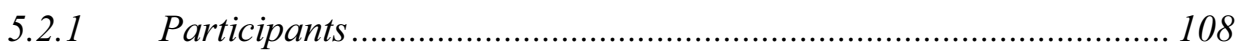

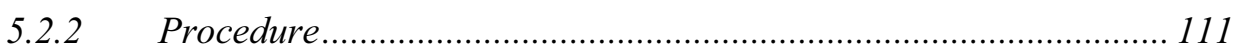

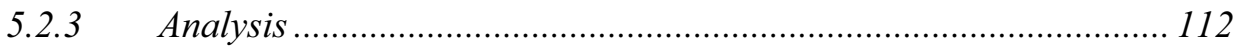

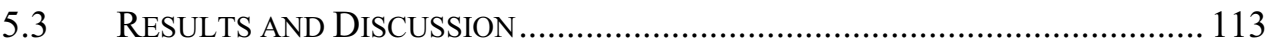

5.3.1 Early sporting experiences......................................................... 113

5.3.2 Factors perceived to underpin sporting talent ............................... 126

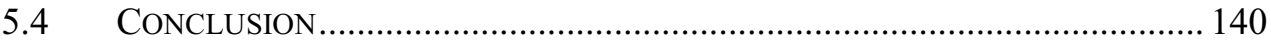

CHAPTER 6 DEVELOPING A MULTI-DIMENSIONAL AND

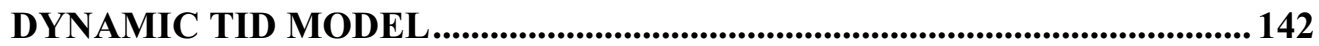

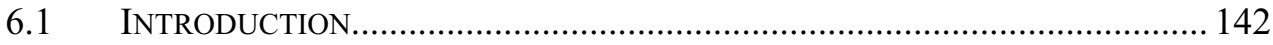

6.2 THEORETICAL CONSIDERATIONS: BASING IDENTIFICATION ON A REVISED

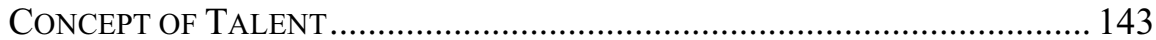

6.2.1 Performance and developmental dispositions ................................ 143

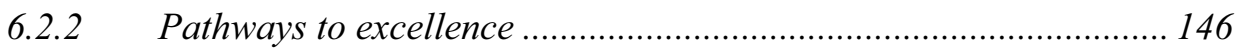

6.2.3 Successful transition from one stage of development to another.... 148

6.2.4 Interaction of elements...................................................................... 151

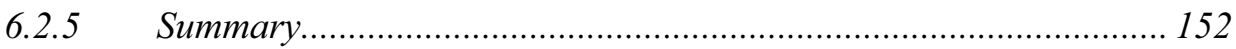

CHAPTER 7 TRANSLATING THEORY TO PRACTICE:

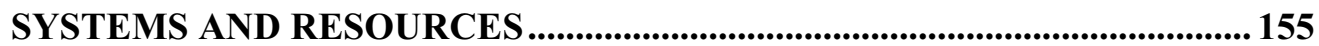

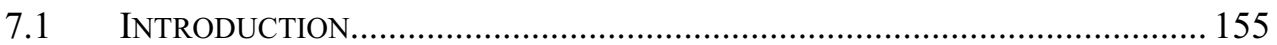

7.1.1 The current context: the role of Physical Education ....................... 155

7.1.2 Transferring the philosophy into sport specific contexts ................. 158

7.2 MAterials for APPlying the PrinciPles UnderpinNing THE PROPOSED

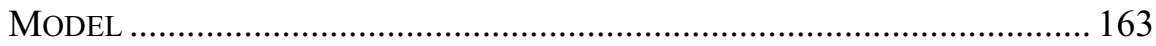

7.2.1 Development of psycho-behavioural characteristics ....................... 163

7.2.2 Summary on the development of psycho-behavioural characteristics...

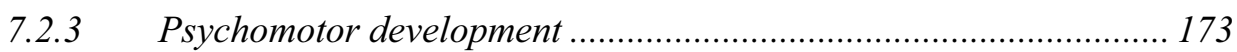

7.2.4 Summary on psychomotor development .......................................... 181

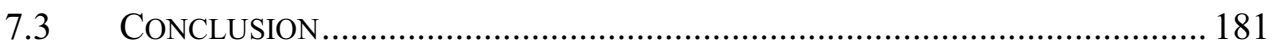




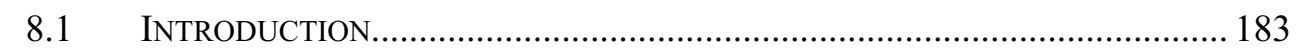

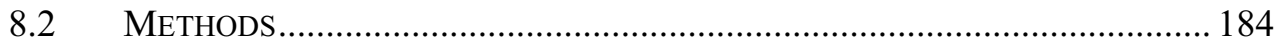

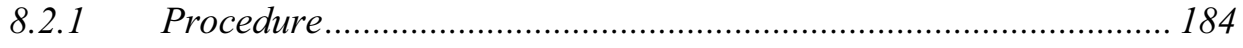

8.2.2 Evaluation of the programme impact.............................................. 189

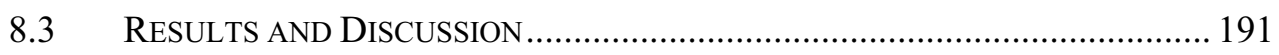

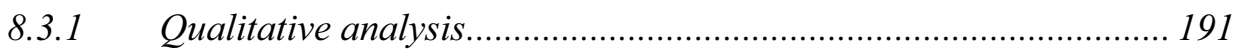

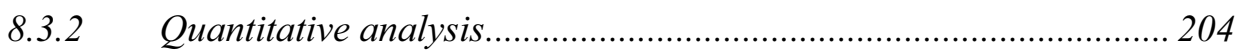

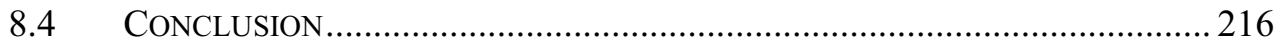

CHAPTER 9 CONCLUSIONS AND FUTURE DIRECTIONS ...... 219

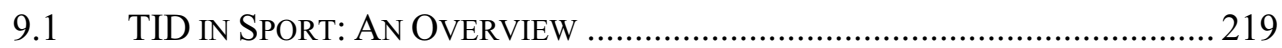

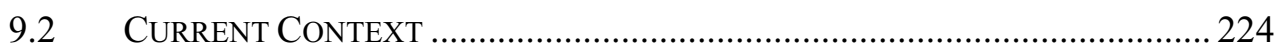

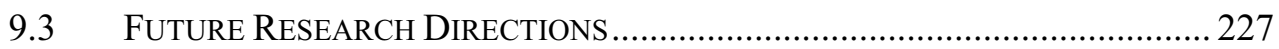

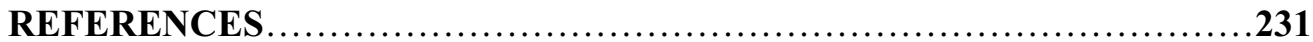

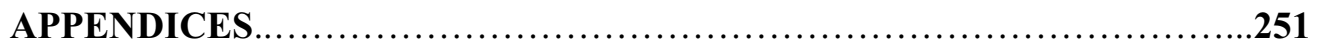

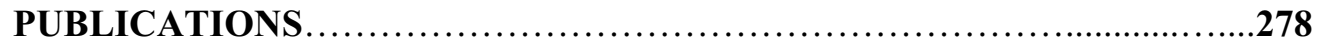




\section{FIGURES}

Figure 1.1 Proportion of available medals gained by GB and Northern Ireland in the Olympics between 1948 and 2000

Figure 1.2 Perceived potential of talent identification procedures to contribute to international success and mass participation (adapted from Strategy Unit, 2002, p.83)

Figure 2.1 Relative importance of psychological, motor and biometric factors for talent identification and performance in Wrestling (adapted from Kunst \& Florescu, 1971).

Figure 4.1 Histograms and normal distribution curves for raw scores on the physical tasks

Figure 4.2 Histograms and normal distribution curves for raw scores on the performance tasks

Figure 4.3 Histograms demonstrating an increasingly normal distribution of performance on the catch task with increasing age.

Figure 4.4 Frequency with which males and females were classified within each percentile group on a selection of the Sport Interactive tasks.

Figure 4.5 Cross-sectional representation of dynamic growth patterns of 12 children between the age of 11 and 14 years 102

Figure 6.1 Proposed contribution of physical, motor and psychological dispositions to the development and performance of an athlete 146

Figure 6.2 Stages of development previously identified within sport (adapted from Bloom, 1985, Kreiner-Phillips and Orlick, 1992, \& Cote, 1999).

Figure 6.3 The role of psycho-behavioural characteristics in facilitating the successful negotiation of developmental transitions

Figure 6.4 A proposed multi-dimensional and dynamic model of talent identification and development in sport 154 
Figure 7.1 Proposed System for Promoting a Coherent and Theoretically Driven Approach to TiD within Sport

Figure 7.2 Example of level one psycho-behaviour activity. 169

Figure 7.3 Example of level two psycho-behaviour activity 170

Figure 7.4 Examples of how imagery could be effectively employed during training and competition in gymnastics (Level 3) 172

Figure 7.5 Examples of effective coach systems and behaviours for promoting the application of imagery within training in gymnastics (Level 3). 172

Figure 7.6 Level one psychomotor example card: catching 178

Figure 7.7 Level two psychomotor example card: object control during invasion games

Figure 7.8 'Level three' card showing how 'level one' and 'level two' psychomotor resources can be employed by football coaches 180

Figure 8.1 Cross-sectional analysis conducted on North Ayrshire data 205

Figure 8.2 Level three quantitative analysis 209

Figure 8.3 Longitudinal data analysis conducted in Stirling 210

Figure 8.4 Mean changes in baseline self-determination values following involvement in the DPYPS programme for primary seven Stirling children .. 213

Figure 8.5 Mean changes in baseline perceived physical competence values following involvement in the DPYPS programme for primary seven Stirling children.

Figure 8.6 Mean changes in baseline self-motivation values following involvement in the DPYPS programme for primary seven Stirling children

Figure 8.7 Mean changes in baseline self-determination values following involvement in the DPYPS programme for primary seven North Ayrshire children. 
Figure 8.8 Mean changes in baseline perceived physical competence values following involvement in the DPYPS programme for primary seven North Ayrshire.

Figure 8.9 Mean changes in baseline self-motivation values following involvement in the DPYPS programme for primary seven North Ayrshire children

Figure D.1 Overview of the interview conducted with teachers at the conclusion of the DPYPS programme 258

Figure D.2 Overview of the interview conducted with children at the conclusion of the DPYPS programme 261

Figure E.1 Questionnaire used to measure self-motivation, perceived physical competence and self-determination (compiled using items from the SelfMotivation Inventory modified for children (SMI-C) (Biddle et al, 1996), perceived physical competence scale of the Self-Description Questionnaire (SDQ) (Marsh, 1990, 1996) and Locus of Causality for Exercise Scale (Markland \& Hardy, 1997)

Figure E.2 The Young Peoples Physical Activity Questionnaire (Jess, 1999b).....267 


\section{TABLES}

Table 1.1 Advantages of Using Scientific Criteria in the Process of Talent Identification (adapted from Bompa, 1999).

Table 3.1 Olympic Medal Table Position of Cuba, USSR and GDR/ Germany from

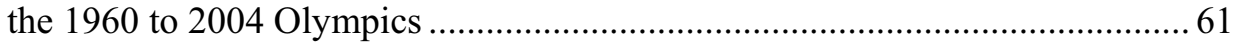

Table 3.2 Battery of Tests Administered within Talent Search (1994) ..................... 66

Table 3.3 Athlete Achievements in Talent Search 1994-97 f................................... 70

Table 4.1 Attributes Employed as Talent Criteria within Sport Interactive .............. 77

Table 4.2 Quotes used within the Sport Interactive Manual as Rationale for the Inclusion for Each of the 11 Tasks within Sport Interactive (adapted from the Talent Search manual, Australian Sport Commission, 1993) ............................. 78

Table 4.3 Example of Algorithms Employed for Calculating a Child's Performance Capabilities across 12 Sports 83

Table 4.4 Biased Sport Recommendation: Percentage of Time that Sport Interactive Recommended Twelve Sports as the Most Appropriate or One of the Three Most Appropriate Sports for an Individual

Table 4.5 Rank Correlation on Sport Interactive Tasks over a One-Year Period.... 104

Table 4.6 Correlation between the Physical and Performances Factors in Sport Interactive 105

Table 5.1 Demographic and Sporting Information for the Athletes Interviewed .... 110

Table 5.2 Key Themes Explored in Semi-Structured Interviews 112

Table 5.3 Themes and Sub-Themes Related to Early Sporting Experiences that Emerged from the Athlete Interviews

Table 5.4 Themes and Sub-Themes Related to Successful Development in Sport that Emerged from the Athlete Interviews 
Table 7.1 Concepts and Objectives Promoted within the Psycho-Behavioural Level One Curriculum.

Table 7.2 Concepts and Objectives Promoted within the Level Two PsychoBehavioural Curriculum

Table 8.1 Number of Participants and Personnel Interviewed about the DPYPS Programme

Table A.1 Algorithms used within the Talent Search/ Sport Interactive Programs to calculate sport recommendations for females 250

Table A.2 Algorithms used within the Talent Search/ Sport Interactive programs to calculate sport recommendations for males 252

Table B.1 Overview of the semi-structured interview conducted with successful athletes and significant others 


\section{EQUATIONS}

Equation 3.1: Simonton's proposed formula for Talent (from Simonton, 1999, p.443)

51 


\section{Acknowledgements}

I would like to thank all those who made this journey possible. Thanks are extended to Prof. Dave Collins for his support and guidance through-out the PhD process. I would also like to thank sportscotland for their support and in particular Lawrie Randak and Elaine Wolstencroft. A special thanks to the teachers from North Ayrshire and Stirling with whom I interacted during this project. Without your enthusiasm and willingness to step out of the comfort zone this research would not have been possible. A special thanks to Russ, Katie, Rob and Lynsey for your support and input through-out this research.

I would also like to acknowledge all the participants who took part in this research. A special thanks to athletes and their parents for their willingness to reflect openly on their personal experiences.

Thank-you to my parents for their support throughout my 'extended' education. Finally, thank-you Chris for your support, valuable insights and enduring patience. 


\section{Abstract}

The early identification of talented individuals is considered increasingly important across many performance domains. Traditional concepts of talent have primarily emphasized genetically driven variables, proclaiming that exceptional abilities are the result of favourable genes matched to the required performance domain. Consequently, an oversimplified concept of sporting talent exists where the focus has typically been on discrete, one-dimensional measures at unstable periods in the athlete's development. Talent identification processes adopted by several countries around the world have evolved from this oversimplified concept of talent and are unlikely to reflect adequately how talent emerges in sport. In fact, retrospective interviews with successful athletes emphasized that a range of factors impact success within sport and these are not solely governed by genetic determinants of performance. In particular, athletes highlighted the crucial role that psychology can have on the ability of an individual to translate potential to performance. It is concluded that TI models need to place a greater emphasis on the development of potentially talented performers rather than early identification. In this thesis, the concept of talent is revised as a complex, dynamical system in which future behaviours emerge from an interaction of key determinants such as psychobehavioural characteristics, motor abilities, and physical characteristics. A generic model of talent identification and development (TID) that addresses these issues, and resources that enable its practical application, is proposed. Initial findings from this pilot study are discussed and implications for further work are provided. 


\section{CHAPTER 1 INTRODUCTION}

The perfecting of one's self is the fundamental base of all progress and all moral development.

Confucius, BC 551-479, Chinese Ethical Teacher, Philosopher

\subsection{Overview}

International success in sport is considered by many as the pinnacle of human achievement. Sporting events such as the Olympic Games are followed by billions of people from all around the world and present prime opportunities for nations to gain worldwide recognition and prestige. Data offered by the International Olympic Committee reports that over 11,000 athletes from 202 countries participated in the 2004 Olympic Games in Athens and the Games were watched by an estimated 4 billion television viewers. It is widely accepted by governments, the media and the public that the International Olympic Committees medal table is an indicator of a nation's success (Sport Industry Research Centre, 2003). Therefore, success within the Olympic Games, and other international sporting events, has become a priority for countries around the world. However, whilst the Olympic Games have expanded and medal winning opportunities have increased, performance by GB and NI athletes has been relatively static leading to a loss in the proportion of available medals won since 1950 (see Figure 1.1).

Investment in elite sport within Britain has considerably increased since the 1996 Olympic Games in Atlanta (Sport Industry Research Centre, 2003). For example, the introduction of the National Lottery scheme in 1993 has resulted in increased investment in the development of talented British athletes. If such investments are to have a positive influence on British sport, it is apparent that they must be targeted towards athletes that have the greatest potential of producing successful performances at major international events. A thorough understanding of the determinants of successful development and performance in sport would facilitate 
the identification of the most talented athletes and enable sport policy makers to make rational allocations and long-range planning decisions concerning funding. Unfortunately, limitations of current procedures for identifying talented athletes have been reported and it has become apparent that potential talent is often overlooked and scarce resources inappropriately allocated (Helsen, Hodges, Van Winckel, \& Starkes, 2000). Concerns with TI processes are not limited to sport and have been reported across performance domains including dance (Baum, Owen, \& Oreck, 1996), art (Clark \& Zimmerman, 1984) and education (Rimm, 1984; Rimm, Davis, \& Bien, 1982).

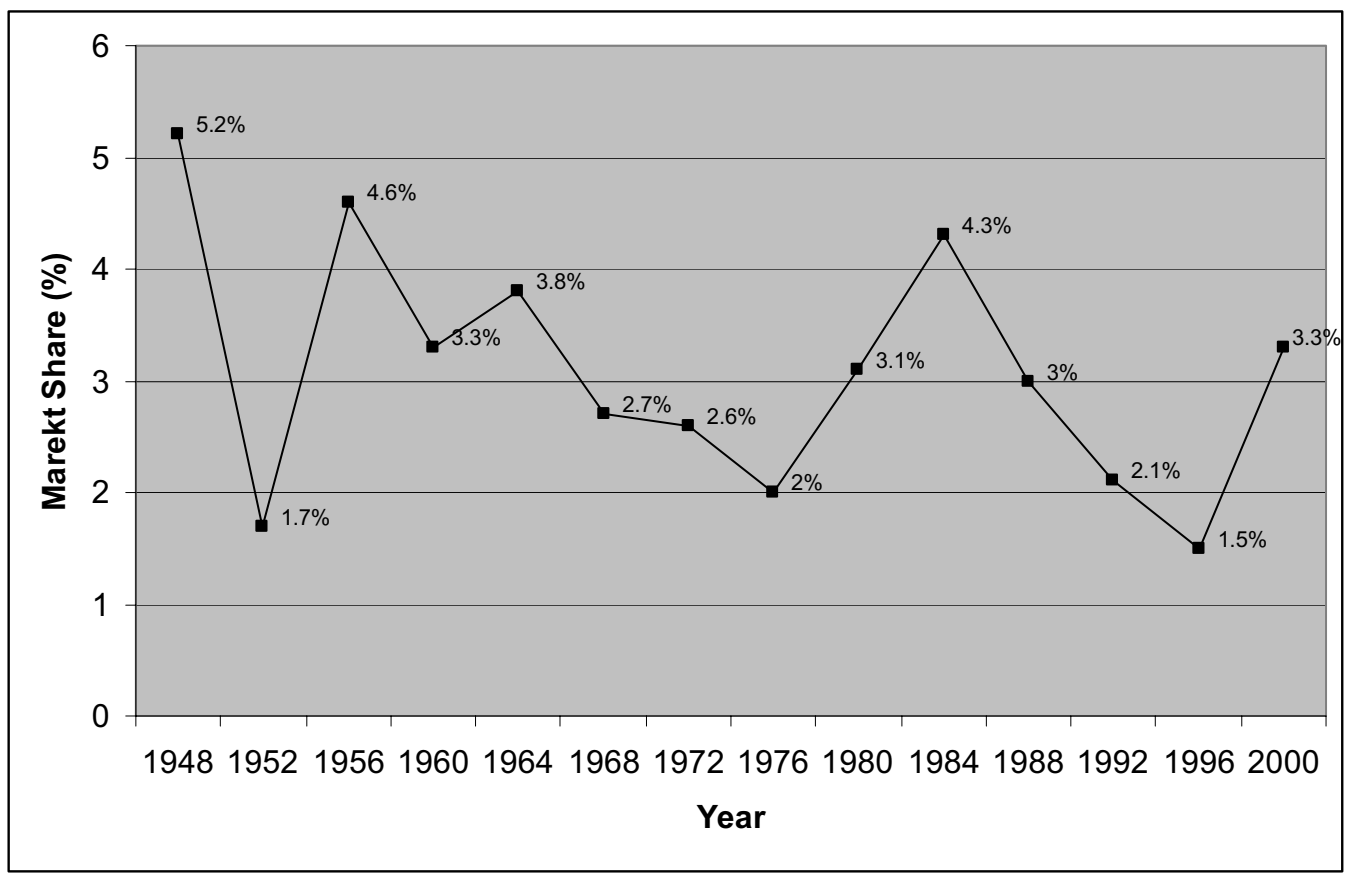

Figure 1.1 Proportion of available medals gained by GB and Northern Ireland in the Olympics between 1948 and 2000

There are two predominant methods that broadly capture how talented athletes are currently identified within sport: (a) natural selection, and (b) scientific selection (Bompa, 1999). 'Natural selection' is aimed at identifying talented individuals that are already participating within a sport due to the recognition of performance or 
scouting. As such, 'natural selection' processes rely on talented individuals to 'happen upon' the sport they are most likely to excel in even though involvement may result purely from peer or parental interests, proximity of facilities, or of the sport's popularity in that geographical area. As an example of how the popularity of a sport can affect participation, consider basketball participation within the US, one of the top three sports for this country. Greenberg (1999) reported that every year 20,000 collegiate level basketball players attempt to join the professional ranks. Clearly, the time, money, and staff required to support the long-term commitment required of all of these athletes is not available and some selection must occur. In fact, Greenberg highlights how only $0.3 \%$ of the original 20,000 hopefuls sign contracts with professional teams. In contrast, young athletes are less likely to become involved in less popular sports, even though their talent may be greater within these sports. Whilst the ability of scouts or coaches to identify talented individuals should never be underestimated, it is a very subjective process (Williams \& Reilly, 2000), and the odds against identifying children who have the talent to become a successful adult performer are likely to be enormous. Against this backdrop, considerable interest currently exists with regards to the potential of establishing 'scientific selection' processes.

'Scientific selection' processes can be viewed as a more proactive procedure by which identification of the talented occurs as a result of testing individuals on values that are associated with expertise within a certain sport. For example, what are the physical, physiological and psychological attributes that affect performance within football or sprinting? By using scientific research to identify the criteria that elite athletes possess, and the optimum environment for nurturing these criteria, resources can be targeted at those individuals that have the greatest potential of becoming outstanding performers. In fact, the early identification of the talented has been highlighted as one of the most important concerns of contemporary sport (Bompa, 1985, 1990; Harre, 1982). Bompa (1999) also presented a list of the advantages of utilising science to identify excellence within sport (see Table 1.1). Alongside this appeal, is the perceived potential of TI procedures to also generate increased health 
benefits and contribute to "reduced NHS costs, reduced absenteeism and possible increases in productivity" (Strategy Unit, 2002p.83, see Figure 1.2).

\section{Table 1.1}

Advantages of Using Scientific Criteria in the Process of Talent Identification (adapted from Bompa, 1999)

Advantages of Using Scientific Criteria in the Process of Talent Identification

Substantially reduces the time required to reach high performance by selecting individuals who are gifted in sport

Eliminates a high volume of work, energy, and talent on the part of the coach. The coach's training effectiveness is enhanced by training primarily those athletes with superior abilities

Increases competitiveness and the number of athletes aiming at and reaching high-performance levels. As a result, there is a stronger and more homogenous national team capable of better international performance

Increases an athlete's self confidence, because his or her performance dynamics are known to be more dramatic than other athletes of the same age who did not go through the selection process

Indirectly facilitates applying scientific training, because sport scientists who assist in talent identification can be motivated to continue to monitor athletes training. 


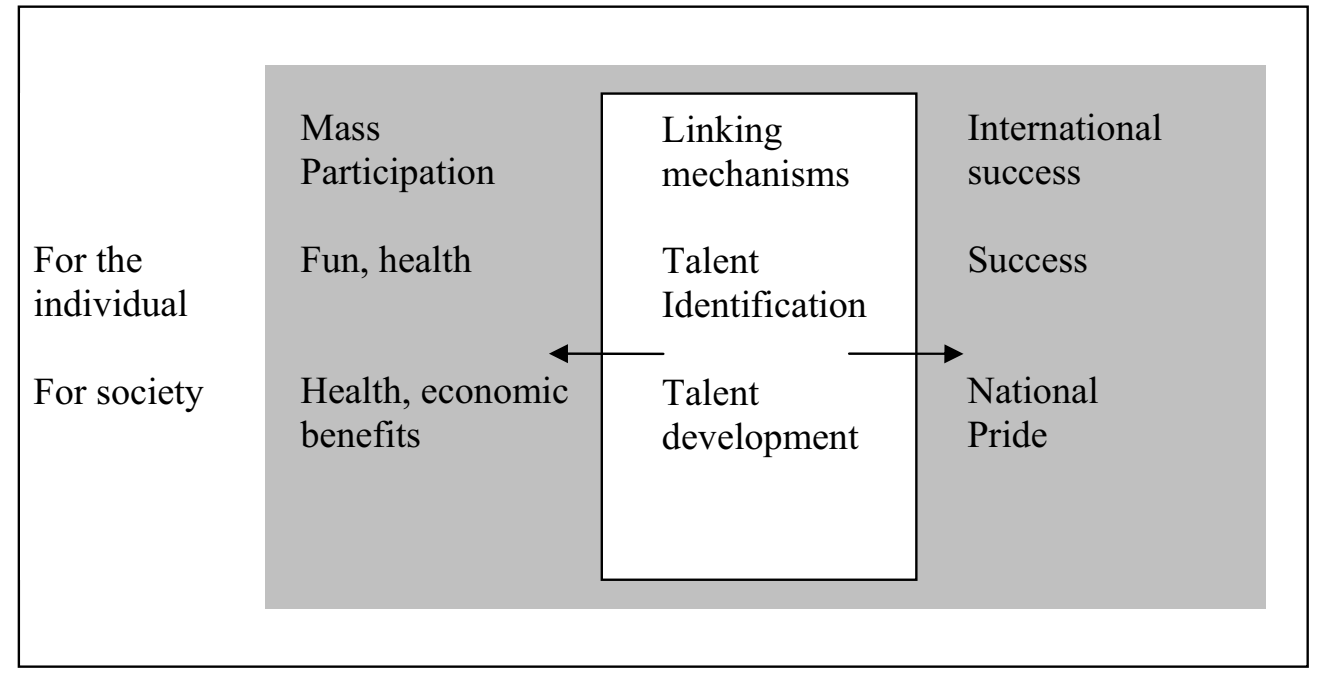

Figure 1.2 Perceived potential of talent identification procedures to contribute to international success and mass participation (adapted from Strategy Unit, 2002, p.83)

The appeal of establishing a 'scientific' talent identification process has led to many nations looking at strategies being employed by countries that typically excel at major international sporting events (e.g., Australia). Consequently, considerable resources have been expended across the world in attempting to transfer TI processes to less successful sporting nations. Despite such trends, limited conclusive research has been reported on determinants of excellence. In fact, Holyoak (1994) highlighted "a disconcerting lack of constancy in the correlates of expertise" (p.309). Further, little proof exists that TI strategies have contributed to the accomplishment of successful sporting nations (Hill, 2002; Regnier, Salmela, \& Russell, 1993). Therefore, caution should be exercised when downloading TI processes from one country to another and considerable focus given to establishing the empirical basis for the criteria being employed to identify sporting talent. When looking to implement other country's talent identification programmes, consideration should also be given to the unique constraints (e.g., population size, sport development structure, the link between school and community sport, availability of funding, etc.) that are likely to be experienced by different nations as they pursue sporting excellence. 
In summary, a scientific process that enables talented athletes to be identified is clearly appealing. However, the $\$ 64,000$ question remains; is there an optimally effective means of TI and, if so, what is it? Consequently, the purpose of this research is to identify those factors that influence the talent identification and development (TID) process and the implications for establishing scientific TI processes. Accordingly, this thesis considers attributes that underpin the successful development and performance of individuals within sport and implications for talent identification and development processes. The specific objectives of the thesis were:

i. To identify those attributes that research has highlighted impact the capacity of individuals to develop into successful international athletes

ii. Based on current knowledge regarding determinants of development and performance in sport, to theoretically analyse current TI approaches employed within sport

iii. To empirically evaluate the effectiveness of a traditional approach being employed to identify talent within sport

iv. To develop a theoretically driven approach to identifying and developing talent within sport

v. To empirically evaluate the effectiveness of the proposed method for identifying talent within sport.

vi. To provide future recommendations for personnel involved in the identification and development of athletes

In order to meet these objectives, the research programme was sub-divided into 8 main parts: (a) Characteristics of development and excellence, (b) The current context: conceptual and practical models of talent identification, (c) Talent Search: An empirical analysis of a traditional approach to identifying the talented, (d) How should talent be identified and developed: Experiences of world-class athletes, (e) Developing a multi-dimensional and dynamic TID model, (f) Translating theory to practice: Systems and resources, (g) Evaluation of the multi-dimensional and 
dynamic TID model, and (h) Conclusions and future directions. A brief outline of each of these sections follows.

\subsection{Characteristics of Development and Excellence (Chapter 2)}

This chapter examines influential factors relating to translating sporting potential into world-class performance. Many researchers and practitioners have emphasised the need for processes to focus on innate factors. Accordingly, initial consideration is given to the possible use of anthropometrical and physiological measures as indicators of potential. Due to the instability of anthropometrical and physiological factors during maturation, the limitation of employing these factors to identify talent is highlighted.

Following the consideration of innate determinants of performance, the importance of fundamental movement skills (e.g., balance) to an individual's potential within sport is considered. Unlike anthropometrical factors, an individual's performance on fundamental movement skills will be partly influenced by the environment. Consequently, the importance of ensuring that all children have appropriate movement experiences prior to being tested on these skills is highlighted.

Finally, the role of psychological and behavioural factors in obtaining and maintaining world-class performances is considered. It is highlighted that a talented sportsperson not only needs a range of attributes that have been found to benefit performance within a specific sport (e.g., being tall for basketball), but also requires the capacity to manage the pressures they will encounter as they pursue a pathway to excellence. The role of psycho-behavioural characteristics in facilitating this process is highlighted. 


\subsection{The Current Context: Conceptual and Practical Models of Talent Identification (Chapter 3)}

This chapter focuses on current processes employed in identifying talented children into a sport and is subdivided into three main sections:

(a) Conceptual Models of Talent Identification

A number of conceptual models of talent identification present in the research literature are reviewed. Whilst these models typically recognise the multidimensional nature of talent, they only focus on those attributes that are likely to facilitate or inhibit performance (e.g., speed for sprinting) with little or emphasis on factors that enable an individual to successfully manage the pressures they will encounter as they negotiate the complex pathway to excellence. One exception is the multi-dimensional and dynamic model proposed by Simonton (1999) that looks at talent across a range of performance domains. The features of Simonton's TI model and implications for the identification of talented athletes are discussed.

(b) Practical Models of Talent Identification

This section provides a review of TI processes that are currently or have recently been employed around the world. Emphasis is given to two identification programmes that have purportedly met with considerable success, the GDR and Australian talent identification systems. Unfortunately, empirical weaknesses for these models are apparent. Alternative explanations for the sporting success of GDR and Australia are presented. 


\subsection{How do Traditional TI Processes Employed in Sport do in Practice? (Chapter 4)}

Although many empirical weaknesses underpin the Australian TI approach, current processes for identifying the talented are increasingly being employed based on this approach. One such approach is the Scottish Sport Interactive approach. Chapter four evaluates the effectiveness of employing the 'Sport Interactive' approach in practice. Unfortunately, the study highlighted many practical problems that underscored the conceptual weaknesses previously highlighted.

\subsection{How Should Talent Be Identified and Developed: Theoretical and Developmental Considerations (Chapter 5)}

This chapter highlights the importance of acknowledging the multi-dimensional and dynamic nature of sporting talent within TID processes. Recognising the potential impact of psychological factors on the capacity of an individual to become an elite performer, the need for TID processes to place greater emphasis on the promotion of these behaviours is highlighted. In order to test the proposed framework, interviews with world-class athletes explored perceived precursors of successful development and performance in sport. This chapter describes these factors and discusses the findings based on the principles presented in the preceding chapters.

\subsection{Developing a Multi-Dimensional and Dynamic TID Model (Chapter 6)}

In this chapter, the concept of talent is revised as a complex, dynamical system in which future behaviours emerge from an interaction of key performance determinants such as psycho-behavioural characteristics, motor abilities, and physical characteristics. A generic model of talent identification and development that acknowledges this multi-dimensional and dynamic concept of talent is proposed. 


\subsection{Translating Theory to Practice: Systems and Resources (Chapter 7)}

This chapter presents a system for practitioners that will enable them to adhere to the principles advocated within the TID model proposed in the preceding chapter.

Resources that enable the promotion of psycho-behavioural characteristics alongside psychomotor development are presented. The proposed system enables a coherent application of TID principles within primary schools, secondary schools and by National Governing Bodies of Sport.

\subsection{Evaluation of the Multi-Dimensional and Dynamic TID Model (Chapter 8)}

To test the proposed TID model, the system and resources presented in the preceding chapter were piloted in Scotland. Psycho-behavioural characteristics and psychomotor skills were promoted in tandem within the primary school and secondary school context. Additionally, resources and training enabled coaches to promote psycho-behavioural application within sport specific contexts. Although the programme only ran for a relatively short period, due to funding pressures, a range of positive influences that the programme had on the participants are highlighted.

\subsection{Conclusions and Future Directions (Chapter 9)}

The final chapter summarises the findings of the thesis before considering the position that sporting organisations are currently taking with regards to TID. It is emphasised that a number of challenges must be tackled if organisations are to implement successful TID processes that reflect a multi-dimensional and dynamic concept of talent. Finally, directions for future research are suggested. 


\title{
CHAPTER 2 CHARACTERISTICS OF DEVELOPMENT AND EXCELLENCE
}

\author{
“A genius! for 37 years I've practiced 14 hours a day, and \\ now they call me a genius" (Pablo Srasate, violin virtuoso \\ and composer, cited in Simonton, 1999, p.435).
}

\subsection{Introduction}

Identifying attributes that characterize exceptional performers has interested researchers for many years (e.g., Regnier et al., 1993). When individuals excel at international sporting events, questions are often asked with regards to what factors enable the athlete to produce such outstanding performance. For example, Smith (2003) reflects on whether such performances are a result of "superior coaching, access to good facilities and beginning training at a young age or could their success be attributable to underlying biological predispositions?" (p. 1105). This debate over the extent that talented performances ${ }^{1}$ are results of nature (genetic endowment) or nurture has raged for some time. This chapter begins to address this question by reviewing research that has explored determinants of expertise and in particular those factors that contribute to talented performance within sport. As such, the following section briefly overviews the nature via nurture debate before considering attributes that research has identified as determinants of excellence.

\subsection{Nature via Nurture}

'Nativists' (proponents of the view that talent is innate) believe that the environment plays a minimal role in the development of talent and support the concept that key determinants of sporting talent can be identified early on. The thinking here is that as 
the major determinants of talent are under genetic control, then the absence of these variables during childhood will imply that an individual does not have the potential to excel, even if provided with appropriate developmental experiences. For example, if a child is not tall for his age, he will never be a rower.

Nativists have identified many phenomena that they perceive support the predominant influence of genes in determining the talent of an individual. Firstly, accounts of individuals achieving brilliance in the apparent absence of opportunity (e.g., Fowler, 1981; Howe, 1999) are numerous, implying that the environment plays a minimal role in the development of talent. Outside sport, Mozart's outstanding development has been well documented by many researchers (e.g., Howe, 1999). He was able to compose music by the age of four, was an accomplished performer on two instruments by the age of six, and demonstrated amazing feats of memory when he wrote out the complex score of 'Allegri's Miserere' after hearing it just twice. Whilst many examples exist of athletes whose performances stood out from their peers at an early age (e.g., Tiger Woods, Serena Williams, Michael Owen), there is less evidence of young athletes successfully competing against adult performers prior to carrying out a lengthy training period of several years. Although this suggests the crucial role of the environment for development in sport, the importance of physical maturity in sport may confound the issue. In fact, the role of physique is apparent when considering that sports where a small physique is beneficial (e.g., female gymnastics) the top competitors are commonly adolescents (Shephard, 1998). In contrast, athletes tend not to become elite performers in contact sports (e.g., rugby) until their late twenties or early thirties (Smith, 2003).

'Nativists' also claim that there is a significant body of evidence indicating that certain individuals progress at a faster rate than other comparable individuals despite the lack of any substantial effort (Ericsson, Krampe, \& Tesch-Romer, 1993; Sloboda

\footnotetext{
${ }^{1}$ Talent in general (not just sporting talent)
} 
\& Howe, 1991; Sosniak, 1985 in Bloom, 1985). The implication is that if individuals are innately talented, they can quickly acquire an exceptional level of performance once they have mastered the basic skills and knowledge. However, biographical material disproves this notion with experts from a wide range of domains consistently taking part in extended practice before exceptional performance is obtained (Ericsson et al., 1993). Further, a demonstration of a ceiling effect in performance, despite ongoing training, has led many researchers to conclude that performance is controlled by genetic factors:

So long as he is a novice, he perhaps flatters himself there is hardly an assignable limit to the education of his muscles; but the daily gain is soon discovered to diminish, and at last it vanishes altogether. His maximum performance becomes a rigidly determinate quantity. (Galton, 1892, p.15)

However, research has shown that highly experienced individuals can increase their level of performance as a result of deliberate quality practice. Deliberate practice is defined as "a highly structured activity, the explicit goal of which is to improve performance" (Erricson et al., 1993, p.368). For example, Bryan and Harter (1899) identified plateaus in skills acquisition for Morse Code operators where participants were unable to attain further improvement for long periods of time. However, Keller (1958) showed that, through deliberate practice, participants could overcome these plateaus which may have been a result of inadequate training strategies being employed. Within sport, world's-best performances continue to improve. Whilst some of these improvements are due to equipment and rule changes, improvements are dramatic even in events where minor changes have occurred (e.g., running and swimming). For example, the winner of the men's marathon in the 1896 Olympic Games completed the race in just under 2 hours and 59 minutes. This is 8 minutes slower than the last placed finisher $\left(81^{\text {st }}\right.$ position) in the men's marathon in the 2004 Olympic Games. The wining time for this marathon was 2 hours 10 minutes and 55 seconds. Ericsson et al. (1993) attribute these performance improvements to better quality training and infer that "stable levels of performance after extended experience are not rigidly limited by unmodifiable, possibly innate, factors, but can be further increased by deliberate efforts" (p.366). The increased attention placed on such 
aspects as scientific training principles (Muller, Benko, Raschner, \& Schwameder, 2000) and sport science research (Goldsmith, 2000), such as better nutrition, preparation and recovery strategies, are likely to have contributed to a better understanding of training processes within various sports.

Of course, if genetic factors rigidly determine maximal performance, and will not adapt through training, monitoring for such factors within children could be assumed to provide effective indicators of talent. Traditional concepts of talent have primarily attributed talent to nature, proclaiming that exceptional abilities are genetically transmitted (Durand-Bush \& Salmela, 1996). For example, Howe, Davidson, and Sloboda (1998) provided an explicit definition of talent that includes five properties: (a) talent is at least partly innate; (b) trained people will be able to identify advanced indications of talent; (c) early indications of talent provide a basis for predicting who is likely to excel; (d) only a minority are talented; and (e) talents are relatively domain-specific. Accordingly, such perceptions of talent have resulted in an almost exclusive focus on genetic characteristics within TI systems. However, opponents to the 'nativists' perception of talent believe that genetic make-up plays a secondary role to that played by the environment (Ericsson et al., 1993). They highlight the importance of creating the 'right' environment and opportunities in order to elicit talent and furthermore, identify many phenomena that they perceive support the predominant influence of the environment in determining the talent of an individual.

Recent research on expert performance and expertise has shown that important characteristics of experts' superior performance are acquired through experience, and that the effect of practice on performance is larger than was initially believed. For example, quality practice over an extended period has been shown to be a crucial determinant of an individual's ability to develop the range of skills required to excel at the world-class level. For instance, the 10,000 hours of deliberate training required to excel, originally recognized by Ericsson and Charness in 1994, is now a widely accepted principle; although the lack of theory underpinning the research has been highlighted as a concern (Davids, 2000). Whilst quality of training is ultimately 
likely to be more important than the quantity of training, this rule has been applied successfully in many domains including music (Gustin, 1985), mathematics (Helsen, Starkes, \& Hodges, 1998; Hodges \& Starkes, 1996; Kalinowski, 1985; Starkes, Deakin, Allard, Hodges, \& Hayes, 1996; Wallingford, 1975; Young \& Salmela, 2002) and sport (Howe, Davidson, \& Sloboda, 1996; Sloboda \& Howe, 1991). Furthermore, it is important to note that no individual cited in research has ever reached high levels of attainment in the absence of regular and frequent practice. For example, Raskin (1936, cited in Howe et al., 1996) reviewed the careers of 120 important scientists and 123 poets and authors and concluded that on average more than 10 years had elapsed between first work and best work. Additionally, within music, Sloboda and Howe (1991) report that there is no account of anyone that practised for 2 hours/day in music but failed to reach high levels of achievement.

Proponents of the 'nurture' view of talent also highlight accounts from individuals who do not report immediately displaying talent within their discipline. For example, Sloboda and Howe (1999) talked to 42 pupils of a specialist music school and found that individuals did not remember any early spontaneous involvement with music; in all cases, lessons seemed to precede exceptionality. In addition, parents provided opportunities to practise and learn, and encouraged their children every step of the way; almost two thirds ( $\mathrm{n}=28)$ had a musical instrument present in the house from birth. In fact, most children started music lessons because parents thought it was important and parents took a keen interest in their child's musical training. For example, $93 \%$ took a direct role in regulating practice, which was essential as only 6 of the 42 pupils interviewed were totally self-motivated. Based on such evidence, Simonton (1999) stated, "it is extremely likely that environmental factors, including deliberate practice, account for far more variance in performance than does innate capacity in every salient talent domain" (p.454).

Whilst proponents of the nature or nurture viewpoints have tended to polarise the nature via nurture debate, the 'Darwinian' approach acknowledges the contribution of both genes and the environment to talent and proposes that an individual's 
potential becomes actualised through the evolutionary interaction of innate capacities and 'ecological niches' available in family, school and workplace (e.g., Howe, 1999). In other words, although the potential performance of an individual will be influenced by his/her genetic make-up, potential performance will never be achieved without the correct experience and opportunity. Whilst the nature versus nurture viewpoint continues to rage today, this interactionist perspective is not new. For example, in 1874, Galton stated that the idiom "nature and nurture" is a:

Convenient jingle of words, for it separates under two distinct heads the innumerable elements of which personality is composed. Nature is all that a man brings with himself into the world; nurture is every influence that affects him after his birth. The distinction is clear: the one produces the infant such as it actually is, including its latent faculties of growth and mind: the other affords the environment amid which the growth takes place, by which natural tendencies may be strengthened or thwarted or wholly new ones implanted. (Galton, 1874, p.12)

In fact, the ongoing nature-nurture debate underscores the importance of combining talent detection/ identification and development (TID, e.g., Durand-Bush \& Salmela, 1996), as it is apparent that athletic talent is a complex mix of genetic factors and a conducive practice environment, rather than simply the result of one of these factors. Despite this important concept, research looking to explain sporting expertise continues to focus on 'genetic' determinants of performance. Even though performance is clearly made up of a number of dimensions, the majority of research in this area displays a one-dimensional focus; for example concentrating solely on the anthropometric dimension with little or no consideration of other factors or crucial interactions. Therefore, the key question for such proponents should no longer be whether genetic or environmental factors determine behaviour, but how they interact and what implications exist for TID models. 


\subsection{Characteristics of Elite Athletes}

\subsubsection{Physiological and anthropometric correlates of success}

As early as the 1920 s, researchers were examining the potential of anthropometric (e.g., height) and physiological (e.g., strength) measures as discriminating factors between athletes involved in different sporting events. The list of variables considered was wide-ranging, from simple consideration of age, height, and weight to more extensive studies containing many anthropometric measurements, somatotyping, and tissue analysis. However, although numerous studies have contrasted senior and junior athletes, relatively few have examined the characteristics of the 'world-class' performer. As TI procedures aim to identify those who have the capacity to excel at the world level, the rest of this review will focus mostly on those studies that have examined truly elite levels, rather than potentially 'cloud the issue' with the plethora of other available data.

From as early as the 1928 Olympic games in Amsterdam (Kohlrausch, 1929, cited in Tanner, 1964), researchers have exploited the opportunity to examine the elite athletes competing. These studies have considered basic factors, such as height, weight, and age, (e.g., Jokl, 1964) to more extensive research on the size, shape, composition, and proportions of individuals (De Garay, Levine, \& Carter, 1974). Initially, researchers concentrated primarily on the dimensions of track and field athletes. However, as the number of events within the Olympics increased, so did the range of athletes studied. Although statistical analyses within these early studies were limited, data consistently demonstrated that, irrespective of nationality, distinct profiles were evident for individuals in a range of different sporting events.

The employment of the statistical procedure 'discriminant function analysis' (Tanner, 1964) provided a unique contribution to the discussion of anthropometric and physiological differentiation. Tanner was able to identify groups of variables that best differentiated among athletes within different events. Consequently, distinct 
combinations of anthropometric and physiological attributes were shown to be important for success within specific events:

It seems that if you are large and have aspirations as a track athlete you have (always in general) a choice of the $400 \mathrm{~m}$, $110 \mathrm{~m}$ hurdles, $400 \mathrm{~m}$ hurdles and $800 \mathrm{~m}$. If heavily muscled, that is built like a sprinter, $6 \mathrm{ft} 2 \mathrm{in}$. and able to do $10.4 \mathrm{sec}$. for the $100 \mathrm{~m}$, then try the $400 \mathrm{~m}$. If a little slighter in muscle, and a little slower over the $100 \mathrm{~m}$, then try the $800 \mathrm{~m}$, or else the $400 \mathrm{~m}$ hurdles. The ideal high hurdler should have long but powerful legs in relation to his body, powerful arms so that he can balance the leg clearance movements and by reaction speed up the legs in their drive forward, and the skier's sense of rhythm. (Tanner, 1964, p.109)

In a similar fashion, Tittel's (1965) research mathematically confirmed that multiple anthropometric and physiological measures were able to distinguish between athletes competing in different events in the Olympic games.

Kohlraush (1929, cited in Tanner, 1964), Correnti and Zauli (1964), Tanner (1964) and Tittel (1965) have all provided useful information on the profiles of Olympic athletes. However, each of these studies were limited, both in terms of the number of athletes analysed, and because only male athletes were considered. In extending this early work, De Garay et al. (1974) looked at the physiological and anthropometric profile of 1265 male and female athletes across 13 sports (129 separate events) in the 1968 Olympics in Mexico City. Measurements were compared with a control group of 370 non-athletes. De Garay et al.'s work confirmed and developed awareness of distinct anthropometric and physiological profiles for successful Olympic athletes in different sporting events.

The comparatively close relationship that was established between an athlete's anthropometric and physiological characteristics and their sporting event has resulted in the common belief, held by both coaches and sport scientists, that profiling young children on 'innate' anthropometric and physiological measures will enable the 
identification of individuals who have the potential to be successful in a specific event (Petiot, Salmela, \& Hoshizaki, 1987). Thus, Grabiner and McKelvain (1987) stated, "the ability to identify young people whose profile is consistent with that of elite gymnasts may enhance the sport development of the individual by giving information about future success" (p.121). This position assumes that mature levels of innate characteristics are predetermined and can only be influenced by extreme environmental conditions (e.g., malnutrition). Conversely, characteristics that are not innate are influenced continually by the environment and the individual's experiences. It is therefore unlikely that mature levels of these latter variables can be predicted. However, such assumptions inevitably are limited since, (1) anthropometric and physiological factors are not always consistent performance determinants, and (2) physiological and anthropometric factors are unstable during adolescence. Accordingly, the next section considers these features, and their implications for the efficacy of anthropometric and physiological talent identification models.

\section{Anthropometric and physiological measures are not always consistent performance determinants.}

The task demands that underpin different events imply that certain physiques are advantageous in some events but disadvantageous in other events (Tanner, 1964). For instance, in discus, the speed of the discus at the moment of release is of prime importance in determining how far it will go. For a given angular velocity (dependent on how fast the thrower turns) the speed is proportional to the length of the 'lever' (the arm) throwing the discus. Therefore, long arms will always be advantageous. In contrast, short arms are advantageous in weight lifting since less force would need to be exerted by the muscles to lift the weight.

Although initial research (Tanner, 1964) found that anthropometric (e.g., height) and physiological (e.g., strength) measures are able to distinguish between successful athletes involved in different athletic events (e.g., $100 \mathrm{~m}$ and $400 \mathrm{~m}$ runners), recent research has failed to replicate this finding. For example, both Van der Walt (1988) 
and de Garay et al. (1974) found that, whilst some sports were typified by certain anthropometric and physiological profiles, distinct profiles were not established for all events. For instance, de Garay et al. found that whilst Olympic sprinters had distinctive profiles, the profiles of male rowers, cyclists, and swimmers were indistinguishable. This inability of physiological and anthropometric measures to classify an athlete's event has also been reported in gymnastics (Regnier \& Salmela, 1987) and with Ultra-man competitors (Baxter-Jones \& Helms, 1996). Further, the Training Of Young British Athletes (TOYA) study (Reilly, Williams, Nevill, \& Franks, 2000) found no distinct profiles for successful adolescent male footballers, female swimmers and male and female gymnasts.

Thus, whilst physiological and anthropometric distinctions would appear to provide a promising avenue for identifying individuals with the potential to succeed in specific sports, recent research highlights the problems with employing such an approach. The extent to which physique can distinguish between athletes in different events may be partly dependent on the complexity of the event. For example, consider the dynamic environment experienced by players involved in team sports such as football or basketball:

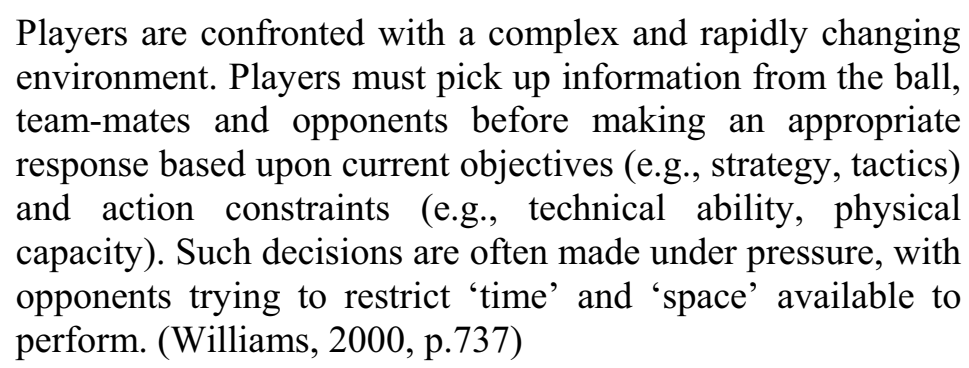

Contrast these demands with those of individual sports (e.g., track and field, rowing, cycling), where the environment is stable and predictable and there are discrete objective measures of performance. In support of the need to consider the complexity of events, de Garay et al. (1974) found that Olympic sprinters had distinctive anthropometric profiles. In basketball however, even though height was considered advantageous and most players tended to be tall, relatively small players still had 
their place. Similarly, marked differences have been observed in the anthropometric and physiological characteristics of top football players (Reilly, 1990). By contrast however, Reilly et al. (2000) were able to distinguish between the performance of elite and sub-elite football players by using a combination of anthropometric, physiological, psychological and soccer-specific skills, supporting the argument that a complex TID approach is needed.

Although, it has been highlighted that the contribution of physique to success is likely to be greater in closed skill sports, even here many examples exist of individuals who have excelled without the anthropometric and physiological profile perceived necessary to succeed. For example, a former Italian athlete Pietro Mennea showed an early interest in athletics and was fully committed to his training. However, as a youth he was given little hope since it was believed that he did not have the required physique. Despite this lack of encouragement, Pietro Mennea persevered with his training and when he was 25 years old broke the $200 \mathrm{~m}$ world record. This 200m world record stood for 17 years (1979-1996).

The search for anthropometric and physiological determinants of performance has also highlighted that the determinants of success vary across different age groups (e.g., Fleishman, 1972; Jancarik \& Salmela, 1987; Regnier \& Salmela, 1987). For example, Regnier and Salmela (1987) looked at determinants of performance in gymnasts between the age of 10 and 26, and found that not one physiological and anthropometric variable was among the five best determinants of performance across all age groups. For example, leg power was one of the five best determinants of performance within the 15-16 and 17-19 age groups but did not contribute to the regression equations within the remaining age groups. Similarly, arm power was only significant for those gymnasts performing within the 12-13 and 20+ age groups. This sort of evidence for age related determinants of performance has led researchers to call for talent detection and identification models that reflect these changes. Regnier and Salmela (1987) stated that "separate analysis must be done on each age group in order to identify what group of variables best predicts success for that particular age 
group" (p.144). Similarly, Sol (1987) highlighted the need for longitudinal research to find predictive test items at various ages.

There is a further problem however. The underlying assumption supporting unique talent detection and identification models at different ages is that the individual who is performing the best at any one age group is the individual with the most talent for eventual success. Unfortunately, such an assumption is unfounded. For example, it has been established that adolescents who excel at strength sports (e.g., rugby, weight-lifting) tend to be "early maturers" (Blanksby, 1980; Bloomfield, 1995; Shakespear, 1980) whilst "late maturers" tend to excel in coordination sports (e.g., rowing, gymnastics) (De Garay et al., 1974; Moore, Collins, Burwitz, \& Jess, 1998). Therefore, adolescent performances, rather than reflecting the talent of an individual, may say more about his/her physical maturity. As such, talent identification models that screen for anthropometric and physiological variables are likely to identify adolescents who happen to have the physical advantages at the time of testing, as opposed to identifying the individuals with the most talent

Consider a selection policy that positively discriminates towards those individuals who are able to overpower their less mature competitors through size and strength. For a 'late maturer' to develop successfully along the athletic continuum, they would have to be technically superior just to 'hang in there' (Van der Walt, 1988). Crucially however, those few late maturers who do persevere until they obtain mature physical levels are likely eventually to surpass the performance of the early maturers who have not been required to develop optimum technical skills, nor even perhaps develop and exhibit similarly high levels of work rate and determination! Additionally, once 'caught up' by these late developers, the early maturers often drop out; frustrated perhaps by their sudden inability to compete with these technically superior athletes and their lack of experience in working through difficulties. 
In summary, two problems are likely to result from TI models that rely solely on anthropometric and physiological determinants of talent. Firstly, such models, which initially favour early maturers, may be prematurely eliminating many athletes who have potential. Secondly, due to emphasising the importance of strength and size, evidence suggests that early maturers who do have talent are also disadvantaged by not being required to develop appropriate technical skills until it becomes too late. Similar criticisms can also be applied against selection policies that favour late maturers (e.g., gymnastics). Clearly, the distinction between 'performance' and 'talent' is crucial if talented athletes are going to be given optimal opportunities to develop. The limitations of TI models that solely or predominately focus on anthropometric and physiological determinants of performance is also apparent when considering research that has looked to identify attributes that distinguish between the performance of world class athletes competing in the same event. This issue is discussed in the next section.

\section{Distinguishing between performances of world-class athletes}

In addition to studies that increasingly highlight the inability of physiological and anthropometric variables to distinguish consistently between athletes competing in different events, profiles based on these variables also fail to distinguish between the performances of world-class individuals competing within the same event. In a typical study, Van Ingen Schenau, Koning, Bakker and De Groot (1996) looked at performance-influencing factors for Dutch speed skaters competing in the Junior National Championships. A total of 237 different technical, physiological, anthropometric, and psychological parameters were collected. Although the parameters assessed included 164 technique parameters that had previously been found to distinguish elite skaters from those performing at lower levels, Van Ingen Schenau et al found that only trunk position and the direction of push-off (push-off angle phi) correlated consistently with skating performance ( $r=0.61$ to 0.73 and $r=$ 0.65 to -0.70 , respectively). The absence of meaningful correlations for any of the other physiological and anthropometrical variables reflects early research which has reported that direction of variation around the mean on determining attributes for 
Olympic athletes was not found to relate to performance (e.g., Tanner, 1964).

Furthermore, in the finals of major championships, physiological and anthropometric values are likely to become matched and factors such as mental focus become all important (McDonald, 1984; Rushall, 1989).

A related failure of physiological and anthropometric measures is their inability to discriminate between individuals who can and cannot maintain world-class levels of performances once these have been achieved. It is apparent that the physiological and anthropometric profiles of an individual who excels at the world-class level on one occasion do not prohibit success: however, many athletes fail to maintain this standard. For example, Kreiner-Phillips and Orlick (1993) found that, out of 17 athletes who had won major international titles in a range of sports, only seven continued to maintain their level of performance. The remaining athletes either experienced prolonged performance slumps $(n=6)$ or were never able to reproduce comparative performances $(n=4)$. Interestingly, Kreiner-Phillips and Orlick found that psychological factors were able to distinguish between these three groups.

In summary, research that has looked to identify determinants of sporting excellence has primarily focused on physiological and anthropometric determinants of performance. However, recent research has questioned the ability of these variables to distinguish among athletes in different events. It may be that physiological and anthropometric factors are more influential in closed sports (stable environment). However, in open sports, other factors, such as decision-making decrease the significance of such variables. Further, physiological and anthropometric factors are unable to distinguish between performances within finals of major championships. Finally, even if physiological and anthropometrical determinants of performance within a specific sport were successfully identified, as the following section considers, their emphasis within TI processes would still be problematic as mature values are hard to predict. 


\section{Physiological and anthropometric factors are unstable during adolescence}

\section{Physiological determinants of performance}

Even if physiological measures were consistently shown to distinguish between successful athletes in various sports, regular training is known to alter values on such factors (e.g., strength and flexibility).For example, previous research has shown mature elite swimmers to be superior to the average population in many physical capacities and physiological functions (e.g., body composition, chest depth and shoulder flexibility), and it has been assumed that these differences emerge during adolescence or early post-adolescence (Bloomfield \& Blanksby, 1971; Bloomfield, Blanksby, \& Ackland, 1990). Therefore, ascertaining when such differences emerge would appear to provide useful information for incorporating into talent identification processes. However, Bloomfield et al. (1990) showed how variables previously correlated with successful swimming performance do not begin to discriminate elite performers from control populations until the later stages (stages four and five) of pubescent development. For example, although shoulder flexibility has previously been found to discriminate between mature swimmers and noncompetitors (Bloomfield \& Blanksby, 1971), Bloomfield et al. (1990) found no differences between the flexibility of adolescent swimmers and non-swimmers. They concluded that flexibility differentiation must occur after adolescence; presumably as a result of regular training, and not as a result of some performance precursor.

Ericsson and Lehmann (1996) also highlighted the crucial impact training has on physiological variables and stated that:

We have found that, with the single exception of height, current evidence for domain-specific characteristics (talent) among expert performers can be better accounted for by extended intense practice, which causes physiological, anatomical, and even neurological adaptations in the body. (p.297)

In other words, weaknesses on certain physiological performance determinants can be remedied through appropriate training and also may be compensated by strengths 
in other areas. Providing support for the impact of the environment on 'genetic' factors, Ericsson and Lehmann (1996) cite empirical research which has highlighted that (a) differences between individuals in the general population and elite athletes are greatly reduced when training is decreased, and (b) participants can successfully acquire several perceptual, motor, and cognitive capacities through deliberate practice. Consequently, poor values on a physiological variables during childhood does not necessarily limit potential as appropriate experiences may result in required, or alternative, adaptations taking place. Therefore, whilst physiological profiling can generate a useful database against which talented players may be compared in order to tease out precursors of elitism, the use of such measures for identifying talents and "selecting out" individuals is questionable and arguably even unethical.

\section{Anthropometric determinants of performance}

Unlike physiological measures, it is widely accepted that most anthropometric characteristics are innate attributes. This has led to TI processes based on the view that these genetic influences limit performance capacity in sport (Plomin, 1991). In fact, the inclusion of parameters that are largely genetically determined (e.g., height) within talent detection and identification models is problematic. Although to a large degree pre-determined, the anthropometric growth patterns of individuals are known to be non-linear and, therefore, adult and adolescent values may not correlate. As an example, an adolescent who is taller than his or her peers may develop into a tall adult, but may also be average or below average height. The implication is clear: "the identification of some positive characteristic in a pre-adolescent child ... does not guarantee that the characteristic will remain through-out the process of maturation toward the adult form" (Ackland \& Bloomfield, 1996, p.57). Hence, the inclusion of any anthropometric variable within a talent detection and identification model would be problematic, unless inter-individual differences on that variable were maintained into adulthood. Unfortunately though, characteristics that have a strong genetic determination are often represented as being stable over time. For example, in a British Olympic Association report on TI and selection, Borms (1994) recognised the significance of the stability of a variable ("the maintenance of relative rankings 
within the distribution among a group of peers over time", p.8). Borms went on to imply that characteristics that have a strong genetic determination are always stable. However, using our earlier example, whilst eventual height is largely predetermined, height is not relatively stable overtime. Unfortunately, the age at which mature levels of many anthropometric factors can be forecast is undecided, as very little research has looked at the stability of the proportions of the growing child and the adolescent (Bloomfield, 1995; Borms, 1994).

In fact, Ackland and Bloomfield (1996) did carry out a five-year research study into the stability of body segments within adolescents. It was found that differences between groups of adolescents on proportional breadth variables were sustained over the five years. However, many segment lengths either failed to stabilise or did not do so until mid-adolescence. In the former case, initial differences between individuals for lower limb variables were not maintained. Ackland and Bloomfield's findings emphasise the inappropriateness of employing anthropometric measurements, and in particular lower limb measurements, as early indicators of key performance determinants. Similarly, the prediction of adult somatotype from a child's known physique type at a young age is also difficult (Hebbelinck, Ross, Carter, \& Borms, 1980). Reviewing research on stability of physiques, Borms (1994) stated:

The extent to which the event of puberty modified an individual's prepubertal physique was never totally predictable. This posed a serious problem for those who were looking for ideal physique type among children of a tender age. (p.11)

\section{Summary}

The search for stable genetic factors that can predict superior performance in sport has been largely unsuccessful. Whilst, physiological and anthropometric distinctions between athletes competing in different events have been identified, these influences have not been found to be stable over time. For example, work with preadolescent 
athletes (Blanksby, Bloomfield, Ponchard, \& Ackland, 1986; Ericsson et al., 1993; Regnier \& Salmela, 1987) has demonstrated the instability of anthropometric and physiological measures. Consequently, TI procedures should not employ such factors as determinants of talent before the adolescent growth period. In other words, TI models that solely rely on anthropometric and physiological determinants of talent would only work if the measurement of the key variables occurred once it was known that their relative values between individuals were stable. Gender differences in the onset of peak values would also need to be acknowledged (Malina \& Bouchard, 1991). Unfortunately, such models would be problematic to develop since the stability of many factors (e.g., agility, flexibility and speed), which are accepted as being important to success in various sporting events (e.g., hockey, swimming and tennis), have not been studied in a systematic way (Bloomfield, 1995). Further, the delayed identification of individuals into sport would likely be resisted due to the clear correlation that has been established between the number of years of deliberate practice and success (Jess, Collins, \& Burwitz, 1999). The bottom line is that the present exclusive or predominant emphasis of innate, nature-driven factors in talent detection and identification processes appears unfounded.

\subsubsection{Fundamental movement skills}

Participation in sport requires individuals to perform a wide array of different movements. Many of these movements are complex, specialised skills used in specific physical activities (e.g., top slice in tennis or the spike in volleyball). However, the majority of these specialised movements are underpinned by common skills (e.g., running, jumping, throwing). For instance, to be successful at triple jump, an individual must be able to run, jump, hop, leap, and land. These basic movements, which are common to a range of activities, are known as fundamental motor abilities and are defined as:

A general template for a movement. The template becomes the basis of a number of specific skills, for example ... an underarm throw is a movement pattern and bowling in 
rounders is a specific skill that develops from it. (Department of Education and Science, 1991, p.26)

Fundamental motor abilities can be divided into three broad categories: travelling, object control and balance (Jess, 1999a).

The development of these fundamental movement skills are seen as the 'building blocks' for future successful performance and involvement in more specialised games, sports, dance and recreational activities (Armstrong, 1990; Department of Education and Science, 1991; Jess et al., 1999; Sports Council, 1993). As such, inadequate development holds implications for more than just sport performance. For example, the importance of developing fundamental movement skills has been emphasised by Pivarnik (1979), Seefeldt, Haubensricke and Reuchslein (1979) (1997), Seefeldt and Ewing (1997) and Tyler (1991). Seefeldt et al (1979) stated that:

Children who possess inadequate motor skills are often relegated to a life of exclusion from organised and free play experiences of their peers, and subsequently, to a lifetime of inactivity because of their frustration in early movement behaviour. (p.21)

Other authors have also supported the wide-ranging implications of poor fundamental movement skills. Skinner and Piek (2001), in considering the psychosocial implications of poor motor coordination, stated that their research had "indicated that poor motor skills may have adverse social and emotional implications for children and adolescents. The difficulties experienced are not confined to the movement domain but may affect how children and adolescents view themselves physically, socially and scholastically" (p.13). Consequently, fundamental movement skills are seen as essential precursors to both excellence in sport and successful participation in health related activities.

Returning to a performance sport focus, the early possession of these skills emerges as a key precursor. In a survey of elite English sports performers, Moore et al. (1998) identified that coaches believed that, unless a child had developed the fundamental 
movement skills required within an activity by twelve or thirteen, success within that activity would be beyond reach. Further, coaches reported that a broad base of fundamental motor abilities characterized children with high potential:

You can see the girl who has been to dance or gymnastics. Her balance is already well developed and she can move on quite quickly, whereas some other kids need to learn how to land on one foot without falling over. (p.36, Moore et al., 1998)

Generally it had been believed that these abilities were inherent and that children would develop them naturally by the age of seven if given the opportunity to explore different ways of moving (Gallahue, 1982). However, it is now recognised that innate views of fundamental movement skills are too simplistic, and wellcoordinated production of these skills will only occur with appropriate experiences (Bouffard, Watkinson, Thompson, Caugrove Dunn, \& Romanow, 1996; Logan, 1985; Wall, 2004; Wall, McClements, Bouffard, Findlay, \& Taylor, 1985).

Unfortunately, recent investigations from different parts of the world suggest that most young children do not receive appropriate movement opportunities (e.g., Reuschlein \& Vogel, 1985; Ross, Dotson, Gilbert, \& Katz, 1985). Relatedly, young children are exhibiting increasingly poor levels of movement competency (Currie, Hurrelmann, Settertobulte, Smith, \& Todd, 1999; Currie, Roberts, Settertobulte, Morgan, Smith, Samdal, \& Barnekow Rasmussen, 2004). Within the Development of Talent Study (Moore et al., 1998), it was found that coaches and teachers believed that children were 'movement illiterate' due to not having (or exploiting) the opportunities to develop adequate levels of basic motor abilities.

Consequently, whilst anecdotal and research evidence supports that fundamental motor abilities are essential to sporting success, it does not appear that children are currently being provided with (or exploiting) appropriate movement experiences. Unfortunately, the monitoring of fundamental motor abilities within TI programmes will likely lead to the selection of individuals who have had the relevant experiences, 
rather than the selection of children with most potential. Therefore, as a minimum requirement, talent identification schemes need to be preceded by a fundamental motor abilities programme that is available to all. Such a process would also provide children with key motor skills that would enable successful involvement in either health-related physical activity or performance sport.

\section{Early specialisation of youngsters}

In the UK, government initiatives (e.g., Sport: Raising the Game, Department of National Heritage, 1995; Young and Active?, Health Education Authority, 1998) are increasingly attempting to influence physical activity development throughout the childhood years. However, many such schemes also encourage (implicitly or explicitly) early specialisation in sports (e.g., mini-sport) with the result that children are exposed to sport specific basic skills rather than generic motor abilities. For example, within English Football, 56 centres of excellence currently exist and each of these recruits young footballers from the age of 11 years. Children are scouted by professional clubs and are then, from the age of 11 years, developed through the centres of excellence. This can lead to an intensity of involvement that can limit the potential for involvement in a diverse range of activities (i.e., children are discouraged from other sports or do not have the time). However, sport-specific development programmes are based on the concept that early specialization ensures that the 'talented' are provided with appropriate developmental opportunities for them to translate potential into performance at the elite level:

"it is a desirable goal not only for coaches, physical educators, and instructors but also for counselors and psychologists in the motor domain to detect the talent of a child as early as possible, in order to develop an appropriate training program". (p.270, Lidor \& Lavyan, 2002)

As well as concerns over the readiness of a child to cope with the physical and mental demands of intense training (Baker, 2003; Dalton, 1992), from a

developmental point of view it has been recommended that involvement in more than 
one physical activity at an early age should be beneficial at later stages of development (Gallahue, 1996; Haywood, 1993). In terms of long term physical activity involvement (and long-term health), many individuals drop out of sport and are likely to discontinue physical activity altogether if they do not have, or perceive that they do not have, the skills required to participate in an alternative (Wiersma, 2000). Furthermore, early specialisation is likely to lead to any immature fundamental motor patterns being carried forward and, at least temporarily, becoming part of an individual's pattern used in performing a sports skill (American Academy of Paediatrics, 2000; Wall, 2004). In other words, rather than acting as a building block, the incorrect fundamental movement skill may become the stumbling block. In contrast, involvement in diversified activities promote the acquisition of a variety of fundamental motors skills, such as balance and hand-eye coordination under different conditions, such as those existing in two different activities (e.g., soccer and track and field, volleyball and swimming) (Schmidt \& Lee, 1999). The problems that may result if individuals do not develop a broad range of movement skills that they are able to adapt successfully to sport specific contexts has previously been highlighted by Starkes and Allard (1993). Starkes and Allard highlighted that young basketball players cognitive capacity to 'read' a game can be ahead of their motor capacity to implement their intentions. Such disparity can lead to frustration and possible withdrawal from a sport.

In terms of involvement in performance sport, recent research by Lidor and Lavyan (2002) supported the benefits of diversified physical activity involvement during childhood. Within their study, they contrasted elite athletes with sub-elite athletes and found that the elite athletes tended to get involved in their sports and specialize later compared with the sub-elites. Similarly, Stevenson (1990) found that diversified early involvement did not disadvantage elite field hockey, rugby and water polo players. Furthermore, a recent study of expert decision makers from the sports of basketball, netball, and field hockey, found that participation in other relevant activities (e.g. other sports where dynamic decision-making is necessary) during early phases of development actually augmented the physical and cognitive skills necessary in their primary sport (Baker, Côté, \& Abernethy, 2003). Additionally, 
since successful athletes often excel in a sport other than the one they are involved in initially (Moore et al., 1998), individuals seem to benefit from a broad base of motor abilities that they can transfer from one sport to another.

\section{Summary}

In summary, generic motor patterns underpin all sports and it is important that children develop these skills if they are going to excel, or indeed participate. Accordingly, any TID programme needs to be preceded by movement opportunities to develop these key attributes. However, children do not currently appear to be provided with these opportunities. Conversely, much of our current TID comes about through luck in terms of chance involvement in specific sport activities and a process of early selection within a club setting. However, it is unlikely that such a sport specific system of TID could effectively support children who are selected initially and then drop out, or identify individuals with potential talent but who have not had relevant movement experiences.

\subsubsection{Psychological determinants of excellence}

Researchers have paid considerable attention to the psychological characteristics associated with elite athletic performance. Recent research across a variety of achievement settings has established mental characteristics as crucial to, or even causative of, elite performance (McCaffrey \& Orlick, 1989; Orlick \& Partington, 1988). However, although current TID models are based on distinctions between elite and non-elite athletes, these models tend to have a one-dimensional focus on physiological and anthropometric factors with little, if any, emphasis given to psychological determinants of excellence. A range of issues may contribute to this bias such as a research bias towards more 'tangible' determinants of sporting excellence (e.g., speed, size and strength), or applied sport psychology being a relatively new discipline. 


\section{Performance determinants}

Although research has traditionally emphasised the physique of the successful athlete, preliminary studies that sought to identify psychological factors associated with high-level athletic success were conducted in the 1970s. Whilst these initial studies were only modestly successful (Morgan, 1980), subsequent research that has focused on mental skills (e.g., goal setting, imagery) as opposed to personality variables (e.g., introversion, extroversion) has successfully identified psychological determinants of performance (Mahoney, 1989; Smith \& Christensen, 1995; Thomas, Murphy, \& Hardy, 1999). For instance, McCaffrey and Orlick (1989) found that top touring professional golfers could be distinguished from lesser skilled club professionals on a number of psychological factors. Orlick and Partington (1988) also found a number of common 'elements of excellence' for elite Canadian athletes. Similarly, an investigation by Gould and colleagues (Gould, Finch, \& Jackson, 1993a; Gould, Jackson, \& Finch, 1993b, 1993c), of Olympic medallists and nonmedallists in the 1988 Olympic Games, found that significant psychological distinctions were apparent, relating to mental preparation and pre-competitive cognition and affect (Gould, Eklund, \& Jackson, 1992b), competitive cognition and affect (Gould et al., 1993a) and coping strategies (Orlick \& Partington, 1988). In other words, medallists reported using these strategies as opposed to non-medallists. In another study, Silva, Shultz, Haslam, Martin and Murray (1985) assessed determinants of qualifiers and non-qualifiers in the 1980 United States Olympic wrestling trials. Psycho-behavioural characteristics were able to discriminate between groups with 78\% accuracy. Interestingly, physiological variables were less important and only able to discriminate between performances with $60 \%$ accuracy. Similarly, Orlick and Partington (1988) showed that in terms of physical, technical, and mental preparation of Canadian Olympians, only the latter variable could significantly predict actual Olympic placing.

As a result of work conducted by Orlick and his colleagues across a range of events (McCaffrey \& Orlick, 1989; Orlick \& Partington, 1988; Orlick, Hansen, Reed, \& O'Hara, 1979; Talbot-Honeck \& Orlick, 1998), a combination of pre-event and inevent behaviours have consistently been identified as successfully distinguishing 
between performances of elite and sub-elite class athletes. In support of the influence of psycho-behavioural characteristics on sporting performance, Smith and Christensen (1995) found that the "Athletic Coping Skills Inventory" (ASCI-28, Smith, Schutz, Smoll, \& Ptacek, 1995), which was designed to assess seven psychological skill items that athletes use to manage their sports performance, was a much better predictor of athletic success for professional baseball pitchers than an assessment of physical skills. The seven psycho-behavioural characteristics assessed were: coping with adversity, coachability, concentration, confidence and achievement motivation, goal setting and mental preparation, peaking under pressure and freedom from worry. Additionally, Thomas et al. (1999), using their recently developed "Test of Performance Strategies" self-report instrument, found that both male and female international athletes use a wider range of psycho-behavioural characteristics (goal setting, imagery, activation, self-talk, emotional control, negative thinking and relaxation) in training and competition than those of a lesser standard. Consequently, it would seem crucial that any TID model considers these psychological characteristics of excellence.

In fact the recognition of the role of psychological processes within sporting excellence is not new, and has been previously presented to policy makers within sport. For example, in 1992, Thomson highlighted to the Scottish Sports Council that psychological factors are important determinants of whether potential can be translated into performance. In 1994, Borms highlighted the role of 'behavioural dispositions' in sporting performance within a British Olympic Association report on $\mathrm{TI}$ and selection. Unfortunately however, emphasis on psychological development within sport remains minimal, and little, if any, consideration is given to the impact of psychological characteristics of excellence when looking to identify talented individuals. 


\section{'Getting there' and 'staying there'}

The ability to produce world-class performances consistently is often viewed as the mark of a true champion. In this regard however, both Jackson, Mayocchi, and Dover (1998) and Kreiner-Phillips and Orlick (1993) reported that elite athletes have difficulty maintaining levels of success. The British Amateur Athletic Association reported that, in the 1976 Montreal Olympics, $70 \%$ of athletes failed to produce par performances (McNab, 1981). In the British setting, the increasing need for consistent success in order to retain crucial financial support makes this a pertinent topic for talent-related research. Although considerable attention has been paid to the psychological factors associated with producing elite performances in sport, only recently has research begun to look at the determining factors of continued athletic success. For example, Gould, Jackson and Finch (1993c) found that figure skaters defending a national championship experienced increased expectation and responsibility, and a shifted motivational orientation involving a dislike for "being chased". Kreiner-Phillips and Orlick (1993) found that increased personal and external expectations experienced by athletes having excelled on the world stage affected subsequent performances. As a result, only those athletes (41\%) who were able to handle the demands associated with the increased personal and external expectations and to focus effectively rather than getting caught up in distractions continued to win at the highest level. This research emphasises the importance of some developmental efforts being allocated to 'maintenance skills', a further consideration for inclusion in TID schemes.

\section{Developmental considerations}

The development of effective TID processes is also dependent on the distinction between factors that typify world-class performances, and factors that characterise successful development. It is not unusual for youngsters to appear with the former but without the latter. Reports are common of coaches' exasperation with young performers who, whilst apparently possessing all the necessary anthropometric and physiological attributes to make it, fail to come through or even drop out through a lack of the right mental approach to skill development (Hemery, 1986). However, as 
Freeman (2000) emphasised, distinguishing high level potential as distinct from measurable production is particularly difficult because the true potential of children who are not performing above average is easily missed. As an example, Gardner $(1993 ; 1997)$ in his investigations into great people of the 20th century such as Freud, Einstein and Virginia Woolf, found that only Picasso's success could have been predicted through considering their work production at the age of 20. However, although performance appears to be a weak indicator of potential within all performance domains, as explained in the following section, those individuals that are the most successful in an area of life appear to think and learn differently compared to their less successful peers (Czeschlik \& Rost, 1988; Flynn, 1991; Simonton, 1994; Zha, 1993). Consequently, by understanding these subtle processes, we can begin to predict which individuals will respond most favourably to the developmental opportunities available and therefore those individuals who have the greatest capacity to develop.

Research examining the development of expertise has highlighted that the pathways to achieving excellence are non-linear and that athletes pass through various stages of development as they progress from a novice to an expert in sport (Bloom, 1985; Cote 1999; Durand-Bush \& Salmela, 2001). Bloom's research in 1985 explored the development of athletes, musicians and academics and considerably added to our understanding of the non-linear development of experts. Van Tassel-Baska (2001) highlights how a key component of Bloom's work was the focus on the evolution of talent as opposed to seeing talent as a phenomenon governed solely by genetic predispositions. Bloom (1985) highlighted three distinct stages of development in the athletic career (Initiation, Development and Mastery) and stressed the influence of environment on the progress of individuals within each of these stages. For example, Bloom highlighted that champion tennis players benefited from being instructed by increasingly able coaches as they progressed. More recently, Côté (1999) presented the 'stages of sport participation' model, which looked at involvement in sport up to the age of 18 years and also identified the 'sampling', the 'specializing' and the 'investment' years: 
In general, the sampling years are characterized by a lower frequency of deliberate practice and a higher frequency of deliberate play; the specializing years are marked by more equal amounts of deliberate play and deliberate practice; and the investment years are characterized by a higher frequency of deliberate practice and a lower frequency of deliberate play (Côté, 1999, p. 413).

Côté also highlighted that there was likely to be a fourth stage of development typified by the maintenance and perfection of skills. This is consistent with work by Kreiner-Phillips and Orlick (1992) that highlighted the distinction between 'getting there' (producing a world class performance) and 'staying there' (consistently producing world-class performances).

Although further research is required to establish the generality of these four stages of development, the existence of stages of development suggests that not only will athletes need to deal with the pressures within each stage, but crucial to their development will be the ability to make and deal with the changes required to successfully transfer between stages. Therefore, while both the environment and the genetic make up of an individual appear to play a vital role in determining the potential 'talent' of an individual in sport, an additional consideration is the factors that impact the ability of an athlete to negotiate the transitions encountered on the path to excellence. For instance, why are some individuals able to initiate the changes required to make the transition from one stage of development to the next while others fail to make the initial changes that are required (e.g., increasing the number of deliberate practice, changing coaches)? Similarly, why are some individuals able to deal with and progress through the inevitable setbacks (e.g., injury) they encounter during their development while the same setback may lead to other individuals dropping out of the sport altogether?

Research that explores the behaviours and characteristics of individuals who have the capacity to develop in sport is limited. However, research across other performance domains (e.g., academia, music, art) that has attempted to research the concept of 
underachievement and excellence may provide a valuable insight. Although difficult to define, McCall et al. (1992) refer to underachievement as the "discrepancy between actual and expected performance" (p.2). Researchers interested in the concept of underachievement and excellence have identified key psycho-behavioural characteristics (meta-activities) that refer to both appropriate attitudes and the adoption of effective strategies within the learning environment as key to the development process. For example, Freeman (2000) stated that:

The degrees to which talent can be strengthened and mobilised depends on the acquisition of the metaactivities needed for autonomy in learning. This not only means involving metacognitive "overview" and the direction of one's own thought processes, but also encouraging the mixture of attitudes, including curiosity, persistence, and confidence, as well as the efficient use of learning strategies, such as planning, monitoring, and evaluation. (p.238)

The following section considers how attitudes and meta-cognitive strategies may influence the extent that an individual fulfils and maintains their potential in their achievement setting.

\section{The impact of attitudes on achieving potential}

High attainment is increasingly being attributed to an interaction between unusual talent and high levels of motivation (Heller \& Viek, 2000; Ziegler \& Raul, 2000). In repeated observations, it was found that excellently achieving subjects in the area of mental development exhibited, without exception, higher levels of competence motivation and were clearly and significantly more persistent and enthusiastic than less successful individuals (Meij, Riksen-Walraven, \& van Lieshout, 1995). Thus, the level of an individual's motivation will determine the frequency and persistence of his or her interactions with the relevant environment, and thereby will influence his or her development. In this regard, Riksen-Walraven and Zevalkink (2000) stated that, "given that the motivation of competence in a given field literally drives a person towards interactions that foster development, competence motivation can be considered as the primary "engine" of development" (p.204-205). This strong relationship between motivation and attainment has also been reported by Bloom 
(1985), Sosniak (1985), Gottfried, Gottfried, Bathurst and Guerin (1994) and Csikszentmihalyi, Rathunde and Whalen (1997) in the areas of sport, music, academia and art respectively. Cote, Baker and Abernethy (2003) suggest that, in the early stages of development, sport specific play activities $\left(\right.$ deliberate play $^{2}$ ) that are inherently enjoyable and motivating play an important role in providing individuals with a stimulus to carry out the more effortful practice activities required to progress from a novice to an expert. Interestingly, research that highlights the strong relationship between motivation and attainment also implies that neither physique nor initial performance alone is a good predictor of adult attainment as the motivation to develop and excel must also be present. Therefore, while performance itself can be a false indicator of potential, especially in sport where maturational status can play such a significant role, the child's own interests appear to be an excellent, but often neglected, indicator of adult attainment (Hany, 1996; Milgram \& Hong, 1997).

Clearly, motivation and the perceived competence to interact with the relevant environment are important precursors to development. However, to maximise skill acquisition and development, motivated behaviour also needs to be appropriately focused in order to produce quality practice. Indeed, research has highlighted that individuals who achieve the greatest success, as well as being highly motivated, consistently employ strategies (metacognitive strategies), which optimise focus and learning (Freeman, 2000; Kunst \& Florescu, 1971). Metacognitive strategies are defined as "strategies that reflect on cognitive processes" (Flavell, 1987). Examples of metacognitive strategies are the self-regulatory learning strategies of goal setting and imagery. Within the sport arena, these strategies are normally referred to as psycho-behavioural characteristics. Within this thesis, metacognitive strategies and psycho-behavioural characteristics are used to refer to psychological strategies that a person employs when learning or performing a task.

\footnotetext{
${ }^{2}$ Within deliberate play, unlike when playing a game, the rules and parameters of activities can be modified to better meet the demands of the participants (Soberlak and Cote, 2003).
} 
The use of metacognitive strategies to fulfil potential

Researchers across disciplines (e.g., education, surgery, sport, music) have shown that metacognitive strategies can enhance achievement (Kreiner-Phillips \& Orlick, 1992; McDonald \& Orlick, 1994; McDonald, Orlick, \& Letts, 1995; McPherson, 2005; Schunk, 1990). Within education, Zha (1993) reported that high-level achievers use self-regulatory learning strategies more often and more effectively. For example, Morrone and Pintrich (1997) reported that high achievers set goals frequently and consistently across tasks more often than low achievers. Conversely, dropouts and underachievers have been found to have difficulty with establishing and working towards long-range goals and rewards (Citizens for Better Schools, 1995). McPherson (2005) cites research which emphasises that high achievers are "characterized by their capacity to choose and apply appropriate strategies, which in turn help them learn faster because they are able to integrate new knowledge and skills more quickly" (p. 6). Expanding this research to explore the development of young children's skill in playing a musical instrument, McPherson reported that his ...

findings extend previous research on skill acquisition by proposing that conceptions based on the amount of practice undertaken or that focus exclusively on children's ability to reproduce rehearsed literature from notation are inadequate to understanding the early stages of instrumental development. It is proposed that a more coherent explanation comes from understanding the range of strategies children employ when performing and that the sophistication of children's mental strategies provides an important means for understanding why some progress effortlessly in contrast to others who struggle and fail. (p.5)

Research that has looked at the individuals who achieve success within sport has also highlighted the role of metacognitive strategies (e.g., Kreiner-Phillips \& Orlick, 1992; Orlick \& Partington, 1988). Orlick (1996) highlighted that psycho-behavioural characteristics can help athletes' improve maximally from practice. Similarly, a variety of metacognitive strategies or psycho-behavioural characteristics would 
appear to characterise athletes who have the potential to acquire and consolidate skills (e.g., Boyce, 1992; Waskiewicz \& Zajac, 2001). In fact, the important role of psychology in translating potential to talent within sport was highlighted by Kunst and Florescu in 1971 when they outlined the different impact that psychological capacity, motor capacity and biometric qualities will have on performance and development within wrestling (see Error! Reference source not found.). Whilst motor capacity was considered the most important factor for wrestling performance, psychological factors were considered most important for identifying talent. Bompa (1999) also proposed that psychological capacity is the most important factor in talent identification, although once again specifically in wrestling:

In talent identification, it is more important for someone uninitiated to wrestling to possess the main psychological traits and the desire to wrestle, because you cannot expect a beginner to have developed the motor capacity. (p.286)

Although yet to be extensively examined in sport, the crucial role of psychobehavioural characteristics has also been highlighted by research that has looked at the ability of an individual to overcome adversity (Durand-Bush \& Salmela, 2002; Gould, Dieffenbach, \& Moffett, 2002; Holt \& Dunn, 2004; Vernacchia, McGuire, Reardon, \& Templin, 2000). As Holt and Dunn (2004) stated:

If a player maintains a disciplined lifestyle, makes the necessary sacrifices, develops a strong commitment, is able to rebound from setbacks, and receives adequate support, he potentially increases his chances of moving on to the next level. If not, it is more likely that he will (a) stay where he is until these conditions prevail, (b) be released from his club (in which case he may re-enter the sport at a lower level), or (c) drop out.

Without this resiliency, promising young athletes will be unable to fulfil their potential irrespective of their physiological and anthropometric credentials. 
Main factors for talent identification in wrestling

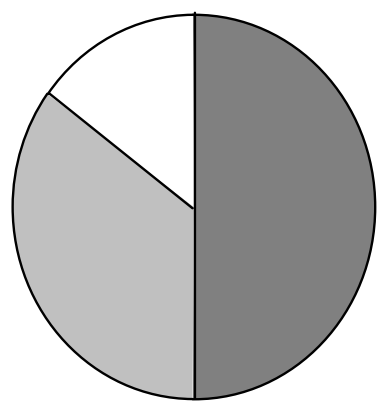

Main factors for performance in wrestling

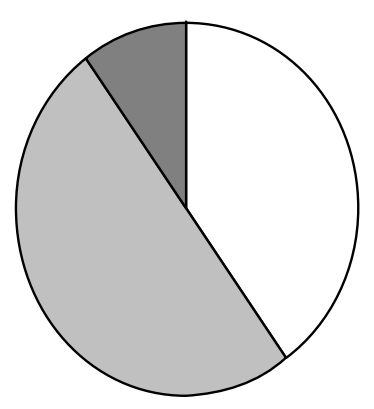

Psychological Capacity

Motor Capacity

Biometric Qualities

Figure 2.1 Relative importance of psychological, motor and biometric factors for talent identification and performance in Wrestling (adapted from Kunst \& Florescu, 1971)

Crucially, as was highlighted in the previous section, as well as being key determinants of developmental capacity, metacognitive strategies have also been established as significant pre-event and in-event behaviours for obtaining success (Gould, Eklund, \& Jackson, 1992a; Gould et al., 1992b) and producing consistent performances within sport (Kreiner-Phillips \& Orlick, 1992). Therefore, whilst TID systems need to consider determinants of performance, resources also need to be targeted towards determinants of the ability to acquire and consolidate skills, since athletes who do not have such developmental potential may still score highly on many performance determinants. That is, an individual who has a lack of capacity to improve may still score highly on anthropometric and physiological measures, and therefore be selected into a talent development initiative. Interestingly for the present context, those adolescents who successfully persevere within a sport, although their maturity status puts them at a performance disadvantage, are likely to have progressed due to factors such as motivation and mental toughness. Unfortunately however, whilst several practical and scientific articles have been published on the psychology of performance (e.g., Loehr \& Gullikson, 2001; Taylor \& Shaw, 2002), 
less emphasis has been placed on the psychology of development (Lippman \& Rushall, 1993).

\subsection{Summary of Research on Determinants of Excellence}

Considerable interest has been given to identifying determinants of excellence within sport. Unfortunately however, although this chapter has emphasised the multidimensional nature of talent, the majority of research has been one-dimensional in nature and has focused on identifying physiological and anthropometric determinants of performance. Further, although considerable research attests to the crucial role of psycho-behavioural characteristics to the development of sporting talent, traditional conceptions of talent have placed minimal emphasis on the processes involved in becoming an elite athlete. As such, existing conceptions of talent need to be reconceptualised to acknowledge the multi-dimensional and dynamic nature of talent, in order to account more fully for advances in our understanding of human learning and achievement (Regnier et al., 1993, p.298). Within the next chapter, we shall determine whether existing conceptual and practical model of TID are falling into the same trap. 


\title{
CHAPTER 3 THE CURRENT CONTEXT: CONCEPTUAL AND PRACTICAL MODELS OF TALENT IDENTIFICATION
}

\author{
"perceptions of talent are diverse and complex. ... As a \\ consequence there is no consensus of opinion, nationally or \\ internationally, regarding the theory and practice of talent \\ identification, selection and development in sport." (Williams \\ \& Franks, 1998, p.159)
}

\subsection{Introduction}

Whilst a range of factors impact on the ability of an individual to excel within any performance domain, Chapter 2 highlighted how research into determinants of excellence within sport has typically been one-dimensional. The next step is to examine conceptual models (i.e., models presented in the literature) and practical models (i.e., procedures being employed in practice to identify talented athletes) and evaluate their effectiveness in catering for a multi-dimensional and dynamic concept of sporting talent.

\subsection{A Review of Conceptual Models of Talent Identification}

\subsubsection{Traditional models of identifying talent}

Several sport-specific conceptual models of talent identification have been proposed over the years. These models have been developed to identify the presumed underlying determinants of potential and to provide a procedure for detecting those determinants within a population of potential athletes. Empirical research that has identified unique attributes of the elite has provided the foundation for such processes and resulted in a focus on attributes that can be reduced to simple and measurable units. For example, Harre (1982, cited in Durand-Bush \& Salmela, 2001) produced what has been described as "probably one of the most complete talent detection models in the literature" (Durand-Bush \& Salmela, 2001, p.272). This 
model is based on the assumption that only through training can one determine if a youngster has the required attributes to succeed. Accordingly, Harre highlights the importance of putting as many youngsters through training programmes as possible. Beyond the training environment, Harre also proposes that talent will only result with appropriate nurturing from parents and peers. This recognition of the role of significant others in translating sporting potential to talent is consistent with work conducted by Bloom (1985) across a variety of domains. Having identified the role of the training and social environment of the developing athlete, Harre defines specific rules for talent identification:

a. Talent identification should be done in two stages. In the first, all children showing good all-around athletic ability are identified. In the second stage, these individuals are classified according to skills associated with certain sports.

b. Talent identification must be based on factors that are both critical to top-level performance and highly determined by heredity.

c. Characteristics and abilities of each individual have to be evaluated in relation to their level of biological development.

d. Talent identification cannot rely exclusively on physical attributes, but must incorporate some psychological and social variables that help an athlete succeed.

Regnier et el (1993) point out that these four rules, together with the two preliminary conditions, are the basis for Harre's talent identification model. Specifically, the model proposes that individuals are initially identified based on objective tests of ability (height, running speed, endurance, coordination, ability in game situations and 'athletic versatility'), building on the premise that detection should be based on those performance determinants which characterize top level of competition.

Whilst Harre's model contains a number of positive features, it could be argued that these are not fully developed and lack explanation. For example, Harre underscores that biological development can impact performance. However, means of accounting for variable biological development rates are not highlighted. Harre also emphasises the relevance of psychological and social variables. Another positive 
feature is the consideration of the impact that psychological factors were proposed to have on the capacity of an individual to develop into a successful elite athlete (see Chapter 2). Specifically, attitude toward sports in school, participation in extracurricular sports activities, and the personality development of the ideal "young socialist" are identified by Harre. Unfortunately however, the mechanisms by which these attributes influence the development of talent and the implications for TI processes are not clear. The model also stresses 'potential for improvement', which is measured by reaction to training programmes before selection to stage two of the model, an issue that would appear to be related to psychosocial factors.

In attempting a more comprehensive approach to TI, Havlicek, Komadel, Komarik, and Simkova (1982, cited in Regnier et al., 1993) present a conceptual model that recognises the multi-dimensional nature of sports performance. Whilst innate attributes of performance are seen as the major determinants of talent, Havlicek et al. recognise that factors influenced by the environment can also have a significant influence on talent. Consequently, the researchers prioritise innate factors such as height in selecting the talented, followed by factors that are trainable but genetically influenced (e.g., speed), and finally factors that can be nurtured (e.g., motivation). However, like Harre's model, this model does not distinguish between variables that gauge potential and performance.

Gimbel's (1976, cited in Regnier et al., 1993) model embraced both nature and nurture perspectives, and highlighted multiple determinants of talent. These include physiological and morphological factors, trainability, and motivation; all of which may underlie performance within a range of sports. Recognising the need for prolonged deliberate practice, Gimbel advocates that individuals must be identified at 8 to 9 years of age. However, it has clearly been established that adult levels of physiological and morphological factors cannot be predicted during early childhood and, consequently Gimbel proposes a 'recovery period' where uncertain cases are supported for one year. Unfortunately, this feature is also problematic since those individuals selected at any stage will be identified based on determinants of performance rather than potential. Whilst the former will have significance in terms 
of an individual's capacity to be successful within a competitive environment, the latter are important if an individual is going to have the ability to acquire relevant attributes and successfully develop in their chosen sport. Indeed, Gimbel himself recognises that it is impossible to predict talent from such tests because of biological age differences between children; an acknowledgement which offers tacit support for consideration of determinants of potential as opposed to determinants of performance. Positively, Gimbel does recognise the importance of psychological variables and highlights how these variables have been neglected in predictive models. Accordingly, he advocates identifying the psychological factors underlying performance. However, once again no consideration is given to the attributes that underpin successful development within sport.

Montpetit and Cazorla (1982) expanded Gimbel's model (1976, cited in DurandBush \& Salmela, 2001) to include details on the identification of morphological and physiological determinants of performance. They suggested that, initially, profiles of elite athletes based upon conventional physiological testing procedures are determined. The stability of these variables should then be verified through longitudinal testing, and only then may variables be applied to younger populations. A similar suggestion emerged from Bompa (1985), who developed a conceptual model of talent detection based on the system then commonly employed within the Eastern European countries. His model emphasises three types of performance determinants, namely: (1) motor capacities (perceptual and motor skills, endurance, strength, and power), (2) physiological capacities, and (3) morphological attributes. Detection is based on the direct comparison of physiological and morphological profiles from younger performers to those of elite athletes. As before, both models are based on the belief that determinants of performance and potential are synonymous.

Of interest is the basis on which Geron (1978) produced his model of talent detection. Geron's model outlined three procedures for establishing a talent identification model: (a) the determination of an "elite athlete" profile in a given sport, (b) the identification, through longitudinal studies, of variables that are 
strongly related to success and are highly dependent on heredity, and (c) the determination of age periods when the genetic dimension of selected factors are the most powerful. Underpinning these procedures is acknowledgement of the need to distinguish between the characteristics of a champion and the qualities required for an individual to become a champion. Additionally, recognising that biological age can significantly impact an individual's performance on variables related to success, the model advocates that the profiling of individuals on innate determinants should only be completed at the age by which the factors have been established to be at their peak. Clearly however, many of the qualities required for an individual to become a champion are not innate, and once again, inconsistencies are apparent between the model and the tenets offered for its basis.

In summary, the majority of conceptual models have been developed in order to provide a scientific "framework around which research and professional efforts in sport talent detection could be organized to develop detection instruments for any sport" (Simonton, 1999, p.303). Somewhat paradoxically however, the justification for the attributes identified within conceptual models as determinants of talent appears to lack scientific rigour. In particular, many conceptual models do not appear to be sensitive to the nature-nurture debate and are founded on the conception that early 'innate' indicators of talent exist. This has resulted in talent being reduced to a few simple measures (e.g., weight, endurance and strength) that are assumed to develop in a linear/predictable fashion. Whilst it may initially seem surprising that such simplistic approaches have been established in order to identify talent, Chauveau (1999) highlights that, when attempting to understand phenomena which are considered complex, reducing a concept to a few simple measures is a "natural reflex". An exception to these 'simplistic approaches' is a conceptual model of talent identification and development proposed by Simonton in 1999 .

\subsubsection{An Alternative model for identifying and developing talent}

In contrast to the somewhat consistent pattern of the earlier work, Simonton (1999) provided a unique contribution to conceptual models of talent detection and 
identification. Whilst Simonton's model was intended to characterize talent development across a range of performance domains (e.g., science, sport and the arts) it begins to address some of the concerns that have been raised with traditional TI models. Like previous conceptual models, Simonton's model highlights the multidimensional nature of talent and recognises physical, physiological, cognitive and dispositional components. However, the model, which is based on both longitudinal and cross sectional research, distinguishes between determinants of performance and attributes that enable an individual to successfully develop within their chosen sport. For example, research within education, music and sport has demonstrated how talented individuals appear to be able to learn skills at a faster rate than the less talented (Bjorklund, 2000; McPherson, 2005). Of course, this increased rate of learning can be explained by innate intellectual ability. Additionally, dispositional attributes "such as unusual energy and special interests" that optimise intensity and focus could be contributing factors (Simonton, 1999, p.436). In addressing this question, and its importance for the effective design of TID, Simonton recognises that differences in levels of excellence can only be partly attributed to innate factors. Therefore, the influence of the environment during development is considered crucial:

It is extremely likely that the environmental factors, including deliberate practice, account for far more variance in performance than does innate capacity in every salient talent domain. (Simonton, 1999, p.454)

The influence of the environment has been largely undervalued within both previous conceptual models and research into talent. However, within Simonton's model, both individual differences (somewhat confusingly termed emergenic factors) and how these individual differences develop across the formative years of a person's life (epigenetic) are considered.

The formulation of Simonton's TI model is based on the notion that a number of components can contribute to the existence of talent within any domain, and that these factors interact in a multiplicative rather than an additive manner. Therefore, Simonton (1999) argued that a number of weighted components must be considered 
within each talent domain, such as genetically driven traits as well as environmentally-influenced, developmental factors. Consequently the 'formula' for talent is not comprised of static, independent performance-based measures but rather, of factors that interact and change as a function of time thereby contributing to a range of possible developmental trajectories. To reflect the exponential and dynamic nature of talent, Simonton produced the following equation (see Equation 3.1) where $\mathrm{P}_{\mathrm{i}}(\mathrm{t})$ is potential talent at time $\mathrm{t}$ for the $i$ th individual, $\mathrm{C}_{\mathrm{ij}}$ is the individual's score on component $j(i=1,2,3, \ldots \mathrm{N})$ and $\mathrm{w}_{\mathrm{j}}$ is the weight given to the $j$ th component. The symbol $\Pi$ indicates that each contributing component (or performance determinant) is multiplied together reflecting the exponential and nonlinear nature that a change in each variable can have on predicted talent.

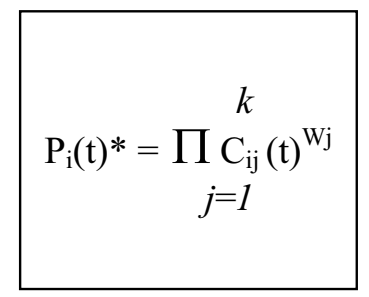

Equation 3.1 Simonton's proposed formula for Talent (from Simonton, 1999, p.443)

At this time, such a model would need considerable development before it can be used for simulations of TI in sport (e.g., to select key talent determinants and the individual exponents to be attached to each). For example, in applying the 'formula' to rowing, further research would need to be conducted in order to identify all factors that contribute to the development and performance of participants.

The use of nonlinear mathematical modelling to depict probabilistic distributions of human behaviour has proved successful in a wide range of applications, including population growth (May, 1974), neural assemblies (Meyer-Lindenberg, Ziemann, Hajak, Cohen, \& Berman, 2002), and even in plotting the behavioural patterns of criminals (Walters, 2002). Perhaps the richest body of evidence can be found in the motor development literature (for a review see Thelen \& Smith, 1994). For example, 
Wimmers, Savelsbergh, Beek and Hopkins (1998) have produced data from a longitudinal study indicating the discontinuous jump in infant behaviour from reaching without grasping being predominant, to a state in which reaching with grasping is predominant. This behavioural characteristic, known in dynamical terms as a bifurcation, is common in dynamical systems which have many tuneable parameters and hence could evolve along several different potential trajectories (a classic example is the Hénon map, Kelso, 1995). Simonton's (1999) model predicts that exceptional behaviour could develop in an exponential fashion as a function of many, more specific parameters in a similar fashion to many other nonlinear dynamical events, such as the escalation of a serial criminal's rate of offences. In sport, these parameters are likely to include anthropometric variables (such as height and muscle-fibre ratio), psycho-behavioural characteristics (such as commitment and self-evaluation), and perceptual-motor characteristics (such as agility and hand-eye coordination). It is interesting to note that several of these variables possess qualities that are transferable across situations and, possibly, different sports. Longitudinal research plotting the development of a group of talented athletes would enable the nonlinear distribution characteristics that emerge over time as predicted within Simonton's (1999) approach to be examined.

Unlike previous models, Simonton's multiplicative model of talent has major implications for comprehending individual differences and how these develop over time. As such, Simonton offers four direct implications for the process of talent identification and development:

1. The domain in which an individual displays talent will not be determined by any highly specialized component but rather by "the specific weighted multiplicative integration of the contributing innate components" (Simonton, 1999, p.438). 
2. Individuals talented within the same domain will all have some value of each necessary component, since a multiplicative model implies that absence of any component will mean no talent ${ }^{3}$. However, individuals' values on these components will vary. Consequently, there are an infinite number of formulae for talent within any domain.

3. Exceptional talent within any domain will be extremely rare. Firstly, many individuals will have no talent due to the absence of one of the components. Secondly, whilst the incidence of any component will be normally distributed, their product within a multiplicative model will not be.

4. The number of components essential for performance will vary from domain to domain. Some domains will be complex with a large number of essential components; for instance, contrast closed and open skilled sports.

A number of considerations for TID can be inferred from the emergenic model. Firstly, an individual who scores highly on any one particular component will not necessarily have talent since actual progress and attainment will depend upon the multiplicative profile of all the components essential to excellence within the domain. For example, if someone displays a high level of speed, their potential within a sport also will depend upon the other determinants of success, such as power, determination and coping skills. Additionally, children can display disparate scores on the determinants but be equally talented. Consequently, this model implies that predictability of talent is low if component scores are considered separately rather than multiplicative effects are considered. Additionally, research that attempts to correlate success in a domain with individual components will be unsuccessful since those who excel inevitably will display a range of levels on each component.

\footnotetext{
${ }^{3}$ Within sport, it is difficult to conceive where a zero value can be attributed to any talent component (e.g., motivation, speed, strength).
} 
The clear implication of Simonton's model (1999) is that an over-emphasis on onedimensional considerations of individual differences is likely to be unsuccessful:

The individual-differences model, for all its potential utility, remains too simplistic. The central deficiency is its static nature. .... The static conception of talent is plainly wrong. Talent development must instead entail some form of epigenesis. That is, starting with a relatively undifferentiated state, the various traits slowly appear and differentiate over time. ... Infancy, adolescence, and even adulthood will see the latent components undergoing various transformations. (Simonton, 1999, p.442)

This realisation that component values change with maturation helps explain a number of phenomena observed in talented individuals. Firstly, late and early bloomers will be evident within any talent domain. The early bloomer will be the individual who has adequate values of all components of talent at an early age. However, late developers may still possess the full range of necessary characteristics, but have one or more components that do not begin development until much later:

Just because a trait claims a genetic foundation does not automatically mean that the trait appears all at once. On the contrary, many characteristics, even if under demonstrably genetic control, take many years, even decades, to emerge. (Simonton, 1999, p.449)

Once again, the need to distinguish between determinants of performance and determinants of potential is apparent. For example, an individual may excel in rugby at an early age due to their size and strength, but this does not mean that they have developed the components of talent early. Rather, an athlete could possess a surreptitious set of components, which happen to suit them, for that particular sport at that particular time. Further, high values on determinants of performance during early development (e.g., speed and strength) may even delay the development of other important components (e.g., resolve, dexterity). 
Additionally, the epigenetic part of Simonton's model (1999) also explains why it is difficult to identify early signs of talent. If a child does not display a component, it maybe because the component is absent or that it will not develop until later. Due to the late emergence of components, as age increases, the probability of correctly identifying 'potentially talented' individuals will increase. Clearly therefore, the earlier a talent detection and identification procedure is employed, the more likely it is that potentially talented individuals will be eliminated.

The epigenetic part of Simonton's model (1999) can also account for those individuals who show promise but never realise their potential. This loss of talent can be due to a relatively slower rate of increase in the multiplicative value of the required components of talent. Alternatively, however, it can be accounted for by an absolute loss in the value of the potential talent (e.g., as a result of injury). Additionally, since the components within a domain may be the same as those required in another domain, as individual differences develop, the athlete may become better suited to a domain other than the one they were originally involved in. For example, Maurice Green (100m gold medallist at 2000 Olympics and bronze medallist at 2004 Olympics) grew up playing American football and came close to accepting a scholarship to play college football, before deciding his future lay on the track. This domain change by individuals has already been identified as an important component within British sport (Moore et al., 1998).

Finally, Simonton's epigenetic model (1999) highlights the difficulty of predicting talent. Due to its dynamic nature, "not only may the composition of a given talent change as a person ages, but the optimal talent domain may change as well" (Simonton, 1999, p.445). Consequently, it would appear to be of greater value to identify determinants of development and help individuals "equipped to progress" in sport develop the necessary attributes for success.

The focus of Simonton's TID model is on the components required for an individual to get to the top of their chosen performance domain. Once an individual has achieved excellence within their domain, recent research within sport highlights that 
athletes need to cope with additional demands (e.g., concept of being chased, media pressures) if they are to remain at the top. However, Simonton's model does not distinguish between getting to the top and staying at the top. As such, the model could be usefully developed to consider maintenance skills.

\subsubsection{Summary}

The limitations of the majority of current conceptual models of talent detection and identification are apparent. Specifically, these models have looked to reduce performance to a few simplistic variables even though such variables are likely to be poor predictors of an individual's talent. As outstanding human achievements will be a result of "some varying balance between training and experience (nurture) on one hand and innate differences in capacities and talents (nature) on the other" (Ericsson \& Lehmann, 1996, p.274), problems are confounded further by a tendency to emphasise only those performance determinants that are perceived to be 'innate' rather than 'develop-able'. Whilst many conceptual models do highlight the importance of psychological factors, the focus on innate determinants has resulted in primary emphasis being placed upon physiological and morphological attributes, even though eventual adult levels of these variables are hard to predict from childhood measurements. Finally, the focus on performance determinants has meant that the importance of identifying how an individual actualises their talent within the competitive environment and maintains success once achieved has not been acknowledged within the majority of conceptual models.

An exception is the model proposed by Simonton (1999), which, uniquely, does distinguish between determinants of performance and development. Recognition of the influence of the environment on innate components of talent and the multiplicative influence of these components provides a unique contribution to the area of talent detection and identification and accounts for a number of phenomena that are observed within sport and non-sport domains (e.g., late developers, the apparent 'loss' of talent, etc.). Accordingly, one would hope to see these principles 
at work in the most effective TID schemes. The next section will enable this judgement through a focus on actual schemes currently employed around the world.

\subsection{A Review of Talent Identification Processes Employed in Practice}

\subsubsection{Introduction}

Ziemainz and Gublin (2002) highlight that several countries have gone to great lengths to establish comprehensive TI programmes over the last 30 years, but only a few nations have ever been successful in implementing these in the long run. Therefore, whilst there has been an increased recognition of the value of employing effective TI processes, athletes around the world continue to be commonly selected into a range of sports by 'natural selection' methods. For example, the UK continues to select individuals into talented development programmes (e.g., elite academies), as a result of individual performances rather than through a search for presumed underlying determinants of potential. This was recently reflected in a British Olympic Association report where $85 \%$ of football coaches, $67 \%$ of tennis coaches, $77 \%$ of swimming coaches and $48 \%$ of gymnastic coaches reported that they did not employ any screening devices when identifying talent (Rowley, 1994). The absence of systematic talent identification and development processes within the UK may contribute to the recent claim that world class performances in athletics is a result of exceptional athletes of the day rather than to a system that continually produces champions in specific events (Sport Industry Research Centre, 2003). In fact, within their report, the Sport Industry Research Centre highlighted that the most successful countries in the Olympics are those that produce winners in the same events time after time and are not dependent on one talented individual. For example, Australia has consistently produced world-class swimmers over the last 10 years and such continuation may reflect more effective processes for identifying and developing the talented. 
A review of TID practices currently being employed around the world clearly highlights that a lack of systematic TI processes is not unique to the UK. For example, a recent report highlighted how New Zealand has no consistent approach to TI and TD (Mahon, 2004). Within Japan, the TID system was recently described as a "Black cat in the darkness" (Engilish Institute of Sport, 2003), in other words a black hole with no national programmes or schemes to bring young athletes through the system. Within Germany, Ziemainz and Gublin (2002) suggest talent identification is more or less left to chance as measures are not implemented systematically, and there is a lack of commitment towards fixed test parameters with little cooperation between schools and clubs. In fact, it has been recently highlighted that the screening criterion applied most frequently in Germany, Canada, the USSR, Sweden, Brazil and the United States for selection into development squads and sport schools, is competition results (Digel, 2002; Ferreira, 1986; Kozel, 1996; Riordan, 1990; Thomson, 1992). Once at this level, athletes continue only if they can 'produce the goods'. The rationale often stated for employing the 'natural' selection methods it that those with talent will fight their way to the top. Unfortunately however, an evaluation of natural selection processes highlights that such approaches may be leading to many talented individuals being overlooked.

\subsubsection{The problem with natural selection processes}

A 12 month age gap can make an enormous difference in performance capability in youth competitions (Barnsley \& Thompson, 1988). Therefore, selection processes that are based on performances of children are likely to lead to a disproportionate number of sport participants tending to be born in the early part of the selection year, as already reflected in Chapter 2:

Where advanced physical development is an advantage, the youngest players (biologically and chronologically) are considerably disadvantaged. Many 'talented' children may be overlooked simply because they are born too late in the selection year and are thus less developed physically. (Helsen et al., 2000, p.730) 
The impact of physical maturity is highlighted by research from around the world that has found similar asymmetries in birthdate distributions across a variety of team sports. For example, Barnsley, Thompson, \& Legault (1992) found that players within all teams in the 1990 World Cup and under-17s and under-20s tournaments in football tended to be born within the early part of the selection year. Twenty-four countries are represented within the World Cup indicating a worldwide trend within football. These research findings imply that although it has clearly been established within Chapter 2 that talent detection and identification processes based on performance levels will de-select potentially talented individuals, such processes continue to prevail today.

A detailed example of the impact of relative age in selection processes was emphasised recently in Belgium football. Helsen et al. (2000) highlighted how, until 1997, the Belgium selection year started on 1 August and ended on 31 July. Youth players born between August and October (the early part of the selection year) were more likely to be identified as talented and eventually become successful senior players. In contrast, players born later in the selection year tended to drop out of football as early as 12 years of age. However, the change in the start of selection in 1997 to the first of January has resulted in a shift in birth-dates of individuals being selected. Only individuals within the 16 to 18 age group did not experience this shift. This is probably because those players who were born in the first and second quarters of the year (January to July) were deselected before the age of 16, due to the old selection process. This finding highlights the problem with employing performance criteria for identifying talent since those individuals born later in the selection year are likely to be later maturers. Of relevance, Malina, Pena-Reyes, Eisenmann, Horta, Rodrigues, and Miller (2000) found that within Portugal, football appeared systematically to exclude late maturing boys and favour average and early maturing boys. Consequently, late maturers are likely to be eliminated during adolescence and will not have the opportunity to develop the required skills to be reselected into the sport once they have matured physically. 
In summary, approaches that rely on natural selection processes are likely to overlook many potentially talented children as better performance may be a result of physical maturity rather than being an indication of talent. Whilst such processes continue to be employed and often prevail within sport today, a gradual recognition of the limitations of natural selection processes, along with increased competition on the international arena has resulted in greater interest in the benefits that an effective scientific TID system could provide.

\subsubsection{Scientific selection processes}

An increased interest in establishing objective measures of talent is reflected by sporting organisations around the world conducting research into the potential of criterion-based models of talent identification. Such models are perceived to be more scientific than relying on natural selection methods. For example, in early 2000 , sportscotland commissioned a review of talent identification and development processes with particular reference to models of practice used elsewhere in the world (Abbott, Collins, Martindale, \& Sowerby, 2002). Ongoing research being conducted for UK sport is developing a cross-national study of the policy factors that lead to international sporting success (Sport Industry Research Centre, 2003). Within New Zealand, a TID taskforce was established in 2003 in order to compile a report that explored international best practice in talent identification and development (Mahon, 2004). This research ultimately aims to exploit best practices and has led to considerable focus being paid to both the Communist approaches to TID and the more recent Talent Search approach adopted by Australia. As such, the following section provides an overview of these approaches and evaluates their effectiveness in the context of the preceding chapters. Unfortunately, as will be highlighted, the current focus has led to the establishment of TID practices that primarily focus on a small number of anthropometric and physiological criteria of talent and are based on an inappropriate static conception of talent. 


\section{Communist approaches to TID}

Communist nations have experienced considerable success in sport on the international arena; for example consider the performance of the USSR, GDR and Cuba within the Olympic Games (see Table 3.1). In 1988, the Soviet Union dominated medals won in the 23 sports in the summer Olympics and the twelve sports in the winter Olympics. As a consequence of this success, some nations in the West have looked with envy at the talent detection and nurturing systems employed in the Communist nations (Riordan, 1993). Unfortunately, a thorough analysis of the talent detection and identification procedures is hindered due both to limited information available on the specific criterion, and some 'strong conjecture' as to the ethics of the procedures employed (Riordan, 1993). Nevertheless, a review of talent detection and identification procedures that are documented within the literature follows.

Table 3.1

Olympic Medal Table Position of Cuba, USSR and GDR/ Germany from the 1960 to $\underline{2004 \text { Olympics }}$

Position in Medal Table between 1960 and 2004

Country $19601964 \quad 1968 \quad 1972 \quad 1976 \quad 1980 \quad 1984 \quad 1988 \quad 1992 \quad 1996 \quad 2000 \quad 2004$

\begin{tabular}{lcccccccccc|c|c|c|c}
\hline Cuba & $53^{\text {rd }}$ & $32^{\text {nd }}$ & $31^{\text {st }}$ & $15^{\text {th }}$ & $8^{\text {th }}$ & $4^{\text {th }}$ & - & - & $5^{\text {th }}$ & $8^{\text {th }}$ & $10^{\text {th }}$ & $11^{\text {th }}$ \\
USSR & $1^{\text {st }}$ & $2^{\text {nd }}$ & $2^{\text {nd }}$ & $1^{\text {st }}$ & 1 st & $1^{\text {st }}$ & - & $1^{\text {st }}$ & $1^{\text {st }}$ & $2^{\text {nd }}$ & $2^{\text {nd }}$ & $3^{\text {rd }}$ \\
GDR $/$ & $10^{\text {th }}$ & $11^{\text {th }}$ & $5^{\text {th }}$ & $3^{\text {rd }}$ & $2^{\text {nd }}$ & $2^{\text {nd }}$ & $3^{\text {rd }}$ & $2^{\text {nd }}$ & $3^{\text {rd } *}$ & $3^{\text {rd } *}$ & $5^{\text {th }} *$ & $6^{\text {th }}$ \\
Ger* & & & & & & & & & & & & \\
\hline
\end{tabular}

* Competed as Germany following unification

The use of scientific talent identification programmes was initiated within East and Central European countries (Bompa, 1994). These models were based almost exclusively on identifying the physical and anthropometrical characteristics of elites in younger athletes. Indeed, the Olympic success of Bulgaria, Romania, and East Germany in the 1960s and 1970s has been attributed largely to scientific talent 
detection processes (Bompa, 1994). As a result of successful sporting countries employing anthropometric based TI models, similar systems have emerged, and continue to emerge, worldwide. For example, within China, the selection of gymnasts occurs by considering the physical and anthropometrical profile of children aged 7 to 9 years (Ho, 1987). Within Canada, although ultimate selection is determined by performance within competition, initial selection of gymnasts is also based on physique:

The Canadian testing program has concentrated very heavily on physical characteristics [e.g., weight and height] when considering young athletes, since their chances to succeed are slim when they don't have those qualities. (Bajin, 1987, p.37)

The problems with talent identification programmes that are based on perceived anthropometrical and physiological determinants of performance have been highlighted; namely, that the physically mature will tend to be identified for strength sports and the less mature for coordination sports. In addition, such processes fail to recognise the impact of the environment within the talent development processes.

Within the communist nations, the age at which an individual specialises in elitesport programmes varies depending upon the sport. However, early specialisation is very common in the Soviet Union. The earliest specialisation occurs in women's gymnastics, swimming and figure skating, with selection occurring at ages 4 to 5 years of age (Jefferies, 1986) when prediction of mature values of anthropometrical and physiological determinants of performance are low. Whilst it is recognised that these are relatively 'young-focused' activities, senior levels of competition for most sports do not begin until an individual has reached 17 years (Bompa, 1999). Thus, the problems of early identification failing to predict eventual size will be even more exacerbated. Further, such processes encourage early sports specialisation and the 'selected' are unlikely to develop the fundamental movement skills needed if transition between sports is desired. 


\section{Why such success for the Communist nations?}

The competitive success of the Soviet states seemingly verifies the superiority and efficacy of the communist nations' talent identification procedures. However, the lack of empirical support for the processes employed implies that there may be alternative explanations for their performance. An analysis of the sporting culture of these countries and their underpinning philosophy of sport involvement may provide one such alternative.

In examining this social context, Riordan (1990) highlights how, since the Russian revolution of 1917, sport within Eastern Europe (Russia, Poland, Bulgaria, Czechoslovakia and, to a lesser degree, Hungary and Romania), developed under direct central control and became an arena for defeating one's 'ideological opponents'. This led to radical change in the political attitudes to sports in both capitalist and communist states, especially within the Soviet Union (Riordan, 1993). Winning was not something to be congratulated but was expected. Riordan (1993) quotes Andrei Karpox, a ski coach:

In 1952 we had prepared a good team for the world championships. Not long before them I was summoned to the USSR Sports Committee and asked whether I could give a guarantee that we would win. We well knew what could happen should we not keep our word - knowing when the demand for invariable success came. I said I could not give a hundred percent guarantee. Then I was told we would not be going (p.249)

The scope and strength of this expectation was intense. For example, in the 1952 Olympic Games, the USSR was joint winners of the medal table with the USA. However, because they had not "won" the Games outright, the entire USSR squad suffered some disgrace upon its return.

The importance attributed by the USSR to sport was further highlighted in 1951, when they joined the Olympic movement and began providing financial support to potential world champions so they could train on a full time basis: 
Valuable resources were used to buy foreign sports equipment and to pay dollar bonuses to athletes who won Olympic and world championship medals. For a gold medal at the Seoul 1988 Olympics, for example, Soviet recipients gained 12,000 rubles $(6,000$ for silver and 4,000 for bronze medals; since the Soviet team won 55 gold medals and 132 medals overall, it cost the USSR Sports Committee about a million rubles (almost half paid in dollars) in bonuses alone. (Riordan, 1993, p.253)

Riordan (1993) highlights how funds were provided for athletes within sports that had a minority following (e.g., rowing, weightlifting and wrestling) so that the socialist states were ensured of dominating at the Olympics. Thus, the success of the USSR is not that surprising when considering that professionals were competing against true amateurs. Additionally, it is now well documented that there was widespread use of performance enhancing drugs with athletes as young as 7-8 years old.

\section{Summary}

Whilst the practical success of East European athletes on the international arena is evident, no quantitative estimation has been produced regarding the contribution of the talent identification processes employed. Indeed, it has been argued that the procedures were empirically flawed. Riordan (1986) warned against "believing that either the Soviet or the GDR TI system is scientifically tried and tested from start to finish" (p.228) and that "over half of those selected in the early stages of TI for sports schools do not attain the anticipated performance levels" (p.227). The sporting success of communist countries is therefore much more likely to be a result of their sporting culture than talent identification procedures. Considerable time and money has been invested into the development of potential world champions since the 1950s. Additionally, some consideration must be given to the role of performance enhancing drugs in their success. In short, building a talent identification system on the basis of the communist success would appear to be both empirically and ethically flawed. 
The centrally governed approach to sports development adopted by Eastern Europe was very different to that employed by the West (e.g., North America, UK, and Australia) where National Governing Bodies of Sport were both separate from one another and independent of the government. Only recently have Western nations looked to exploit the potential of employing systematic TI processes. The Sport Industry Research Centre (2003) highlight how "the demise of the eastern bloc in Europe and other communist countries around the world in the late 1980s and early 1990s left a legacy of sports development that many countries have drawn influence from" (p.9). They highlight that,

Whilst the more specific and infamous techniques of talent identification at a very early age based on anthropometrics, doping and punishing training regimes driven by sport science may not have been adopted some of the general principles have clearly been transferred into current elite development systems around the world. This has both enabled and contributed to a strategic approach to elite sports development being adopted. (Sport Industry Research Centre, 2003, p.9)

One such approach is the 'Talent Search' programme established by Australia in 1994. Talent search was designed to assist Olympic sports identify talented young athletes and prepare them for participation at the highest level of sport (Sport Industry Research Centre, 2003). The introduction of Talent Search has coincided with increased international sporting success for Australia (Hoare, 1998), and this has generated considerable interest in the approach. Consequently, the following section reviews the 'Talent Search' approach to identifying talented athletes. 


\section{Talent Search}

Talent Search, as with the majority of TI practices, focuses on employing a small number of criteria to identify the talented across a range of sports. A "battery of eight physical and physiological measurements and assessments" (Hoare, 1996, p.4) are administered and scores are inputted into a computer based interactive $\mathrm{CD}$ that generates a list of sports "based on a model of desirable characteristics that has been developed at a discipline-specific level for a variety of sports" (Hoare \& Warr, 2000, p.751) (see Table 3.4). As such, the programme appears to offer a clear and simple data-driven means of guiding individuals towards 'appropriate' sports. For example, the programme associates height and weight negatively and upper body strength and leg power positively with performance in gymnastics. In contrast, height, weight, upper body strength and leg power are all positively associated with performance in hammer throwing. Consequently, an individual who scores well on upper body height, depending on the rest of their profile, may be guided towards participation in hammer throwing. Whilst previous research has had some success in identifying unique anthropometrical, physical and physiological profiles associated with success in different sports (see Chapter 2), a number of additional factors need to be considered in relation to the efficacy of employing the Talent Search approach.

Table 3.2

Battery of Tests Administered within Talent Search (1994)

Variables Measured

Height $(\mathrm{cm})$

Sitting Height $(\mathrm{cm})$

Body Mass $(\mathrm{kg})$

Arm Span (cm)

Seated Basketball Throw $(\mathrm{cm})$

Vertical Jump (cm)

40 Metre Sprint (secs)

Multistage Fitness (level and shuttle) 


\subsubsection{The empirical basis of Talent Search}

\section{Focusing on physical determinants of talent}

Although, anthropometric, physical and physiological variables have been correlated positively with performance, the determinants of performance and potential at adolescence are likely to differ. Due to their unstable nature, mature values are hard to predict. For instance, an individual who is relatively small during adolescence will not necessarily retain this characteristic into adulthood. In similar fashion, since aerobic capacity is affected by body mass and maturity (Welsman \& Armstrong, 2000), performance on the multi-stage fitness test is also unlikely to remain relatively stable between individuals. Similar problems exist with measuring anaerobic capacity since the metabolic characteristics underpinning the relevant energy responses are also subject to growth influences. In a BOA report on TI and selection, Borms (1994) reported "the full range of capabilities for anaerobic responses would not be evident until the later stages of adolescence or during young adulthood, making it difficult to predict ability in younger subjects" (p.4). Beunen, Malina, Van't Hof, Simons, Ostyn, Renson, and Van Gerven (1981) highlighted the influence of anthropometric dimensions, skeletal maturity, socio-cultural factors and sports participation on running speed, flexibility and explosive, static, function and trunk strength.

Additional analysis of the weightings within Talent Search highlights that, as per the research results presented earlier, early maturers are likely to be identified for strength sports (e.g., rugby) and late maturers for coordination and gymnastic type sports (e.g., diving). For example, Talent Search negatively correlates height with 'talent' in gymnastics. Therefore, later maturers are more likely to be identified as talented gymnasts. In contrast, height is positively associated with performance in volleyball and early maturers are more likely to be identified as 'talented' for this sport. However, individuals in both of these groups may not maintain this beneficial physical profile into adulthood. Clearly, Talent Search does not distinguish between the determinants of performance and potential and therefore is unlikely to be effective in identifying talented individuals. In fact, what is most surprising is that 
the scheme has received so much attention when its tenets are so obviously questioned by the empirical literature.

There are other concerns with the Talent Search approach. Even if performance determinants did equate with potential during adolescence, research has shown clearly that the determinants of performance for females and males are rather different (Ackland \& Bloomfield, 1996; Carter \& Ackland, 1998; Pollock, Pels, Foster, \& Holum, 1986). For example, Carter and Ackland (1998) found substantial differences in size, proportion, somatotype and body composition between male and female senior divers. However, within Talent Search, no distinction is made between female and male values within any sport.

Finally, it also has been shown that, as performance levels improve the importance of anthropometrical factors declines. This is particularly true for team sports where factors such as effective scanning and decision-making are an integral part of performance, and play an increasingly powerful role in discriminating elite from intermediate performers (Hoare \& Warr, 2000). In summary, any talent detection and identification model that only considers biological factors is unlikely to be monitoring true determinants of potential. Indeed, research has shown that the attributes that determine the extent that an individual is able to progress along the athletic continuum are largely behavioural in nature (Kunst \& Florescu, 1971). That is, there appears to be a certain behavioural focus that an individual needs in order to acquire and perfect skills. Further, the performance of an individual once they have mastered skills also appears to be influenced heavily by psychological factors (Kreiner-Phillips \& Orlick, 1993). However, Talent Search does not consider such factors, a serious limitation to its capacity to tease out those with the potential to succeed.

\section{Focusing on basic skills as determinants of talent}

As well as anthropometrical, physical and physiological factors, Sport Interactive profiles individuals on a small range of basic skills (See Table 3.5). Research has 
been cited already in Chapter 2 that shows that to be successful within sports/ activities, individuals require the relevant fundamental motor abilities (e.g., Seefeldt et al., 1979). For example, the ability to catch a ball clearly underpins successful performance in sports such as cricket and netball. However, since these skills are not innate (Gallahue, 1982), performance levels of individuals will be influenced by individual circumstances and in particular the quality of prior movement experiences. Therefore, poor performance on motor tasks may imply a lack of prior relevant movement experiences rather than a lack of talent per se.

In conclusion, it would appear the Talent Search approach of identifying talented athletes is conceptually unsound. Talent Search is likely to identify those adolescents who are able to perform best within a specific sport at the time of testing, but consideration of the literature would suggest that it might fail to detect those with potential talent. Crucial omissions, coupled with oversimplifications based on a limited range of variables are the major apparent flaws of Talent Search. However, the sporting success currently being experienced by Australia, and the recognition of the benefits of establishing criterion based talent identification models, is resulting in many countries seizing on the Talent Search approach (e.g., France, UK and South Africa). Consequently, the next section considers the extent that the sporting success of Australia can be attributed to the deployment of the Talent Search approach.

\subsubsection{The role of Talent Search in the sporting success of Australia}

The Talent Search programme is widely considered to have been a success in identifying potential elite performers, with the often-cited example of an Olympic gold medallist identified from the 1988-rowing programme (Hahn, 1990). In 1994, after Sydney was awarded the Olympic Games, Talent Search developed into a national talent detection programme (Hoare, 1998). Children were screened for potential within athletics, canoeing, cycling, rowing, swimming, triathlon, water polo and weightlifting. Multiple world junior championship medallists and representatives were identified as a result of the national Talent Search programme (see Table 3.5). The obvious question is therefore, if Talent Search is so fundamentally flawed, how 
has it produced such enviable outcomes? Based on an in-depth consideration of the available data and information, it would appear that this success is due to a combination of factors including the complexity of the focus sports, the age at which individuals were profiled and the sporting culture of Australia.

Table 3.3

Athlete Achievements in Talent Search 1994-97

\begin{tabular}{l|l}
\hline Achievement: & $\begin{array}{c}\text { Number of Talent } \\
\text { Search Athletes }\end{array}$ \\
\hline World junior championships - medallist & 16 \\
World junior championships representation & 54 \\
National junior championships & 201 \\
National junior championships - placing $\left(1^{\text {st }}-3^{\text {rd }}\right)$ & 491 \\
State sport institute/ academy of sport scholarship & 31 \\
\hline
\end{tabular}

Firstly, the differential effectiveness of the programme on different sports must be considered. Within Chapter 2 it was suggested that anthropometrical and physical determinants are likely to be better predictors of performance within closed rather than open skill sports. It was argued that within open skill sports (e.g., rugby), due largely to the dynamic and unpredictable environment, there are multiple determinants of performance and consequently the significance of physique declines. It is noticeable that Talent Search has concentrated on identifying talent in closed sports that are characterised by a comparatively stable and predictable environment. These sports have included athletics, canoeing, cycling, rowing and weightlifting (Hoare \& Warr, 2000). Therefore, the success of Talent Search is likely to be inflated somewhat if only these sports are considered.

A second important consideration relates to the apparent success of Talent Search in the face of the considerable literature that attests to the instability of biological factors through adolescence. An explanation for these apparently paradoxical results 
is evident when the procedures employed within the focus sports are analysed.

Whilst the programme was originally designed to be employed with 14-16 year olds, an age group where anthropometrical and physiological factors are likely to be highly unstable, the identification of talent for the cycling and women's rowing programmes targeted 16-18 year olds. At this age group, both males and females will be post pubertal, and anthropometrical and physiological factors will be comparatively stabilised. That is, relative differences among individuals will be maintained into adulthood. Consequently, the employment of Talent Search with 1618 year olds allowed those individuals with favourable and relatively stable physiques for the closed sport of rowing and cycling to be identified. It is interesting to note that the major success of Talent Search has been reported within these sports.

The third potentially confounding factor relates to the social context in which Talent Search was developed, namely the Australian culture:

Organized sport looms large in the lives of many Australian children because it is so inescapably a part of the adult culture. The pressure to participate, or to back up a decision not to, is there both at school and outside. (The National Times, Feb. 3-9, 1984, p.20)

During the late $19^{\text {th }}$ and early $20^{\text {th }}$ century, sport increasingly became, and continues to be, an enormously important vehicle for cultural expression within Australia. The significance of sport to Australia is evidenced by the adulation experienced by successful sportsmen and sportswomen (Magdalinski, 2000), and the reference of sport in Australia as a national 'religion' or 'obsession' (e.g., Jobling, 1987). Horne (1965, cited in Jobling, 1987) stated that:

Sport to many Australians is life and the rest a shadow. Sport has been the one national institution that has had no "knockers". To many it is considered a sign of degeneracy not to be interested in it. To play sport or watch others and to read and talk about it is to uphold the nation and build its character. Australia's success at competitive international sport is considered an important part of its foreign policy. (p.92) 
Sporting nationalism was initiated within Australia following the success of Edwin Flack as their first gold medallist at Athens 1896. This nationalism was maintained and cultivated throughout the 'glory days' of the Melbourne Olympics (1956), the desolate years of the 1970s, and the return of Australia to the international sporting stage in the 1980s (Magdalinski, 2000, p.320). Consequently, Australia ended the 20 th century and began the $21^{\text {st }}$ century with a sense of identity founded on its athletic heritage. Whilst Magdalinski clearly demonstrates how this athletic heritage is 'largely mythical', since it is founded on the 'reconstruction' of an imagined history based on the "projection of selected memories and the obliteration of rejected memories" (p.320), their 'reconstruction' of the past only serves to highlight the significance attributed to sport in the Australian culture. The establishment of sport as a central feature of the national culture has led to its formation as a "potent expression of the nation's soul" (Horton, 2000, p.66), which has resulted in high levels of participation and attrition:

Sport can, and does, communicate a sense of identity and belonging and the relationship between family and junior sporting achievement was and is a major socializing force that emanated, and emanates, from the process of sport in Australia. The competitive intensity of junior sport and the nature of its support are, and have been, two of the most significant characteristics of the Australian sport culture that have assured sport its pre-eminence in post and present Australian society. (Horton, 2000, p.80-81)

A strong relationship between the number of players within a sport and success at international level is likely. For example, Australia's senior and junior female netball squads currently are both ranked number one in the world whilst England is ranked third and fourth respectively. If we compare the netball participation bases, 350,000 athletes are registered in Australia compared to only 47,000 in England. Clearly, and especially if TID processes rely on natural selection of individuals into sport or selection from current participants, the nation that has the larger participation base will probably develop more world-class athletes. Consequently, the influence of culture must be considered when looking for the determinants of sporting success 
within a nation, and this would appear to have had a considerable influence on the performance of Australia. Specifically, the support, status and rewards offered to an athlete in Australia are so great compared to the British scene that the transfer of any approach is likely to be fraught with difficulty. Nevertheless, practices around the world are increasingly employing Talent Search, or a similar approach, as the basis on which to establish TID processes with little or no recognition of the importance of acknowledging the unique social, physical, and cultural conditions existing in different countries when designing talent systems (Borms, 1994). In fact, in 2001, the UK purchased the licence to employ the Talent Search approach and the programme was subsequently piloted in Scotland.

In summary, the Australian Talent Search programme evaluates children on four physical and six performance tasks to identify youngsters with the physical attributes associated with success within a specific sport. Unfortunately, theoretical analysis of the programme highlights a number of weaknesses with this approach:

i. Even if the physical variables being assessed are advantageous to performance in a specific sport (and some concerns are apparent here), research has clearly shown that relative values are highly unstable throughout adolescence (Ackland \& Bloomfield, 1996) and favourable physical profiles may not be maintained into adulthood.

ii. Identification of 'talented' individuals based on proficiency on specific tasks (e.g., shuttle run) is also problematic since research has established a direct link between performance and physique, and therefore the physical maturity, of a child.

iii. The Talent Search approach only focuses on characteristics associated with performance and fails to recognise attributes that are required to develop successfully within sport.

Irrespective of these conceptual problems, considerable interest has been generated in adopting this approach. A Scottish pilot study implemented in 2001 provided an 
opportunity to evaluate the extent that the Talent Search approach can be effectively employed in practice and this study is reported in the next chapter. 


\section{CHAPTER 4 TALENT SEARCH: AN EMPIRICAL ANALYSIS OF A TRADITIONAL APPROACH TO IDENTIFYING THE TALENTED}

\subsection{Introduction}

Whilst the previous chapter established theoretical problems with the Talent Search approach, practices around the world are increasingly employing the programme, or a similar approach, as the basis for TID processes (e.g., UK athletics, Peter Snell Institute in New Zealand). Therefore, the purpose of this chapter is to look beyond the theoretical limitations and consider the extent that sporting practitioners can utilise the Talent Search approach to shape their TID procedures. A Scottish pilot study implemented in 2001 that was based on the Australian Talent Search model enabled this evaluation to occur.

Looking to establish an effective TI process, Scotland piloted a traditional physical and performance-based model of TID, the Sport Interactive model. Based on the Australian Talent Search model that forms the basis of many TI programmes in Britain (e.g., UK athletics, British rowing), Sport Interactive is a computer based interactive $\mathrm{CD}$ that directs a child towards sports based on his/her profile on a generic set of physical and performance variables (See Table 4.1). The physical and performance components within Sport Interactive were incorporated based on the assumption by the Australian Sports Commission that they link significantly with sporting performance (see Table 4.2) (Australian Sports Commission, 1993).

Unfortunately, no evidence is presented in the pack or is available in journals to support the contention that these 10 tasks are key predictors of sports competence. As such, the basis on which these factors were chosen is unclear, other than a 'common sense', face valid assumption. Additionally, and even more surprisingly, the same assumptions appear to determine the extent to which each factor is then weighted within the calculations of sport suitability. For example, whilst limb-eye co-ordination is considered as relevant for performance in both table tennis and 
fencing, it has been assigned a greater weighting within table tennis; due, presumably, to an assumption that it is of greater importance within table tennis performance (see Appendix A). Even if this assumption is accepted, the exact balance or combination of factors employed in the various weightings is unsubstantiated.

In summary, although Sport Search and Talent Search (and their subsequent reiterations) are often viewed as cutting edge, there is no underlying rationale presented nor empirical research published which offers justification for the use of these particular factors in the combinations prescribed. In fact, no evidence of any systematic evaluation of the efficacy of this approach could be found! Accordingly, this first empirical study within the thesis analyses data collected during the piloting of Sport Interactive in Scotland and its effectiveness as a tool for identifying 'talented' children in sport. 
Table 4.1

Attributes Employed as Talent Criteria within Sport Interactive

\begin{tabular}{ll}
\hline Attributes Measured & Overview of Attributes \\
\hline Standing Height & $\begin{array}{l}\text { The vertical distance from the floor to the top of the } \\
\text { head. }\end{array}$ \\
The vertical distance from the sitting surface to the top \\
of the head. It is the total of the trunk, neck, and head \\
length.
\end{tabular}


Table 4.2

Quotes used within the Sport Interactive Manual as Rationale for the Inclusion for

Each of the 11 Tasks within Sport Interactive (adapted from the Talent Search

manual, Australian Sport Commission, 1993)

\begin{tabular}{|c|c|}
\hline Component & Rationale for Inclusion in Sport Interactive \\
\hline $\begin{array}{l}\text { Standing } \\
\text { Height }\end{array}$ & $\begin{array}{l}\text { "Standing height can be an important factor in a number of sports. } \\
\text { Basketball and rowers are usually tall while weightlifters are often } \\
\text { small in stature". }\end{array}$ \\
\hline $\begin{array}{l}\text { Sitting } \\
\text { Height }\end{array}$ & $\begin{array}{l}\text { "The ratio of sitting height to standing height is relevant to } \\
\text { performance in a number of sports. In high jump, it is better for this } \\
\text { ratio to be low indicating that the legs are long relative to the trunk". }\end{array}$ \\
\hline $\begin{array}{l}\text { Body } \\
\text { Weight }\end{array}$ & $\begin{array}{l}\text { "Body weight may be relevant in certain sports. For example, distance } \\
\text { running requires light individuals whereas in some sports there may } \\
\text { be an advantage in the young person being heavier (e.g., throwing } \\
\text { events in athletics)". }\end{array}$ \\
\hline Arm Span & $\begin{array}{l}\text { "Arm span is relevant to sports such as rowing and throwing events } \\
\text { where a greater span benefits performance". }\end{array}$ \\
\hline Catch & $\begin{array}{l}\text { "Limb--eye co-ordination is an important performance indicator in } \\
\text { many team game balls, where young people are required to track and } \\
\text { intercept balls." }\end{array}$ \\
\hline $\begin{array}{l}\text { Basketball } \\
\text { Throw }\end{array}$ & $\begin{array}{l}\text { "The basketball throw is designed to measure upper body strength. } \\
\text { Sports requiring a high degree of upper body strength include rowing, } \\
\text { canoeing and weight lifting." }\end{array}$ \\
\hline $\begin{array}{l}\text { Vertical } \\
\text { Jump }\end{array}$ & $\begin{array}{l}\text { "Explosive power in the legs is related to performance in many sports } \\
\text { such as sprint cycling and weightlifting". }\end{array}$ \\
\hline Agility & $\begin{array}{l}\text { "Agility (the ability to change the direction of the body quickly) is an } \\
\text { important component in many team sports, together with some } \\
\text { individual sports such as squash and tennis." }\end{array}$ \\
\hline Sprint & $\begin{array}{l}\text { "The ability to run quickly from a stationery position is required in } \\
\text { many team games such as netball and cricket. Speed is also important } \\
\text { in sports requiring short bursts of activity at high intensity such as } \\
\text { sprint running." }\end{array}$ \\
\hline Shuttle Run & $\begin{array}{l}\text { "Aerobic fitness is an important component of a number of } \\
\text { endurance-based sports, such as long-distance swimming, cycling or } \\
\text { running. The shuttle run (mutli-stage fitness test) is used to assess } \\
\text { aerobic fitness." }\end{array}$ \\
\hline
\end{tabular}




\subsection{Method}

\subsubsection{Procedure}

In 2000, sportscotland implemented Sport Interactive in schools from three local authority regions of Scotland for 18 months. Within each of these regions, a 'Sport Interactive coordinator' was seconded to oversee the implementation of the initiative. All decisions regarding the design of the initiative (e.g., the identification of participating schools, the age of participants, the length of initiative) were determined by sportscotland and the 'Sport Interactive' coordinators.

Alongside the implementation of Sport Interactive, sportscotland commissioned an independent review of the initiative. This chapter provides an evaluation of the sportscotland initiative based on this independent review. Complete results on the ten Sport Interactive tasks (see Table 4.3) were obtained for 2498 children aged 10 to 14 years. The participants consisted of 1217 females (mean age $=12.48, \underline{\mathrm{SD}}=.65$ ) and 1239 males (mean age $=12.54, \underline{\mathrm{SD}}=.65$ ) from three regions of Scotland: Borders (445 females and 469 males), Glasgow (415 females and 420 males), and North Ayrshire (357 females and 350 males). Additionally, 390 of the children from the Glasgow region were re-tested on the 10 Sport Interactive tasks approximately one year after their initial test ${ }^{4}$. Informed consent was obtained from a parent/guardian prior to participation of children in the Sport Interactive research.

\footnotetext{
${ }^{4}$ Only the 'Sport Interactive coordinator' from Glasgow tested children on the Sport Interactive tasks on two separate occasions. The Sport Interactive coordinator for Glasgow reported that the classes retested were those where the schools were able and happy to release the children in order for the required tests to be conducted.
} 


\subsubsection{Analysis}

Based on theoretical considerations presented within Chapter 2 and generally accepted statistical principles (Thomas \& Nelson, 2001) at least four criteria would appear to be necessary if Sport Interactive is to effectively realise its stated aim; namely, "to help sports identify talented athletes and prepare them for participation in domestic, national and eventually international competition" (Australian Sports Commission, n.d.). These are as follows.

\section{Discriminability}

Given that Sport Interactive aims to predict sporting talent based on proficiency on a combination of physical and performance criteria, the tasks employed must effectively discriminate between the ability of the children on these criteria.

\section{Appropriate norms}

To interpret performances in a meaningful way, performances on tasks must be compared with normative data from a representative group.

\section{Appropriate algorithms and weightings}

The algorithms and weightings employed must be both appropriate and justifiable. That is, within Sport Interactive, the relative importance attributed to height, weight, upper body strength, leg power and agility within the gymnastic algorithm must be appropriately correlated with (and possibly causative of) gymnastics performances, and strictly, shown to be so.

\section{Relative performance stability on selection criteria.}

Finally, given that all the above criteria were met, a TI programme could then only effectively identify those children with the most potential to excel at the senior level if relative values on the variables remain into adulthood. 
Based on data collected during the 18-month Sport Interactive pilot, the following section considers the extent that Sport Interactive met these four pre-requisites of effectiveness.

\subsection{Results and Discussion}

\subsubsection{Criterion one: ability to discriminate between performances on tasks}

As previously highlighted, the participants involved in Sport Interactive completed a series of 11 physical and performance tasks. The values that the individuals obtain on these tasks are then entered into the Sport Interactive computer program. Sport Interactive automatically calculates a profile of the young person's performance on these tasks, in comparison to norms from Australian children, and highlights the sports that best match this profile through the use of algorithms. Table 4.3 provides a selection of the algorithms employed to calculate the performance capabilities of children in specific sports. Therefore, given that the tasks are predictive (and the following section highlights some concerns here), they must then be capable of producing a combination which accurately discriminates between children of different overall ability. In developing the original package, the Australian Sports Commission (1993) highlighted the importance of tasks discriminating between the performances of young people. Interestingly, they equated adequate discriminablity with the need for normal distribution of scores to be apparent.

The ability to discriminate between the performances of young people was a prerequisite. That is, at each age performance should be normally distributed. This means that some young people would perform above or below average with the majority falling around the center. There should be no right or left skew in the results (Australian Sports Commission, 1993)

However, although normal distribution implies adequate discriminability between performances, non-normal distribution may not necessarily imply an inability to 
discriminate. For example, a frequency plot of scores may be positively skewed but still be able to identify the best $10 \%$ of performers. Therefore, in order to evaluate the ability of each of the variables to discriminate adequately between subjects, histograms were employed to allow the spread of the data to be explored. Looking at Figure 4.1 and Figure 4.2, it is apparent that a sufficient range of values was achieved on all of the physical and performance tasks, and therefore individual performances on the same task could be compared. 
Table 4.3

Example of Algorithms Employed for Calculating a Child's Performance

Capabilities across 12 Sports

Sport Interactive Tasks

\begin{tabular}{|c|c|c|c|c|c|c|c|c|c|c|}
\hline & $\begin{array}{l}\overrightarrow{\vec{E}} \\
\cdot \overrightarrow{0} \\
\vec{I}\end{array}$ & 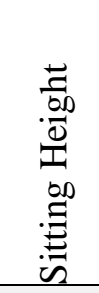 & $\begin{array}{l}\vec{E} \\
\frac{000}{00} \\
3\end{array}$ & 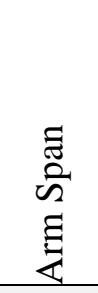 & 总 & 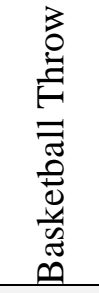 & 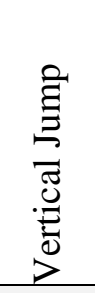 & 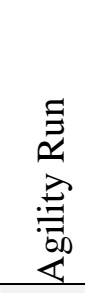 & 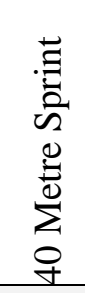 & 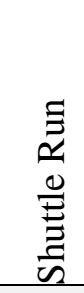 \\
\hline Archery & 0.00 & 0.00 & 0.00 & 0.00 & 0.38 & 0.31 & 0.31 & 0.00 & 0.00 & 0.00 \\
\hline $\begin{array}{l}\text { Badminton } \\
\text { Snnrt }\end{array}$ & 0.00 & 0.00 & 0.00 & 0.00 & 0.30 & 0.10 & 0.10 & 0.29 & 0.00 & 0.21 \\
\hline Curling & 0.00 & 0.00 & 0.00 & 0.00 & 0.30 & 0.15 & 0.00 & 0.25 & 0.00 & 0.30 \\
\hline Gymnastics & -0.20 & 0.00 & -0.20 & 0.00 & 0.00 & 0.19 & 0.21 & 0.20 & 0.00 & 0.00 \\
\hline Hockey & 0.00 & 0.00 & 0.00 & 0.00 & 0.30 & 0.10 & 0.00 & 0.26 & 0.14 & 0.20 \\
\hline High jump & 0.20 & -0.20 & -0.08 & 0.00 & 0.00 & 0.00 & 0.52 & 0.00 & 0.00 & 0.00 \\
\hline Judo & 0.00 & 0.14 & 0.00 & 0.00 & 0.00 & 0.31 & 0.30 & 0.10 & 0.00 & 0.15 \\
\hline Lawn Tennis & 0.00 & 0.00 & 0.00 & 0.00 & 0.28 & 0.12 & 0.10 & 0.20 & 0.20 & 0.10 \\
\hline Netball & 0.00 & 0.00 & 0.00 & 0.00 & 0.30 & 0.00 & 0.21 & 0.20 & 0.10 & 0.19 \\
\hline Rugby Union & 0.00 & 0.00 & 0.10 & 0.00 & 0.30 & 0.20 & 0.00 & 0.20 & 0.20 & 0.00 \\
\hline Swimming & 0.11 & 0.00 & 0.00 & 0.11 & 0.00 & 0.29 & 0.00 & 0.00 & 0.20 & 0.29 \\
\hline Table Tennis & 0.00 & 0.00 & 0.00 & 0.00 & 0.44 & 0.00 & 0.10 & 0.31 & 0.05 & 0.10 \\
\hline
\end{tabular}




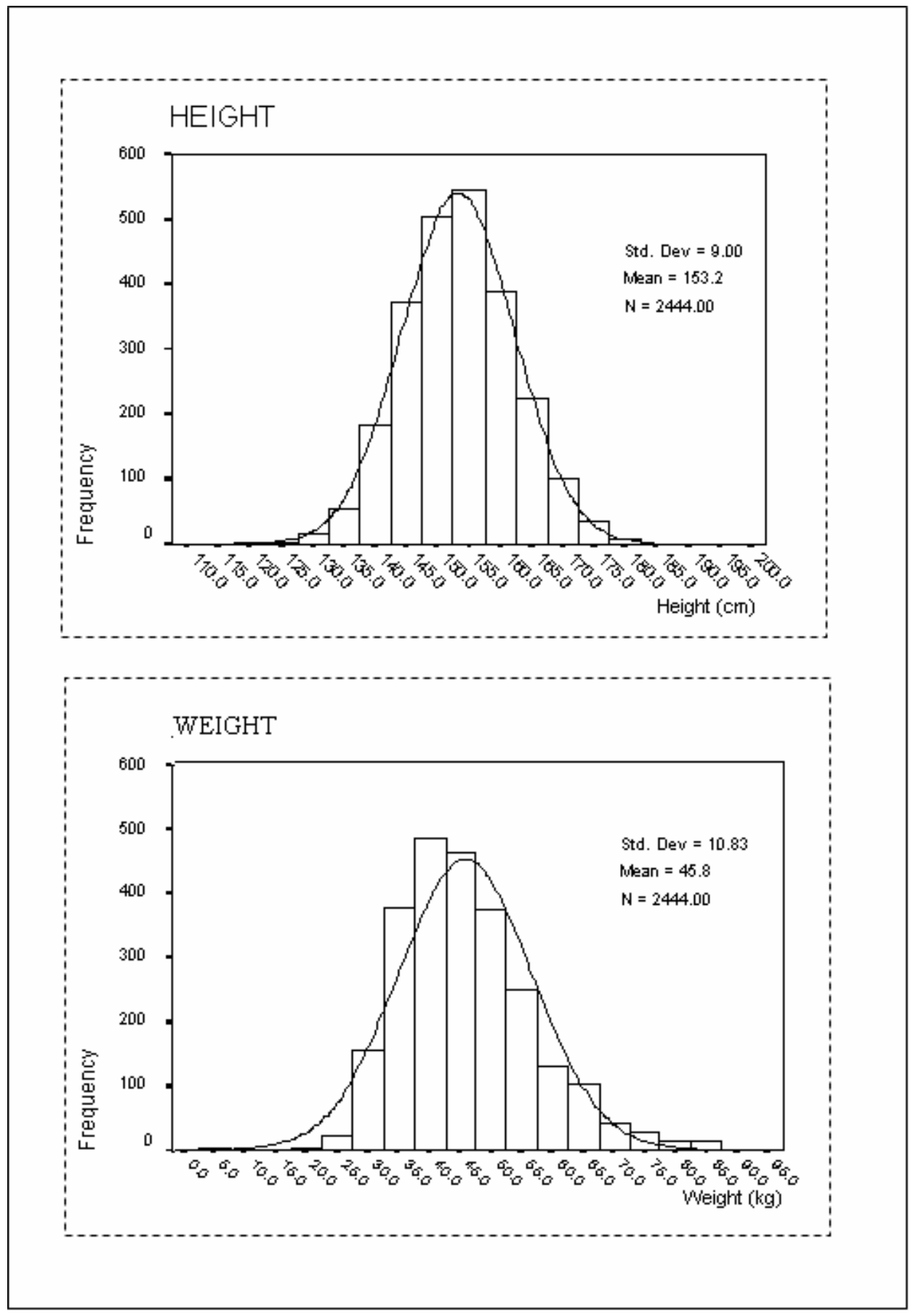

Figure 4.1 Histograms and normal distribution curves for raw scores on the physical tasks 


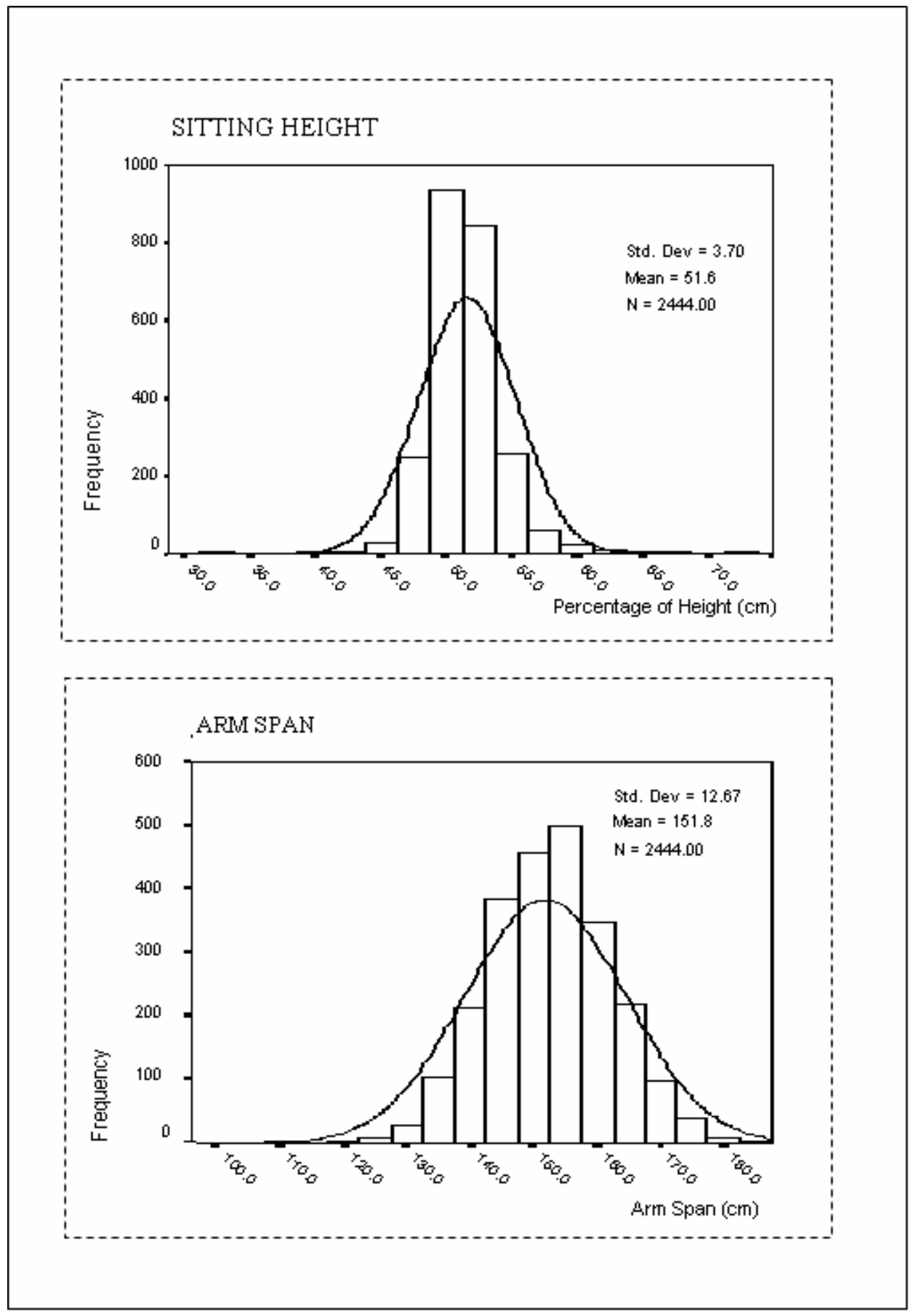

Figure 4.1 cont. Histograms and normal distribution curves for raw scores on the physical tasks 


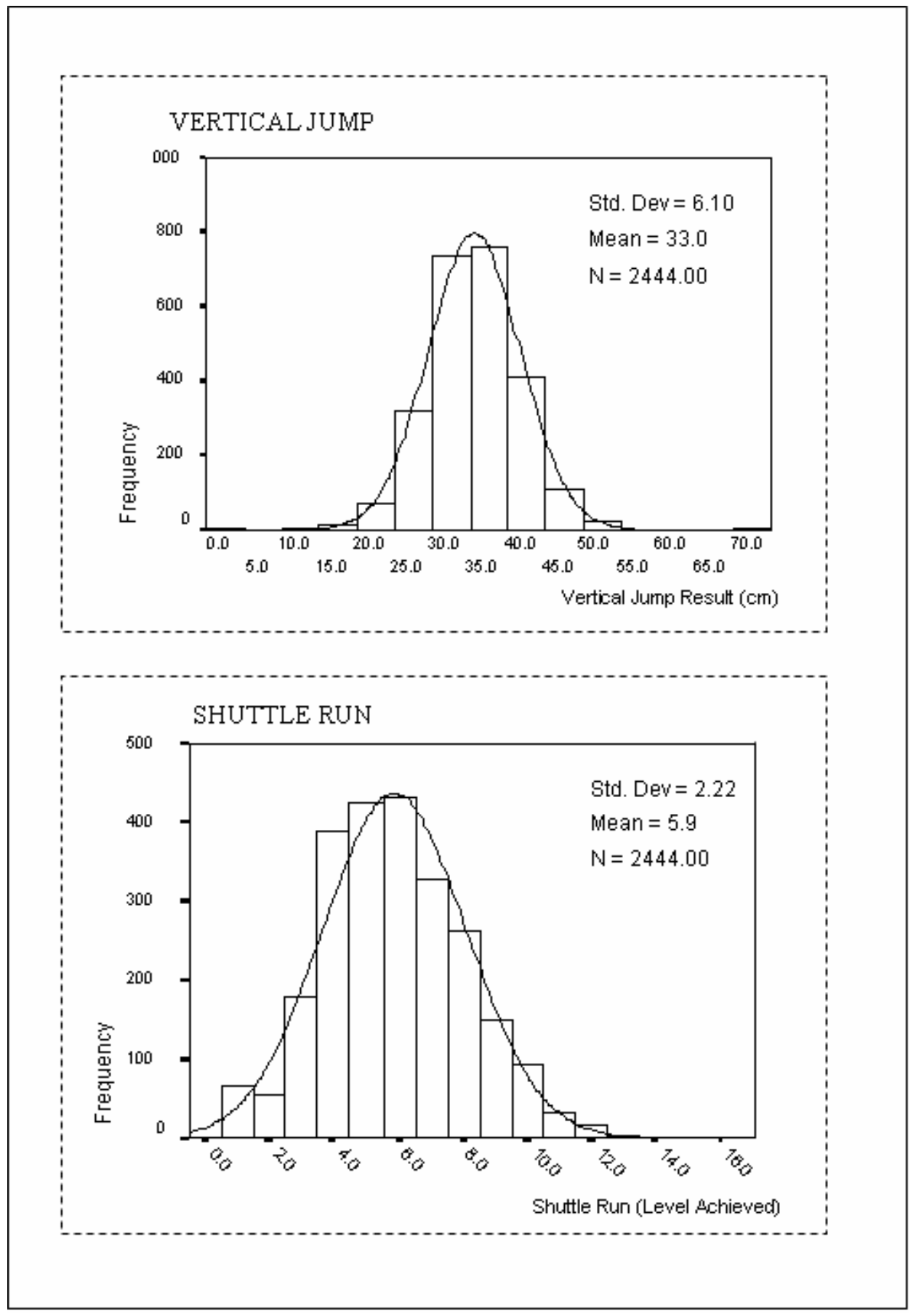

Figure 4.1 cont. Histograms and normal distribution curves for raw scores on the performance tasks 


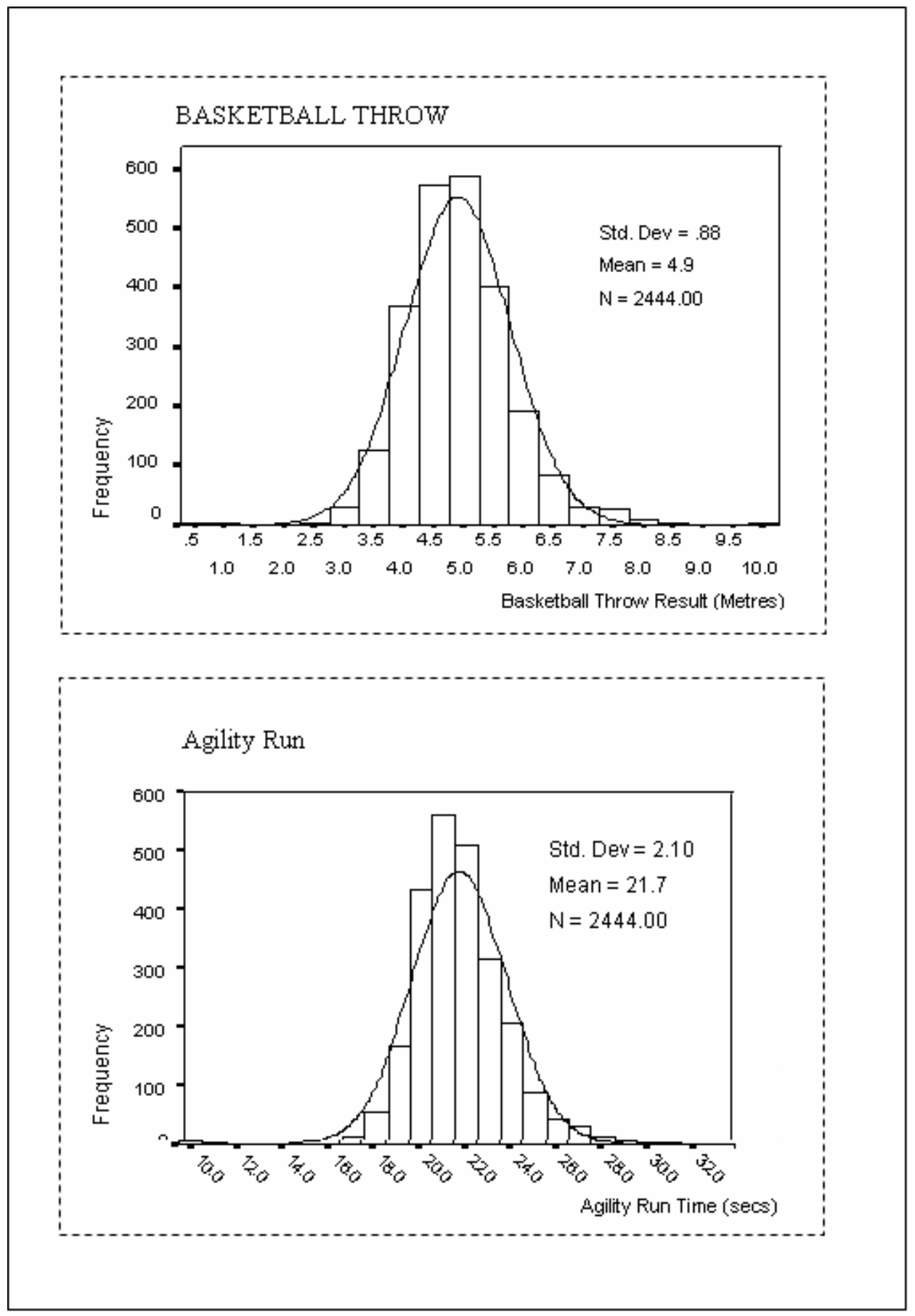

Figure 4.2 Histograms and normal distribution curves for raw scores on the performance tasks 


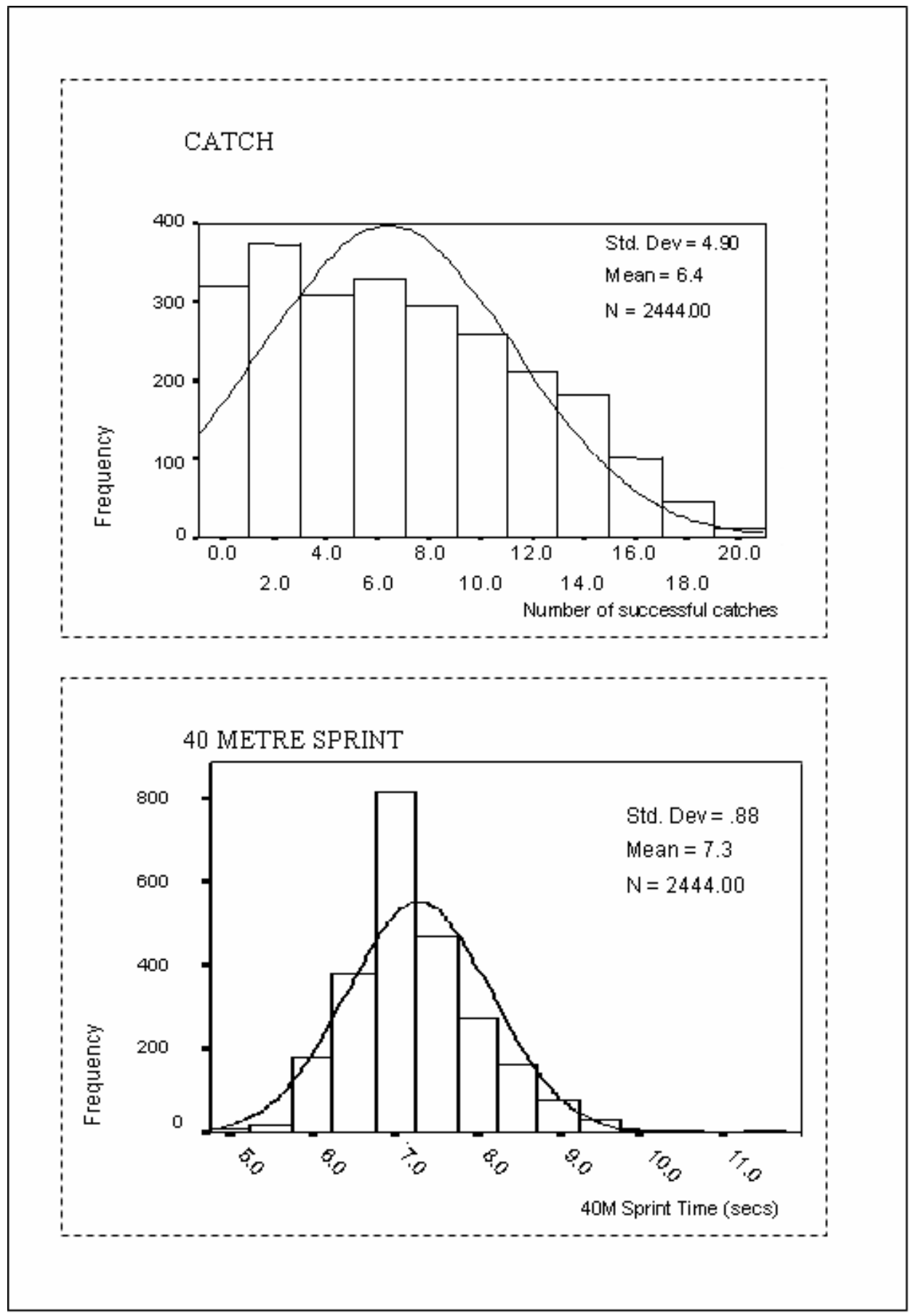

Figure 4.2 cont. Histograms and normal distribution curves for raw scores on the performance tasks 
In order for sport recommendations to occur, the Sport Interactive program must be able to compare a performance on one task with that on another. Consequently, the Talent Search programme converts raw data to percentiles based on Australian norms prior to highlighting the sports that match an individual's profile. In order for this process to be effective it would be expected that data be normally distributed once converted to percentiles. In this respect, it is interesting to note that, prior to conversion, raw scores for the Scottish children were normally distributed on all of the physical tasks and six of the seven performance tasks. However, raw scores for the limb-eye co-ordination task (the catch task) were heavily skewed (i.e., the majority of children are scoring at the lower end of the scoring continuum, see Figure 4.2). The non-normal distribution of raw scores on the catch task could be due to any one or a combination of three factors: (a) An inappropriate protocol for the testing of children, (b) an inappropriate scoring procedure being adopted, or (c) because the tasks are too difficult at the age tested.

Non-normal distribution of children's scores on the catch task was apparent across the three pilot areas, suggesting that testing protocols were consistent. However, consideration of Figure 4.3 demonstrates that children's scores became more normally distributed in the case of older children (age 13 years and older), possibly suggesting that the task was too difficult for the younger participants (age 11 years and 12 years). Therefore, at the very least, if Sport Interactive is to be employed with children who are less than 13 years of age, a more appropriate limb-eye coordination task needs to be developed. Indeed, ensuring that the tasks were appropriate across the 11 to 15 years age span was identified as a prerequisite by the Australian Sports Commission for the success of Talent Search (Australian Sports Commission, 1993). Since limb-eye co-ordination is only measured by the catch task, the distribution of scores is a major concern when employing Sport Interactive as a TI tool as this factor 'loads on' (i.e., is a performance determinant for) 21 out of the 50 sports cited.

In summary, participants achieved a range of scores on all of the Sport Interactive tasks. However, the Scottish children's performances on the catch task were heavily 
skewed. Further analysis of the performances achieved on this task clearly showed that the tasks was unable to adequately discriminate between the performance levels of the younger children (age $=11$ ). Therefore, since the majority of the younger children involved in Sport Interactive were unsuccessful at the catch task, further work would appear necessary in order to develop an appropriate limb-eye coordination task, or battery of tasks, that is appropriate across the different age groups. Of course, the use of appropriate norm data can overcome problems that accrue from skewed raw data. Unfortunately however, the following section highlights major concerns with the Australian norm data employed within the Scottish Sport Interactive programme. 


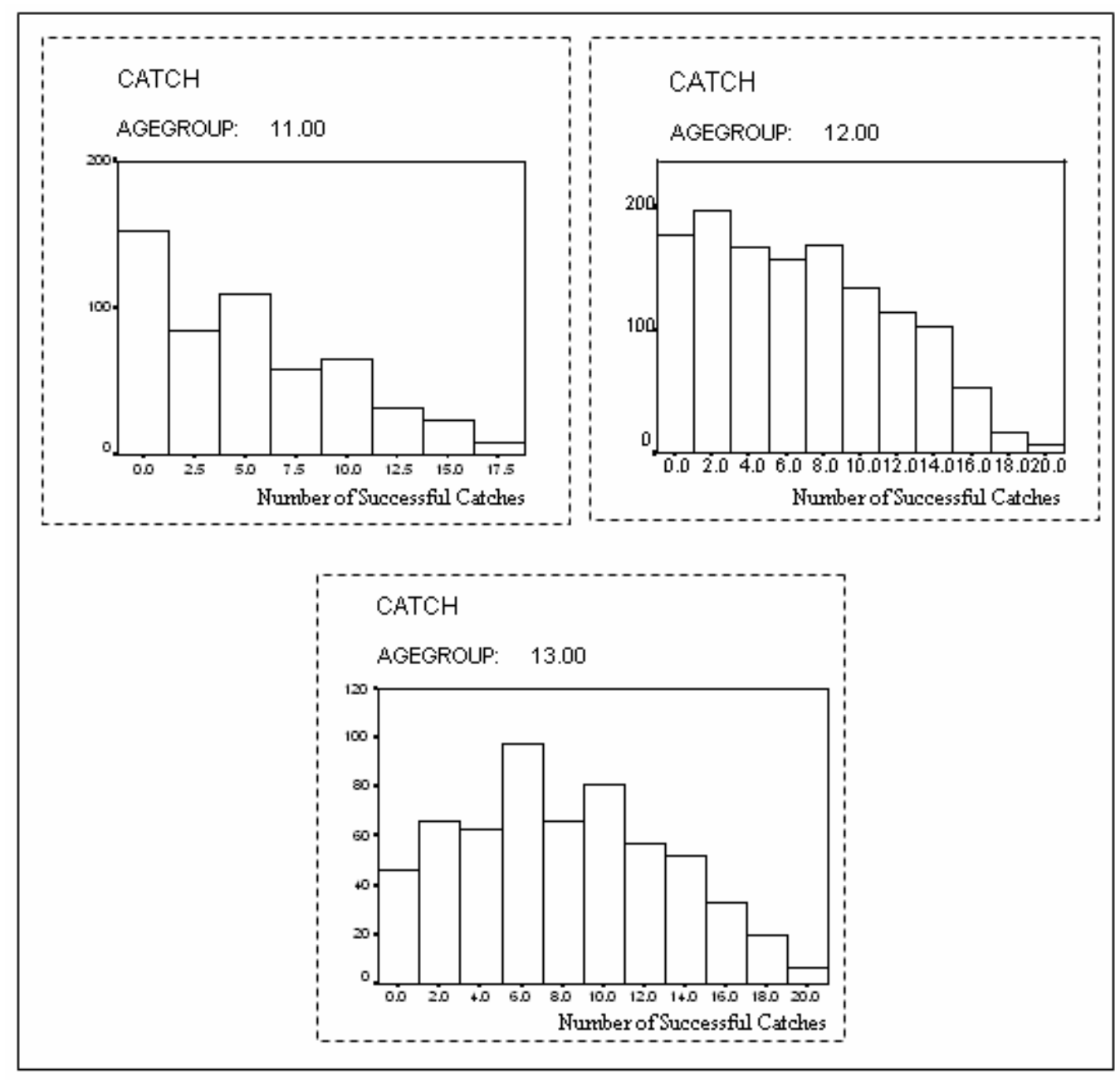

Figure 4.3 Histograms demonstrating an increasingly normal distribution of performance on the catch task with increasing age 


\subsubsection{Criterion two: interpretation of scores by comparison with a representative population}

The results on each of the physical and performance tasks within Sport Interactive do not necessarily have to be normally distributed at each age group, provided the results can be meaningfully interpreted by comparing them to an appropriate norm population. To combine them meaningfully however, some 'standardized scoring system' must be used (to combine height in $\mathrm{cm}$ and weight in $\mathrm{Kg}$ for example). Within Sport Interactive, this process was facilitated by the use of percentiles that are based on Australian norms. When employing such normative scores, it is crucial that the values accurately represent the population being studied. However, whilst Sport Interactive provides unique norms for each sex and each age group compared to the performances of Australian adolescents, the extent to which Scottish and Australian children are representative of each other needs careful consideration.

In order to establish the appropriateness of the norms employed, the Scottish children's data were converted to percentiles based on the Australian norms and the frequency with which children were classified into each of the percentiles was calculated. If the Australian normative data offers an appropriate representation for the Scottish children, one would expect that the majority of children's scores would be converted into the mid-percentile groups, with relatively few scores in the lower or upper percentiles. Figure 4.4 graphically represents the distribution of normative values on a selection of physical and performance tasks for both females and males following percentile conversions. On some tasks, the distribution of the normative values implies that the majority of Scottish children are scoring relatively better than their Australian counterparts (e.g., on the vertical jump). However, for other tasks, Scottish children's scores are lower than the scores achieved by the Australian children (e.g., on the catch task).

Further analysis of percentile distributions on the catch tasks across the age groups shows that little discrimination is occurring between the performances of the younger participants since 458 out of the 537 11-year-old participants were classified into the 
$30^{\text {th }}$ percentile or below. In contrast, only eight of these 11-year-old participants were ranked into the $80^{\text {th }}$ percentile on the catch task, with no participants being classified into the $90^{\text {th }}$ or $100^{\text {th }}$ percentile. These results further question the suitability of both the catch task and the Australian based norm data employed within the Scottish Sport Interactive programme. 


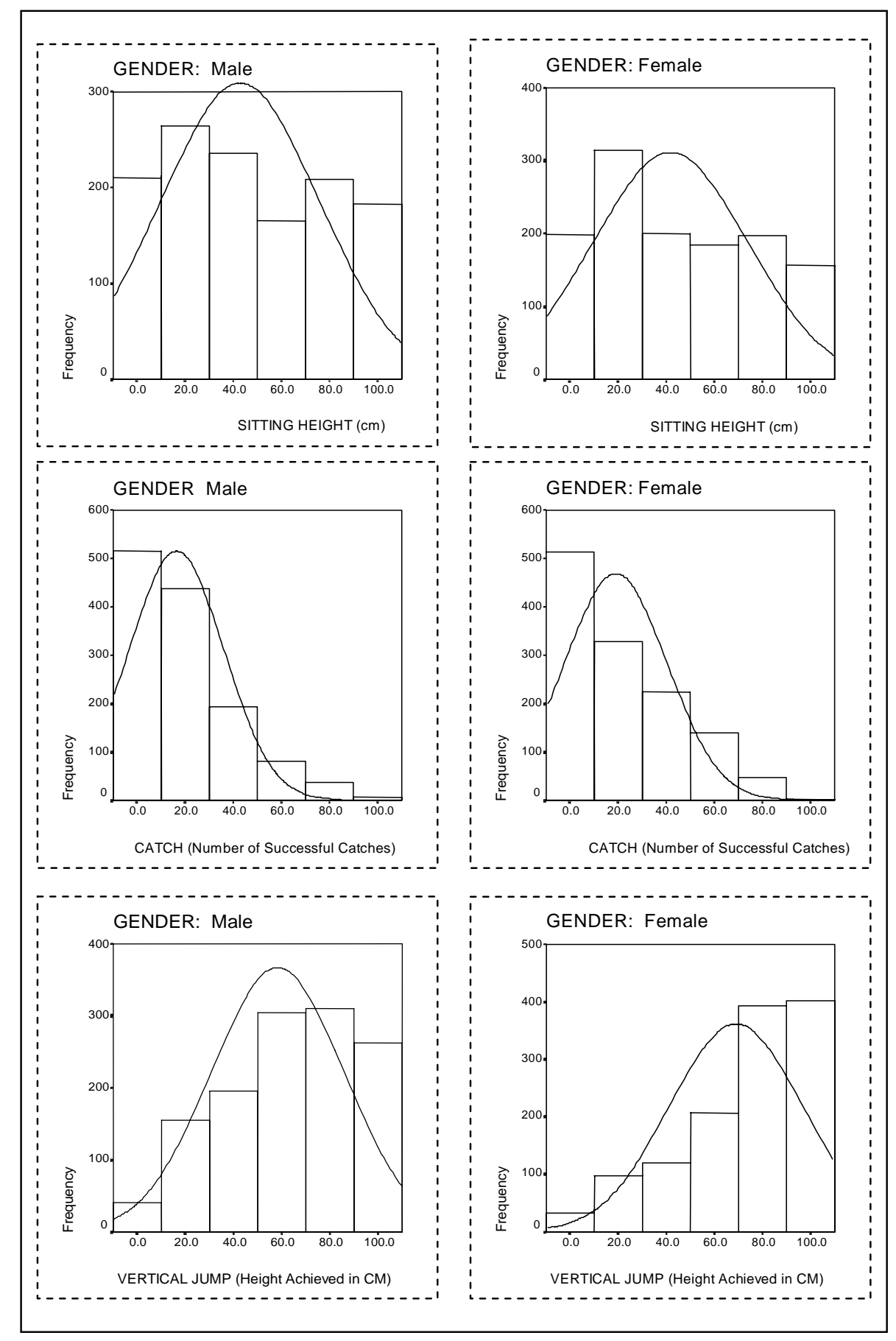

Figure 4.4 Frequency with which males and females were classified within each percentile group on a selection of the Sport Interactive tasks 
The performance differences for Scottish and Australian children across the 11 tasks may be attributable to poor or different testing procedures or the use of inappropriate normative values, or a combination of both. Scottish children may be dissimilar to Australian children due to differences on a range of factors such as sporting cultures, weather, facilities or sporting icons (Horton, 2000). However, regardless of the reason for the non-normal distribution of percentile scores for the Scottish children, biased sport recommendations occur (see Table 4.4), and therefore major limitations result for the use of the Sport Interactive computer program as a TI or sport counselling tool outside Australia.

As previously described, Sport Interactive directs a child depending on the scores they achieve on the tasks identified by the Australian Sports Commission (1993) as being correlated with performance in specific sports. Therefore, as the majority of Scottish children (compared to Australian children) scored poorly on the catch tasks and well on the vertical jump, they are unlikely to be directed towards activities where hand-eye co-ordination is identified as important (e.g., tennis) and/or lowerlimb strength is non-essential (e.g., cricket). This bias is evident when the number of times a sport was recommended as the most appropriate, or one of the top three most appropriate, sports for an individual within the Sport Interactive pilot is considered (see Table 4.4). For instance, a large percentage of children (35\%) were directed to high jump but none ( $0 \%$ ) was directed towards curling. Table 4.4 clearly demonstrates that those sports in which lower-limb strength is correlated the most with performance are most frequently recommended (e.g., high jump, long jump, sprinting). Therefore, although a child may be substantially better than their Scottish counterparts on a combination of tasks identified by the Australian Sport Commission as indicators of success within a sport, children may be deselected due to the procedure of contrasting performances with unrepresentative Australian norms. 
Table 4.4

Biased Sport Recommendation: Percentage of Time that Sport Interactive

$\underline{\text { Recommended Twelve Sports as the Most Appropriate or One of the Three Most }}$ Appropriate Sports for an Individual

\begin{tabular}{|c|c|c|c|c|c|}
\hline \multirow[t]{2}{*}{ Sport } & \multicolumn{2}{|c|}{$\begin{array}{c}\text { Times Sport In } \\
\text { Top } 3\end{array}$} & \multicolumn{2}{|c|}{$\begin{array}{c}\text { Times Sport In } \\
\text { Top } 1 \\
\end{array}$} & \multirow{2}{*}{$\begin{array}{l}\text { Tasks Included in } \\
\text { Algorithm* }\end{array}$} \\
\hline & Males & Females & Males & Females & \\
\hline High-jump & $40.01 \%$ & $31.73 \%$ & $26.18 \%$ & $20.3 \%$ & $\begin{array}{l}\text { Vertical Jump (+ve) } \\
\text { Sitting Height (-ve) }\end{array}$ \\
\hline Long-jump & $28.46 \%$ & $37.49 \%$ & $0.08 \%$ & $0.08 \%$ & $\begin{array}{l}\text { Vertical Jump (+ve) } \\
\text { Sitting Height (-ve) }\end{array}$ \\
\hline Sprinting & $39.47 \%$ & $49.64 \%$ & $27.36 \%$ & $38.77 \%$ & Vertical Jump (+ve) \\
\hline Hurdling & $12.12 \%$ & $19.74 \%$ & $0 \%$ & $0 \%$ & $\begin{array}{l}\text { Vertical Jump (+ve) } \\
\text { Sitting Height (-ve) }\end{array}$ \\
\hline Karate & $3.54 \%$ & $4.16 \%$ & $0.47 \%$ & $0.8 \%$ & $\begin{array}{l}\text { Sitting Height (-ve) } \\
\text { Vertical Jump (+ve) }\end{array}$ \\
\hline Triathlon & $1.65 \%$ & $1.52 \%$ & $0.31 \%$ & $0.08 \%$ & $\begin{array}{l}\text { Vertical Jump (+ve) } \\
\text { Shuttle Run (+ve) }\end{array}$ \\
\hline Shot-put & $16.35 \%$ & $11.03 \%$ & $7.0 \%$ & $5.44 \%$ & $\begin{array}{c}\text { Vertical Jump (+ve) } \\
\text { Basketball Throw (+ve) }\end{array}$ \\
\hline $\begin{array}{c}\text { Skiing } \\
\text { (Down Hill) }\end{array}$ & $10.69 \%$ & $4.77 \%$ & $3.2 \%$ & $5.44 \%$ & $\begin{array}{c}\text { Catch }(+\mathrm{ve}) \\
\text { Basketball Throw }(+\mathrm{ve})\end{array}$ \\
\hline Curling & $0 \%$ & $0 \%$ & $0 \%$ & $0 \%$ & $\begin{array}{c}\text { Basketball Throw (+ve) } \\
\text { Catch }(+v e)\end{array}$ \\
\hline Hockey & $0 \%$ & $0 \%$ & $0 \%$ & $0 \%$ & $\begin{array}{c}\text { Catch }(+\mathrm{ve}) \\
\text { Basketball Throw }(+\mathrm{ve})\end{array}$ \\
\hline Tennis & $0 \%$ & $0 \%$ & $0 \%$ & $0 \%$ & $\begin{array}{c}\text { Catch }(+\mathrm{ve}) \\
\text { Basketball Throw }(+\mathrm{ve})\end{array}$ \\
\hline Squash & $0 \%$ & $0 \%$ & $0 \%$ & $0 \%$ & $\begin{array}{c}\text { Catch (+ve) } \\
\text { Basketball Throw (+ve) }\end{array}$ \\
\hline aption: & $+v e=$ & po & e & With & $\begin{array}{l}\text { gorithm } \\
\text { gorithm }\end{array}$ \\
\hline
\end{tabular}


Once more, these results clearly question the appropriateness of comparing the performance of Scottish children with those of Australians, since a child's relative performance on a task compared to his or her Scottish counterparts may be misrepresented once converted into a percentile score. All these problems highlight that, at the very least, some orthonormalising procedure must be applied (e.g., using a log transform to normally distribute the data), or that British norms must be developed and universally employed. Additionally, the problems that arose from employing Australian norms should emphasize the limitations of the wholesale transfer of a programme from one context to another especially in the absence of a thorough analysis of the concepts that underpin the model. Such transfer would seem particularly problematic with diverse sporting cultures such as Scotland and Australia.

Of course, one could argue that if an individual is to achieve success on the international arena (and this surely is the basic purpose of a performance oriented TI scheme), performance on key attributes must be comparable with peers around the world. Crucially however, as highlighted in the following section, the Australian Sport Commission has presented no data supporting the predictive or criterion validity of the tasks, either singularly or in combination, as effective predictors of eventual performance. Therefore, whilst Sport Interactive assumes that a child with good upper body strength, leg power, agility and aerobic capacity will have the potential to excel in water skiing, no evidence exists that validates this assumption. 


\subsubsection{Criterion three: appropriateness of the algorithms employed to direct children towards different sports}

Table 4.3 provides an example of the algorithms employed within Sport Interactive to calculate the performance capabilities of children in specific sports. Sport recommendations are calculated by applying the algorithms to the percentile scores obtained by children on the eleven tasks ${ }^{5}$. Unfortunately, the Australian Sports Commission has not reported any research that validates the appropriateness of the tasks employed and the weightings applied to the different tasks across the different sports. Indeed, as was highlighted within Chapter 2, considerable research exists that suggests their use is inappropriate (Baxter-Jones \& Helms, 1996; de Garay, Levy, \& Carter, 1974; Dettweiler, Daehne, \& Loots, 1991; Regnier \& Salmela, 1987; Van der Walt, 1988). Therefore, there is limited, if any, scientific evidence that the algorithms employed within Sport Interactive are appropriate and justifiable performance determinants.

Even if physical and performance variables were able to predict success within a sport, Regnier et al. (1993) highlights that these performance determinants will differ according to age. Studies on rugby, for instance, indicate that kinanthropometric variables are the most significant components for determining performance levels at $10 y r s$, but that these variables decline in significance by age 16 (Pienaar \& Spamer, 1994, 1996, 1998; Van der Merwe, 1997 as cited in Nieuwenhuis et al., 2002). These results support the contention that young children's performance in sport is likely to be significantly influenced by physical maturity. However, as late developers mature and 'catch-up' with the early developers, anthropometric factors are less able to distinguish between performance levels. In contrast, the relative importance attributed to physical and performance factors remain stable across all age groups within the Sport Interactive programme!

\footnotetext{
${ }^{5}$ Some concern exists over the use of parametric statistical procedures as percentiles are on an ordinal scale (Brown, 1976, p.9).
} 
A further validity complication follows from sex differences. Although research has established that unique performance and physical profiles are important for competence in different sports (although not specifically the tasks employed within Sport Interactive), the relative importance of the different performance determinants within the same sport have often been found to be sex-specific (Bloomfield et al., 1990; Pollock et al., 1986). For example, Carter and Ackland (1998) found substantial differences in size, proportion, somatotype, and body composition between male and female senior divers. Ideally, these differences should be catered for within the task weightings for sports. However, these gender differences are not acknowledged within the Sport Interactive programme.

In summary, basing the selection of talented children on the physical and performance algorithms employed within Sport Interactive is questionable for a number of reasons. Firstly, the relationship between performance on the Sport Interactive tasks and performance in various sports has not been explored adequately. Additionally, different variables have been found to be prominent at different stages in the same sport, and for females and males at the same stage. As such, TI and TD models must be combined processes which acknowledge that success in childhood will not necessarily lead to success in adolescence and adulthood since an individual's potential will be affected by a range of variables associated with growth, maturation and development (Malina, 1997). Therefore, to account for this dynamic nature of talent, it appears that determinants of excellence must go beyond the physique and age related performance capacities of a child.

\subsubsection{Criterion four: relative stability}

390 participants were tested twice on the eleven Sport Interactive tasks. Of these, 351 children had not been involved in phase two of the Sport Interactive initiative; a talent development programme offered only to those children that were identified as 
the most talented ${ }^{6}$. Thus, any pre-post differences were primarily due to maturational rather than training related changes (reliability issues of the testing procedure not withstanding). Accordingly, analysis of the test-retest data of these 351 children allowed a consideration of growth and development changes over a one-year period and the extent that children's performances on the Sport Interactive tasks were stable from one year to the next. Figure 4.5 shows a random sample of these boys and girls at the different age groups (age 11, 12, 13 and 14), and clearly illustrates how children's scores on the four physical components did not reflect the relative stability required during this stage of adolescents to predict adult values. This instability has been attributed to both growth and development (Malina, 1997). Ages of children involved within the Scottish Sport Interactive pilot ranged from 10 to 14 years; a highly unstable period of adolescence. For example, most girls have a growth spurt between 10 and 13 years of age, and at this age, it is not unusual for girls to experience growth rates between 10 to 12 centimetres per year. Boys enter a similar period of rapid growth a little later, between 12 and 16 years (Rowley, 1992).

A Spearman correlation analysis on the rank scores of children over two test periods allowed relative stability of individuals on the physical and performance tasks to be further explored. The Spearman rank correlation coefficient was an intuitively appealing statistic since children are guided toward different sports based on their relative scores on the Sport Interactive tasks. Additionally, the Spearman correlation

\footnotetext{
${ }^{6}$ The Sport Interactive data were treated differently by each of the three regions in order to identify the most 'talented' children. For instance, within the Glasgow region, female and male scores on each of the tasks were evaluated by comparing performances within the same year. In order to conduct this evaluation, scores on each task were ranked for each group of children (split by year and gender). Those children that had (a) two or more core tasks (multistage fitness run, the 40 metres sprint, or agility task) that were in the top five of their group, or, (b) had more than one core task (multistage fitness run, the 40 metres sprint, or agility task) in the top 10 and had at least three other tasks that were ranked within the top 30 scores were invited to a talent development programme. Within North Ayrshire, children's performances were evaluated based on the Australian norms and those who had one or more core tasks (basketball throw, shuttle run, 40 metres sprint, and agility run) in the $90^{\text {th }}$ percentile or two or more core tasks in the $80^{\text {th }}$ percentile were invited to attend the talent development programme.
} 
procedure can be applied to data that are not normally distributed (as is the case here), and could therefore be used to analyze children's scores on the catch task.

Table 4.5 illustrates the rank correlation scores for male and female performances on the tasks for each age group. High instability is evident on both the physical and performance tasks, with no variable obtaining a one-year test-retest value above 0.7 across all ages. Since the Sport Interactive tests are used to select, and thereby deselect, children out of sports development programmes based on the perceived desirability of their profile for that specific activity (e.g., high-jumpers are identified as having excellent leg power and long legs) a higher reliability coefficient would appear to be essential. 


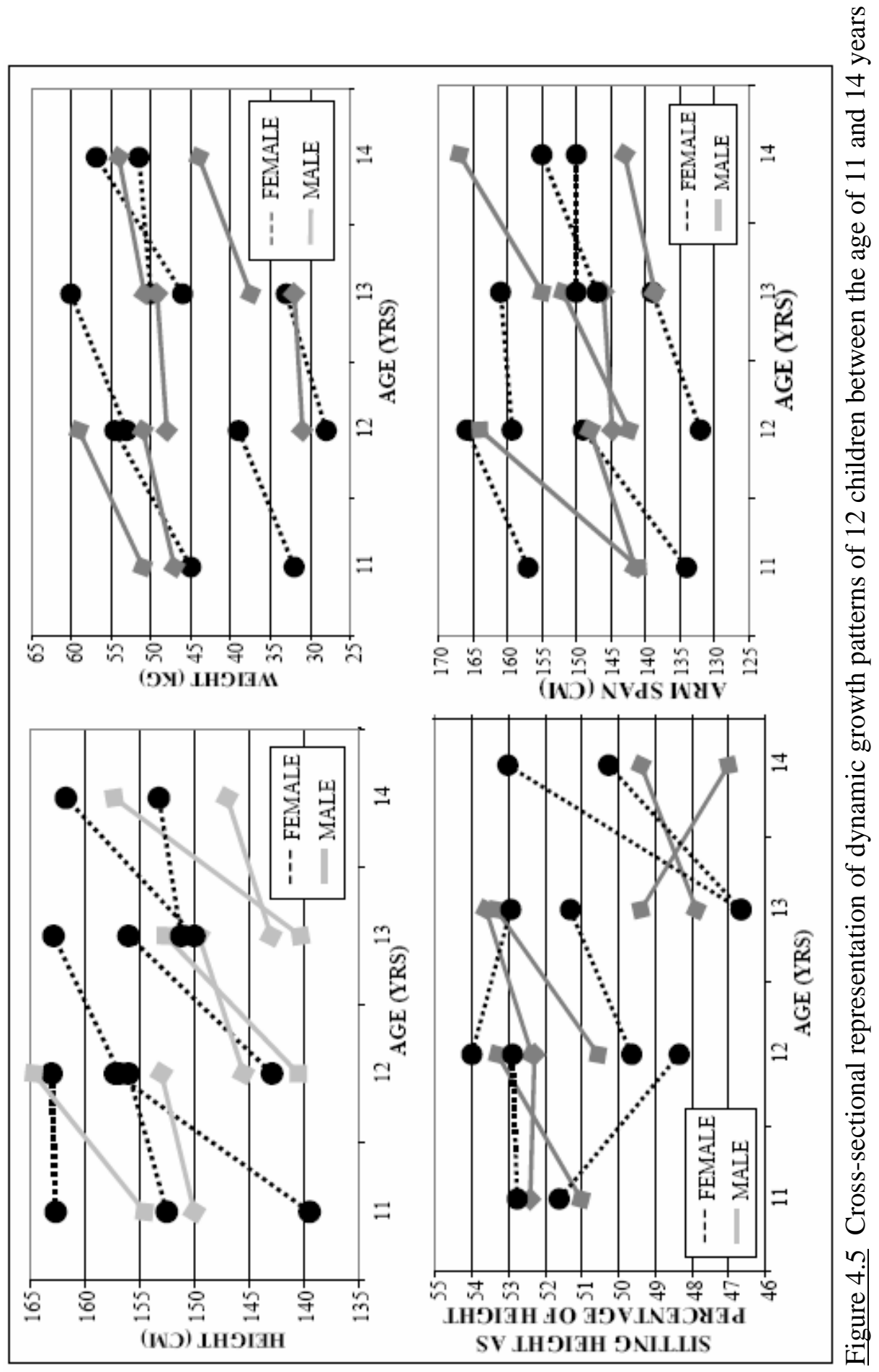

Talent Search: An Empirical Analysis 
The instability observed on the physical factors over time is not surprising since physical maturity is known to differ greatly between individuals during adolescence. As previously highlighted, research has also shown that the performance capacity of an individual will be directly influenced by their physique; therefore the instability observed on the performance tasks is also not surprising. Indeed, significant correlations between one, or more, of the scores obtained by individuals on the physical and performance components of Sport Interactive were apparent (see Table 4.6). As physique was unstable over the test period, competencies on the Sport Interactive performance tasks (e.g., the shuttle run) would also be expected to be (and indeed were) unstable over time. The unstable nature of these physique and performance scores indicates there are serious flaws in the assumption that a sport that is 'suited' to a child will remain appropriate into adulthood and that TI processes can be based upon this concept.

In summary, the low test-retest correlation scores displayed on the 10 tasks over time questions the ability of Sport Interactive to effectively identify children who will develop the physique and performance profile that typify successful senior athletes. This concern is particularly apparent when these 'predictive' measures are made at younger ages. In other words, whilst children are being monitored on factors that the Australian Sports Commission (1993) have linked to sporting performance, growth and developmental changes result in relatively unstable scores on these tests overtime. Consequently, these tasks cannot be appropriate predictors of an individual's potential to compete successfully as a senior international sportsperson. As an example, an individual may be guided towards high jump at twelve because they have long legs in comparison to their peers. However, this physique advantage may be due to the child being an early maturer and this favourable characteristic may not be maintained into adulthood. Further, even if a child has, and maintains, the physical profile that typifies successful athletes in a specific sport, they may still not have the capacity to develop and therefore resources may continue to be targeted inappropriately. 
Table 4.5

$\underline{\text { Rank Correlation on Sport Interactive Tasks over a One-Year Period }}$

\begin{tabular}{|c|c|c|c|c|}
\hline \multirow{2}{*}{ Tasks } & \multirow{2}{*}{ Gender } & \multicolumn{3}{|c|}{ Initial Test Age } \\
\hline & & 11 years & 12 years & 13 years \\
\hline \multirow[t]{2}{*}{ Standing Height } & Female & .805 & .650 & .489 \\
\hline & Male & .794 & .510 & .672 \\
\hline \multirow[t]{2}{*}{ Sitting Height } & Female & .137 & .385 & .640 \\
\hline & Male & .064 & .516 & .515 \\
\hline \multirow[t]{2}{*}{ Body Weight } & Female & .866 & .669 & .729 \\
\hline & Male & .923 & .613 & .679 \\
\hline \multirow[t]{2}{*}{ Arm Span } & Female & .691 & .622 & .500 \\
\hline & Male & .498 & .557 & .705 \\
\hline \multirow[t]{2}{*}{ Catch Task } & Female & .561 & .377 & .421 \\
\hline & Male & .426 & .397 & .495 \\
\hline \multirow[t]{2}{*}{ Basketball Throw } & Female & .699 & .513 & .664 \\
\hline & Male & .804 & .399 & .687 \\
\hline \multirow[t]{2}{*}{ Vertical Jump } & Female & .650 & .359 & .596 \\
\hline & Male & .321 & .405 & .493 \\
\hline \multirow[t]{2}{*}{ Agility Run } & Female & .482 & .365 & .587 \\
\hline & Male & .304 & .365 & .558 \\
\hline \multirow[t]{2}{*}{40 Metres Sprint } & Female & .486 & .017 & .247 \\
\hline & Male & .257 & .265 & .247 \\
\hline \multirow[t]{2}{*}{ Shuttle Run } & Female & .695 & .423 & .489 \\
\hline & Male & .551 & .464 & .371 \\
\hline
\end{tabular}


Table 4.6

Correlation between the Physical and Performances Factors in Sport Interactive

\begin{tabular}{|c|c|c|c|c|}
\hline \multirow{2}{*}{ Performance Task } & \multicolumn{4}{|c|}{ Rank Correlation Value } \\
\hline & Height & Weight & Sitting Height & Arm Span \\
\hline Catch $^{1}$ & $.184 * *$ & $.020^{\mathrm{NS}}$ & $.011^{\mathrm{NS}}$ & $.095^{*}$ \\
\hline Basketball Throw ${ }^{1}$ & $.551 * *$ & $.445 * *$ & $-0.47 * *$ & $.276^{* *}$ \\
\hline Vertical Jump ${ }^{1}$ & $.219 * *$ & $-.041 *$ & $-0.124 * *$ & $.039^{\mathrm{NS}}$ \\
\hline Agility Run ${ }^{2}$ & $-.003^{N S}$ & $-.194 * *$ & $-0.96^{*}$ & $.000^{\mathrm{NS}}$ \\
\hline 40 Metres Sprint ${ }^{2}$ & $-.157 * *$ & $.093 * *$ & $.026^{\mathrm{NS}}$ & $-.065^{\mathrm{NS}}$ \\
\hline Shuttle Run ${ }^{1}$ & $.072 * *$ & $-.224 * *$ & $-.033^{\mathrm{NS}}$ & $-.015^{\mathrm{NS}}$ \\
\hline
\end{tabular}

Note:

* Correlation is significant at 0.05 level $\quad{ }^{1}$ High score implies better competence

** Correlation is significant at 0.01 level $\quad{ }^{2}$ Low score implies better competence

In relation to the stability of physique and performance criteria, talent identification and development processes should be combined and selection should not only consider age group performances (which can be greatly affected by growth and maturation, see Chapter 2), but should also reflect the progress and behaviour of an individual within a development programme. Traditional programmes, such as Sport Interactive and Talent Search, may prematurely eliminate many potentially talented, but late maturing youngsters. Additionally, such models may lead to the demotivation of children from a sport (and potentially all sport) since early selection of an individual, due to his/her display of age group excellence, may be closely followed by de-selection once their physical advantage disappears. For example, in age group swimming it is not uncommon for a child to be successful in one age group only to be relegated to a low position in the rankings when he/she moves to the next age group (Malina, 1997). As Ericsson et al. (1993) have highlighted, achieving success within any domain is a long-term process (typically 10,000 hours of formal practice). Consequently, it is imperative that support mechanisms (emotional, financial and coach) are consistently available across this development process. 
Unfortunately, traditional TI models, where 'talent' is identified and subsequently funded based on age group performances, do not optimally facilitate this long-term development process.

\subsection{Conclusions}

The previous chapter has emphasized both the dynamic (a child's profile on required components change overtime) and multi-dimensional (an optimum physical profile does not guarantee the child has the capacity to develop into a successful performer) nature of talent. Data presented clearly highlight the limitations of employing either physical or performance tasks, or a combination of both, as the main criteria to identify children for, and eliminate children from, TID programmes. What is surprising is that TI programmes that emphasize the physique and performance capacities of adolescents continue to receive substantial support even though the extent that they have contributed to the accomplishment of successful sporting nations is not known (Hill, 2002). Clearly, a shift in emphasis needs to occur if TID programmes are to be effective since, as previously highlighted, the key indicators of the capacity an individual has to develop appear to be psycho-behavioural in nature. In other words, regardless of their physical and skill prowess, an individual will only successfully develop in sport if they optimize the development opportunities they are afforded by adopting an appropriate focus within and between training and competition.

Furthermore, the ethic of employing approaches based on this static conception of talent is, at least, questionable since children are being deselected based on a 'weakness' that may be compensated through maturity and appropriate development. The limitations inherent in Sport Interactive highlight the need for personnel involved in TID to analyze rigorously the efficacy of the philosophies that underpin a programme. Further, if the philosophies underpinning a programme are sound, consideration also needs to be given to the extent that these philosophies can be transferred to and be adhered to within different contexts. 


\title{
CHAPTER 5 HOW SHOULD TALENT BE IDENTIFIED AND DEVELOPED? EXPERIENCES OF WORLD-CLASS ATHLETES
}

\author{
"A truly scientific account of exceptional performance must \\ completely describe both the development leading to \\ exceptional performance and the genetic and acquired \\ characteristics that mediate it" (Ericsson et al., 1993, p.363)
}

\subsection{Introduction}

As the preceding chapters have outlined, the potential of establishing scientific TI programmes is an appealing concept. However, identifying individuals with the greatest potential to excel in sport presents a major challenge. If talent is to be understood, and efficacious TID processes developed and implemented, it is essential that theory and practice become more sensitive to the complexities that are suggested by a multi-dimensional and dynamic view of talent and its determinants. As Ericsson et al (1993) highlight in the statement above, exceptional performance not only results from optimum performance characteristics (e.g., height, decision making) but also requires an individual successfully to negotiate the pathway to excellence. Therefore, excelling within sport typically requires an individual to adjust to many setbacks (e.g., non-selection, de-selection, injury, performance slumps) and advancements (e.g., changing coaches, changing teams, gaining international selection, increased training). Unfortunately however, little research has directly addressed the issue of what factors distinguish those athletes who successfully exploit their talent from those who do not (Fisher \& Borms, 1990; Lidor \& Lavyan, 2002; Matsudo, 1996). Clearly, an increased awareness of the current development processes of elite athletes would help ensure an appropriate emphasis is given to the range of variables that impact development and help optimize TID processes (Lidor \& Lavyan, 2002). While longitudinal studies would provide useful insight into the development experiences of successful athletes, these are difficult to conduct due to time and cost constraints typically imposed on research. In the absence of 
longitudinal research, Lidor and Lavyan (1997) highlight how retrospective studies that interview individuals who have reached world-class levels can provide insight into attributes perceived to impact talent identification and development. Therefore, the purpose of the research presented in this section was to conduct retrospective interviews with world-class athletes to gain an insight into the factors that distinguish between those who emerge and fail to emerge among the talented. Corroborating interviews with a parent/guardian/significant other were also conducted for each athlete.

\subsection{Method}

\subsubsection{Participants}

Data were collected from female $(n=4)$ and male $(n=3)$ world-class athletes and a parent for each of the athletes $(n=7)$. Interviewees were identified and recruited based on having competed at world-class level in their sport and being known to the supervisor of this thesis. When identifying potential athletes, emphasis was placed on seeking out individuals who had been "consistent" outstanding performers in their chosen sports over a number of years (e.g., placing in a World event several years in a row). This criterion enabled factors that impacted the development process from initiation in sport to obtaining and maintaining world-class status to be explored. The ages of the athletes ranged from 21 to 37 years $(M=30.1$ years, $S D=5.0$ years $)$ and each had competed at the top of their sport between 4 and 13 years $(M=7.5$ years, $\mathrm{SD}=2.8$ years). At the time of the interview, five of the athletes continued to participate in senior international competitions whilst two of the athletes had retired from international competition in the previous two years. Interviewing athletes across a range of sports ensured that those selected were clearly among the top in their field. Additional demographic and sporting information for all athletes is presented in Table 5.1. Interviews were also carried out with a parent or guardian of each athlete that was perceived to have contributed significantly to their development; athletes were asked to identify the individual that best fulfilled this criterion at the conclusion 
of their interview. Prior to the commencement of the interviews, confidentiality and anonymity was emphasised and participants provided informed consent. 


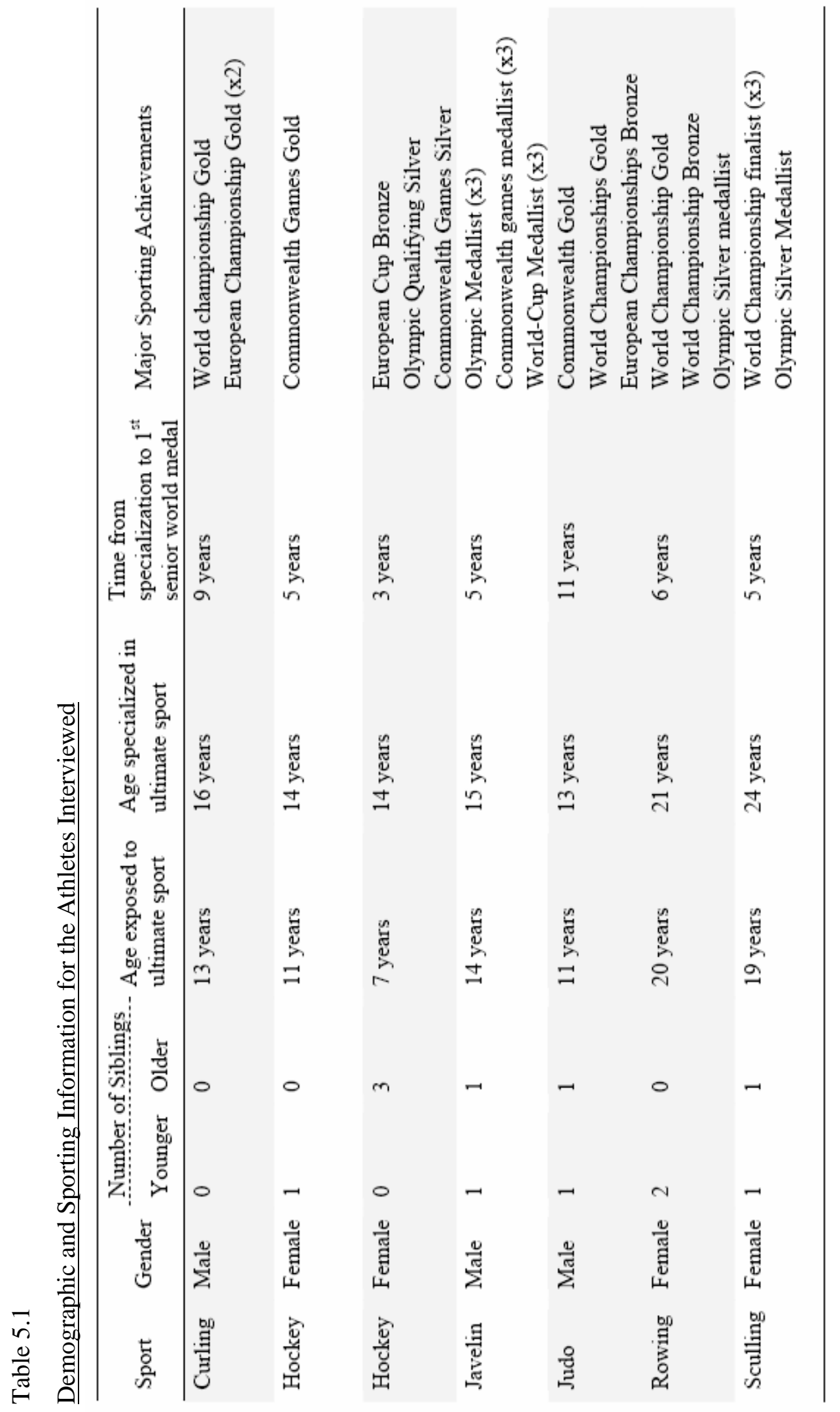

How Should Talent be Identified and Developed? 


\subsubsection{Procedure}

The aim of this study was to identify attributes that were perceived to have contributed to the development of an athlete into a successful and consistent worldclass performer. Prior to meeting the athletes and parents, a semi-structured interview was drawn-up. The interview was designed to enable athletes to map out their development in sport from early childhood to achieving and maintaining world-class performances (see Table 5.2). Athletes were initially asked to describe what he/she remembered to be their first recollection of physical activity before detailing how they developed from this initial experience into becoming a world-class athlete. Based on issues previously identified within the sport science literature as facilitating and inhibiting the development of elite athletes (e.g., role of significant others, dealing with setbacks, access to resources, competing commitments, physical attributes), potential follow-up probes were prepared for each area of interest to allow the focus to move from the general to the specific (see Appendix B). The same issues were discussed with the athletes and parents. On meeting the interviewees, it was explained that the purpose of the interview was to gain an insight into factors that they perceived contributed to their (their son's/daughter's) development into a world-class athlete. Anonymity and confidentiality was assured. Interviews lasted between 60 and 90 minutes. All interviews were recorded and transcribed in full. 
Table 5.2

$\underline{\text { Key Themes Explored in Semi-Structured Interviews }}$

\section{Key Interview Question}

Q1 How did you (your son/ daughter) become involved in sport and progress from initial involvement to where you are (he/she is) today?

Q2 Why did you (he/she) specialise in your (his/her) sport?

Q3 When and why did you realise you (your son/daughter) had the potential to be very good at sport?

Q4 Were there any points in your (son /daughter's) development that you (he/she) found particularly difficult?

Q5 What factors distinguished you (your son/daughter) from those who did not demonstrate talent?

Q6 What factors distinguished you (your son/daughter) and other 'talented' athletes that did not quite make it?

Q7 Did you (your son/daughter) face any different challenges when you were (he/she was) striving to get to the top compared to trying to remain at the top?

\subsubsection{Analysis}

Interviews were transcribed in full and content analyzed. Inductive content analysis, which allows themes and categories to emerge from the data (Scanlan, Stein, \& Ravizza, 1989), was employed. Athletes' quotations were used to depict the raw data themes that formed the first level of analysis of the data. Entire quotations that represented participants' perceptions of either (a) early sporting experiences or (b) determinants of talent were selected. Producing a summary statement describing each quotation created raw data themes. Following the recommendations of Krane, Andersen, and Strean (1997), an inter-rater reliability check was conducted at this stage by having an independent person critically question the summary statements to ensure that they accurately reflected quotations. This reliability check was conducted by a sport psychologist with previous experience in inductively analysing interview data. A high level of agreement (96\%) was achieved. Where disagreements occurred, 
consensus was achieved through further discussion. Once raw data themes were compiled, an inductive analysis of the data was undertaken in order to generate higher order themes that linked similar raw data themes together into a higher-order concept. The inductive process of comparing and contrasting continued until it was deemed not possible to locate further underlying uniformities to create a higher-level theme (Scanlan et al., 1989).

\subsection{Results and Discussion}

The purpose of this retrospective study was to explore the mechanisms perceived by world-class athletes and significant others to have impacted on their development from initiation into sport up to attaining and maintaining world-class status. The information is organized into two main sections. The early sporting experiences of the athletes are discussed in the first section. The second section explores the attributes perceived to underpin sporting talent and is subdivided into (a) issues related to successfully developing within sport, and (b) issues pertaining to producing and maintaining world-class performances.

\subsubsection{Early sporting experiences}

Athletes, and their parents, reflected on the processes and events they remembered occurring during their initial steps into their respective sports. This first section deals with the nature of these early sporting experiences. Specifically, the nature of sporting involvement during initial years, the influence of parents on early sporting involvement and the degree of perceived success during early sporting endeavours are considered (see Table 5.3).

Although one of the athletes reported that they did not participate much in sporting activities during school years due to a medical condition, the remaining participants reported an active involvement in sporting activities during their early years. This early years involvement typically involved playing a range of activities with siblings and/or watching parents coach or participate in various sports. Five athletes reported 
that sport was an integral part of their family life, with parents perceived to have been a major source influencing the athlete's initiation into sport. These athletes reported having at least one parent who played sport competitively, coached a sports team, and/ or taught physical education during the athletes' childhood:

You know it's only the fact that I was involved in sport; we went to sports meetings every Saturday. When I say I was involved I lived it, you know I mean golf is part time compared to me athletics, I dreamt it, slept athletics, even when I got married... so they would go to sports meetings every Saturday and out of the blue he wanted to throw the javelin. [Javelin thrower's father]

This is consistent with recent research that has found that both parental encouragement and having a parent who exercises positively promotes physical activity in children (Tergerson \& King, 2002; Weiss, 2000). While the parents of two of the athletes' (siblings) did not have links with physical education or competitive sports, these athletes reported that their parents enjoyed leisure activities such as sailing and walking which had provided them with positive experiences from a young age. 


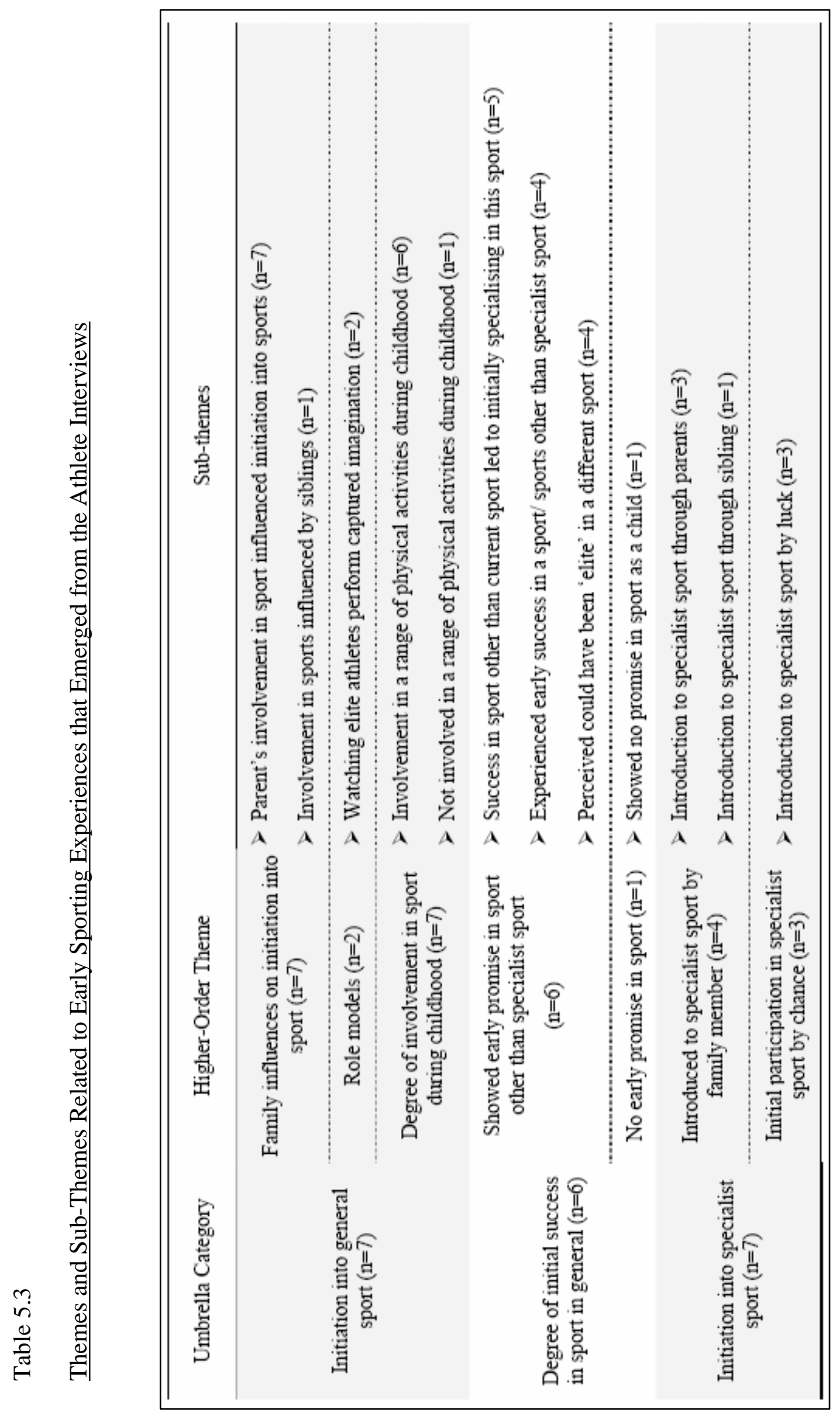




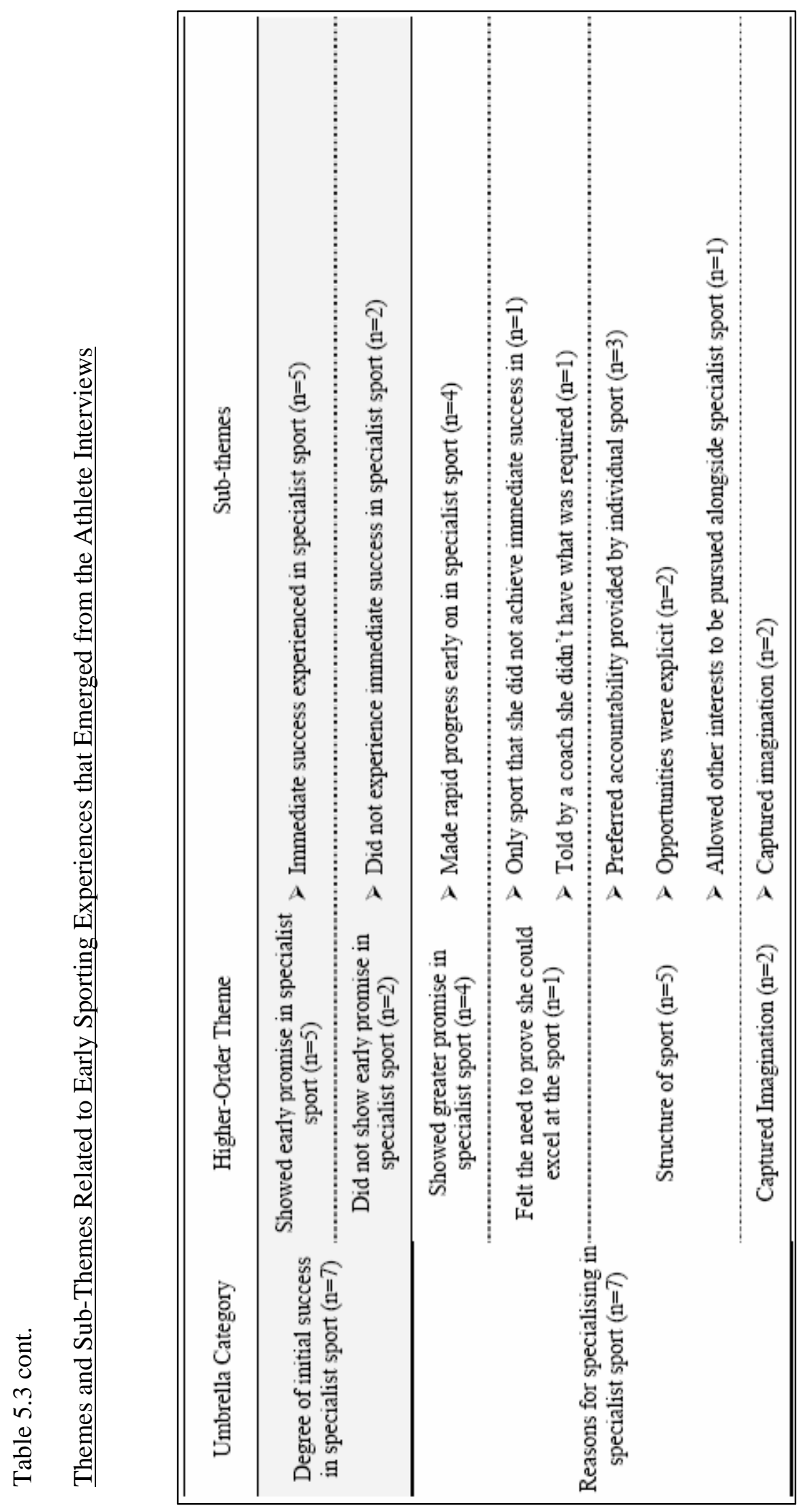

How Should Talent be Identified and Developed? 
The influence of other family members was also apparent when interviewees described the interaction of the athlete with their siblings. All but one of the athletes interviewed had brothers and/or sisters (see Table 5.1) and reported regularly taking part in sporting activities in the "back garden". All of these athletes believed that these family activities had positively facilitated their motor skill development. Parents also highlighted the positive impact that siblings had on the development of the athletes $(n=6)$ :

I think possibly with [my daughter] one of the differences might be that being a girl and playing amongst the boys really develops a talent that was already there and I mean she started playing as well at a young age in the men's hockey club and I think that probably again enabled her to really develop those skills. And the boys (the 3 older brothers) are good. Two of them play for national league hockey clubs so [all four of them] did have a high level of skill so they had a 'two on two' game right from the start. They used to play hockey on the patio in their rollerboots actually. They rollerhockeyed on the patio and in that small situation you have to develop good skills [Hockey player's mother]

Additionally, the competitive nature of all athletes was stressed and both parents and athletes thought that sibling rivalry had contributed to the early development of this characteristic.

I love competing. I've got an older brother and my dad, you know, used to encourage me to beat my older brother .... So it was never, you know, it was never easy. So yeah, from a sort of athletic perspective and on a needs basis, you know, there was lot of sequence of events through those early days [in my life] that created in a way my sort of personality now, and it's ideal for a javelin thrower. [Javelin thrower]

If his older brother, nearly 2 years older than him, if they did press ups, when his older brother did 20, [he] would do 21, you know he was that type of kid and he was a competitor, he wanted to do one better. [Javelin thrower's father] 
Those athletes without siblings were also perceived to have been highly competitive from a young age and this competitiveness was often attributed to a combination of genes and modelling the behaviour of parents:

It must be in the genes, because I suppose a little bit of that I can see myself in it, I was always determined if I met a challenge I'd like to try and meet it and I do like challenges myself but I don't know, apart from in the genes I wouldn't like to say. I suppose it's because we always faced her with challenges of catching a ball and she wanted to be able to do it I suppose. ... If they watched someone like me play, I was always a very determined player ... and I think they definitely pick it up from certainly observing parents. [Hockey player's mother]

\section{Broad or narrow sporting involvement.}

Generic sport involvement is thought to contribute to the development of large and well-organized schemata of movements (Schmidt \& Lee, 1999) due to practice of a variety of fundamental motor skills under various conditions. This broad skill development may be an important element of elite sports where athletes are required to adapt skill execution to meet task demands that are likely to vary from one situation to the next.

With the exception of the athlete whose participation in sport during childhood was limited due to a medical condition, all of the participants took part in a range of sports during early years. The success of the athletes across their broad sporting involvement varied. For instance, one of the hockey players reported excelling across sports from a young age. This athlete's mother also reflected on this early success:

She was actually the first girl in Nottinghamshire to become a member of the area football team, she played county cricket until she was 13 I think and also county tennis ... I think one year she was captain of the boys cricket team at school, so she just enjoyed it [Hockey players mother] 
However, while the javelin thrower reported doing "all right" across sports (e.g., "I'd maybe get to a school first team and stuff like that in rugby"), "he didn't show early signs of being talented in sport, he was no better than anybody else" [father]. Further, not only did some of the athletes feel that they did not stand out across the sports that they took part in during early years, the degree of early success in the sport that they eventually excelled within also varied:

It took me 3 years to win my novice pot [to go from novice to senior status]. [Sculler]

I improved quite quickly in the beginning. I'd say the first time I threw was 20 , maybe 25 meters maximum, and I went and practiced and within a very short space of time I got around 40 meters within literally a few months of practice. [Javelin thrower]

This variation in the degree of early sporting success experienced by these athletes' highlights the danger of relying on performance indicators of talent. It is of interest that while the father of the javelin thrower highlighted that early performances within sport did not emphasize his son's talent, his willingness to move out of his comfort zone and make personal sacrifices in order to further his development may have been a useful early indicator of potential:

He wanted to be better all the time. He chased coaches, I mean I coached him only until he was English School Champion and verging on International and then he was looking for something better and although at the time it was a little bit tearful, I'd been at athletics all me life it was obviously for the best [Javelin thrower's father]

As well as alluding to determinants of development going beyond performance capacity, athletes also discussed the importance of psychological factors during early sporting experiences. For example, the javelin thrower felt that, outside of javelin, he did not display athletic talent. However, rather than attributing this lack of talent to 
physical weaknesses or skills deficiencies, he perceived that his lack of success was primarily due to a lack of self-belief:

I don't think I would have shone [in any other sport but javelin]. I didn't have the belief [in other sports], I didn't have. There were people a lot better than me and I was quite, well not happy, but I accepted that they were better than me. And the javelin throwing, for some reason, if somebody beats me I don't accept that they're better than me. [Javelin thrower]

Similarly, the curler did not experience early success within his sport and attributed this lack of early success to a poor psychological approach to training and competing rather than due to the absence of physical talent:

I'm really annoyed at myself that I wasted my first six years in competitive sport. Because I could've been an awful lot better and it was purely because I was having so much fun playing the sport. [Curler]

Four of the athletes perceived they could have excelled in a sport other than the one in which they ultimately specialized. Once again, psychological attributes were thought to underpin this ability to excel:

I think I would have come through [in rugby]. I think it is possible to come through with the right attitude, to come through the other system of rugby just by applying yourself. [Judo player]

I'm fairly sure that I'd have been able to make it in other sports apart from curling. ... it's got to be hand-eye coordination, it's got to be awareness of body and actually a desire to win [that would have enabled me to make it in other sports]. But again, there's a lot about dedication as well. There's a massive amount of people who are very talented but don't have the complete dedication that'll enable you to triumph in a sport. [Curler] 
All of the athletes interviewed highlighted the importance of having the belief in one's own ability to succeed. For example, reconsider the javelin thrower who highlighted that a lack of self-belief had significantly contributed to his lack of success in sports beyond Javelin. Considerable research supports the importance of self-belief in sport. Specifically, research has highlighted how perceived competence is important for both the uptake and maintenance of physical activity involvement. For instance, Jess, Collins and Burwitz (1999) highlighted how low physical activity levels post growth spurt is much more a concomitant of perceived competence than it is lack of knowledge or even opportunity. Further, Lumpkin, Stoll, and Beller (1999) reported that in the absence of self-belief, many athletes might drop out of sport. Therefore, these results may suggest that perceived competence is a necessary attribute for individuals to realize their sporting talent. An implication of these data is that sports that focus on physical determinants of performance will provide little reinforcement to talented but late maturing individuals, and such processes may lead to these individuals withdrawing from a sport before their talent is recognized.

Irrespective of the degree of success the athletes experienced in the range of activities they participated in, multi-sport activity was perceived to have contributed to their successful development within their ultimate sport:

I just look at the guys who curl with me, and there's no one who I couldn't point at and say, he's an all- round sportsman. The guys that I curl with are very very sport minded, they've all had a very broad background in sport... they've all got very good hand-eye co-ordination. You could put them into any sport and they will be better than average, even if they haven't played the sport before. And you could just bet your life on that because you know, they've been cricketers, badminton players, footballers - they've all excelled at something as well as curling. [Curler]

Current research is increasingly supporting the benefits of participation in a range of relevant activities during childhood (e.g., Baker, 2003; Barynina \& Vaitsekhovskii, 1992). Therefore, the current trend of encouraging children to choose between sports at increasingly younger ages may actually disadvantage an individual's development within sport. 


\section{Sport specialization}

The age of exposure of the athletes into their ultimate sport varied from 7 years to 20 years of age (see Table 5.1). Additionally, the length of time between an individual's initial exposure to a sport and his/her specialization in that sport also varied from less than a year to seven years. For example, one of the rowers did not become involved in their sport until 19 years of age and specialization did not occur for another 5 years as she continued to pursue her shot putting career. In contrast, the other rower specialised within her first year of involvement in the sport at 21 years of age. Related research has suggested that successful athletes tend to specialize in their sport later than those athletes that are less successful. For example, Lidor and Lavyan (2002) found that sub-elite athletes tended to get involved in their sports and specialize earlier compared with elite athletes.

A high degree of variability in the length of time it took the athletes to excel in their chosen sport was apparent and this appears to strengthen the view that the length of a sport specific developmental programme may not be as important as its content (Davids, 2000; Singer \& Janelle, 1999). These data also provide evidence that not only is a broad range of sports involvement typical for those attaining elite status, but participation in a range of activities can occur over an extended period of time and early specialization is not a prerequisite of expertise. In fact, six of the athletes highlighted that their major focus was initially on a sport other than the one they eventually excelled in.

\section{Specialization triggers}

An athlete's rate of improvement within a sport appeared to be a major determinant of their decision to specialize. The three athletes (Judo player, Rower, and Javelin thrower) who specialized within two years of initial involvement in their sport, mentioned that the progress within their specialist sport was immediately greater compared to that in other sports. Once again, perceived competence appears to be an important component underpinning the successful development of these athletes 
within their sport. For instance, consider the unique reinforcement experienced by the rower from her early rowing performances and feedback from others:

We got a coach and he had a lot of belief in me and said 'you could be really good at this' and all of a sudden there was a sport that I seemed to excel at relative to other people. [Rower]

The Javelin athlete, although having had some success within previous sports also highlighted how positive reinforcement was much greater in javelin from early in his involvement:

I was amazed at the sort of progress that I'd made [in javelin], compared to my other sort of sporting activities. [Javelin thrower]

Crucial to the Judo player's decision to specialize within 2 years of first becoming involved in the sport appears to be the positive reinforcement he acquired from early performances in Judo. While also experiencing success in other sports, the structure of Judo, which enabled this athlete to monitor progress as he advanced through belts, clearly provided a more explicit reinforcement for this athlete. Also of importance appears to be the athlete's perception that he had total responsibility for the outcome of a performance in judo whereas in rugby performance was also dependant on teammates:

I think I realized very quickly 'I am quite good at this'. I can tolerate the pain and if I push myself ... I moved up the grades very quickly. I got instant gratification - three months I was orange belt, six months I was blue belt and I think when I was 15 I was a black belt. I was very young. In terms of success I was always being rewarded for the effort I was putting in. I was never taking a step backwards. Through my whole career it has always been an upward curve. There has never been a dip. ...... I never won anything in rugby. It is a team event ... you are relying on other folk. Invariably no matter how good I played at rugby the other guys weren't playing as hard as I was and it could get frustrating. [Judo player] 
The implication here may be that development systems are needed within team sports that allow an individual to monitor personal as well as team performances. The early development of effective goal setting principles that enables an individual to monitor progress may facilitate this process.

For three of the four athletes who specialized after being involved in their sport a number of years, development across sports was perceived to have initially been similar. For instance, the hockey player, who specialized seven years after initial exposure to the sport, continued to pursue swimming until her progress within hockey became greater. In contrast, the sculler experienced little success during her initial exposure to rowing, and therefore, having invested a considerable number of years into shot putting, it is not surprising that she continued to pursue this sport over the next five years. However, there came a time when she realized that, although she was one of the best shot putters in Britain, she did not have the capacity to excel on the world stage:

I had given it [shot putting] a really good shot, hung on with the best coaches in the world and it really wasn't panning out - the rate of improvement wasn't really there. If I had carried on going year in and year out then I probably would have got there but at that rate, I wasn't going to get there. I think the highest I got was maybe 6th/5th outdoors - something like that throwing about $15.20 / 15.30$ [meters] ... but to be good in the world status you had to be throwing 1920's [19.20 meters] that's a long way off. [Sculler]

Although at this time she was not experiencing positive reinforcement from her rowing performances or coaches, this athlete decided to specialize in rowing. In fact, rather than deterring her from participating in rowing, this lack of reinforcement seemed only to develop an "I'll show you attitude":

Mine [my ambition] was the fact that they told me I would never do it [excel in rowing] and I'd idolized sports people hugely, massive adulation you know the fact that somebody walked in this room or seen someone ... and of course then going to college and starting to rub shoulders with these famous people and realizing that I could do it and if I didn't try .... [Thought left hanging] [Sculler] 
For this athlete, it appears that she had the belief and psychological attributes necessary to make the commitments required to excel in sport, but it took time to identify a sport in which she had adequate physical talent.

Finally, it is apparent that not only is early specialization unnecessary for attaining excellence, but neither is the accepted ' 10 years' of deliberate practice principle proposed by Ericsson (1993); athletes were involved in their sport between 6 and 12 years $(\underline{M}=9.1, \underline{S D}=1.8)$ prior to achieving world-class status (see Table 5.1). This finding supports recent thinking on deliberate practice that highlights that the quality of practice is likely to be more important than the quantity and, with appropriate training, expertise can be achieved in less than 10 years of practice (Singer \& Janelle, 1999).

\section{Summary}

Athletes mentioned a range of issues during their childhood that they perceived had facilitated their future development in sport. In particular, athletes highlighted the importance of having a supportive family that encouraged and facilitated involvement in physical activity. Additionally, seven of the eight athletes interviewed were involved in a range of sporting activities during childhood and perceived that these diverse experiences had benefited their subsequent sporting careers. The age at which the athletes specialized in their sport varied greatly, as did the time it took the athletes to achieve world-class status in their chosen sport. These data suggest that neither early specialization nor the widely accepted '10 years' of deliberate practice principle is a requirement for attaining excellence. 


\subsubsection{Factors perceived to underpin sporting talent}

\section{Determinants of development}

Interviewees were asked to reflect on the attributes that facilitated their (their daughter/son's] successful development in sport (see Table 5.4). To promote this discussion, interviewees were asked to contrast themselves (their son/daughter) with individuals who appeared to be talented in sport but had failed to realize this potential. A consistent finding throughout the interviews was the extent to which psychological attributes were highlighted as a, if not the, crucial factor underpinning the interviewees' successful development (and the lack of progress of others). Further, as well as stressing psychological characteristics, all athletes also deemphasized the role of physical attributes in attaining excellence. In fact, all of the athletes highlighted physical weaknesses they had for their sport or individuals they perceived had better physical talent but failed to excel:

Before Sydney, on the Gold Coast there was a project going on in Australia where they were going round the teams, measuring their physical attributes. They wanted to have your seated height and I wasn't even on the bottom of the scale so physically I wouldn't have made it [selection into rowing]. ...You could select a lot of people who are potentially good at it [rowing] but actually they haven't got the correct mental attributes. [Rower]

You come across players who are very physically gifted. Genetically they are ideal specimens but I suppose it goes down to what they are prepared to put themselves through to gain ... it is very easy to rely on your physical attributes and not work other things.[Judo player]

All interviewees perceived the failure of 'talented' athletes to develop within sport as primarily due to insufficient levels of commitment $(n=7)$. The low level of commitment was attributed to a range of reasons including (a) other commitments/ pressures, (b) an absence of a will to succeed in sport, (c) a lack of awareness of what 
is required to excel and (d) a lack of self-belief. Examples of comments that fell into these four categories are presented below:

(a) Commitments/ Pressures:

There were a lot of girls along the way that have given up that I feel were much better than me. There was one girl at university. She was phenomenal. We are still really good pals but she wanted to do medicine and she chose to do that. I just loved rowing. I still go rowing. I really enjoy getting on the water. I always had something I was aiming for and I wanted to get there. [Rower]

(b) The will to succeed:

I have a brother-in-law who's very very good at football and could have easily been playing professional just now. He's now playing very very high amateur league. But he'll never make professional now, he's 29 years old, he's too late for that. But if I had had his skill, I could've been a professional [football] player. Because I'd have turn around and said, professional football, that's what I'm going to do because I'm good enough, that's what I'm going to do. He turned around and said, I really think I'm good enough to be a professional footballer but mum and dad are saying I've got to have a career. [Curler]

(c) An awareness of what is required to excel:

I look at people and I think that some of them think 'I'm big and all I have to do is follow this training program and I'm going to be good!' That's dangerous because they haven't paid their dues in whatever it is, you know they are not putting in a $110 \%$, they are only putting in $100 \%$. ...I think it's because people tell them if they are big they will be good ... I think the reason these big girls don't do it is because it takes more than just size and ergo scores, it takes the desire to win and the desire you know at all costs. ... [Rower/ Sculler].

(d) Self-belief:

For some reason we were sort of neck and neck [in javelin] for ages and ages and then all of a sudden I leapt and he never came back and he never actually got that back. And I 
put that down to him having lack of belief in himself, for sure. ... He didn't believe that he could do it. I thought he could, but then when I beat him it gave me even more belief in myself because it reinforced, 'Here's this guy who's better than me, you know, as I look at him, but I've beaten him'. You know, all of a sudden it sort of changes how you see yourself. [Javelin thrower]

As well as highlighting how psychological issues had limited the development of other 'talented' athletes, the elite participants highlighted how psychological processes had facilitated their own development within sport. For instance, the Judo player believed that his ability to identify both his strength and weaknesses from a young age had facilitated his development (and the lack of this ability had inhibited the development of other athletes):

I would say that one of my biggest strengths is that I have always looked at the bigger picture. I am strong at doing a ... [judo throw]... so I don't have to practice that every day. What I need to be doing is working on my groundwork. It is identifying your weaknesses. I would suggest that is why a lot of kids do drop out. They get to a certain level and they know that to make the next step how much [work] they are going to have to put into it [their development]. ... In judo, it is very easy to be good, or appear good, with a couple of tricks at a young age. Kids all develop at different ages and strength comes in to it a lot as well but you get players that will only have a couple of things in the repertoire that they are very very good at. ... Then they come unstuck against someone it doesn't work against. [Judo player] 
Table 5.4

Themes and Sub-Themes Related to Successful Development in Sport that Emerged from the Athlete Interviews

\begin{tabular}{|c|c|c|}
\hline $\begin{array}{l}\text { Umbrella } \\
\text { Category }\end{array}$ & $\begin{array}{l}\text { Higher-Order } \\
\text { Themes }\end{array}$ & Sub-themes \\
\hline \multirow{7}{*}{ 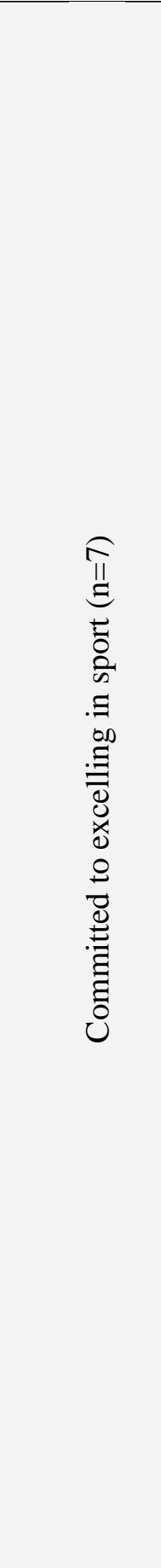 } & $\begin{array}{l}\text { Perseverance/ } \\
\text { determination } \\
\qquad(\mathrm{n}=6)\end{array}$ & $\begin{array}{l}\text { - Shows perseverance at challenging times }(n=4) \\
\text { - Unwillingness to accept failure }(n=2) \\
\text { - Not willing to accept second best }(n=2) \\
\text { - Seeks out opportunities to be one of the best } \\
(n=2) \\
\text { - Willingness to step out of comfort zone }(n=2)\end{array}$ \\
\hline & $\begin{array}{l}\text { Motivation/ } \\
\text { desire to } \\
\text { achieve }(n=4)\end{array}$ & $\begin{array}{l}\text { - Desire to achieve overrides weaknesses }(n=2) \\
\text { - Openness to coaching/ knowledge }(n=2) \\
\text { - Desire most important attribute underpinning } \\
\text { success }(n=1)\end{array}$ \\
\hline & $\begin{array}{l}\text { Self- } \\
\text { determination/ } \\
\text { self-motivation } \\
\quad(n=6)\end{array}$ & $\begin{array}{l}\text { - Will to will accompanied by dedication to put in } \\
\text { hard work }(n=1) \\
\text { - Wiling to put the hard work in }(n=4) \\
\text { - Takes responsibility for own development }(n=4) \\
\text { - Commitment to individual training }(n=2)\end{array}$ \\
\hline & $\begin{array}{l}\text { Need to prove } \\
\text { oneself }(n=6)\end{array}$ & $\begin{array}{l}\text { - Driven to prove oneself }(n=4) \\
\text { - Driven to achieve in individual sports due to } \\
\text { accountability }(n=3) \\
\text { - Accountability for own performances }(n=2)\end{array}$ \\
\hline & $\begin{array}{l}\text { Pursuit of } \\
\text { sporting } \\
\text { excellence as } \\
\text { priority }(n=7)\end{array}$ & $\begin{array}{l}\text { - Willingness to make sacrifices to excel }(n=3) \\
\text { - Arranging life around sporting endeavours }(n=1) \\
(n=3) \\
\text { - } \quad \text { Non-sport commitments prevent some achieving } \\
\text { potential }(n=4)\end{array}$ \\
\hline & $\begin{array}{l}\text { Driven to do } \\
\text { one's best } \\
\quad(n=2)\end{array}$ & $\begin{array}{l}\text { - Drive to fulfil one's potential }(n=4) \\
\text { - 'Good enough' is not good enough }(n=3)\end{array}$ \\
\hline & $\begin{array}{l}\text { Importance of } \\
\text { working on } \\
\text { weaknesses } \\
(n=3)\end{array}$ & $\begin{array}{l}\text { - Understanding of what it takes to excel }(n=2) \\
\text { - Willing to identify and work on weaknesses } \\
(n=1)\end{array}$ \\
\hline
\end{tabular}


Table 5.3 cont.

Themes and Sub-Themes Related to Successful Development in Sport that Emerged from the Athlete Interviews

\begin{tabular}{|c|c|c|}
\hline $\begin{array}{l}\text { Umbrella } \\
\text { Category }\end{array}$ & $\begin{array}{l}\text { Higher-Order } \\
\text { Themes }\end{array}$ & Sub-themes \\
\hline \multirow{3}{*}{ 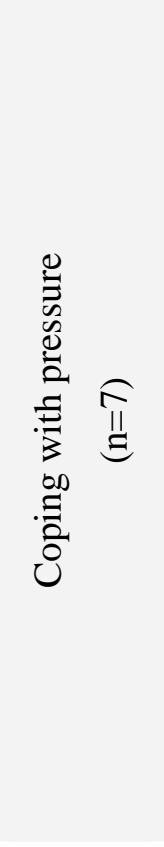 } & $\begin{array}{l}\text { Perseverance } \\
\text { during hard times } \\
\qquad(\mathrm{n}=4)\end{array}$ & $\begin{array}{l}\text { - Coping with hard times }(n=4) \\
\text { - Reacting to hard times positively }(n=3) \\
\text { - Finds a way around obstacles }(n=1)\end{array}$ \\
\hline & $\begin{array}{l}\text { Regulating arousal } \\
\qquad(n=6)\end{array}$ & $\begin{array}{l}\text { - Ability to cope with competitive pressures } \\
(n=2) \\
\text { - Development of Coping Skills to deal with } \\
\text { competitive pressures }(n=1) \\
\text { - Coping with expectations of others }(n=1) \\
\text { - Interpretation of pressures and expectations } \\
(n=4)\end{array}$ \\
\hline & $\begin{array}{c}\text { Realistic } \\
\text { expectations }(n=6)\end{array}$ & $\begin{array}{l}\text { - Coping with being 'chased' }(n=2) \\
\text { - Maintain realistic expectations }(n=3) \\
\text { - Coping with not winning after having excelled } \\
(n=2)\end{array}$ \\
\hline 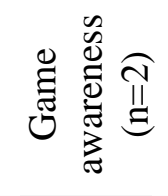 & $\begin{array}{l}\text { Importance of } \\
\text { game awareness } \\
\qquad(\mathrm{n}=2)\end{array}$ & $\begin{array}{l}\text { - Ability to read the game well overrides some } \\
\text { skill weaknesses }(n=1)\end{array}$ \\
\hline \multirow{2}{*}{ 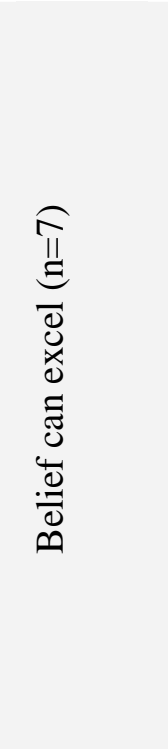 } & $\begin{array}{l}\text { Belief could excel } \\
\text { at sport }(n=6)\end{array}$ & $\begin{array}{l}\text { - Belief could excel from a young age }(n=4) \\
\text { - Belief could excel given right circumstances } \\
(n=2) \\
\text { - Confidence to seek out situations to further } \\
\text { development }(n=2) \\
\text { - Coach reinforced belief could excel }(n=1)\end{array}$ \\
\hline & $\begin{array}{l}\text { Self-belief is } \\
\text { crucial to Success } \\
\qquad(\mathrm{n}=3)\end{array}$ & $\begin{array}{l}\text { Belief a key attribute for excelling at sport } \\
(\mathrm{n}=2) \\
\text { - } \quad \begin{array}{l}\text { Need belief and physical attributes to excel } \\
(\mathrm{n}=1)\end{array} \\
\text { - Can see who has confidence to excel }(\mathrm{n}=1) \\
\text { - Good game awareness as well as good skills } \\
(\mathrm{n}=1)\end{array}$ \\
\hline
\end{tabular}


Table 5.3 cont.

Themes and Sub-Themes Related to Successful Development in Sport that Emerged from the Athlete Interviews

\begin{tabular}{|c|c|c|}
\hline $\begin{array}{l}\text { Umbrella } \\
\text { Category }\end{array}$ & $\begin{array}{l}\text { Higher-Order } \\
\text { Themes }\end{array}$ & Sub-themes \\
\hline \multirow{2}{*}{ 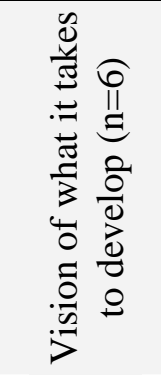 } & $\begin{array}{c}\text { Pathway in sport } \\
\text { was apparent }(n=2)\end{array}$ & $\begin{array}{l}\text { - Aware of next stage of development }(n=1) \\
\text { Vision of where he/she wanted to go within } \\
\text { sport from early on }(n=2)\end{array}$ \\
\hline & $\begin{array}{l}\text { Awareness of what } \\
\text { is required to excel } \\
\qquad(\mathrm{n}=6)\end{array}$ & $\begin{array}{l}\text { - Aware of processes required to progress }(\mathrm{n}=3) \\
\text { - } \quad \text { Lack of awareness slowed progress }(\mathrm{n}=1) \\
\text { - Worked hard to improve }(\mathrm{n}=1)\end{array}$ \\
\hline \multirow{2}{*}{ 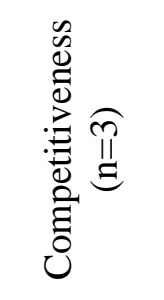 } & $\begin{array}{l}\text { Competitive nature } \\
\text { in sport }(n=3)\end{array}$ & $\begin{array}{l}\text { - Liked being challenged }(\mathrm{n}=2) \\
\text { - } \quad \text { Competitive from a young age }(\mathrm{n}=3)\end{array}$ \\
\hline & $\begin{array}{l}\text { Need to be } \\
\text { competitive to } \\
\text { excel }(n=1)\end{array}$ & - Need to be competitive to excel in sport $(n=1)$ \\
\hline \multirow{4}{*}{ 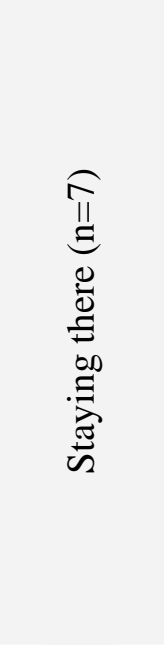 } & $\begin{array}{l}\text { Coping with } \\
\text { pressures of being } \\
\text { chased }(n=7)\end{array}$ & $\begin{array}{l}\text { - Coping with being seen as one of the best } \\
(n=4) \\
\text { - Coping with pressures of being chased }(n=3)\end{array}$ \\
\hline & $\begin{array}{l}\text { Maintaining } \\
\text { realistic } \\
\text { expectations }(n=4)\end{array}$ & $\begin{array}{l}\text { Maintaining realistic expectations }(n=1)] \\
\text { - Coping with not always winning }(n=3)\end{array}$ \\
\hline & $\begin{array}{l}\text { Maintaining the } \\
\text { hunger for success } \\
(\mathrm{n}=3)\end{array}$ & - Maintaining the hunger for success $(n=3)$ \\
\hline & $\begin{array}{l}\text { Willing to step out } \\
\text { of comfort zone } \\
\qquad(\mathrm{n}=2)\end{array}$ & - Willingness to step out of comfort zone $(n=2)$ \\
\hline \multirow{3}{*}{ 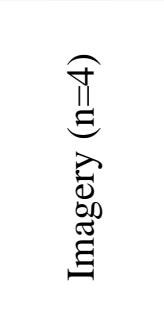 } & $\begin{array}{c}\text { Imagery in skill } \\
\text { development }(n=2)\end{array}$ & - Using imagery to develop skills $(\mathrm{n}=2)$ \\
\hline & $\begin{array}{l}\text { Imagery in race } \\
\text { preparation }(n=3)\end{array}$ & - Using imagery to prepare for races $(n=3)$ \\
\hline & $\begin{array}{l}\text { Imagery to review } \\
\text { performance }(n=1)\end{array}$ & - Using imagery to review performances $(\mathrm{n}=1)$ \\
\hline
\end{tabular}


Table 5.3 cont.

Themes and Sub-Themes Related to Successful Development in Sport that Emerged from the Athlete Interviews

\begin{tabular}{|c|c|c|}
\hline $\begin{array}{l}\text { Umbrella } \\
\text { Category }\end{array}$ & $\begin{array}{l}\text { Higher-Order } \\
\text { Themes }\end{array}$ & Sub-themes \\
\hline 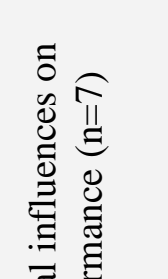 & $\begin{array}{l}\text { Need to look } \\
\text { beyond physical } \\
\text { components of } \\
\text { talent }(n=7)\end{array}$ & $\begin{array}{l}\text { - Excelled despite physical weaknesses }(n=3) \\
\text { - Need to consider technical, psychological and } \\
\text { physiological components alongside physical } \\
(n=6)\end{array}$ \\
\hline 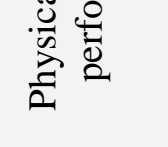 & $\begin{array}{c}\text { Physical } \\
\text { components of } \\
\text { talent }(n=6)\end{array}$ & $\begin{array}{l}\text { - Physical attributes that facilitate performance } \\
(n=6)\end{array}$ \\
\hline
\end{tabular}


In contrast to the 'professional' behaviour adopted by the judo player from early on in his development, the curler felt that progress had suffered due to him not adopting such an approach:

In a team you make a team choice until you become an individual and it wasn't until we sat down, probably '93, and said, come on guys if we actually want to try and win it you know, imagine we made a go of it this year rather than just going out and having a party. And it was around that time that we started going, 'right okay, what do we want to win? Where do we think we can win?' And we looked at the whole program a little bit more scientifically instead of just pitching up at every competition and saying, 'oh come on let's go out and have a party'. ... It's funny because the first year that we actually sat down and we planned things out was the first year we qualified for the men's finals. [Curler]

An additional psychological attribute highlighted by four of the athletes as an important skill was imagery. Athletes highlighted that they had employed imagery processes from early on in their development to facilitate both their development within their sport and their ability to perform optimally in competitions. In terms of development, two of the athletes highlighted the importance of imagery. For example, the judo player highlights how imagery enabled him to translate throws he observed other players executing into his own repertoire of skills:

I watch videos and I see things and think 'that looks quite nice, I'll try that'. Go to the club, bash about a wee bit, might not be successful and then I will sit down with the coach and say 'I have been trying to get this to work ... I'd like to work on it'. I was good at visualization from a young age and seeing something, even just the once at a competition, I'd think 'I'll need to try that, that worked there' and 'he is a similar type player to me so if it worked for him it should work for me'. [Judo player]

As well as athletes referring to an early use of imagery for skill development, three athletes also highlighted how their ability to do imagery had facilitated the transfer of skill to the unique competitive environment. For example, the javelin thrower 
highlighted that the ability to simulate competition environments using imagery was essential within his sport:

That ability to sort of pre-create a scenario before you enact it is what sport is about. Hence, specifically javelin throwing is very much about this because you don't get the chance to throw the way you do in competition very often. ...Somebody's ability to do that is obviously different from one person to the next ... if that [the ability to use imagery to pre-create a scenario] were easily measured I'm sure that would be a good way of finding out who could be good in a skilful, technical event such as javelin throwing. [Javelin thrower]

The curler provided an example of how he used imagery to facilitate competitive performance:

We're [the team are] looking at actually the shot before you've actually thrown the shot, you see the shot you go, 'oh what a great shot', 'oh no I didn't make that shot. Right get that out of my head'. You try it again. And you run it until you make the shot. 'Oh that's what I'll need to do, I'll just do that'. [Curler]

One of the athletes also reflected on how imagery helped him effectively evaluate his performances, a process identified as crucial to successful development within sport:

We do goal setting at the beginning of the year, we do constant reviews. Then we do it for individual games during the championship, we then review each game with mental imagery that goes down to shot level. [Curler]

Possibly linked to the ability of athletes to employ effective imagery, all parents $[n=7]$ highlighted how their son/daughter were very good at recalling sporting situations and used this skill in order to review their performances from early on in their development:

It always amazes me how he can remember the whole competition he can remember that stone that so and so played at the third end and that we were sitting a shot down. I can't 
even remember the third end! Yet he could have run right through the whole game and the same with the golf he would run right through the 18 holes, who played where, and what happened and why and what could have happened and what we should have done. His analysis is tremendous. He's always seemed to have had that [ability to replay a game in his head]. I think that's what got him through a lot of things, the fact that he remembers everything that he was on. He can remember the little bits and pieces of it that make up the whole thing. [Curler's father]

I am always amazed by her ability to recall games ... I think it [her ability to recall every part of a game] probably started as soon as she started playing somehow, yes I think it possibly is something else that is just there, I don't know how that gets there really [Hockey players mother]

Finally, a crucial issue for athletes during their development was their ability to cope with the inevitable setbacks experienced on the path to excellence. Once again, the importance of psychological processes was stressed:

To become a top performer in sport, you need to understand that when things are going well its great but when things are going badly, that is when the problems are really going to arrive. Every successful Olympic gold medallist doesn't have a plain sailing ride on the way and what makes you great is what you do when things go wrong. It took me a long time to learn that. I think if I had been aware of it a lot earlier I would have achieved things quicker. [Rower]

Further, athletes reported how they were typically able to exploit these difficult times by using them as catalysts to reassess their progress and to establish goals that enabled them to improve. For example, the hockey player, while initially distraught on learning that she had been dropped from the English squad, ultimately responded by considering what she could do to improve and ensure that she would make the squad the following year:

When I got the letter [about not being selected] I think I cried for about a whole day - locked myself in the bathroom - my 
mum didn't know what I was doing in there but then after that I thought I should really knuckle down and do my fitness training - I didn't used to do a lot of fitness training but I thought now I've got to take it seriously now and do everything I can to rise to the next level [Hockey player].

She had been dropped at under 16 level and she turned to me and said mum one day I'm going to play an Olympic game and she said I am never going to fail again. [Hockey player's mother] 


\section{Determinants of producing and maintaining world-class performances}

As well as crucial determinants of development, athletes also highlighted

psychological factors as having a significant impact on performance at world-class level $(n=7)$. Athletes reflected on both how 'talented' teammates had failed to excel at the world-class level due to an inability to cope with the psychological pressures of competing $(\mathrm{n}=2)$ and how important it was for them to regulate arousal in order for them to compete successfully $(n=6)$ :

Very easily, I can think of somebody that almost made it. They did everything they could in terms of training, technique wise but there was just something that when it comes to competition they just can't. They have had limited success and they have had moments of great success but at major championships, nothing. [Curler]

You need to develop skills to help you cope with that pressure [in order to compete in major championships]. It [developing coping skills] should be done well before the day you fight. You have to have the mechanisms in place and to know the path you have to take. 'If this happens what will I do? If this happens what will I do?' If you have got anything on your mind when you are competing you are not going to win. ... Don't think you are just going to be able to switch it off. You have to be able to put the mechanism in place months before hand so that you are dealing with issues all along and keeping them far away from competition. [Judo player]

This perceived impact of psychological factors on performance is consistent with research that has established psychological skills as significant pre-event and inevent behaviours for successful performances within sport (Gould et al., 1993b).

Reflecting the athletes' thoughts on the significant impact that psychological factors can have on athletic performance, was the comment by the Javelin thrower that "at the next championships, if I had $80 \%$ physical and $100 \%$ belief I would take that rather than the other way around." 
All athletes $(n=7)$ highlighted pressures they perceived to be unique when striving to retain a major title ('maintenance stage', Durand-Bush \& Salmela, 2001) and the role of psychological processes in coping with these unique pressures:

I remember Steve Redgrave saying 'there is one thing harder than winning. Winning is easy. It is keeping winning that is really hard.' I was like 'it is all right for you to say that isn't it!' but actually winning the World Championships in 99 was just so difficult [after winning in 1998] [Rower]

The perceived importance of psychological processes in successfully remaining at the top of one's sport is consistent with previous research that has looked at the additional pressures experienced by elite athletes (Gould et al., 1993b). An issue that reoccurred across interviews ( $n=7$ ) was the ability to cope with the notion of being chased (rather than doing the chasing) and to respond to this pressure by raising your own game:

There's a massive difference in staying at the top, you have to be visibly better than the next guy. To get to the top you only just have to be better to get there. To stay there you have to be visibly better than him. Because everyone raises their game against you. So you bring out the best in your opposition. Subsequently you have to be better than their best. And that has to be your norm. [Curler]

An issue highlighted as crucial for four of the athletes when competing at the top of their sport was the ability to retain realistic expectations and to accept that world beating performances cannot be produced during every competition:

When you are striving to get to the top it is easy to accept failure on the way. It is a learning curve, a learning process. You accept it. When you get to the top, anytime you get beaten you think you are rubbish. You have had your day. How did you let that happen? In a sport like judo it is impossible not to get beaten. [Judo player]

You are not infallible, everybody can be beaten. What is important is that when it comes to the big tournaments you 
just remember that all the times you get beaten they were for a purpose. They were training. It doesn't matter. Or when you get beat in competitions you just put it down to experience. It is about developing again. Constantly trying to justify all that you are doing. ... [Curler]

The feelings of being chased and the high expectations for performance experienced by athletes attempting to stay at the top of their sport has also been reported by

Gould et al. (1993b) who studied the experiences of elite US national figure skaters. An additional issue that was stressed by two of the athletes in the current study was the recognition that continuing to excel at the top of ones sport requires the willingness to move out of their 'comfort zone':

The first few competitions [after winning the National, World and European championships] we took an absolutely hammering because people just came on, they played out their socks and we went on in our, you know, normal way and said, 'right come on let's play. Everyone's playing really well against us, aren't we unlucky'. And it's not 'til you get past that - we're not being unlucky, everyone's raising their game against us and we're not raising our game past what we expect to have to raise it to, to have to beat them. So if we expect to have to play to $90 \%$ of our ability, that's where we aim for ... what we should be doing is aiming for $100 \%$ of our ability and then we'll make sure we beat them. And that's a difference mindset of what you've got to do. [Curler]

Finally, the ability to retain the hunger for success once a world-class performance has been produced was stressed by three of the athletes:

I remember the scenario is you aim to make the team, you make the team [and then] onto the next thing. So, your desire is always one-step ahead of you so you never feel contentment or contented. Now at the point at which you are content that's dangerous as how do you sustain that contentment? And I know that I was really really content for 6 months. In fact, I would say that there is now inside me a level of contentment and it's a small pocket and its there and it will never go away, but that's my silver medal [Sculler] 


\section{Summary}

Based on the analyses of the retrospective interviews provided by world-class athletes and parents, a number of general observations can be made: (a) Families appear to play a crucial role in socializing individuals into sport, (b) early multi-sport experiences were perceived to significant contribute to the capacity an individual has to excel within a specialist sport, (c) physical attributes can provide a false early indication of talent, (d) psychological strengths were perceived to be able to overcome general physical disadvantages, (e) psychological attributes (e.g., commitment, realistic performance evaluation) were seen as crucial determinants of both development and performance, (f) while these world-class athletes were often initially upset by setbacks they experienced during their development (e.g., not being selected), they reported that such setbacks would ultimately drive them forward in their sport, (g) psychological processes were seen as the main determinant of whether an athlete was able to retain sporting excellence.

\subsection{Conclusion}

The crucial role of psychological factors in facilitating sporting development and performance highlighted by these world-class athletes is consistent with recent research in the area of talent development and supports the need for greater emphasis on psycho-behavioural characteristics within TID programmes. For instance, research that has looked at the individuals who achieve success within sport has highlighted that the employment of psychological processes (e.g., goal setting, planning and performance evaluation) can help athletes improve maximally from practice (Orlick, 1996). Similarly, research has also established the effectiveness of employing psychological skills (e.g., goal setting and imagery) when learning a sports skill (e.g., Boyce, 1992; Waskiewicz \& Zajac, 2001), dealing with difficult times (e.g., overcoming an injury, Ievleva \& Orlick, 1991; Rose \& Jevne, 1993), competing at major events (Gould et al., 1992a, 1992b) and producing consistent performances (Kreiner-Phillips \& Orlick, 1993). Therefore, the theoretical limitations of TID processes that focus on physical and performance variables to the exclusion of psychological processes is supported by the observations of these 
successful athletes. Clearly, TID processes need to evolve to allow for the dynamic and multi-dimensional nature of talent and recognise psychological precursors to development and performance. 


\section{CHAPTER 6 DEVELOPING A MULTI-DIMENSIONAL AND DYNAMIC TID MODEL}

"To build the aptitude theories of tomorrow, we need a language for describing the processes that connect persons and situations - the processes that operate in the interface" (Snow, 1992, p.19).

\subsection{Introduction}

Finding the most effective TI method is a complex problem. In the preceding chapters, major concerns with current TI processes in sport have been presented. It has been argued that the majority of TI models have inappropriately adopted a onedimensional, microscopic approach. As a result, processes have focused on the individual as a unit of analysis and have attempted to identify talented athletes based on discrete, genetically driven, performance measures. Unfortunately however, as Ericsson and Lehmann (1996) state, "individual differences in basic capacities and abilities are surprisingly poor predictors of performance" (p.281) as they only reveal limited information about a person's adaptability and development potential. The problems arise since one-dimensional microscopic approaches treat persons and situations as independent variables rather than integrated systems (Snow, 1992). As Barab and Plucker (2002) highlight, talent should not be viewed as constructs possessed by individuals, but instead, as sets of relations that are actualized through dynamic transactions among the individual, the environment and the socio-cultural context. However, one-dimensional, microscopic approaches for identifying talented athletes remain the prevalent approach across much of the world (see Chapter 3 ). Therefore, it is likely that many talented athletes are being overlooked due to poorly defined and theoretically weak selection tools.

Consequently, and recognising the need to move away from focusing on the individual as a unit of analysis and to place greater emphasises on the development 
of sporting talent, this chapter presents a revised conception of talent. Contrary to many existing models, it is proposed that TI and TD should be considered as combined processes with a greater emphasis on direction and development, instead of the current practice of identification and elimination, thus TiD. Using ideas borrowed from nonlinear dynamics and the study of complex systems, a multidimensional and dynamic model is described in which talent is actualized through dynamic transactions between the individual and the environment. Recognition of processes that facilitate these transactions should lead to greater emphasis on psychobehavioural characteristics and less emphasis, at least initially, on physique and performance. Such an approach accounts more fully for advances in our understanding of human learning and achievement and has implications not only for TI in sport, but to a whole range of performance domains, such as business and the arts (Gould, 2002; Loehr \& Schwartz, 2001; Lubinski \& Benbow, 2000; Simonton, 1999). Finally, the approach advocated will enable talent to be "taken out of the hands of the few and talent development to become an opportunity to all" (Barab and Plucker, 2002, p.167). The increased 'humanism' of this approach may also help close the split between the educational and the sporting community over the ethics of 'elitist' TI. For clarity, the model will be developed piece by piece within the following section before a detailed explanation of how the model can be employed in practice is presented within Chapter 7.

\subsection{Theoretical Considerations: Basing Identification on a Revised Concept of Talent}

\subsubsection{Performance and developmental dispositions}

The proposed $\mathrm{TiD}$ approach acknowledges both performance dispositions (e.g., the ability to deal with pressures of competition) and the dispositions that reflect the capacity of an individual to develop (e.g., the capacity of an individual to adapt to advances and cope with setbacks). This viewpoint, reflected in Figure 6.1, adopts an interdisciplinary perspective on the contribution of physical, motor and psychological dispositions to sporting talent. Initially at least, TiD models should 
primarily be concerned with creating an environment that optimises the potential an individual has to develop within sport. As lack of proficiency in fundamental motor skills may lead to an individual avoiding physically challenging settings, early opportunities should promote the development of these skills and their application to a range of physical settings (Gallahue \& Ozmun, 1995; Seefeldt et al., 1979). Further, as psycho-behavioural characteristics typify the means by which an individual interacts with the environment, and therefore the extent to which they make the most of the opportunities that they are given, the model also advocates increasing emphasis on these key developmental attributes. In other words, psychobehavioural characteristics are seen as key tools in positively facilitating the interaction of an individual with his/her environment and enabling successful negotiation of a path to excellence (or fulfilling one's potential!) (Freeman, 2000). Of course, the model also recognizes that key physical attributes are advantageous and essential to achieve excellence in a chosen sport. However, as these variables will be heavily influenced by both past experiences and physical maturity (Ackland \& Bloomfield, 1996; Bloomfield et al., 1990), non-mature values may be highly unstable and are therefore poor predictors of talent. Nevertheless, as many interdependent and compensatory processes will take place within and between psycho-behavioural characteristics, psychomotors and physical factors, it is crucial that an individual is exposed to opportunities that enable the development of a repertoire of all of these attributes.

Consequently, Figure 6.1 illustrates the relative emphasis required on psychomotor, psycho- behavioural and physical characteristics from early stages of development (i.e., initiation, Cote, 2003) (left side of Figure) to later stages of development (mastery, Cote, 2003) (right side of Figure). During the early stages of development, the figure emphasises that the primary focus should be on providing opportunities for all young children to develop the fundamental motor skills that underpin successful participation in sport specific activities (e.g., by providing opportunities for young children to take part in deliberate play). Alongside this early emphasis on the development of fundamental motor skills, an increasing emphasis on the psychobehavioural characteristics (e.g., self-awareness, goal setting, imagery) is encouraged 
as they enable an individual to exploit developmental opportunities. Figure 6.1 also emphasises that as an individual matures and develops within their chosen sport, the emphasis will shift from monitoring determinants of potential (left side of Figure 6.1) to determinants of performance (right side of Figure 6.1).

The emphasis on psycho-behavioural, psychomotor and physical characteristics within Figure 6.1 acknowledges the relative significance placed on these characteristics by the elite athletes interviewed in the preceding chapter. In addition, the following principles are reflected within Figure 6.1:

1. Proficiency in fundamental motor skills is regarded as essential for future participation in sports and physical activity (Gallahue \& Ozmun, 1995), and is central to the physical competence of children (Rose, 1994). Indirectly, the perceived lack of competence in fundamental motor skills is seen as a barrier to future participation in sport and physical activities for primary aged children (Seefeldt et al., 1979) and for adolescents (Clough, McCormack, \& Trail, 1993; Seefeldt, 1996). If competency (perceived and actual) is not achieved on these generic skills, then an individual may avoid physical settings (Seefeldt et al., 1979) and the 'person-in-situation' (Snow, 1992) interactions required for an individual to achieve their physical potential will not occur. Therefore, early opportunities that promote competence (perceived and actual) on psychomotor skills are advocated within the proposed model.

2. If an individual is to achieve their potential, they need to develop a range of psycho-behavioural characteristics that will enable them actively to optimise their interactions within the physical environments they experience. This principle acknowledges that talent development is a process that involves doing, not acquiring (Barab \& Duffy, 2000; Sfard, 1998).

3. An individual's potential within a physical activity will partly be constrained by his/her physique. However, non-mature physical values (e.g., height) may be highly unstable and are therefore poor predictors of talent. Consequently, early emphasis should be on the development of general fitness components within all children rather than using such variables as determinants of 'talent'. 
4. As a person successfully develops within sport, their capacity to become an elite athlete will be increasingly constrained by psychomotor (e.g., coordination) and perceptual cognitive skills (e.g., decision-making). However, considerable emphasis will still be required on psycho-behavioural characteristics if an individual is to negotiate successfully a pathway to excellence.

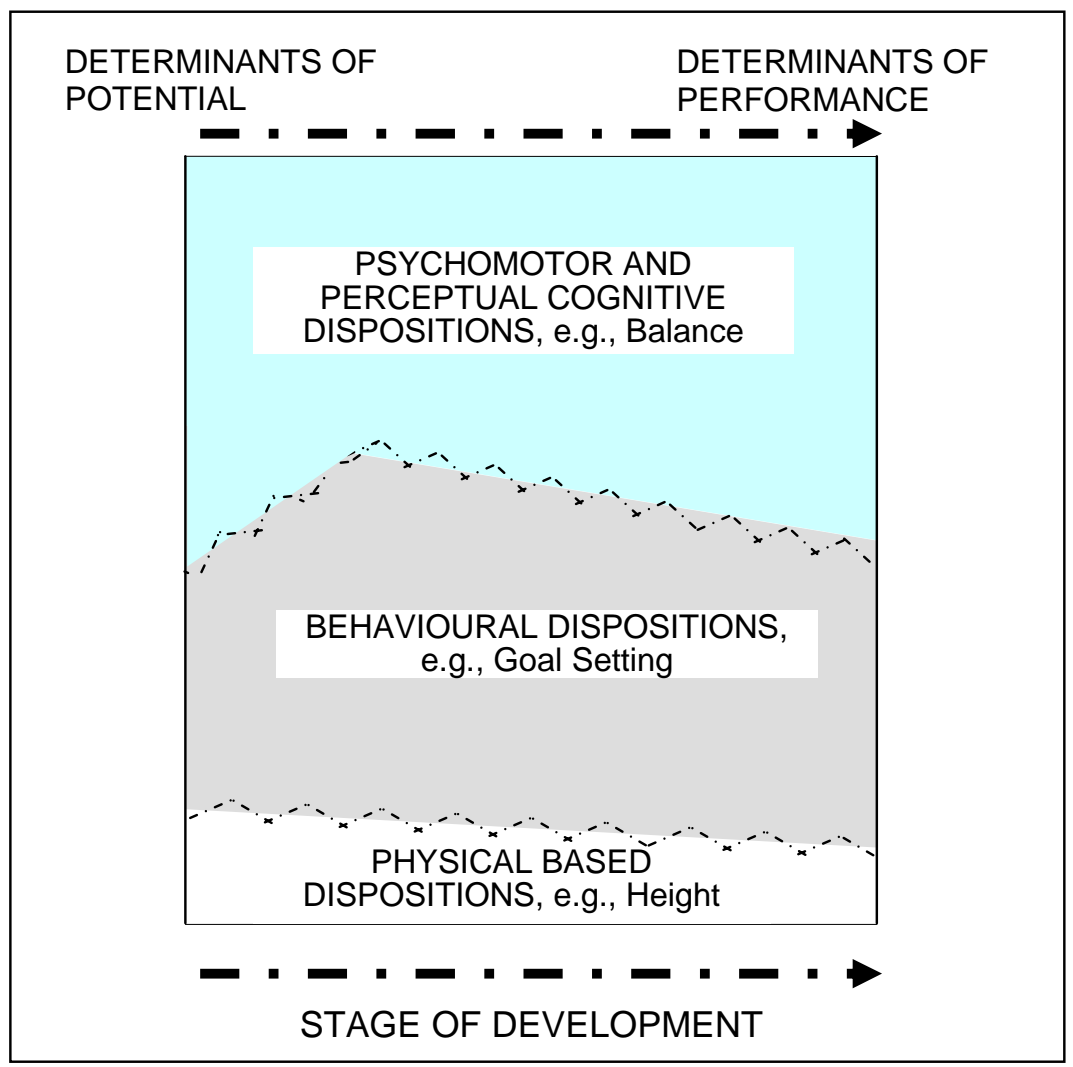

Figure 6.1 Proposed contribution of physical, motor and psychological dispositions to the development and performance of an athlete

\subsubsection{Pathways to excellence}

The model acknowledges that there are multiple pathways to excellence that can emerge within any sport. These pathways are typically complex, where athletes' progress through various stages of development and the requirements of individuals will adjust as they progress through these stages (Bloom, 1985; Cote 1999; Durand- 
Bush, 2000; Tebbenham, 1998). Based on previous research, four stages of development are highlighted within the TiD model. Specifically, the model builds upon the three stages of development identified by Bloom (1985) from his work with US athletes (initiation stage, development stage and mastery stage), and also recognizes the work of Kreiner-Phillips and Orlick's (1992) and Cote (1999) on the distinction between 'getting there' (producing a world-class performance) and 'staying there' (consistently producing world class performances) (see Figure 6.2). Within each of these stages, unique favourable environmental conditions exist and required support will differ. Additionally, it is important to recognise that within each of these stages of development an athlete will encounter many additional challenges such as coping with injury or making a technique change. Such challenges make development and the kind of support required highly idiosyncratic and difficult to predict.

An awareness of the complex pathways to excellence also emphasizes the necessity for performers to make several transitions in their careers. Figure 6.2 highlights variables that Bloom (1985) and Kreiner-Phillips and Orlick (1993) found to characterise various stages of development. The implication is that, for example, to make the transition to the mastery stage of development, an individual will require increased technical coaching and financial support. Therefore, the ability of an athlete to initiate and/or adapt to these changes is key to a successful developmental transition. Consequently, whilst traditional TID approaches typically base their predictions on one or two factors, the proposed model aims to reflect the complex pathways that an athlete may take on the way to excellence. Further research is required to verify stages of development and factors that characterise these stages. 


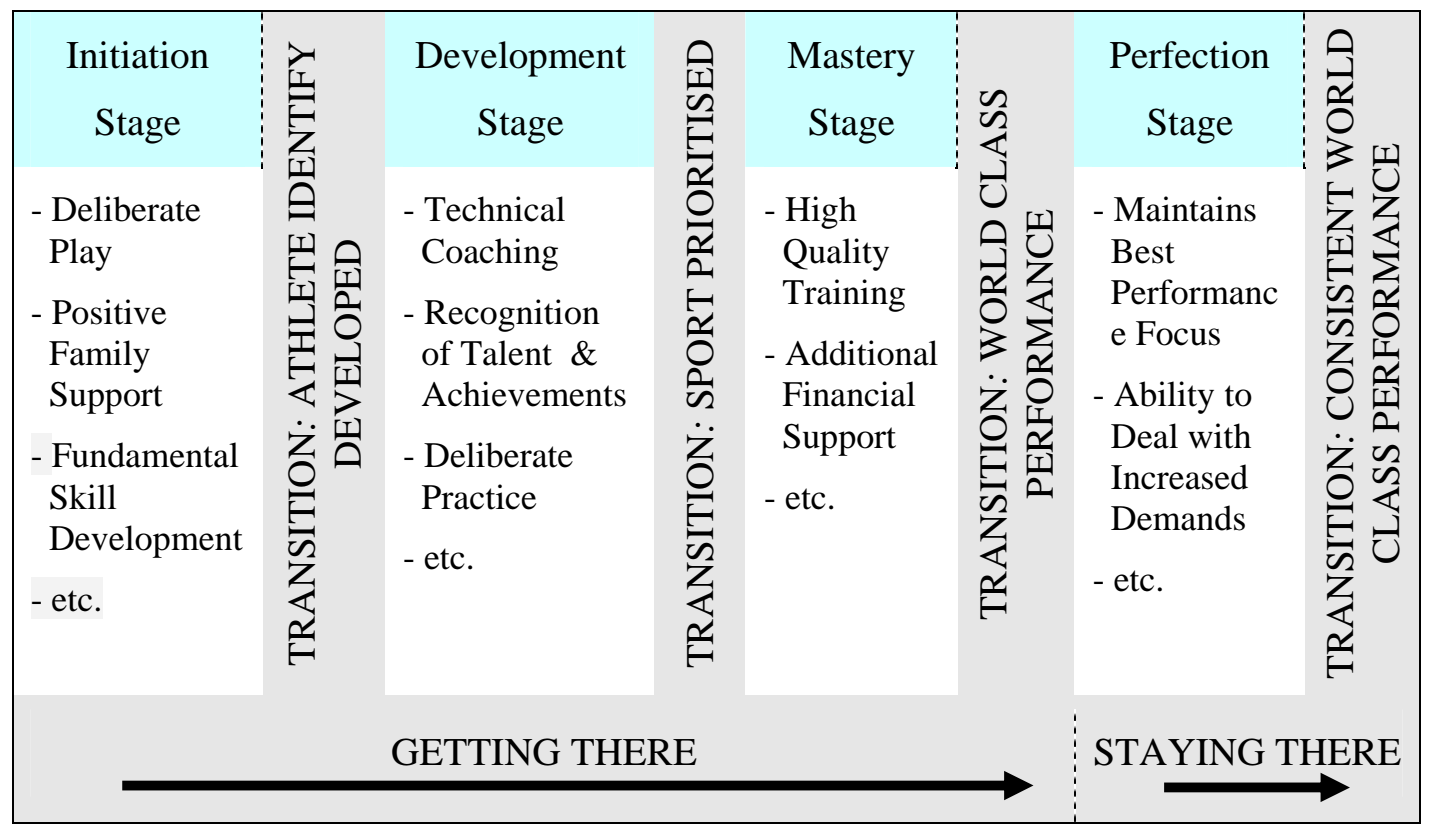

Figure 6.2 Stages of development previously identified within sport (adapted from Bloom, 1985, Kreiner-Phillips and Orlick, 1992, \& Cote, 1999)

\subsubsection{Successful transition from one stage of development to another}

Irrespective of the performance dispositions displayed or the environmental opportunities afforded, an individual only fulfils true potential when they are able to transfer successfully from one stage of development to another in order eventually to achieve consistent performance at the world-class level. The last chapter has shown that this ability to successfully transfer between stages of development is facilitated, and indeed characterized, by an individual developing and applying a range of psycho-behavioural characteristics (such as goal setting, self-reinforcement, and realistic performance evaluation). Further in this regard, consider research by Kreiner-Phillips and Orlick (1992) on the athlete who has obtained international excellence but is unable to reproduce stable, high levels of performance. KreinerPhillips and Orlick highlight that it is only those athletes who, for example, are able to maintain their focus, that are able to be consistent world-class performers. Psycho- 
behavioural characteristics have also been shown to strengthen stable performance characteristics whilst resisting the perturbation of distracting information (Moran, 1996).

Therefore, a key concept underpinning the proposed approach is that early and continual emphasis should be placed on the development and application of key psycho-behavioural characteristics as they will play a crucial role in facilitating the interaction of an individual with the environment and enabling progress from one stage of development to the next (see Figure 6.3). Without the ability to progress, and the skills necessary to cope with challenges, an individual talent will at best remain a potential. This emphasis on psycho-behavioural characteristics reflects the need to acknowledge the processes that enable productive interactions to occur between individuals and situations (Barab \& Plucker, 2002; Snow, 1992). Finally, the model acknowledges that an individual's capacity to make the transition to the next stage of development may be facilitated or inhibited by their motor and physical performance dispositions. For instance, an individual who has an inadequate ratio of fast to slow twitch fibres will be find it extremely difficult to successfully make the transitions to become a world class sprinter. In addition, as an individual develops he/she might ultimately become better suited to an alternative physical domain. For example, an individual who has not developed the required performance disposition to become a successful football player may have the dispositions required to become a $100 \mathrm{~m}$ sprinter. 
Influential Factors that Facilitate Nonlinear Transitions between Stages:

- Psycho-behavioural characteristics (e.g., realistic performance evaluation)

- Psycho-motor (e.g., coordination)

- Physical factors (e.g., Strength)
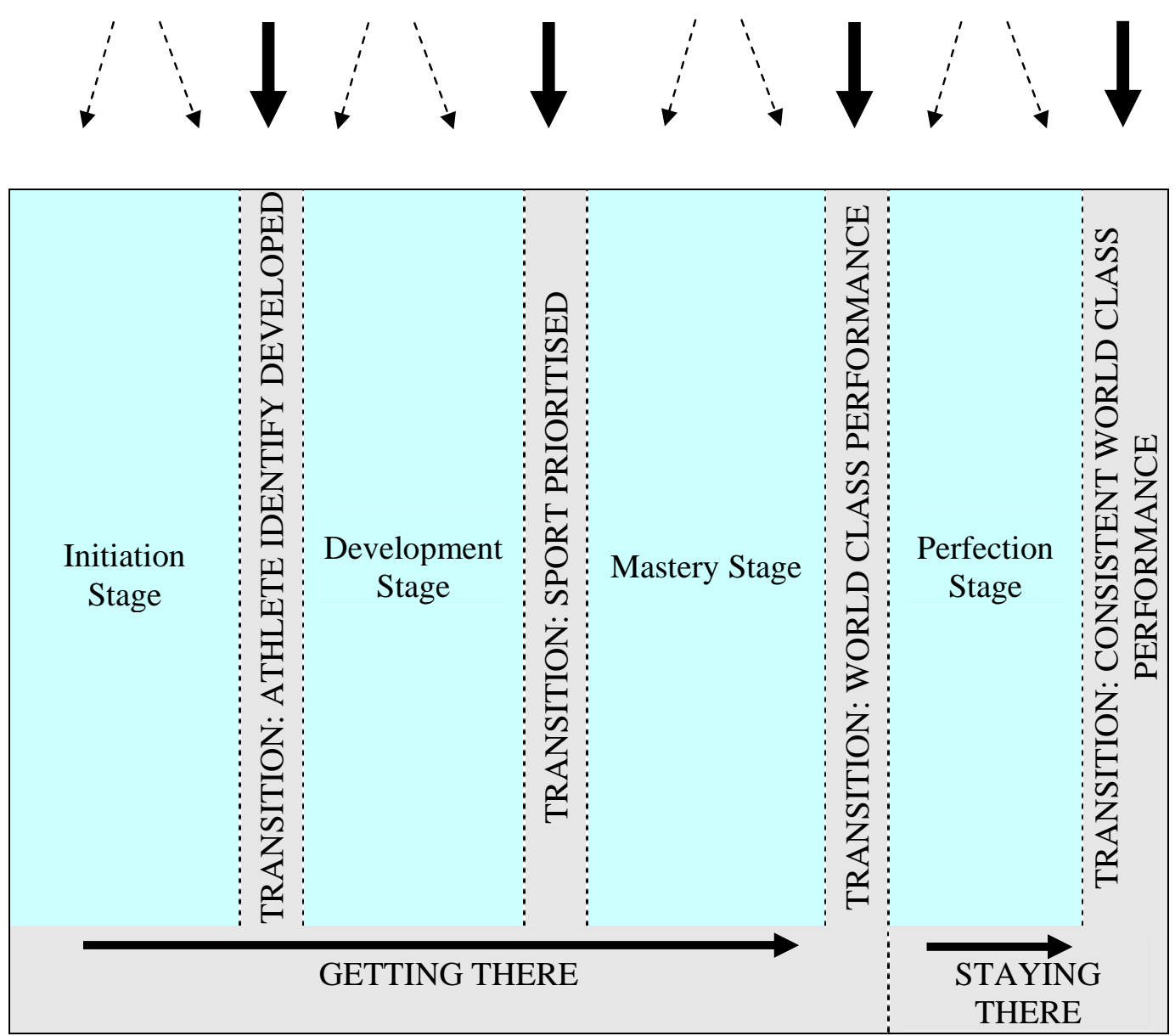

Figure 6.3 The role of psycho-behavioural characteristics in facilitating the successful negotiation of developmental transitions. 


\subsubsection{Interaction of elements}

The proposed model of TiD depicted in Figure 6.4 combines the principles presented within Figure 6.1, Figure 6.2 and Figure 6.3. As such, the model recognizes the dynamic, evolutionary nature of talent and therefore the need to combine TI and TD processes. Consequently, the proposed TiD model requires a shift from the traditional emphasis on selection and elimination to one of development and continual monitoring. While the identification process is typically seen as a precursor to TD, the need initially to place less emphasis on the identification process and greater emphasis on providing athletes with the opportunity to develop factors that underpin successful development is advocated. As such, continual monitoring and development of all components that may influence the fulfilment of an individual's talent is required as opposed to the traditional approach of identifying the 'talented' based on 'one-off' performance observations (e.g., talent scouting in soccer). This approach recognizes that multiple interactive and compensatory processes take place within and between innate capabilities, environmental conditions, and psychobehavioural characteristics. Therefore, individuals should not be identified or deselected on any one component (e.g., height) since an advantage on another, or a combination of other components (e.g., speed and commitment), may compensate for other weaknesses.

Whilst the proposed model places substantial emphasis on the role of psychology in actualising ones' potential, the transition from one stage of development to the next will also be constrained by motor and physical factors. Crucially, the proposed TiD model can also help to guide the support provided to the athlete at different stages of their development and not just serve a selection agenda. In other words, (copying both jargon and approach from Higher Education) coaches and scientists should increasingly adopt a 'formative' as opposed to a 'summative' assessment approach in their TiD efforts. Therefore, selection processes should consider an individual's progress and behaviour (e.g., commitment) during a development programme as opposed to purely considering the summation of a few physical or performance levels. The important point to make is that long-term predictions cannot be made 
solely on the basis of a few physical characteristics due to their unstable and nonlinear development over time. The proposed interaction of potential performance dispositions (psychomotor, behavioural, and physical) and environmental conditions, on the development of an individual in sport is illustrated in Figure 6.4.

The adoption of a multi-dimensional and dynamic model of TiD requires considerable changes to the processes traditionally employed to identify and develop talented athletes. The limitations of TID processes that employ one-off assessment processes to 'pull-out' a few talented children must be acknowledged. In contrast, the approach advocated within this model requires practitioners to recognise that talent is dynamic and that long-term predictions cannot be made on the basis of a few physical and performance characteristics. Instead, the approach advocates long-term monitoring on a range of variables as opposed to the early identification of the most 'talented' based on the summation of a few physical or performance variables. Additionally, practitioners need to place greater emphasis on establishing contexts for learning that support individuals in productively interacting with the environment. As Barab and Plucker (2002) emphasise, "educators must support the development of smart contexts - not simply smart individuals" (p.175). The implications for those practitioners who have typically seen the identification process as a precursor to the TD process, enabled through a 'one-off' assessment process (e.g., talent scouting in soccer), may initially appear overwhelming. Consequently, it is imperative that practical implications are explicit and practitioners are provided with a system and accompanying resources that enable them to adhere to the principles advocated by a multi-dimensional and dynamic model of TID.

\subsubsection{Summary}

In summary, some major concerns with current TI processes in sport have been reviewed and the need for an alternative approach that focuses on the development of talent emphasised. Additionally, the limitation of traditional TI models that have adopted a one-dimensional, microscopic approach in which talent is inappropriately conceived as a set of discrete, performance-based variables has been explored. It is 
likely that many countries around the world are currently not selecting their most potentially talented performers due to poorly defined and theoretically weak selection tools. To address these issues, a generic, multi-dimensional model in which talent identification and talent development (TiD) processes in sport are appropriately balanced has been proposed. In order for the principles advocated within the proposed model to be adhered to in practice, it is important that implications for practitioners are clear and this is addressed in the following chapter. 


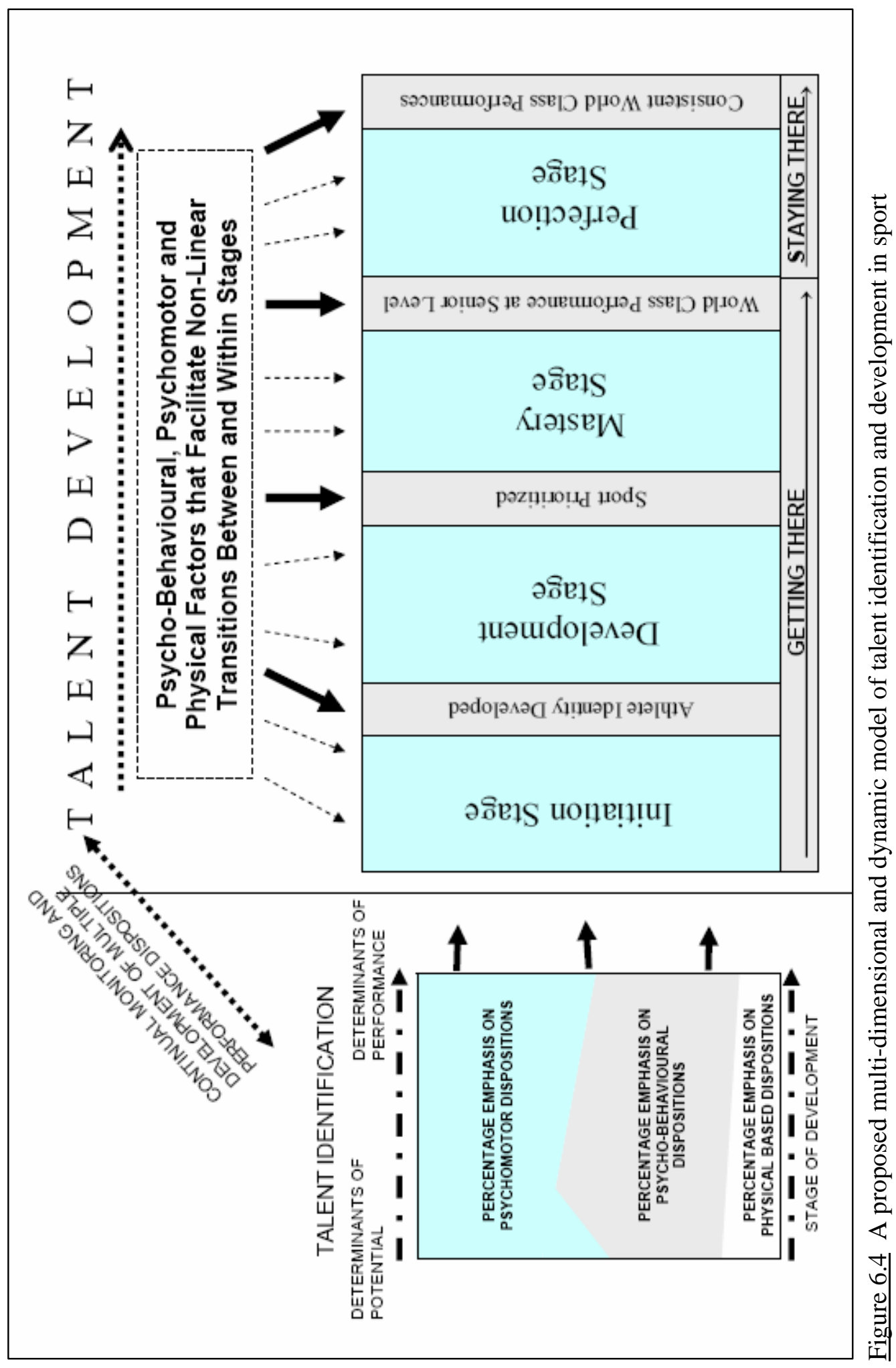

Developing a Multidimensional and Dynamic TID Model 


\section{CHAPTER 7 TRANSLATING THEORY TO PRACTICE: SYSTEMS AND RESOURCES}

The breakdown in communication between theorists, scientists and practitioners suggested that steps must be taken to bridge the gap between research and application. (Chan, 1991, p.183)

\subsection{Introduction}

A TiD model was developed in the preceding chapter that aims to overcome many of the theoretical and empirical weaknesses that are common to traditional approaches. However, whilst an increasing number of researchers are advocating a move away from one-dimensional predictive models of talent, the implications they present for practitioners are complex and often lack clarity. Consequently, this chapter considers processes for practitioners (teachers, coaches, etc.) that will enable them to adhere to the principles advocated. Specifically, consideration is given to how key psychobehavioural characteristics and psychomotor skills can be progressively promoted across primary schools, secondary schools and by National Governing Bodies of Sport. Whilst the primary focus of this thesis is the promotion of psycho-behavioural characteristics that support the ability of an individual to positively interact with the environment and strive towards achieving his/her potential, these skills must be promoted in tandem with psychomotor skills if benefits are to be truly realised. The TiD approach advocated provides a structure for an inclusive approach to physical development where all children are provided with the opportunities to develop the skills that will enable them to successfully participate, and therefore develop, within the physical activity or performance sport contexts.

\subsubsection{The current context: the role of Physical Education}

The crucial role that Physical Education (P.E.) can have in laying the foundation for physical development is increasingly recognized (Balsevich \& Progonjuk, 2001).

The number of physical initiatives within UK schools is evidence of the importance 
attributed to early motor experiences in terms of both promoting a physically active lifestyle and developing the skills required to participate in performance sport. For example, recent or current school based physical initiatives within the UK include: Activemark (SportEngland, 1988 to current), coaching for teachers (Department of Education and Skills \& National Coaching Foundation, 1989), awards for all (Lottery funded programme, 1999), sportsmark (SportEngland, 1998), the Nike/Youth Sport Trust Girls in Sport programme (2000), TOP sport (Lottery funded programme, 1999) and Specialist Sport Colleges (Department for Education and Employment, 1997).

Concerns over the health and activity levels of children and adults within the UK (and indeed around the world) provide substantial justification for increased resources being targeted to promote physical development and positive attitudes towards physical activity (Department of Health, 2001). However, there appears to be a lack of research underpinning the design of these initiatives. For example, a criticism leveled by Slavin (1989) regarding the way educational change in general was largely based on a "fashion trend" as opposed to a more analytic or scientific building process seems to reflect much decision making within the school physical education curriculum today. Recent research has also highlighted how new educational innovations come and go with little or no concern for their efficacy or importance (Stevens, 2004). An additional concern is that little consideration appears to be given to how one initiative can complement other available initiatives. This has resulted in "complex, overlapping and even competing programmes addressing increasingly closely specified or targeted categories of client" (Organisation for Economic Co-operation and Development, 1987).

An additional barrier that must be addressed if P.E. programmes are to become an integral part of long term athlete development are the concerns commonly expressed about performance sport and its perceived conflict with the educational agenda of schools (Kirk \& Gorely, 2000). Concerns include factors such as the degree of control the 'talented' child has over their involvement within a sport system, the impact of talent identification processes on those who do not make the cut, and the 
inability of selection criteria to acknowledge that differences in biological maturity of children will impact performances (Holt, 2002; Kirk \& Gorely, 2000; Malina, 1997). However, a strategy to enable individuals to achieve their potential in sport is not inherently or ethically wrong (Mahon, 2004). In fact, a review of the attributes that underpin successful involvement in performance sport and effective participation in physical activity highlights the same psychomotor (e.g., coordination), perceptual cognitive (e.g., decision making) and psycho-behavioural characteristics (e.g., evaluating progress) (see chapter 2). Indeed, it is a combination of such skills and attitudes that develops the self motivation (Ryan, Frederick, Lepes, Rubio, \& Sheldon, 1997), self-determination (Standage, Duda, \& Ntoumanis, 2003) and perceived physical competence (Boyd, Weinmann, \& Yin, 2002; Markland, 1999) shown to be so crucial to uptake of, and continuation in, physical activity. Consequently, early physical experiences should promote these predispositions to encourage all children to participate readily in physical activities at a level they choose. This focus on appropriate psychomotor, perceptual cognitive and psychobehavioural developmental opportunities for all children should fit well with the broader aims of Physical Education. For example, Department for Education and Employment \& Qualifications and Curriculum Authority (1999) state the following in relation to the Physical Education curriculum:

Physical education develops pupils' physical competence and confidence, and their ability to use these to perform in a range of activities. It [P.E.] promotes physical skilfulness, physical development and a knowledge of the body in action. Physical education provides opportunities for pupils to be creative, competitive and to face up to different challenges as individuals and in groups and teams. It promotes positive attitudes towards active and healthy lifestyles.

Pupils learn how to think in different ways to suit a wide variety of creative, competitive and challenging activities. They learn how to plan, perform and evaluate actions, ideas and performances to improve their quality and effectiveness. Through this process pupils discover their aptitudes, abilities and preferences, and make choices about how to get involved in lifelong physical activity. (Department for Education and Employment \& Qualifications and Curriculum Authority, 1999) 
Therefore, the establishment of a long-term, research-led approach to physical development, physical education and sport performance can have "a sensible and productive relationship which meets the needs of the general population for quality physical education while at the same time meeting the needs of sport performance across the lifespan." (p.119, Kirk \& Gorely, 2000). However, for such a system to be effectively established, a coherent and progressive approach to physical development must be established across schools and community sports. As such, the following section considers the role of National Governing Bodies of Sport in the establishment of a coherent approach to physical development.

\subsubsection{Transferring the philosophy into sport specific contexts}

In order to provide optimal physical experiences for children, coordination needs to be established between organisations (e.g., primary schools, secondary schools and NGBs) to ensure physical development is progressive. Such an approach should enable children to become competent in an array of skills that underpin successful participation in a range of activities and therefore enable them maintain a physically active lifestyle into adulthood. Additionally, a progressive approach to physical development should provide an explicit developmental pathway for those wanting to become involved in performance sport. Unfortunately however, concerns over the lack of coherence and longevity in the physical development of children have recently been expressed (e.g., Kirk \& Macdonald, 1998; Reid, 2003). This lack of coherence is reflected by National Governing Bodies marginalising the role for school sport in the development of sporting talent (Houlihan, 2000), even though a recent English Sports Council survey highlighted that for many athletes, involvement at elite level begins during school years (English Sports Council, 1998). The lack of continuity apparent between physical development programmes is endorsed through the primary focus often being on sporting success at the age group level. This typically results in a focus on the older and stronger children rather than a truly developmental perspective where all children, irrespective of size, are provided with encouragement to develop skills that enable them to progress to the next stage of development. In fact, numerous examples exist of athletes that experience 
considerable success at the youth level but fail to translate this early success into success at the senior level. For example, Fisher (1996) explained how a senior English Football Association coach traced back the England football teams for the World Cups of 1986 and 1990 to find that only one player, goalkeeper Peter Shilton, had played for England at the youth level. Similarly, despite only losing on penalties in the U16 World Football Cup final in 1989, Scotland has failed to exploit this success as a basis for subsequent performance in the adult game (McCleish \& Collins, 2002)

Clearly, the distinction between 'performance' and 'talent' is an important one, but a difference that does not appear to have been grasped fully by sporting organisations (e.g., National Governing Bodies, Funding agencies) and personnel involved in physical development programmes. Indeed, to achieve excellence at the world-class level, excellence at the junior levels may have to be sacrificed since the individuals who will excel at the two levels may be different. That is, the determinants of performance and the determinants of potential during adolescence are likely to be disparate. For example, a child may excel in age group rugby due to his/her advanced physical maturity, however he/she may not have the resilience required to cope with the inevitable setbacks they will encounter as they strive to a world-class performer . In short, traditional talent identification models have been based almost exclusively on the existence of current skills and ability, together with a less evident focus on innate early indicators of talent. Procedures need to evolve so that development coaches pay considerable focus to those factors that are likely to impact the capacity of a young athlete to translate early potential into successful performances at the senior level. This approach requires a shift away from the establishment of short term initiatives that primarily emphasise quick results to justify public investment (Balyi \& Hamilton, 2000; Reid, 2003)

As highlighted across the preceding chapters, the adoption of an approach that emphasises the capacity of an athlete to develop would imply that considerable focus be placed on the promotion of key psycho-behavioural characteristics. Psychobehavioural characteristics appear to significantly impact the capacity of an 
individual to cope with 'unforeseen twists' and therefore to translate potential into successful performances at the senior level. However, whilst coaches typically recognise the crucial role of psychology in translating potential to talent, psychological development is often neglected (Morris, 2000). This dichotomy between understanding and practice may reflect uncertainty regarding how psychological attributes can be optimally promoted alongside psychomotor skill development. In fact, psychological development primarily occurs as a reaction to specific problems rather than being seen as a tool that can be exploited to optimise athletic development (Ferraro \& Rush, 2000; Kremer \& Marchant, 2002; Pain \& Harwood, 2004; Partington \& Orlick, 1987)

Consequently, the production of teaching resources that enable the continued promotion and adaptation of psycho-behavioural characteristics alongside the development of sport specific skills is crucial if a coherent approach to TiD is to be advanced through schools and into sport specific development programmes. Therefore, as well as providing training and resources that enable optimal physical development to occur throughout school life, similar opportunities would enable coaches to continue the promotion of psycho-behavioural characteristics into sport specific contexts.

Figure 7.1 provides an overview of a proposed structure for TiD that promotes coherent processes for physical development by schools and National Governing Bodies of Sport. The structure adheres to the philosophies underpinning a multidimensional and dynamic TiD model. Accordingly, selection of children from 'level one' into 'level two' of the programme should not only focus on performance but should also recognise children that have shown a desire to develop and have persevered (even though they may not be one of the best athletes in the class at this stage). As a child further progresses from 'level two' into 'level three', selection processes should continue to acknowledge the behaviour and attitude of the child. Additionally, children can be recommended to specific sports based on their aptitudes (e.g., physical make-up, ability to scan in team games); however if a child 
wishes to participate in an alternative sport that they appear less suited to, this should not be prevented.

The proposed structure for physical development is grounded in research and designed to be ethically, educationally and developmentally sound. However, one of the biggest challenges facing the effective adaptation of an integrative approach to physical development is likely to be the extent that "coordination, cooperation and communication" (Kirk \& Gorely, 2000, p.131) are commonly pursued. 


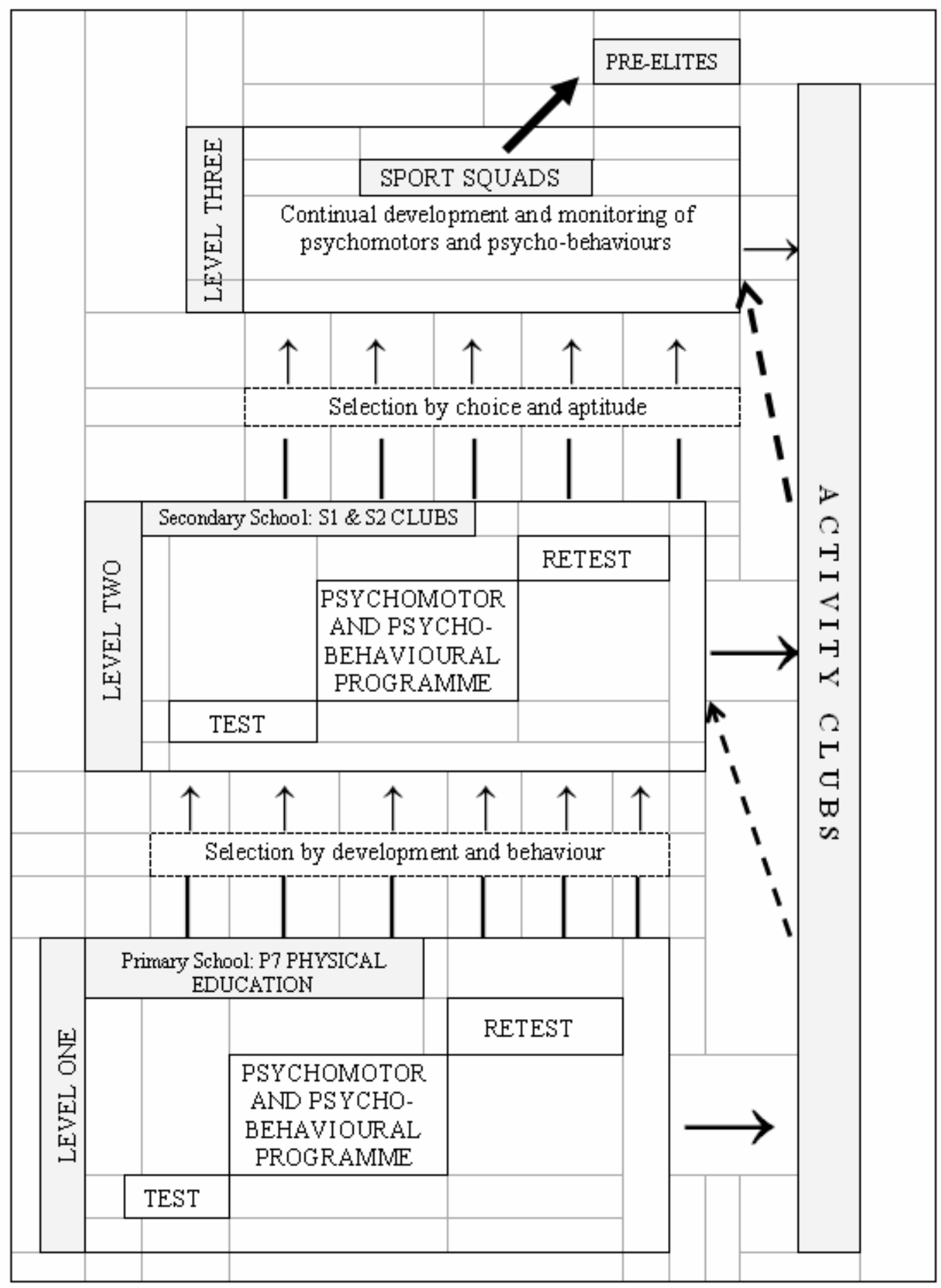

Figure 7.1 Proposed System for Promoting a Coherent and Theoretically Driven Approach to TiD within Sport 


\subsection{Materials for Applying the Principles Underpinning the Proposed Model}

\subsubsection{Development of psycho-behavioural characteristics}

A range of psycho-behavioural characteristics has been associated with individuals who successfully develop within sport, or indeed across performance domains (see Chapter 6). These psycho-behavioural characteristics include (a) goal setting, (b) performance evaluation and self-reinforcement, (c) self-awareness, (d) imagery, (e) planning, (f) commitment and role clarity, (g) evaluating and coping with pressure, and (h) focus and distraction control. Therefore, materials were developed that physical education teachers and coaches could use to facilitate the advancement of psycho-behavioural characteristics in combination with psychomotor development. Once the eight key behaviours highlighted above were established, a number of steps were undertaken to enable the development of user-friendly resources:

a. Firstly, developmental goals were identified for each of the psychobehavioural characteristics at level one (see Table 7.1) and level two (see Table 7.2)

b. A range of activities that target each of the progressive goals were designed

c. The appropriateness of each of the activities in targeting the desire objectives was discussed with three trained sport psychologists. Refinements were made to the activities until all the sport psychologists deemed the content of the activities appropriate.

d. All activities were then discussed and refined with two specialist Physical Education deliverers, and

e. Finally, materials were piloted within primary schools and secondary schools and with NGB coaches (see chapter 8).

The following section presents the materials that evolved from this process. 
Table 7.1

Concepts and Objectives Promoted within the Psycho-Behavioural Level One

Curriculum

\section{Concept Promoted Level One Objectives}

Self-Awareness To recognise that everyone, including themselves, have special strengths

To recognise that it is okay to have different feelings

To recognise that strengths at one task may be weaknesses at another

To recognise that a persons achievement may be perceived differently by different people

Performance

To realise that different people react differently in

Evaluation achievement settings

To get children to think about how they react to their own achievements and how this influences their feelings and behaviour.

To get children to develop an awareness of context - that the same outcome may be perceived differently under different circumstances.

Goal Setting To help children understand the role of goals

To use goals as stepping-stones in order to monitor progress

Imagery

To understand the concept of imagery

To learn how to successfully image

To use imagery to improve confidence and performance

Focus and

To facilitate a child's ability to recognise which cues should

Distraction Control be attended to in different situations 
Table 7.2

Concepts and Objectives Promoted within the Level Two Psycho-Behavioural Curriculum

Concept Objective

Self Awareness and Performance

Evaluation

Goal Setting,

Commitment and

Self-

Reinforcement

Focus and

Distraction Control

\section{$\mathrm{T}$}

To learn strategies to refocus if distracted

Imagery negative emotions aren't weaknesses. interpretations of "facts"

To consistently set process and step goals their performance.
People may usefully be selected, based on their particular blend of (strengths and weaknesses) characteristics

Different emotions are okay .... Irrationally positive or

Getting really good at something involves strengthening strengths but often also strengthening or even weakening

Perceptions, expectations and emotions may distort or colour

To consider the physical, mental \& technical elements of a goal

To use their physical, mental \& technical goals to evaluate

To recognise the importance of focusing on the correct cues

To learn to focus and minimise distractions

To understand the impacts of imagery on performance, both good and bad

To develop imagery skill through response training

To develop coping models in sport and non-sport situations 


\section{Psycho-behavioural materials}

Recognizing that students interpret psycho-behavioural concepts at their own level of growth and development, activities to promote these key behaviours are presented developmentally across three levels, i.e., they were designed for use with upper primary school children (Level 1), lower secondary school children (Level 2), and older children involved in sport specific practices (Level 3). The specific aims of these three progressive levels are to (1) encourage children to realize their level of competence and to self-reinforce, (2) encourage children to begin to take responsibility for their own development, (3) encourage children to aspire to excellence by achieving autonomous development. A complete pack of activities and accompanying manuals across the three development levels are presented in Appendix C. Activities incorporate a range of teaching styles to help students comprehend, acquire and retain the material. The teaching styles include selfreflection, group discussions, role playing, artistic tasks and physical tasks.

In order to understand how the model would work in practice, exemplars of imagery activities at each of the three levels are presented below. It is important to recognise that for the DPYPS programme to achieve all of its aims, the psycho-behavioural resources and accompanying manual were designed to be used in conjunction with a thorough in-service training that provided programme leaders with knowledge on not only how to conduct the practices, but also:

- the philosophy that underpins the programme;

- how the cards link together to form a progression;

- how to use the progression to fit class size and abilities, and;

- the flexibility within the programme so that individual teachers can use the programme in ways that fit their preferred methods and teaching styles. 


\section{Level one}

At the foundation level, the focus of the psycho-behavioural curriculum is the development and employment of five factors that can help children realistically evaluate their level of competence and to begin to self-reinforce their progress:

1. Teacher Led Goal Setting

2. Performance Evaluation

3. Self-Awareness,

4. Imagery, and

5. Focus and Distraction Control

Level one activities were designed to be employed with children between the ages of age 9 and 11 (primary 6 and primary 7) but can be employed with older age groups if the children show limited development of these five fundamental psycho-behavioural characteristics.

At 'level one', the imagery section presents practical tasks that promote the use of imagery and highlights how imagery, if used alongside practice, can help build confidence and improve performance. Figure 7.2 presents an imagery activity that involves self-reflection, group discussion and a physical task.

\section{Level two}

Level two further develops the behaviours acquired at level one. Due to the interrelated nature of the behaviours, tasks often promote two or more of the concepts at the same time. The aim of level two is to encourage the child to begin to take responsibility for their own development. The psycho-behavioural characteristics promoted are:

1. Goal Setting

2. Commitment

3. Performance Evaluation and Self Reinforcement

4. Self Awareness

5. Imagery

6. Focus and Distraction Control 
'Level two' activities are designed to be used with those children who have successfully completed 'level one' tasks. However, children who progress quickly when initially introduced to the 'level one' psycho-behaviour curriculum could be presented with some of the more complex level two exercises.

Imagery activities presented at 'level two' aim to promote the use of controlled imagery during practice and competition. For example, one of the objectives of this level is to show the power of imagery before considering how imagery could be applied to a sport or hobby. An activity designed to achieve this objective is presented within Figure 7.3.

\section{Level three}

Level three is a sport specific level that provides coaches with guidance on how to promote the psycho-behavioural characteristics developed at level one and two within their sport (e.g., netball, football). The seven behaviours promoted at level three are:

1. Goal Setting and Committing to Goals

2. Performance Evaluation and Self Reinforcement

3. Imagery

4. Planning

5. Focus and Distraction Control

6. Perceptions of Pressure, and

7. Quality, Goal Directed, Team and Individual Practice.

Effective application at this level requires sport specific coaches to reflect on the behaviours athletes in their sport display when successfully using psychobehavioural characteristics within training and competition. The effective application of a psycho-behaviour is likely to vary between sports and may also be dependent on the stage of development of an individual. Therefore, coaches are asked to consider "what will you see your athletes doing during training and competition to show that 


\section{Using Imagery to Improve Confidence and Performance}

\section{Part One}

Fupils look al the star shape below and 'inage' Eollowng the route to successfully draw the star in one movement. The pupils are told to hawe a go drawing the star and reflect on how umagery helped.

\section{Part Two}

Pupils watch a video of an athlete who is imaging running around a slalom course (the Illinois agility run) and then reflect on the athlete"s use of imagery. The pupils then image successfully completing the slalom course below before running the slalom course and reflectung on whether imagery helped them
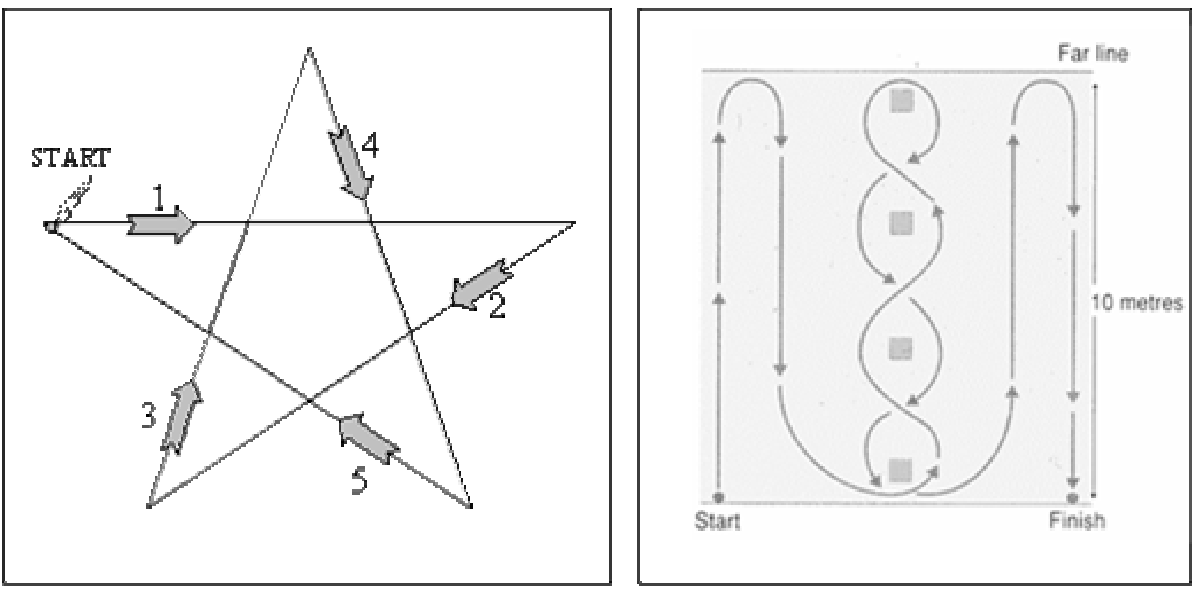

Figure 7.2 Example of level one psycho-behaviour activity 


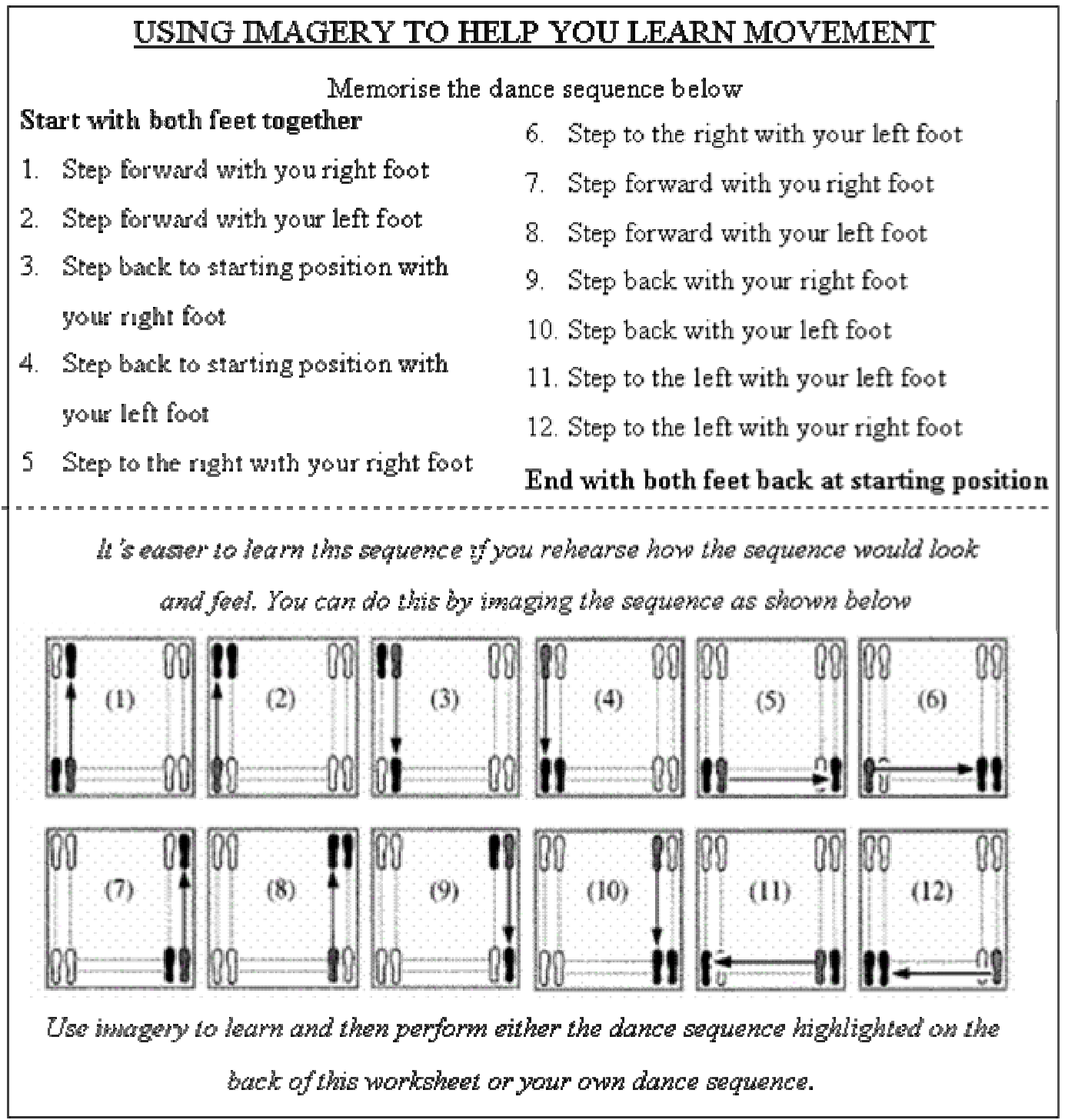

Figure 7.3 Example of level two psycho-behaviour activity 
they have imagery skills?" (see Figure 7.4). Systems and coach behaviours for the imagery behaviours identified are then developed (see Figure 7.5). Within the example presented in Figure 7.5, the gymnastics coach has identified that an athlete that effectively exploits the use of imagery within training would mentally rehearse a move before physically executing it. In order for the coach to encourage athletes to develop this skill, he/she has identified that a system that uses a video of relevant movements as a prompt for imagery would be beneficial. In addition, gymnasts would need to be provided with the time to incorporate any routine changes into their imagery scripts during training. Finally, coaching behaviours that reinforce the appropriate application of imagery by the athlete are identified, for example, praising those gymnasts who spend time mentally preparing for a routine before executing it (see Figure 7.5). 


\begin{tabular}{|l|l|}
\hline \multicolumn{2}{|c|}{ Imagery Behaviours } \\
\hline \multicolumn{1}{|c|}{ Training } & \multicolumn{1}{c|}{ Competition } \\
\hline $\begin{array}{l}\text { 1. Mentally rehearses a new skill } \\
\text { before physically trying it }\end{array}$ & $\begin{array}{l}\text { 1. Mentally and physically } \\
\text { prepares for a competition }\end{array}$ \\
2. & 2. \\
3. & 3. \\
\hline
\end{tabular}

Figure 7.4 Examples of how imagery could be effectively employed during training and competition in gymnastics (Level 3)

\begin{tabular}{|c|c|c|}
\hline \multicolumn{3}{|c|}{ Coach Systems and Behaviours } \\
\hline Athlete Behaviour & Coach System & Coach Behaviour \\
\hline $\begin{array}{l}\text { 1. When learning a new } \\
\text { skill, the athlete mentally } \\
\text { rehearses the skill before } \\
\text { physically trying the skill }\end{array}$ & $\begin{array}{l}\text { a. Use videol } \\
\text { demonstrations to provide a } \\
\text { prompt for imagery. } \\
\text { b. Give my athletes time to } \\
\text { incorporate the new skill } \\
\text { into their imagery script. } \\
\text { c. Allow the athletes to } \\
\text { spend time imaging as well } \\
\text { as doing the new skill }\end{array}$ & $\begin{array}{l}\text { a. Reinforce the role of } \\
\text { imagery } \\
\text { b. Emphasise that to learn } \\
\text { effectively you need to } \\
\text { focus on relevant cues } \\
\text { c. Praise athletes who spend } \\
\text { time mentally preparing for } \\
\text { their attempt }\end{array}$ \\
\hline
\end{tabular}

Figure 7.5 Examples of effective coach systems and behaviours for promoting the application of imagery within training in gymnastics (Level 3) 


\subsubsection{Summary on the development of psycho-behavioural characteristics}

A key concept underpinning the multi-dimensional and dynamic model proposed in the preceding chapter is that an individual will pass through various stages of development, and the ability to make the transition from one stage of development to the next is critical to successful advancement in sport. This ability to transfer successfully between stages of development is facilitated, and indeed characterized, by an individual developing and applying a range of psycho-behavioural strategies (e.g., goal setting, self-reinforcement, realistic performance evaluation). As such, TiD processes should place early and continual emphasis on the development and application of key psycho-behavioural characteristics. The practical activities presented within Appendix $\mathrm{C}$ should provide a framework for practitioners to promote these psycho-behavioural characteristics. However, as previously highlighted, for maximum benefits to accrue, psychomotor development and the development of psycho-behavioural characteristics must be promoted in tandem. Consequently, the following section presents materials to facilitate the development of psychomotors in combination with the advancement of psycho-behavioural characteristics.

\subsubsection{Psychomotor development}

Proficiency (perceived and actual) across a range of fundamental movement skills (e.g., catching and running) has been shown to be central to the physical competence of children (Rose, 1994; Rose, Larkin, \& Berger, 1997), and as essential for future participation in sports and physical activity (Gallahue \& Ozmun, 1995; Okley, Booth, \& Patterson, 2001). By contrast, a perceived lack of competence in fundamental motor skills has been reported to be a barrier to future participation in physical activities for both primary school (Haubenstricker \& Seefeldt, 1986) and secondary school children (Clough et al., 1993). Accordingly, early experiences should encourage children to develop and combine fundamental movement skills in order to build the coordinative structures required within different activities (Bernstein, 1967). For example, the ability to combine the movement of running, 
catching and throwing is of greater relevance to fielders in cricket/ baseball than each in isolation. Research evidence suggests that early diversification facilitates this ability to match 'coordinative structures' with specific situations (Baker, 2003) due to the existence of 'identical movement elements' between tasks (Schmidt \& Wrisberg, 2000). To put it simply, involvement in a range of activities requires fine adjustment to be made to coordinative structures and therefore encourages adaptability. For example, with appropriate developmental experiences, catching a ball by trapping with two hands can be adapted to carrying out a successful movement in cricket that requires the body to be oriented to enable the ball to be caught with one hand and to adapt to variations in ball trajectory. Such diversified activities, as well as facilitating the ability to transfer skills effectively from one task to another, may also facilitate adaptations required within a sport.

As well as the motor skills required to excel within a sport, a considerable literature attests to the superior perceptual cognitive skills displayed by elite athletes. For example, consistent differences emerge between skilled and less skilled players on their anticipation and decision-making skills (Williams, Davids, \& Williams, 1999). Differences are thought to be a reflection of their better knowledge developed through practice and instruction, as opposed to any initial differences in visual hardware such as acuity, colour vision or depth perception. Due to the existence of identical perceptual elements (i.e., performance-related decisions) and conceptual elements (i.e., strategies, guidelines, and rules regarding performance) between tasks (Schmidt \& Wrisberg, 2000), it has been suggested that diversification is likely to facilitate this learning process. For instance, field hockey and soccer both require participants to be aware of and interpret the actions of their opponents in order to be successful; therefore, these sports share this perceptual element. Gymnastics and diving share conceptual elements (e.g., similar rules), as do basketball and netball (e.g., similar strategies). Therefore, involvement in diversified activities at younger ages is likely to facilitate the development of 'identical conceptual and perceptual elements' and therefore, the ability of individuals to adapt their knowledge to different contexts (Baker, Horton, Robertson-Wilson, \& Wall, 2003). 
An additional consideration supports broad-generic rather than narrow-specific preparative activities predominating at younger ages. Research has shown that elite sports people have often transferred from another sport in their late adolescence (Moore et al., 1998). In short, many elites have started life as pre-elites in other areas. Thus, for example, three current British world-class 400M runners started life as junior internationals in BMX riding, gymnastics and trampolining - sports whose differences reflect the early physical profiles and experiences of the three individuals. Early specialization that leads to the development of sport specific skills is likely to hamper the ability of individuals to make later transfers, and hence limit this important cross-fertilization of talent estimated as typifying over $44 \%$ of senior internationals in the UK (Moore et al., 1998).

In summary, research supports the benefit of early physical experiences of youngsters primarily being in diversified activities that promote a basic moves vocabulary (e.g., the ability to catch) and the ability to combine these into increasingly complex coordinative structures (e.g., the ability to run, catch and throw a ball). This concept parallels processes employed within language education where individuals are initially taught words before being required to employ these within increasingly complex phrases and sentences. Diversified physical practices should encourage individuals to adapt coordinative structures to various conceptual and perceptual demands. For several years, physical education specialists have utilized intuitively appealing but relatively atheoretical methods such as 'Games for Understanding' (Bunker \& Thorpe, 1982) and 'Tactical Games' (Griffin, Mitchell \& Oslin, 1997) in an attempt to build children's' generic capacity to understand, and thus get involved in, team games. Such approaches implicitly acknowledge the role of knowledge structures as essential components of preparation for effective play. Recent research has highlighted the mechanisms through which this 'declarative' knowledge (cf. Anderson, 1993) can be developed (e.g., Rovegno, Nevett, Brock, \& Babiarz, 2001) and the apparent generic benefits which accrue in a child's decisionmaking style. Once again, varied experiences offer the best medium to develop this declarative knowledge base, providing games players with the capacity to be more innovative and creative in their (eventually) selected sport. 
While this entire agenda could be met by an effective primary PE programme, recent investigations suggest that current processes are not providing children with the competencies (perceived and actual) required to successfully participate in physical activities (e.g., Currie et al., 2004; Reuschlein \& Vogel, 1985; Ross et al., 1985). Therefore, although the primary focus of this thesis is on the development of psychobehavioural characteristics, a curriculum that enabled the development of motor skills and perceptual-cognitive skills in tandem with the development of psychobehavioural characteristics was also designed. Primary principles and exemplar activities for each of the three developmental levels are highlighted below.

\section{Level one: 'Basic Moves'}

The level-one work cards contain suggested content to help develop basic movements that underpin a variety of sports. Consistent with the categorisation employed by Ulrich (1985), the basic moves promoted include travelling skills (e.g., running and vertical jumping), object control skills (e.g., kicking, catching, throwing), and balancing skills (e.g., static balance and weight transfer). The cards suggest activities for the children that promote each of the basic movements, working along a continuum; starting simply and progressively becoming more difficult (see Figure 7.6). Additionally, as Figure 7.6 shows, the card also highlights critical features and common problems at the various stages of development. In this example with ball catching, the aim of the resource is to enable teachers/coaches to promote progression through an explicit focus on the appropriate key features.

\section{Level two: 'Transitions' programme}

The transitions programme aims to take well-learned basic moves and gradually combine and refine these to allow the generation of increasingly complex, sports-like patterns of movement. The combinations, like the programme as a whole, are designed to be progressive. To aid the teacher/coach, exemplar problems embrace both the individual components and their combination. For example, within Figure 7.7 the learning objective is to develop the transition between receiving and sending 
whilst travelling. If a child is having trouble with the activity, it is highlighted that the cause could be problems within individual movement components (e.g., throwing) or problems combining the individual components (e.g., a poor link between catching and throwing. Finally, as cognitive abilities (e.g., scanning \& decision-making) play a vital role in team game performance, these are developed in tandem with the movement skills (Grehaigne, Godbout and Bouthier, 2001) (see Figure 7.7).

\section{Level three: sport specific programme}

The level three programme looks at how the level one and level two psychomotor cards can provide the foundation for sport specific development. Figure 7.8 highlights the body conditioning, basic moves and transition activities that facilitate performance within football. For example, kicking for accuracy and distance (basic moves cards) and scanning and decision-making (transition cards) activities will promote skills that are required to be proficient at football. 


\section{The Basic Task}

Catch an object in the hands successfully in a well timed simultaneous action and in a balanced position. Key Words: Ready, reach, give.

\section{Example Extension Task}

(7) Throw the ball high; reach high to catch it. Give on contact. What direction are fingers and thumbs pointing on contact? Where are palms facing on contact? Fingers and thumbs should be pointing upwards; palms should be facing each other.

\section{Example Application Tasks}

Throw the ball at a line drawn at waist height on the wall. Can you hit just above and just below the line.

\begin{tabular}{|c|c|}
\hline \multicolumn{2}{|c|}{ MMMATURE } \\
\hline $\begin{array}{c}\text { Example of Critical Feature } \\
\text { Arms are extended and held in front of the } \\
\text { body }\end{array}$ & $\begin{array}{c}\text { Example of Common Problem } \\
\text { e.g., Body movement is limited until contact }\end{array}$ \\
\hline \multicolumn{2}{|c|}{ TRANSITION FROM MMMATURE TO MATURE } \\
\hline $\begin{array}{c}\text { Example of Critical Feature } \\
\text { Elbows held at sides with approximately } 90 \\
\text { degree bend }\end{array}$ & $\begin{array}{c}\text { Example of Critical Feature } \\
\text { Avoidance reaction of eyes closing at contact } \\
\text { with ball }\end{array}$ \\
\hline \multicolumn{2}{|c|}{ MATURE } \\
\hline $\begin{array}{c}\text { Example of Critical Feature } \\
\text { Hands grasp ball in well timed simultaneous } \\
\text { motion - 'give' }\end{array}$ & $\begin{array}{l}\text { Example of Critical Feature } \\
\text { Failure to adjust height of hands in relation to } \\
\text { the trajectory, and force of incoming ball. }\end{array}$ \\
\hline
\end{tabular}

Figure 7.6 Level one psychomotor example card: catching 
Learning Objective: to dewelop the transition between recerwing and sending whulst travell ung Suitable for: catch, overarm/underarm throw, chest/bounce pass, roll, kick and trap.

\section{$\underline{\text { Problem }}=$ catch the ball as quickly as possible and send for distance}

Catch ball from feeder and use an overarm throw, for example, to reach long receiver

Variations: Vary feed (distance, direction, pace), increase distance of target, throw to moving target, alternate hands

\section{PROBLEMS WITH MOVEMENT COMIPONENTS? - refer to Basic Moves card:}

1. Sending: overarm (B8), underarm (B11), chest-pass (B13), roll (B9), hit (B19).

2. Receiving: catching (B20) trapping (B16)

3. Travelling style: running (B1)

\begin{tabular}{|l|l|l|}
\hline Example Problems & \multicolumn{1}{|c|}{ Possible causes } & \multicolumn{1}{|c|}{ Solution } \\
\hline Ball falls short of & $\begin{array}{l}\text { Wrong foot forward } \\
\text { target }\end{array}$ & $\begin{array}{l}\text { Repeat appropriate task from Basic } \\
\text { Moves until movement solution is } \\
\text { appropriate. }\end{array}$ \\
\hline $\begin{array}{l}\text { Catch too low or } \\
\text { too high }\end{array}$ & $\begin{array}{l}\text { Not moving feet to get into } \\
\text { correct position quickly enough }\end{array}$ & $\begin{array}{l}\text { Repeat appropriate extension from } \\
\text { Basic Moves task }\end{array}$ \\
\hline
\end{tabular}

PROBLEMS WITH MOVEMENT COMBINATIONS? -If the individuals are able to perform each of the movement components separately then check the combinations by isolating them (send-receive, receive-travel, send-travel) and identify the potential problems

\begin{tabular}{|l|l|l|}
\hline \multicolumn{1}{|c|}{ Example Problems } & \multicolumn{1}{|c|}{ Possible causes } & \multicolumn{1}{c|}{ Solution } \\
\hline $\begin{array}{l}\text { No fluid link between } \\
\text { catch/throw }\end{array}$ & $\begin{array}{l}\text { Find foot placements } \\
\text { difficult }\end{array}$ & $\begin{array}{l}\text { Work on the feet moving quickly from a } \\
\text { catching stance, stepping back to allow } \\
\text { weight transfer for throw. }\end{array}$ \\
\hline $\begin{array}{l}\text { Need to change hands } \\
\text { between catch and throw }\end{array}$ & $\begin{array}{l}\text { Different dominant } \\
\text { hands for catching } \\
\text { and throwing. }\end{array}$ & $\begin{array}{l}\text { Work to develop both sides equally. } \\
\text { Practice with one hand behind back/ } \\
\text { holding something to prevent its use. }\end{array}$ \\
\hline
\end{tabular}

THE PROBLEM/SOLUTION: Get the children into pairs/groups and ask them to think of reasons why they would need to be able to send for distance (e.g., only free teammate is far away, to get the ball away from own goalbasket quickly, to score)

Figure 7.7 Level two psychomotor example card: object control during invasion games 


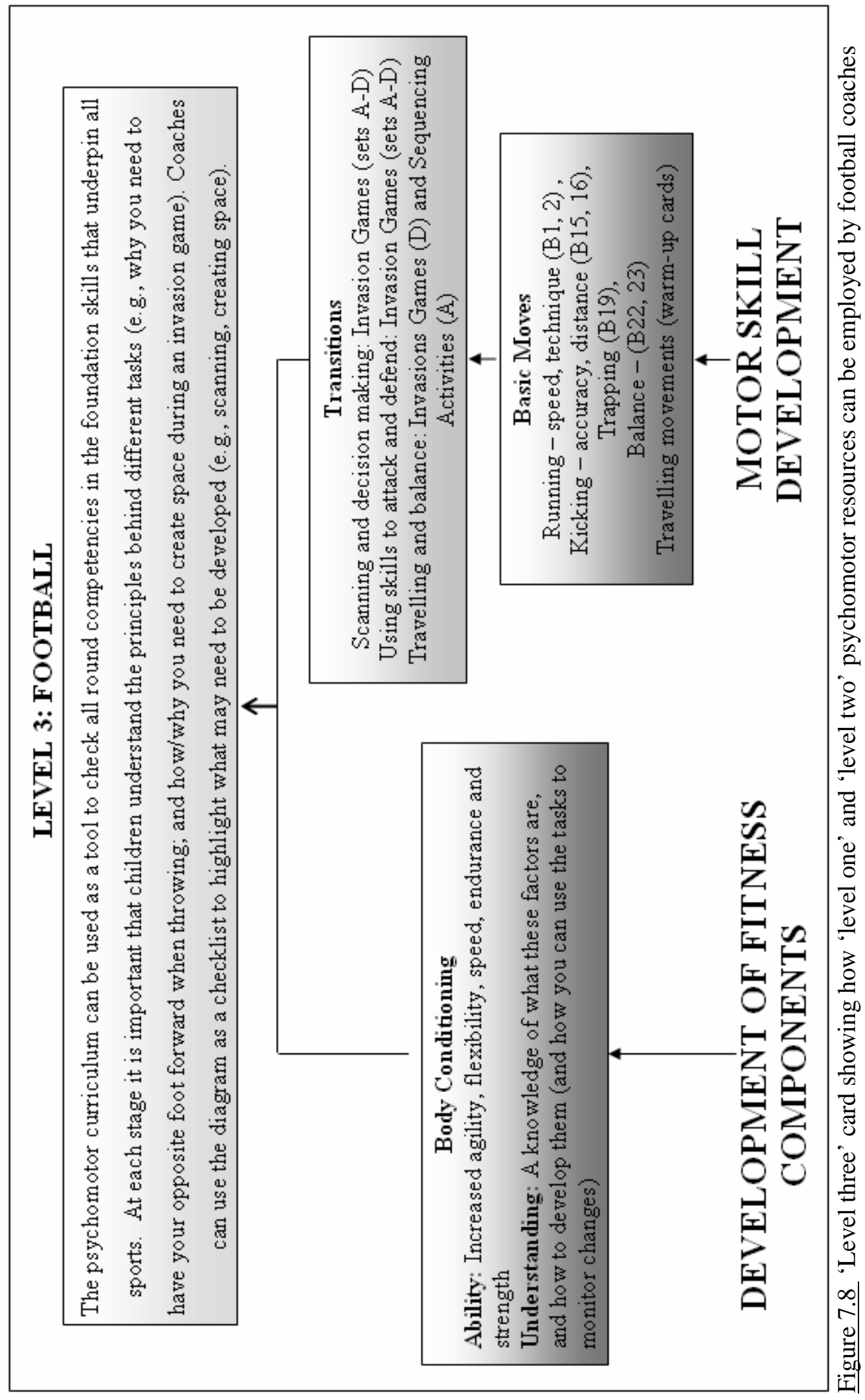

Translating Theory to Practice: System and Resources 


\subsubsection{Summary on psychomotor development}

This section has highlighted the importance of psychomotor dispositions to enable individuals to achieve their potential within sport. As these skills are developmental, however, de-selection should not occur due to lack of proficiency on one of these tasks, but rather opportunities provided for children to develop the required skills. Consequently, this section has explored means by which these skills can be progressively promoted. The curriculum follows a developmental line in three stages, moving from the development of basic components (the "words"), to a transition stage which develops the ability to combine these moves in meaningful ways (the "sentences and paragraphs"), to a final stage in which skills are deployed in game or activity-specific environments (the "stories"). The activities incorporated within each of these three stages range from simple to complex so that one skill can be taught using a range of challenges, enabling a better fit to individual abilities. As highlighted earlier in this chapter however, for maximum benefits to accrue, the development of psychomotors and psycho-behavioural characteristics must be promoted in tandem.

\subsection{Conclusion}

Within chapter 6, a multi-dimensional and dynamic TiD model was proposed. The model advocate that practitioners place a greater emphasis on a child's development, as opposed to the current emphasis on selection and elimination that is typically based on 'one-off' performance observations (e.g., scouting in football). To enable practitioners to implement the TiD approach advocated, practical materials for educationalists and coaches were necessary. Therefore, this chapter presents psychobehavioural and psychomotor resources that enable practitioners to adhere to the principles that underpin the proposed multi-dimensional and dynamic TiD model. In designing the materials, the focus was on providing practical and comprehensive resources that offered practitioners with 'packages' they could rapidly deploy. The combined emphasis on psycho-behavioural and psychomotor characteristics was considered a crucial feature of the proposed system as the majority of TID 
approaches solely consider physical development. Finally, the psycho-behavioural resources have the potential to make multiple contributions to sport development, physical activity promotion and achievement in non-sporting contexts (e.g., music, drama). This is particularly appealing when one considers the funding shortfalls and a range of, often competing, sectoral interests such as education, welfare and elite sports development apparent in today's society (Houlihan, 2000). In order for the proposed TiD framework to be promoted, evidence that the resources are effective and well received by practitioners and participants is needed. Therefore, the appropriateness of the proposed structure and its underpinning philosophies as a framework for TiD was evaluated within Scotland and the findings are reported in the following chapter. 


\section{CHAPTER 8 EVALUATION OF THE MULTI-DIMENSIONAL AND DYNAMIC TID MODEL}

\subsection{Introduction}

Following a review of factors that impact physical development and performance, a new multi-dimensional and dynamic approach to TiD was developed (see Chapter 5 and 6). This approach aimed to negate many of the problems associated with the selection/identification focus by stressing appropriate development opportunities for all individuals. Specifically, the programme pursued a new TiD strategy that explores the concept of equipping young people with the appropriate psycho-behavioural characteristics of excellence whilst providing the fundamental psychomotor and perceptual cognitive skills required for participation in a wide range of physical activities. As these skills can be developed over time, 'talent' identification based on proficiency on one or more of these tasks is not advocated, but rather activities are provided that exploit means by which these skills can be progressively promoted. Indeed, in contrast to the 'traditional perceptions and opposition to elitism', arguments that have bedevilled TID, the new approach advocated was completely educational. For example, the approach offered parallel benefits for a much broader scope of issues including life long physical activity promotion and generic achievement. Therefore, the programme was intended to offer pertinent developmental experiences that provided all children with the opportunity to learn and develop the psychomotor, perceptual cognitive and psycho-behavioural characteristics that promote development and progression towards potential. By equipping children with key mental and physical skills at early stages, they will become empowered to choose to pursue sporting achievement and/or physically active lifestyles when the opportunities present themselves. The programme was termed 'Developing the Potential of Young People in Sport' (DPYPS) and was piloted in partnership with sportscotland, the national sports organisation for Scotland between January 2003 and December 2003. The impact of the DPYPS programme as a whole is reported as any attempt to attribute effect to only one of the 
curricula (i.e., psychomotor or psycho-behaviour) would be a false division due to their co-dependent relationship.

\subsection{Methods}

\subsubsection{Procedure}

Consistent with the TiD system outlined within Chapter 7, the DPYPS programme was designed to provide primary school children with the opportunity to develop psychomotor and psycho-behavioural characteristics that, through the promotion of perceived and actual physical competence, provide the foundation for future successful participation in a range of physical activities ${ }^{7}$. In order to promote a coherent physical development process, an extra curriculum club, emphasising psychomotor and psycho-behavioural characteristics, was also established within secondary schools. Finally, regional coaches were invited to attend a workshop where the research team (a) presented the philosophy of the DPYPS programme, and (b) acted as facilitators whilst coaches considered means by which they could encourage developing athletes to adapt and apply the psycho-behavioural characteristics within sport specific contexts.

In order to evaluate the effectiveness of DPYPS, sportscotland decided to replace the unsuccessful Sport Interactive programme with the DPYPS programme. Regional councils within Scotland were invited to tender for the programme to be piloted within their area. Four regions applied and sportscotland ${ }^{8}$ evaluated the applications based on the following:

\footnotetext{
${ }^{7}$ Successful participation refers to either having the confidence to establish a physically active and healthy lifestyle or to choose to participate in performance sport.

${ }^{8}$ All decisions in relation to identifying pilot regions were made by sportscotland management independently of the research team
} 
curricula (i.e., psychomotor or psycho-behaviour) would be a false division due to their co-dependent relationship.

\subsection{Methods}

\subsubsection{Procedure}

Consistent with the TiD system outlined within Chapter 7, the DPYPS programme was designed to provide primary school children with the opportunity to develop psychomotor and psycho-behavioural characteristics that, through the promotion of perceived and actual physical competence, provide the foundation for future successful participation in a range of physical activities ${ }^{7}$. In order to promote a coherent physical development process, an extra curriculum club, emphasising psychomotor and psycho-behavioural characteristics, was also established within secondary schools. Finally, regional coaches were invited to attend a workshop where the research team (a) presented the philosophy of the DPYPS programme, and (b) acted as facilitators whilst coaches considered means by which they could encourage developing athletes to adapt and apply the psycho-behavioural characteristics within sport specific contexts.

In order to evaluate the effectiveness of DPYPS, sportscotland decided to replace the unsuccessful Sport Interactive programme with the DPYPS programme. Regional councils within Scotland were invited to tender for the programme to be piloted within their area. Four regions applied and sportscotland ${ }^{8}$ evaluated the applications based on the following:

\footnotetext{
${ }^{7}$ Successful participation refers to either having the confidence to establish a physically active and healthy lifestyle or to choose to participate in performance sport.

${ }^{8}$ All decisions in relation to identifying pilot regions were made by sportscotland management independently of the research team
} 
- The extent that the current sporting infrastructure would enable them to support an initiative that required commitment and collaboration between primary school teachers, secondary school teachers and sport specific coaches.

- The willingness of the regional council and schools to commit to the philosophy underpinning DPYPS and the willingness to forego future initiatives that conflict with this philosophy (e.g., not suppoting sporting organisations that utilise the school setting to identify 'talented' individuals based on 'one-off' performance observations)

- The availability of an individual that could be seconded to the programme and could effectively coordinate and deliver the programme within the region.

As a result of this process, sportscotland identified North Ayrshire and Stirling as pilot regions for DPYPS.

Even though the potential benefits of establishing the DPYPS programme in early and mid primary school was acknowledged, it was decided that the DPYPS programme be established in the same years that the previous Sport Interactive programme had been run (i.e., primary school year 7, secondary school year 1 and secondary school year 2). This decision was based on the recognition that the premature axing of the unsuccessful Sport Interactive programme had caused considerable disruption within North Ayrshire schools and it was hoped that providing an alternative would help these schools adjust to the change and simplify the processes required to implement the DPYPS programme. In the event that the DPYPS initiative was successful, the potential of extending the programme down the school was acknowledged.

Within North Ayrshire, the programme was piloted within one secondary school and five feeder primary schools. Within Stirling DPYPS was piloted within two clusters, 
Bannockburn and Balfron. The Bannockburn cluster had one secondary school and five primary schools involved whilst the Balfron cluster had one secondary school and six primary schools involved. This collection of schools resulted in 531 primary school children, 47 secondary school children and 23 teachers participating in the programme. Sport specific coaches $(n=19)$ from each area also attended a workshop that set out to explain the programme and to provide them with the knowledge to embed the philosophy of the programme into their own sport specific context. In addition, in an attempt to promote a coherent system, sports development officers $(n=3)$, school sport coordinators $(n=2)$ and local government agency representatives $(n=2)$ from each of the pilot regions also attended a DPYPS workshop that outlined the philosophy of the DPYPS programme and practical knowledge to apply the concepts into their own context. Finally, two seconded teachers provided planning and delivery support to the teachers administering the programme. Crucially, this process also encouraged coherence to the programme and its underpinning philosophies. The method of programme implementation at each level (primary school, secondary school and sport specific clubs) is described below.

\section{Primary school implementation}

All children within their final year of the 16 primary schools $(n=404)$ participated in the DPYPS programme and received one psychomotor and one psycho-behavioural session a week for a period of at least 10 weeks. In addition, and at their own behest, four primary schools extended the programme to children within year six of primary school $(\mathrm{n}=127)$. The psychomotor sessions replaced the traditional P.E. classes, whilst psycho-behavioural sessions were incorporated into the existing personal and social development (PSD) programmes. In the majority of schools, both psychomotor and psycho-behavioural elements of the programme were taught by the same teacher. It was hoped that this would facilitate the interaction between the two curricula and encourage the children to transfer the skills they learned to other aspects of the curriculum. However, in two schools, due to timetabling issues, the two elements of the programme were led by different teachers. 
aspects of the curriculum. However, in two schools, due to timetabling issues, the two elements of the programme were led by different teachers.

Those teacher(s) from each school who were identified as the individuals who would be delivering the DPYPS programme, were provided with four days of in-service training to learn about the philosophy of the programme and to be introduced to the methods and resources for both the psychomotor and psycho-behavioural curricula (see Appendix C). This in-service training was provided by a team of personnel that included (a) four trained sport-psychologists, (b) two experts from the field of psychomotor development with experience of physical education teaching in both primary and secondary school, and (c) two Specialist PE school teachers seconded to the programme by their respective local authorities. Two of the sport psychologists, one of the psychomotor experts and both of the specialist secondary school teachers also had practical and/or research expertise within coaching. During the training, primary school deliverers were provided with a manual and a Level One and Level Two psychomotor and psycho-behavioural resource pack (see Appendix C). It is important to highlight that, whilst the manual provides some information to help in running the DPYPS programme, it was designed to be used in conjunction with a thorough in-service training in order for the programme to achieve its aims. Ongoing support was also provided to all the primary school teachers throughout the piloting of DPYPS from the two seconded specialist PE teachers. Initially, both the primary school teacher and the seconded teacher planned and team-taught the psychomotor sessions. As the primary school teachers became increasingly competent in, and confident of, using the DPYPS resources, the seconded teacher gradually withdrew their support until the teacher was autonomous in the planning and delivery of the psychomotor sessions. The classroom based nature of the psycho-behavioural curriculum was more familiar to existing class practices (e.g., problem solving, roleplaying, self-reflection and group discussions). As a result, the primary school teachers were autonomous in the planning and delivery of the psycho-behavioural sessions from the beginning, although support was again available from the seconded teacher if required. Although it was expected that the primary teacher would primarily be using the level one psychomotor and psycho-behavioural resources 
(aimed at primary school children), they were also provided with knowledge of how to extend these activities and use level two resources if considered appropriate (e.g., certain students had progressed further than others).

\section{Secondary school implementation}

Year one $(n=312)$ and year two $(n=261)$ children within the three secondary schools were provided with an opportunity to attend an extra curricular DPYPS club. This club was planned and delivered by the specialist P.E. teachers that had been seconded to the DPYPS programme. The club involved attending two sessions a week across 10 weeks, one where the focus was on psychomotor development and one where the focus was on the development of psycho-behavioural characteristics. These two sessions were both conducted at lunchtime or after school, and lasted between 40 and 60 minutes. Unfortunately, the extra-curricular nature of the secondary school club resulted in a small uptake to the programme at both year one $(n=43)$ and year two $(n=20)$.

\section{Club implementation}

Individuals who provided sport specific coaching within the pilot regions (i.e., North Ayrshire \& Stirling) were identified by the respective Councils and were invited to attend a workshop that set out to explain the programme and to provide them with the knowledge to continue the philosophy of the programme into their own sport specific context. In total 19 coaches from a range of sports attended the training days. Seven from 17 invitees and 12 from 21 invitees attended in the two areas respectively. Two of the sport psychologists with practical and research experience within coaching ran this workshop. Coaches were also provided with a workbook containing a series of practical ideas to help guide the thinking of coaches, and, drawing on their knowledge and experience, help produce some practical solutions to promoting the desired application of psycho-behavioural characteristics within a specific sport (see Appendix C). Importantly, this workbook was designed not only to guide individual coach thinking, but also to provide a foundation upon which a 
more consistent and coherent coaching system can be provided to athletes throughout their career. The aim was to bring together as many 'coaching brains' as possible onto the same line of thinking, in order to establish a common understanding of talent development and therefore a coherent process by which coaches, at any level, can work to ensure a common method of effectively recognising and developing talent.

\subsubsection{Evaluation of the programme impact}

\section{Qualitative data analysis: perceptions of participants and deliverers}

In order to evaluate the effectiveness of the programme, interviews were conducted across a wide range of participants to assess perceptions of the philosophy, method and impact of the programme (see Appendix D). Individual interviews were conducted with all primary school deliverers $(n=16)$, secondary school deliverers (i.e., seconded teachers) $(n=2)$, coaches that had attended the DPYPS training $(n=19)$, school sport coordinators $(n=2)$ and local government agencies $(n=2)$. Finally, focus group interviews were conducted with children selected from each of the 16 primary schools $(n=80)$ and three secondary schools $(n=48)$ involved ${ }^{9}$. No interviews were conducted prior to establishing rapport and trust with the interviewees. This was accomplished by being candid with the interviewees and reassuring them that the purpose of the interview was not to evaluate their performance, but rather to gain an understanding of their perceptions of the DPYPS programme and how it could be improved. The interviews, which followed the semistructured format presented in Appendix D, were tape-recorded and transcribed verbatim. Depending on the degree of involvement of the participant, interviews

\footnotetext{
${ }^{9}$ Focus group interviews were conducted with children that were selected from each of the classes that took part in the DPYPS programme. Children were selected by their classroom teacher who were asked to ensure that the group was made up of children with varying physical abilities
} 
lasted between 30 and 90 minutes, and all the interviews were completed within a one-month period.

Following the transcription of the interviews, the raw data for the three pilot regions were arranged in text units, and were then analysed using qualitative inductive methods based on open codes, emerging themes, and emerging categories (Miles \& Huberman, 1994). The open codes were then arranged into themes that were based on the converging responses of a number of participants to minimize the effects of personality and other individual differences, thus leading to the identification of common categories. A reliability check was conducted at this stage by having an independent person critically question the themes identified to ensure that they accurately reflected the responses of participants (as recommended by Krane et al., 1997).

\section{Quantitative data analysis}

In addition to the interview data, several quantitative measures of critical selfperceptions and participation levels were collected from participants. The data collected aimed to assess any change in key attitudinal factors and participation levels over the course of the pilot. The "Young Peoples' Physical Activity Questionnaire" (Jess, 1999b, see Appendix E) measured activity levels. Additionally, the "Young People's Perception Questionnaire" (see appendix E) measured selfdetermination, self-motivation and perceived physical competence and was compiled from three available scales: the Self-Motivation Inventory Modified for Children (Biddle, Akande, Armstrong, Ashcroft, Brooke, \& Goudas, 1996; Weiss, Bredemeier, \& Shewchuk, 1985), the Perceived Physical Competence Scale of the Self-Description Questionnaire (Marsh, 1990, 1996), and an adapted version of the Locus of Causality for Exercise Scale (Markland \& Hardy, 1997). Adequate validity and reliability has been demonstrated for each of these scales (Biddle et al., 1996; Marsh, 1996; Markland \& Hardy, 1997) 
Data were collected at three stages through the pilot programme; namely, December 2002 before the beginning of the programme, mid term in October 2003 and finally post DPYPS in December 2003. Three types of analysis were conducted on this data, details of which are presented along with the results in section 8.3.2.

\subsection{Results and Discussion}

\subsubsection{Qualitative analysis}

\section{Philosophy and methodology of philosophy.}

A highlighted in Table 8.1, a wide range of deliverers were interviewed regarding the DPYPS programme (see Appendix D.1), and perceptions of the philosophy of the programme were very consistent and positive across this diverse representation. To the representatives questioned, DPYPS made sense, represented effective practice, and provided an educational and inclusive basis for children's physical development:

The idea for me about looking at broad based development, getting kids involved, covering good attitudes and values associated with participation is both fundamental to me educationally and from a sporting sense and coaching sense (seconded teacher).

I believe in the philosophy. I think it's a good philosophy and the idea of giving children a good foundation, a good grounding in something before you take them on ... which also comes into other areas, you know, you wouldn't do fractions before children could do tables for example. So I think it makes sense (primary school teacher). 
Table 8.1

Number of Participants and Personnel Interviewed about the DPYPS Programme

\begin{tabular}{|c|c|c|c|c|}
\hline \multirow[b]{2}{*}{ Participant's Role } & \multicolumn{3}{|c|}{ Number of Individuals Interviewed from: } & \multirow[b]{2}{*}{$\begin{array}{c}\text { Total Number } \\
\text { Interviewed }\end{array}$} \\
\hline & $\begin{array}{l}\text { North } \\
\text { Ayrshire } \\
\text { Cluster }\end{array}$ & $\begin{array}{c}\text { Bannockburn } \\
\text { Cluster, Stirling }\end{array}$ & $\begin{array}{l}\text { Balfron } \\
\text { Cluster, } \\
\text { Stirling }\end{array}$ & \\
\hline Teachers & 5 & 5 & 6 & 16 \\
\hline Coaches & 7 & 12 & & 19 \\
\hline $\begin{array}{l}\text { Seconded } \\
\text { Teachers }\end{array}$ & 1 & 1 & & 2 \\
\hline $\begin{array}{l}\text { Active Primary } \\
\text { School } \\
\text { Coordinators }\end{array}$ & 0 & 1 & & 1 \\
\hline P.E. Specialist & 1 & 1 & & 2 \\
\hline $\begin{array}{l}\text { School Sports } \\
\text { Co-ordinator }\end{array}$ & 1 & 0 & & 1 \\
\hline $\begin{array}{c}\text { Local Government } \\
\text { Agencies }\end{array}$ & 1 & 1 & & 1 \\
\hline $\begin{array}{l}\text { Primary School } \\
\text { Participants }\end{array}$ & 24 & 56 & & 80 \\
\hline $\begin{array}{l}\text { Secondary School } \\
\text { Participants }\end{array}$ & 36 & 12 & & 48 \\
\hline
\end{tabular}


A feature of the DPYPS programme perceived to be especially positive was the explicit focus on the development of the knowledge base of the teachers and coaches, both in terms of content and teaching methodology. This was seen as a much needed and crucially important factor to the quality and usefulness of the programme. It was highlighted as an issue that was missing from traditional education courses and needed to be explicitly targeted by other programmes:

I think there's the methodology bit that's really crucial to it. I don't think it's just about the programme in terms of the content of the programme being the practices and the cards. It's the interaction about the philosophical issues about how you keep them involved, how if we're saying we want to get them to be self determined, we want to get them to be motivated (primary school teacher)

What it [the training] did give them [the coaches] was a theory and then a practice and the practice matched the theory. Most coaching courses, there's no theory. It's just this is it, this is what you get and this is what you do and there's not a lot of discussion ... (seconded teacher)

In terms of the content of DPYPS, representatives felt that the explicit development of the physical and mental factors provides crucial aspects of effectively targeting children's development and the promotion of life long participation in sport and activity:

I think it's quite an exciting new approach. Certainly, it looks at key elements that haven't really been addressed in the past, the psycho-behavioural elements and I think these are very, very important if we're looking to develop young people (primary school teacher)

Well I think the rational behind it all is really very sound. ... I like the way that the movement and the behavioural bits are tied together. And I think that is something again that seems obvious but the fact that it's there in front of us ... I've never seen anything like that presented in that way before. (primary school teacher) 
Representatives felt that these key physical and mental factors were not just innate characteristics of some children but can be taught and learned by all youngsters.

Through this physical and mental development, it was perceived that children could be empowered to make more choices about participation, physical activity and sport:

Everyone can get better. Everybody can become more competent, which is important. People will participate in physical activity when they're confident in their own ability to do so. I think people develop at different times, different speeds and 1 think lastly basic skills and attitudes can be learned and have an impact on development and on participation. So for me that was the sort of my view of the underpinning philosophy and that's why we wanted to be involved in a research project, which was looking at an educationally sound programme. (primary school teacher)

In contrast to the DPYPS programme, traditional practices within physical development were seen to be lacking the required focus on the fundamental skills needed for children to make progress, enjoy being active and to be motivated to make the choice to participate:

The education system operates in a block system where specific physical activities are taught, therefore sport specific skills and practices are the focus and this includes TOPS. Often, children do not possess the movement competence to produce these sometimes very complex sport specific skills. Furthermore, quite often, pupils are taught to play just the game without the prerequisite skill development taking place first and this can lead to very negative experiences for a lot of kids. If pupils do not have the perceived or actual skill to take part in the activity, it provides a significant barrier to participation and without participation, you don't get attainment and you get problems (primary school teacher).

It [DPYPS] takes the children back to their basic skills. We all assume by the upper stages of primary school that the children have these basic skills but unfortunately they don't. So it takes them back, reinforces them and then extends them ... those skills. (primary school teacher) 
That training that preceded the implementation of DPYPS provided an underpinning philosophy and methodology as well as explicit developmental content was seen as a positive advantage over other training available from similar initiatives. Teachers and coaches felt that this approach enabled them to be flexible with the content of what they taught and allowed them to adapt practices to cater for the different needs of youngsters:

If they've [teachers have] got an understanding of the philosophies [of a programme], then they can be incredibly flexible in how they use it. And that's the important thing to me, as well as following the philosophies and understanding them. Whereas TOPS or other packages are, there you go, there's a programme of lessons, go and teach them. (seconded teacher)

In parallel, the actual content of the resources were reported to facilitate a developmental and flexible curriculum. Unfortunately however, respondents saw fellow professionals as often confined to teaching a curriculum or set of lessons regardless of their appropriateness to the children and with little or no guidance on what the key emphasis should be.

Participants also highlighted that the philosophy underpinning the DPYPS programme could be used to provide a coherent drive to many of the initiatives currently running. This would mean that a wide range of deliverers would be pushing in the same direction providing consistent ongoing experiences to children. However, in the short-term span that DPYPS had been running, it had yet to impact on this bigger picture:

I think it had a damn good try at it [providing a coherent drive across initiatives] but unfortunately in North Ayrshire, I don't think it did. But it's the same problem that our sports coordinators are having. It's the volunteers that run these things. It's trying to get these volunteers in the first place and then trying to coordinate them between each other. Again, it's not a ... as far as I'm aware, it's not a DPYPS programme issue. It's a local issue. (seconded teacher) 
I think that's been the weakness of the programme, and I wouldn't blame that on the programme. I would blame it on coaching in general, in that Stirling Council has a very, very good policy on coaching but to actually get coaches together and to, you know, present material to coaches and talk them through a new programme, you either hit the wrong coaches or it just ... it was difficult. (seconded teacher)

In order to overcome these barriers, respondents emphasized that the philosophy needed to be developed as a long term, coherent and consistent experience for children with a good team of deliverers supporting and driving it in practice.

In summary, teachers, coaches and specialists all perceived that the philosophy underpinning the DPYPS programme was a positive initial step in a crucial direction that provides an explicit and systematic focus on inclusion, ongoing opportunities and the development of key areas, something that was perceived to be missing from traditional approaches. Deliverers felt that the DPYPS programme was a theoretically and educationally sound programme that could be effectively transferred to the practical setting and positively impact the physical development of children. The following section considers the perceived impact of DPYPS on the children that participated over the short-term span of the pilot programme.

\section{Programme impact}

Deliverers were asked to reflect on the perceived impact of the DPYPS programme on the children who had been involved (see Appendix D.1). These data were supplemented by small focus group interviews with children from each of the classes involved (see Appendix D.2). In total, 22 focus group interviews were conducted with each involving between 6 and 10 children. In considering pupil comments, the vast caveat must be remembered that "anything new seems better"! However, pupils' perceptions are important, since they represent the main 'consumers' of any programme. If pupils did not feel positive about the new programme, or even if comments were marginal, then wider implementation may not be supportable.

Encouragingly, the content of the DPYPS programme was positively received by the 
children, and was perceived to have compared favourably with the usual P.E.

content:

When we did it, we started off on an easy level, then we built up. Harder and harder and harder and harder. So it's kind of... we got a good variation of different things unlike in the P.E. sessions that we used to have, they were quite boring. Every time before we did DPYPS, we did the same thing each term and it wasn't any different. We'd done that for two years and it wasn't challenging any more.(primary school pupil)

Deliverers' comments paralleled those made by pupils. In particular, the structure and progressive nature of the DPYPS system was identified as a particularly positive feature:

I've thoroughly enjoyed it [the DPYPS programme] and I know the kids have enjoyed it and I've got to say that this has been the best P.E. that certainly this school's had. (primary school teacher)

I can only say from speaking to the head teachers that they've been absolutely delighted with it, you know, and they've been really positive about the whole programme. (seconded teacher)

It was felt that the structure of the DPYPS programme had provided a framework in which children had been able to gain positive physical experiences and positively impact children's actual and perceived physical competence:

Watching the children, I don't think this year I have had anyone worried about gym, which has happened in the past, because they have really worried about this gymnastics before, it gets to them you know, maybe some children that are physically challenged - they don't have the worry that they had before which was a real problem for some children if they were big. They are not conspicuous now because its all mixed you know they don't dwell on that for too long, they go onto something else they can do so they are more ready to take part in work. (primary school teacher) 
I think confidence certainly [has improved]. Confidence at just trying things and just, you know, giving it an attempt or not being afraid to fail, not being afraid to, you know, you're not gonna succeed all the time or first time, that you're gonna make mistakes. And that's something that DPYPS can bring in. That, you know, it's something a good teacher will do but maybe not ... you know, maybe not think about it a great deal. But I think DPYPS does give a lot of confidence and I think that's certainly something I've seen. (primary school teacher)

Children also reported that they had greater actual and perceived physical competence since participating in DPYPS:

I'm confident, more confident because I' $m$ better at things now [since doing DPYPS] that I didn't used to be, things I couldn't do. I used to be scared of doing tackling in football but I don't know what happened to me but I'm not now. (primary school pupil)

[I've changed since doing the programme] because I just feel that I should take part in everything now. Because I feel that I've got better at some things, so I'm better at them, so I feel like taking part in them more. It's made me like feel more determined because before if I couldn't do it I just didn't go. Now, I try it out and if I can't really do it, then I keep going and try and get better at it. (secondary school pupil)

As a consequence, children were actively seeking sports experiences rather than feeling inhibited by their lack of ability.

When we did football I wasn't that good at it but we had a few DPYPS lessons and I like it now and I've joined a club now. (primary school pupil)

In gymnastics and running I'm better now because I'm not that good at gymnastics, I'm not that good at running, but I like other sports. And now I have this goal at the end of it. I quite like running now. I go cross country running. (primary school pupil) 
Participants also appeared to be more secure in themselves, confident to make mistakes but keep trying. These characteristics, typical of a self-determining approach, were used to facilitate activity:

It [DPYPS] helped me with the confidence thing because I do dancing in like a theatre company thing and I'm not like all that good at dancing - I'm alright! I can basically do them but sometimes like I just can't remember what order they go in but I'm sure like before I did DPYPS I would get all worked up maybe if I'd got behind and everyone else was way ahead of me but now I just laugh at myself and try and pick up where everyone else is. (primary school pupil)

If I didn't do well in a race, I'd just think, "Mhmm, I'll just not race them again", but now I'll try harder and try again and again and again. (primary school pupil)

I would say they [the children who've done the DPYPS programme] try other things around what they think they are good at because they have had a taste of all sorts of things that they might not have tried before. So they might think that now I'll have a go at hockey or I might be good at basketball because they can see that they can shoot, or they are good at defending or whatever and they might have just considered only football before so you are bringing other areas into their lives that they might not have tried before so when they go to the secondary school they have got more choices and they might try more. (primary school teacher)

The role of self-determination as an 'inoculation' against peer pressures was also well demonstrated by participant responses:

It's changed me just a little bit because I like sport but none of my friends go to the ones that I want to go to, so I never used to go. And then, it made me think I should go anyway because it doesn't matter if you don't go with your friends. Because I went to play football but none of my friends go. (secondary school pupil) 
Me, my brother and my sister used to set up obstacle courses and my brother's a big athlete kind of person and he used to always get a really good time doing it. So we time each other and he kept saying that I was really rubbish at it. And, after all I learnt [in the psycho-behavioural sessions of DPYPS], I just thought it doesn't matter what he thinks, and I ended beating my personal best and coming quite close to it and it really helped. (primary school pupil)

There was good evidence for pupils transferring the skills gained from the programme to other challenges, even though staff had expressed some concerns about their own ability to facilitate this transfer:

I found the goal setting useful because in climbing we had to abseil and we did abseil off the top of the church where the church bells were and I was scared and I broke the abseil into stages so I could get used to it before. (primary school pupil)

I go horse-riding and when I like, go to show-jumping competitions, before I go into the arena, I now think about the strides going into the jumps and things and the strides between all the jumps and then I know when to like, go over them and things. (secondary school pupil)

Finally, the programme appeared to have positively influenced tolerance in pupils, making them more hardy and persevering in the face of challenge, and more empathetic towards others. As such, the programme had achieved its broader aims, influencing moral cognitions as well as performance specific ones:

Everyone has different stages and you know you've worked really hard. There still might be someone who beats you but you should be proud of how hard you've tried and how well you did. You shouldn't laugh at people if they can't do something that you can do because everybody has different levels (primary school pupil) 
They [the children] are more willing I think to accept people into a team now than they were before. It used to be quite frustrating sometimes ... for instance if you were playing maybe football 5 aside and they knew that that person wasn't very good at that they wouldn't want them in their side. They don't question it now they just all get stuck in ... (primary school teacher)

In terms of evaluating the real impact of the programme, many of the specialists and coaches felt that it was far too soon to be able to see the full benefits that the programme could have. The objectives of DPYPS were perceived to be both long term and far-reaching. Accordingly, both time and effort were required to reap the benefits the programme potentially offered:

I think we've got a long way to go. I don't think there's any doubt about that. I think, you know, it's just chipping slowly but being consistent. I think that's always the model that's worked for me, you know, revolutions don't happen overnight. Or if they do happen, they don't become very stable. I think it takes time and it takes a bit of energy and it takes a bit of continued momentum to keep it going cos it's easy to get dispirited and just sometimes it doesn't work and there's problems happen and there's personalities come in and they don't really apply the philosophy in the way you want and it takes time. So you've just got to keep working at it. There's no short-term quick fix solution to this. It just takes time and sometimes time is not what you have because you've got deadlines on programmes, you know. Sport Scotland is quite time limited. You're not going to have a big impact over that amount of time. So it needs to be clearly understood that it will take time. You're changing a whole values and attitudes system and that's really hard. (Local Government Agent)

Many deliverers were therefore surprised at the scope of impact that DPYPS appeared to have had on children given its short-term span. This was particularly pertinent with regards to the attitudes towards P.E., and children's development from their new experiences:

I know the teachers have been very, very positive in the impact the actual P.E. programme has had ... some of the 
teachers have fed back and said, it's [the psycho-behavioural development has] been a very positive [feature] but more surprise for me is the impact that kids have responded too, you know, and they've said, this has been great, you know, ... this is brilliant. I've changed in this way or I've tried this now or I've done this now, I'm confident at going and doing this. So that's been really positive for me. (seconded teacher)

\section{Future directions}

All deliverers were keen to see the programme continue. Even without further funding, many felt that DPYPS had made a very positive and lasting contribution to their teaching:

I would continue to use the resources even if the programme was discontinued ... because its a reference ... we were always talking about trying to find a new resource and we've looked at various things but they all tend to be much of a muchness and I think that if you can allow children to enjoy something you have got them halfway there already so I am being very positive and everything but I've not actually found anything bad about it [DPYPS], I've really quite enjoyed doing it with them. (primary school teacher)

I would love to see the [DPYPS] programme continued. Very much so. I would absolutely love it. (primary school teacher)

Many felt that, with some adaptation, the programme should be extended to stress the health components and consequent benefits. Others stressed that the programme could serve as a universal philosophy, offering structure across the P.E., and even within the wider curriculum. Some even addressed its integration with other initiatives:

I'm not sure that the content just now would work down the school but it could be adapted. A lot of it is simple enough for down the school and they would enjoy it too and there is a lack of that sort of thing in school like you know personal 
and social material that's quite good for them and it works in with health as well. (primary school teacher)

I just think it could go further down the school and be sort of whole school sort of philosophy, if you like, to how we do P.E. (primary school teacher)

In summary, qualitative data offered a clear and unequivocal support for the programme and its impact. All individuals involved in the delivery of the programme felt that the approach had the potential to enhance physical development and positive attitudes towards physical activity. These positive observations were strengthened by comments made by children who reported having enjoyed the programme and provided evidence that they had internalized and used the psychobehavioural lessons in their sport and everyday lives. To explore further the potential of the DPYPS programme, the following section presents quantitative data on selfperceptions and participation levels. 


\subsubsection{Quantitative analysis}

As previously highlighted, several quantitative measures of critical self-perception and participation levels were collected. Significant attitudinal and behavioural improvement was not expected within the relatively short time span of the programme. When interpreting the data, it is important to note, as past research shows (e.g. Sallis, 1993), that the trend is towards a natural decline in participation and perception rates from year to year. Therefore, while one would ultimately look for an increase in participation and attitudes over time to show improvement, this must be considered within the context of the current trend for declining levels of physical activity as children get older.

Data were collected at three times during the programme; December 2002, October 2003 and December 2003. This enabled three types of analysis:

i. Cross Sectional Analysis: This analysis contrasted participation and perception levels of children following their involvement in the DPYPS programme with the previous year's cohort who had not been involved in the DPYPS programme

ii. Longitudinal Analysis: This analysis contrasted participants' selfperception and participation levels prior to and following their involvement in the DPYPS programme

iii. Perception Group Analysis: This analysis looked at whether the DPYPS programme impacted differently on children who, at the commencement of the programme, had low, medium and high levels of physical selfperceptions differently.

\section{Cross-sectional analysis}

In December 2002, prior to the commencement of the DPYPS programme, baseline self-perception and participation data of North Ayrshire children were collected from children in year seven of the five feeder primary schools $(n=151)$ and the first year of 
the secondary school $(n=163)$.. The data were contrasted with data collected from children in primary year seven of the feeder primary schools and the first year of the secondary in December 2003 at the conclusion of the DPYPS programme. As of December 2003, 127 children entering year seven of primary school had been involved in the DPYPS programme for 10 weeks when they were in primary year six. Additionally, 151 children entering year one of secondary school had been involved in the DPYPS programme for 20 weeks during their final year at primary school (see Figure 8.1).

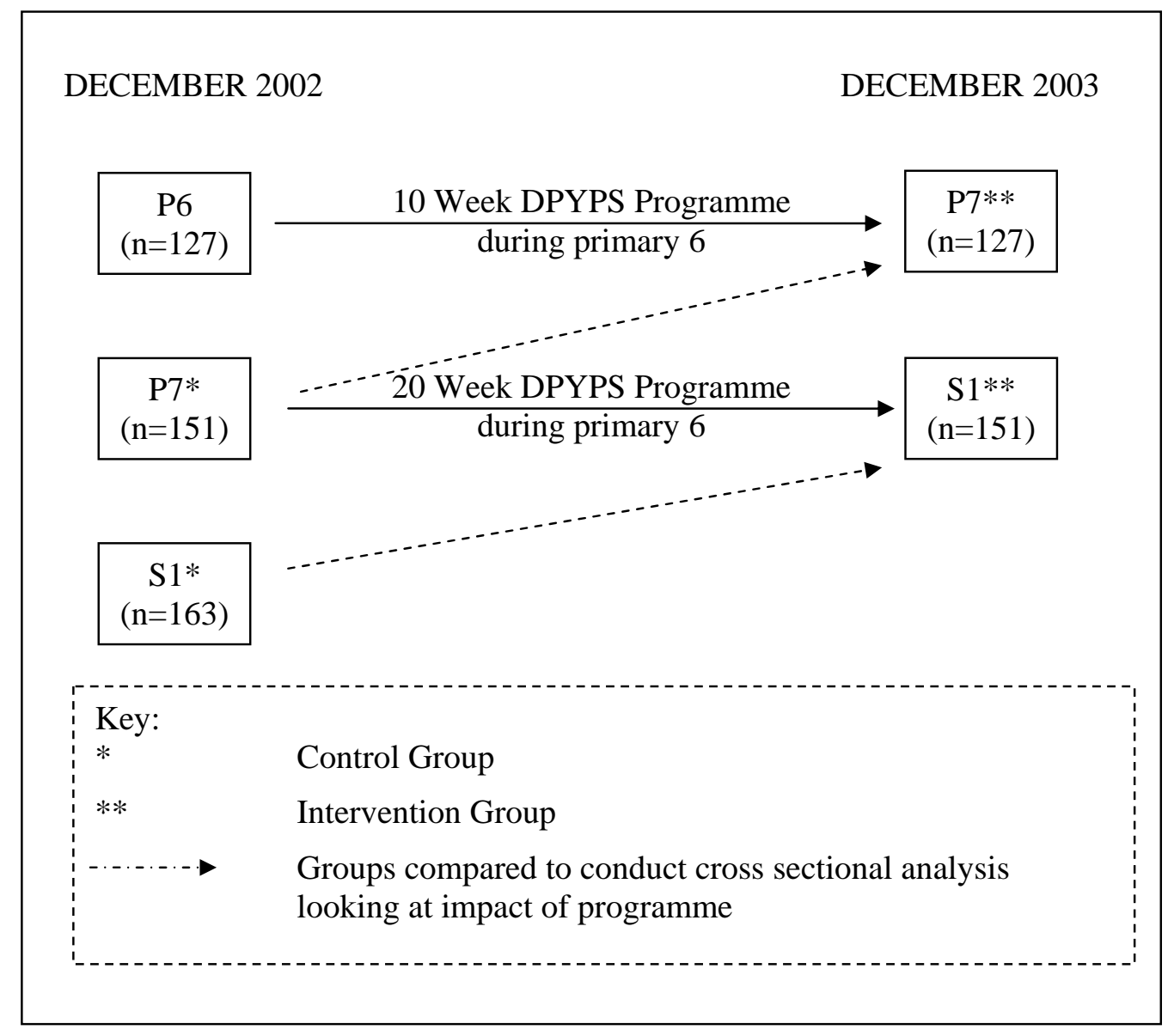

Figure 8.1 Cross-sectional analysis conducted on North Ayrshire data 
This analysis was only conducted on children within the North Ayrshire cluster due to the delayed commencement of the DPYPS programme in the Stirling cluster ${ }^{10}$. This delayed commencement resulted in Stirling schools only running the programme between October 2003 and December 2003. As a consequence, there was no comparison available between cohorts over the timescale of a year and this level of analysis was not possible.

Additionally, whilst the North Ayrshire cluster did run the programme over a year, several problems prevented this cross-sectional analysis being conducted for children who participated in the DPYPS programme at the secondary school level. The first reason relates to the fact that the secondary school response to the club was ad hoc. The S1 and S2 groups who chose to take part had one 10-week block of DPYPS each. The S2 group were trained between January and March 2003, and the S1 group between May and June 2003. Neither the S1 nor S2 clubs were able to run between October and December 2003 due to the unavailability of the school gym facility. Secondly, over the whole year there was a comparatively small uptake to the programme (S1 - 30, S2 - 20). These issues, combined with the ad hoc nature of the programme in secondary schools, render the cross-sectional year group analysis far less meaningful and add no additional value on top of the individual tracking data that will be presented later. Indeed, due to the voluntary nature of the DPYPS programme within the secondary school, even to split the cross-sectional analysis into groups of those who took part and those who didn't (DPYPS verses control) would leave the problem where it would not be possible to differentiate between the effects of DPYPS programme and the characteristics of those who choose to take part.

\footnotetext{
${ }^{10}$ This delayed commencement of the DPYPS programme within the Stirling cluster was due to delays the local authority encountered in seconding a teacher to overview the programme within their region.
} 


\section{Results obtained from the cross-sectional analysis}

These issues notwithstanding, the cross-sectional analysis allowed two separate evaluations of the impact of the DPYPS program: (a) the impact of a 10-week block of the programme on children in year six of primary school $(n=127)$ and $(b)$ the impact of a 20-week programme on children in their final year of primary school $(n=151)$.

\section{Impact of a 10-week block of the DPYPS programme during Primary 6}

No statistically significant differences were found in the participation levels of the group that had received a 10 week block of the DPYPS programme in Primary 6 $(n=127)$ when compared to the previous cohort who had not received the DPYPS training $(\mathrm{n}=151)(\mathrm{F}(1,273)=0.226, \mathrm{P}>0.05)$. Additionally, no significant differences in self-perceptions were apparent between the participants and controls (Perceived physical competence: $F(1,216)=0.02$, p $>0.05$; Self-motivation: $F(1$, $216)=0.02, \mathrm{p}>0.05$; Self-determination: $\mathrm{F}(1,216)=0.024, \mathrm{p}>0.05)$.

\section{Impact of a 20-week block of the DPYPS programme during Primary 7}

Again, no statistically significant differences were found in the participation levels of the group that had received a 20 week block of the DPYPS programme in primary 7 $(\mathrm{n}=151)$ when compared to the previous cohort who had not received the DPYPS training $(\mathrm{n}=163)(\mathrm{F}(1,306)=0.016, \mathrm{p}>0.05)$. However, although the 10-week training group showed no significant differences in self-perceptions as compared to the control group, some statistically significant differences were apparent for those children who participated in the 20-week training group, compared to the control group (Perceived physical competence: F $(1,292)=12.155$, p <0.01; Self-motivation: $\mathrm{F}(1,292)=7.829, \mathrm{p}<0.01$; Self-determination: $\mathrm{F}(1,292)=3.097, \mathrm{p}>0.05)$. These data provide initial support for the qualitative data where deliverers and participants highlighted the potential of the program to have a positive influence on the perceived physical competence and self-determination levels of participants. 


\section{Results obtained from the longitudinal analysis}

The longitudinal data analysis involved contrasting children's participation and selfperception levels prior to the commencement of the programme with their levels at the conclusion of the programme. Due to the delayed commencement of the programme in Stirling, data from North Ayrshire and Stirling were treated differently:

\section{Overview of analysis conducted on longitudinal data from North Ayrshire}

Within North Ayrshire, the longitudinal data analysis involved tracking children who, at the commencement of the programme, were initially in the seventh year of primary school (participants $=127$, controls $=0^{11}$ ), the first year of secondary school (participants $=28$, controls $=113$ ) and the second year of secondary school (participants $=19$, controls $=142$ ) through to the first year, second and third year of secondary school respectively. This level of analysis had the additional benefits of control groups being available at year one and two as depicted in Figure 8.2.

Unfortunately, this level three analysis only occurred in North Ayrshire for the reasons outlined earlier (i.e., the delayed commencement of the programme in Stirling).

\footnotetext{
${ }^{11}$ No control group was available at this level as all children in year seven of the primary schools involved in the pilot participated in the DPYPS programme
} 


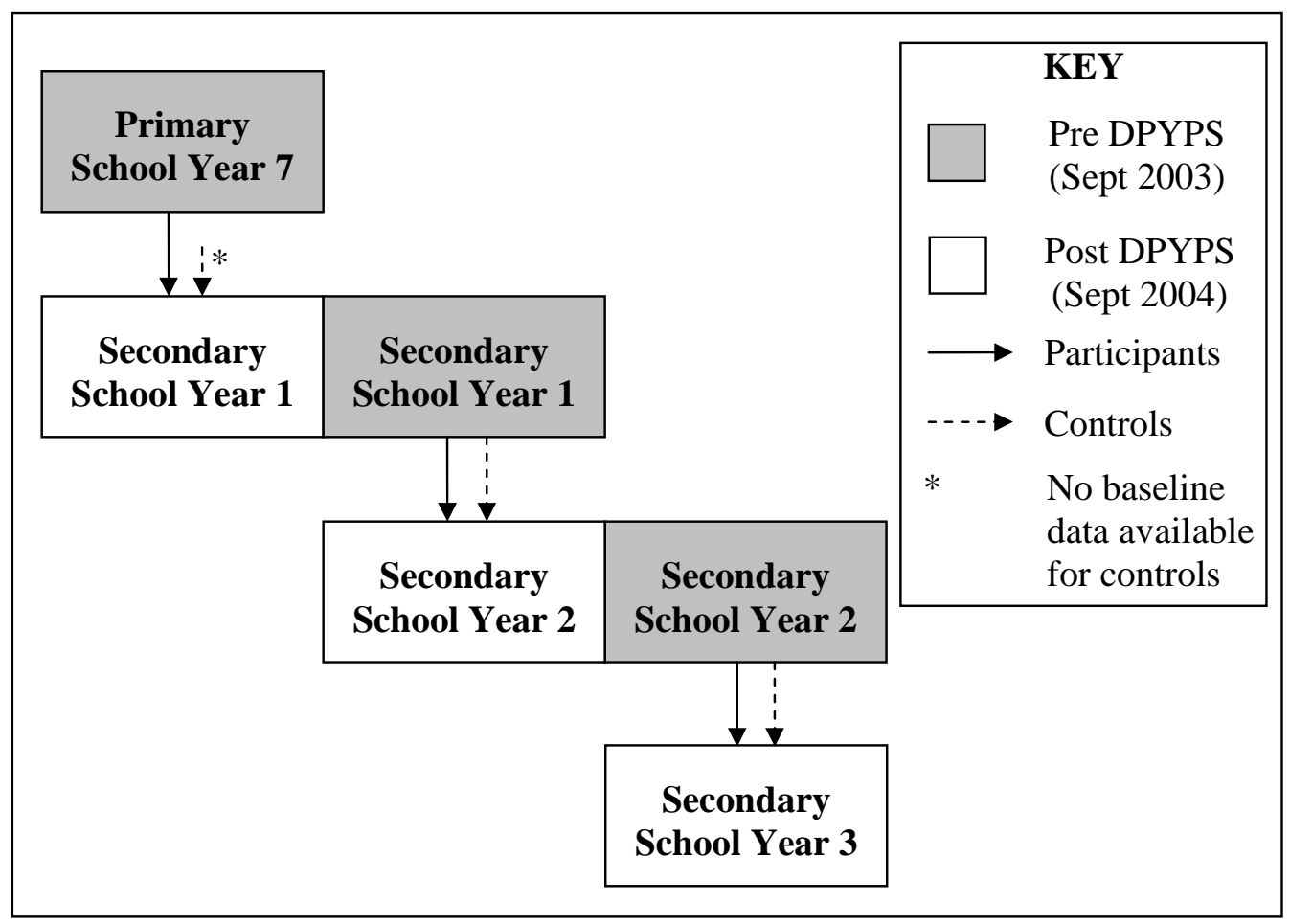

Figure 8.2 Level three quantitative analysis

\section{Overview of analysis conducted on longitudinal data from Stirling}

Within Stirling the longitudinal data analysis was restricted to a comparison of selfperception and participation levels for primary seven children prior to and following their involvement in a 10-week block of the DPYPS programme $(n=253)$.

Unfortunately, as all primary school within the Stirling region involved in the piloting of DPYPS were involved in the programme and all children within primary seven in these schools took part, this level of analysis was limited by the absence of a control group and results should be interpreted with care. This level of analysis is depicted in Figure 8.3. 


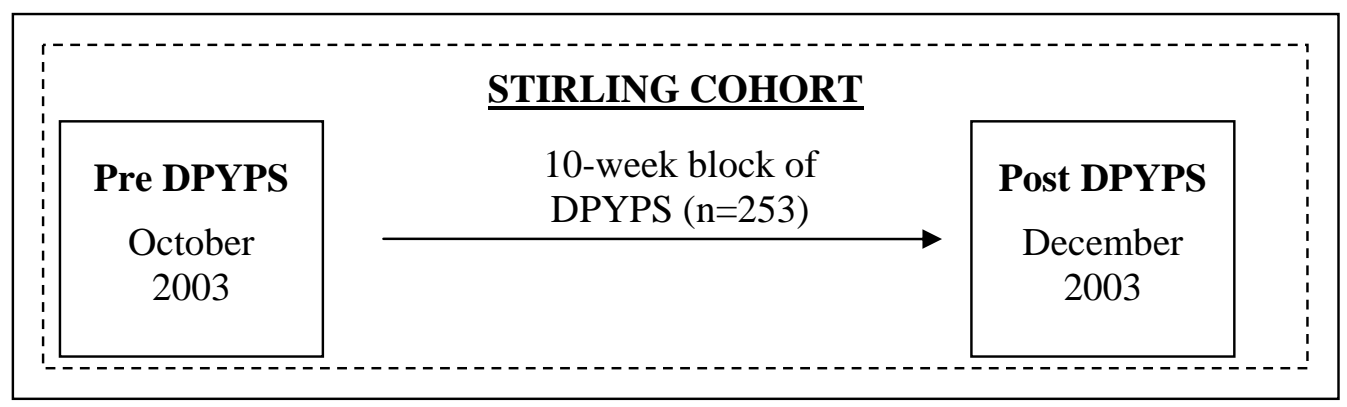

Figure 8.3 Longitudinal data analysis conducted in Stirling

\section{$\underline{\text { Results obtained from the North Ayrshire longitudinal analysis }}$}

Typical drops in both participation and self-perception levels were apparent for those children who moved into year one and year two, regardless of group (DPYPS or control). Interestingly however, the group of children moving from year two through to year three of secondary school showed a statistically significant interaction effect $(\mathrm{F}(1,160)=3.886, \mathrm{p} \leq 0.05)$ where those who participated in the DPYPS programme increased the amount of physical activity clubs they attended from an average of 1.9 to 2.1 clubs whilst those who chose not to participate showed a decline $(\underline{\mathrm{M}}=1.24$ to 1.05 clubs). No significant interaction effects for self-perception levels were observed. However, those who chose to become involved in the DPYPS programme had higher self-perceptions initially and after the programme. It would be interesting to see, if the DPYPS was made part of the curriculum within secondary schools, what effect it would have on those children who have lower perception and more inactive lifestyles.

\section{Results Obtained from the Stirling Longitudinal Data Analysis}

Initial support for a positive impact of the combined psychomotor and psychobehavioural programme was revealed through this level analysis. In particular, a statistically significant improvement in participation levels was apparent for primary 7, with children attending an average of 1.9 clubs at the conclusion of the programme compared to an 1.2 clubs at the commencement of the programme $(\mathrm{F}(1,250)=$ 10.956, $\mathrm{p}<0.01$ ). Whilst the absence of controls means that these data should be interpreted with care, they lie in contrast to research that has highlighted that 
participation levels of children at this age steadily decline (Sallis, 1993) and support the comments made by the children regarding their increased willingness to try different physical activities and persevere in the face of challenges. Furthermore, statistically significant improvements in all self-perceptions were apparent following involvement in the 10 week DPYPS programme (self-determination: $\mathrm{F}(1,238)=$ 4.426, $\mathrm{p} \leq 0.05$; self-motivation: $\mathrm{F}(1,238)=8.024, \mathrm{p} \leq 0.05$; perceived physical competence: $\mathrm{F}(1,238)=5.665, \mathrm{p} \leq 0.05)$.

\section{Self-perception group analysis}

The final analysis involved classifying P7 children based on their self-perceptions at the commencement of the DPYPS programme. Children were classified as having either low, medium or high values on each of the three self-perception variables (self-determination, perceived physical competence and self-motivation). This categorisation was based on percentile groups where the 'low perception group' were those that had a mean score below the $33^{\text {rd }}$ percentile, the 'medium perception group' had a mean score between the $33^{\text {rd }}$ and $66^{\text {th }}$ percentile and the 'high perception group' above the $66^{\text {th }}$ percentile. This classification enabled a consideration of whether the programme impacted children that initially had high, medium or low self-perceptions differently. Separate analyses were completed for the Stirling and North Ayrshire Cohorts. Unfortunately, once again, as all children in primary year seven were involved in the DPYPS programme, no control group was available.

\section{Results obtained from the self-perception group analysis}

The data show a significantly different effect of the DPYPS programme depending on the perception group a child was in at the start of the programme (i.e., low, mid or high). This was consistent across each of the three constructs for Stirling (Perceived physical competence $(\mathrm{F}(2,238)=22.779, \mathrm{p} \leq 0.01)$; Self-motivation $(\mathrm{F}(2,238)=$ 11.643, $\mathrm{p} \leq 0.01)$; Self-determination $(\mathrm{F}(2,238)=36.77, \mathrm{p} \leq 0.01)$ and two of the constructs for North Ayrshire (self determination $(\mathrm{F}(2,121)=8.86, \mathrm{p} \leq 0.01)$ and 
self motivation $(\mathrm{F}(2,121)=3.514, \mathrm{p} \leq 0.05)$. Interestingly, it appeared that positive changes in self-perceptions were greater for those participants who initially had lower self-perceptions. Whilst children with mid range scores on self-perceptions were also positively affected by their involvement in the DPYPS programme (but typically to a lower degree than those in the low group), those who had high selfperceptions at the beginning of the DPYPS programme were 'negatively' affected, although self-perceptions remained high (see Figure 8.4 to Figure 8.9). This trend was apparent for both males and females. Perhaps the programme leads to a 'rationalisation' in these confident children. In other words, through completing the psycho-behavioural activities focusing on, for example, increased self-awareness, those children that initially had high levels of perceived physical competence may have developed an increased recognition of both their strengths and weaknesses resulting in a more realistic perception of their physical competencies. In addition, participation in a range of physical activities that highlight skill development as opposed to performance and that require individuals to utilise a wide range of physical skills, may also lead to a reassessment of one's current proficiency level. Finally, the observation that it was typically only those children with high selfperceptions that opted to be involved in the secondary school programme may provide a case for compulsory implementation at secondary school as well as at primary. 


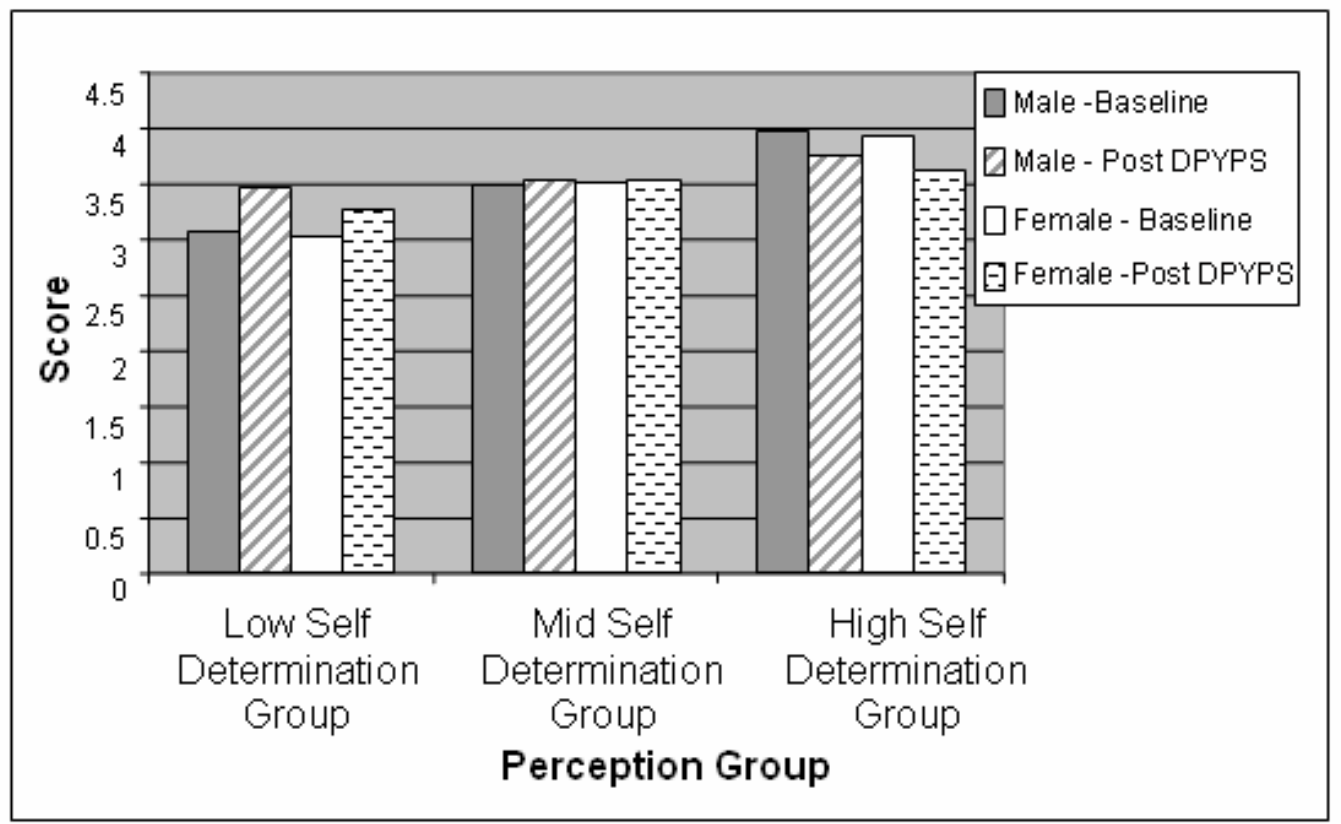

Figure 8.4 Mean changes in baseline self-determination values following involvement in the DPYPS programme for primary seven Stirling children

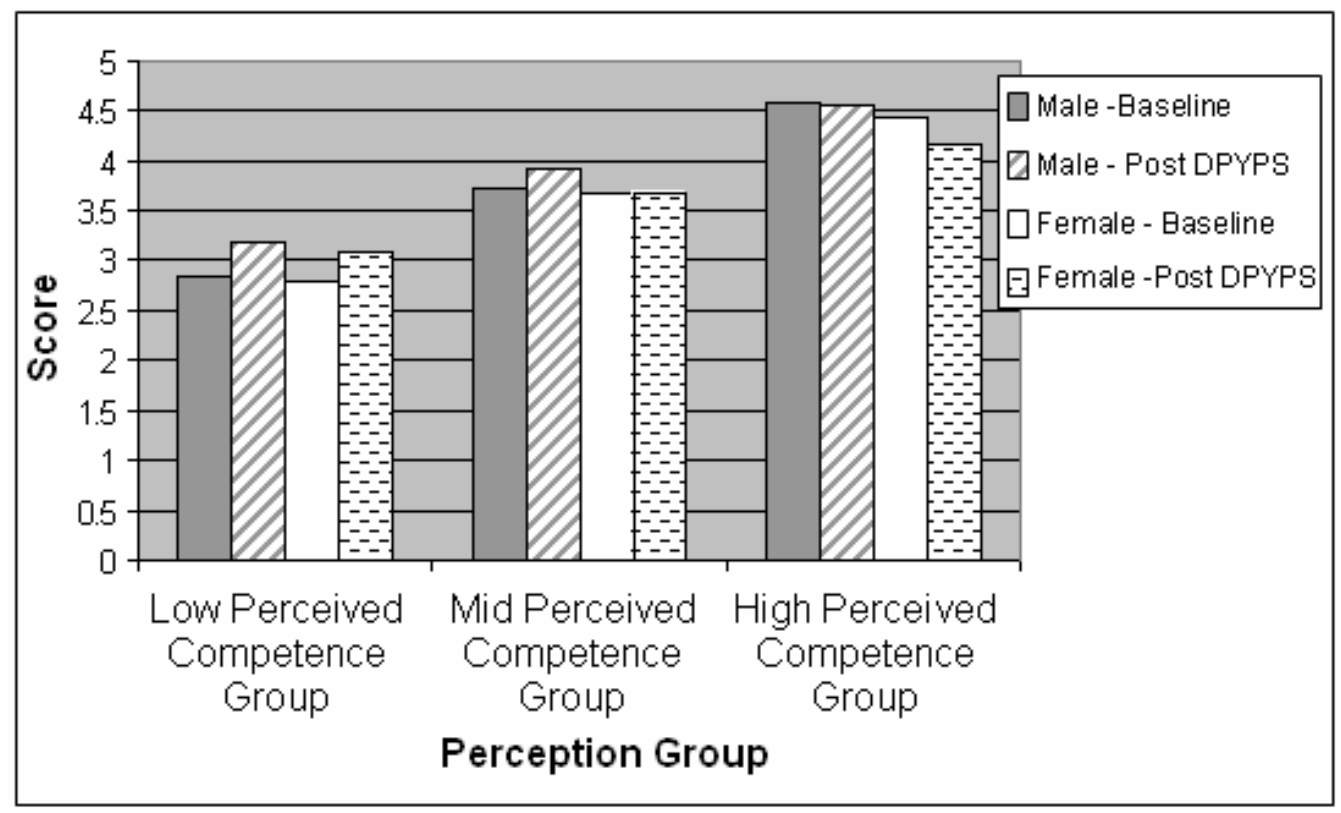

Figure 8.5 Mean changes in baseline perceived physical competence values following involvement in the DPYPS programme for primary seven Stirling children 


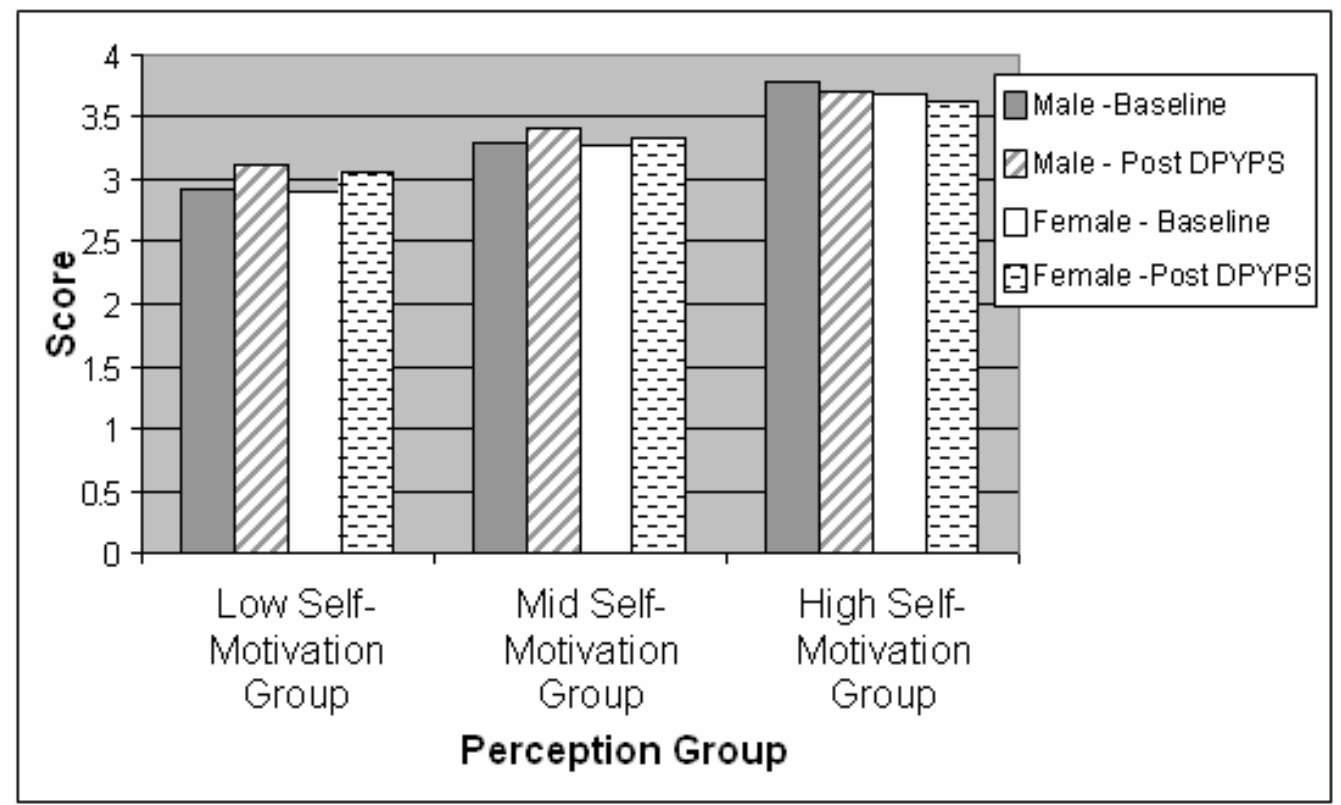

Figure 8.6 Mean changes in baseline self-motivation values following involvement in the DPYPS programme for primary seven Stirling children

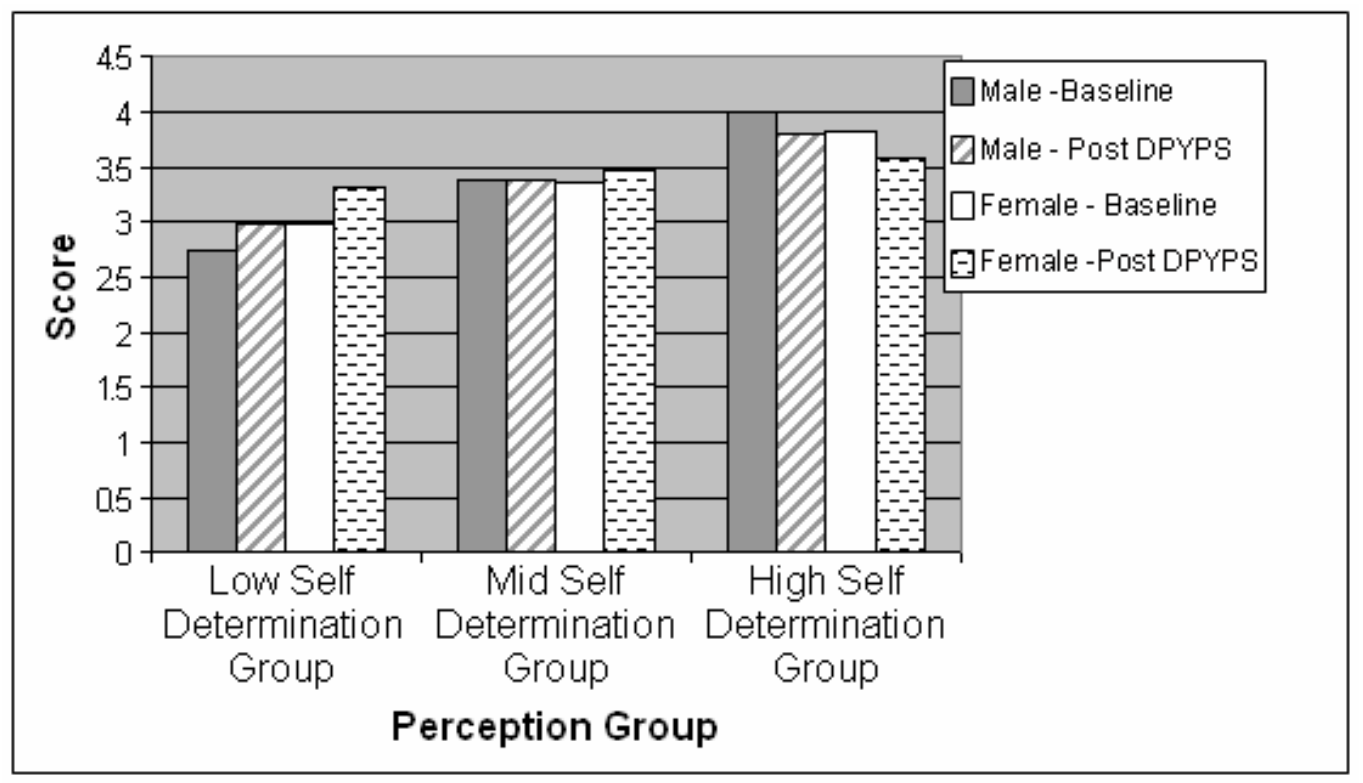

Figure 8.7 Mean changes in baseline self-determination values following involvement in the DPYPS programme for primary seven North Ayrshire children 


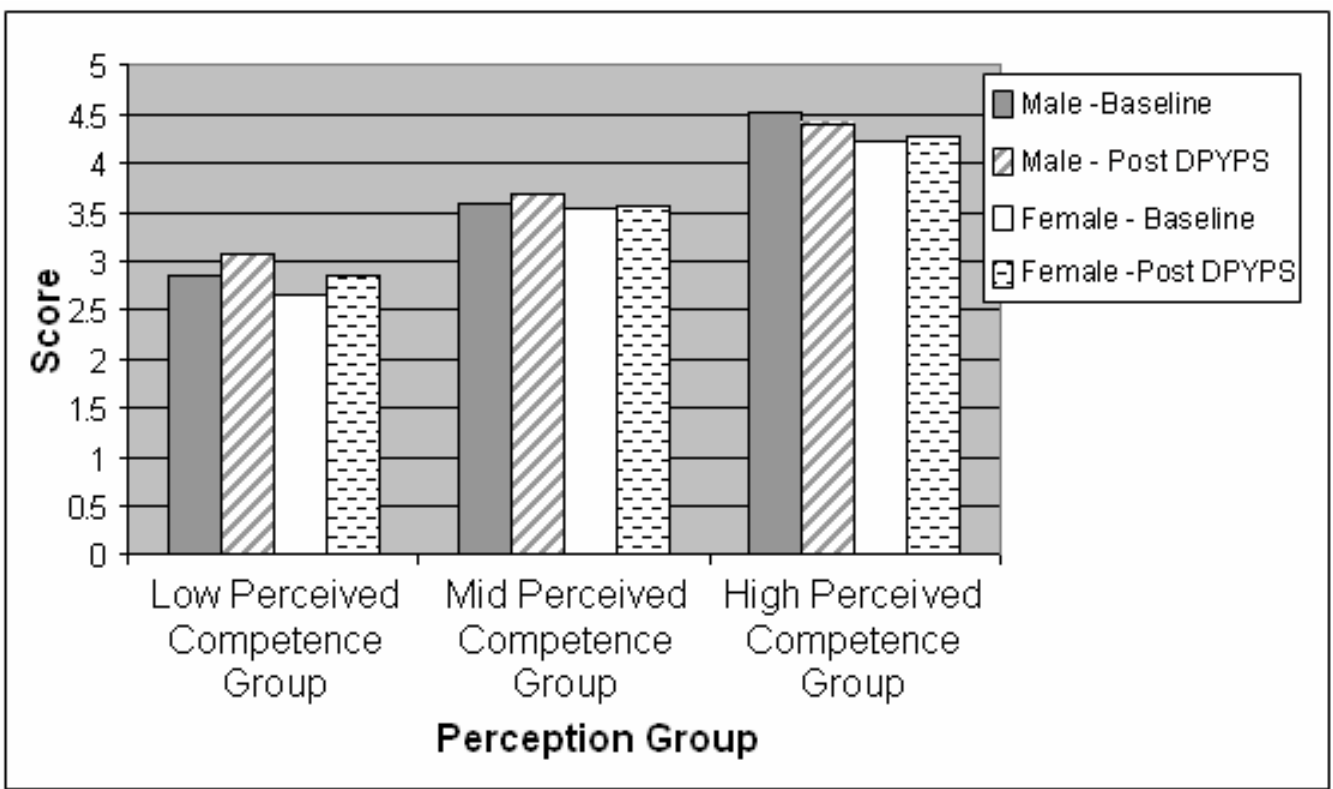

Figure 8.8 Mean changes in baseline perceived physical competence values following involvement in the DPYPS programme for primary seven North Ayrshire

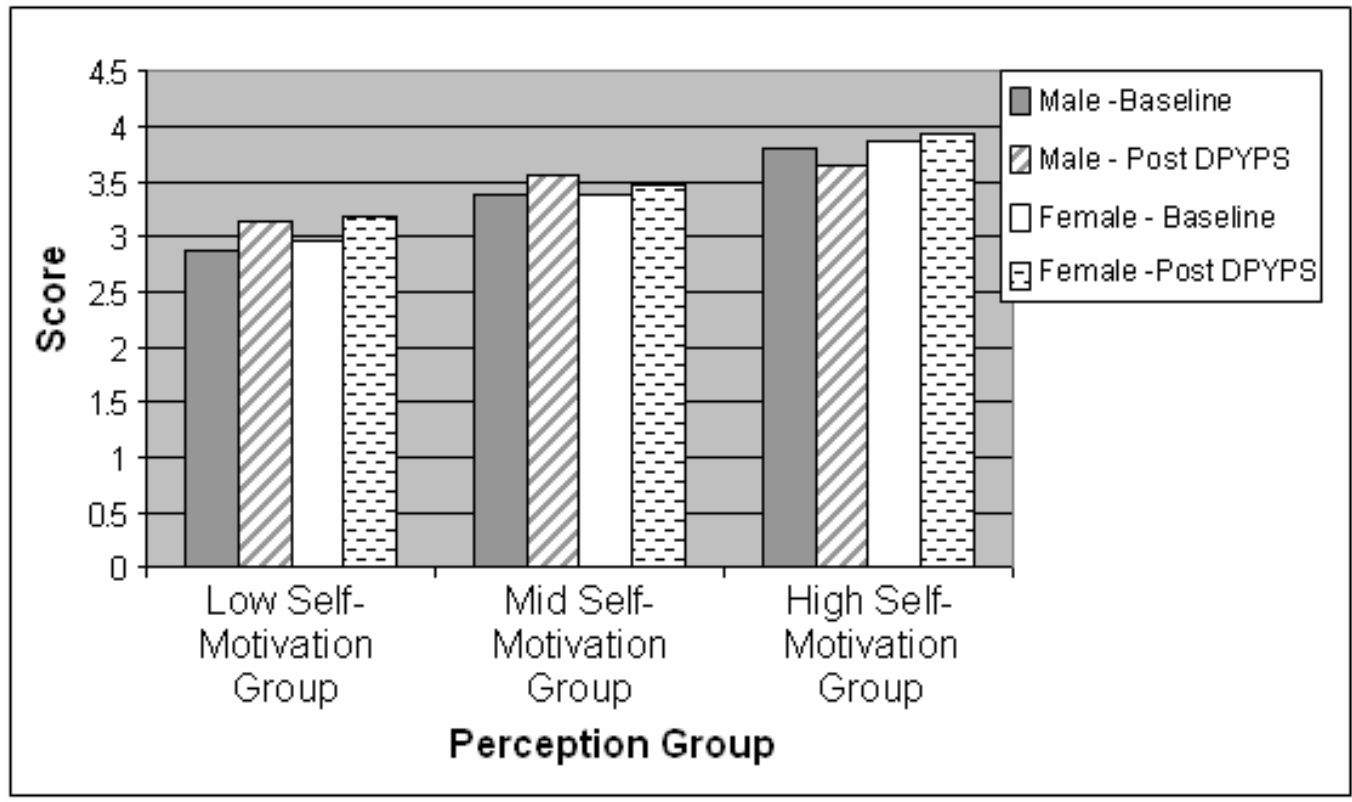

Figure 8.9 Mean changes in baseline self-motivation values following involvement in the DPYPS programme for primary seven North Ayrshire children 


\section{Summary}

Changing behaviour, in conjunction with attitudes, is the ultimate goal for any participation promotion initiative. However, behaviour change is also the most

difficult thing to achieve, and the time scale afforded to the DPYPS pilot programme was recognized as too short to expect such a significant impact. Furthermore, comments by the local government agencies, specialists and seconded teachers also highlighted that to change participation and perceptions was an unrealistic expectation considering the short-term nature of the pilot. Against this limitation, however, the trends apparent within the quantitative data were extremely positive, and, whilst less clear, reflected the same trends as the qualitative data.

\subsection{Conclusion}

Over the years, numerous authors have supported and expanded upon the idea that effective research conducted in the school setting is necessary in order to best serve children and families (Froehle \& Fuqua, 1981; O'Connell, 2002; Pine, 1981).

However, previous research that has been conducted within schools has predominantly adopted a traditional research paradigm, where "the view has been that research in schools should be conducted in much the same manner as it would be carried out in the laboratory, with random assignment of subjects to groups and of groups to treatments, manipulation of an independent variable, inferred cause and effect, and concern for the generalisability of the results" (O'Connell, 2002, p.5). Notably, O'Connell also highlights how such experimental methodologies may not be conducive to the school setting. For example, within this study, all year seven children within the pilot primary schools were involved in the DPYPS programme and consequently no control group was available. This absence of a control group reflected the culture of the primary schools where children were already placed into certain groups (i.e., classes) and all children within this group were involved in the same physical education classes. Consequently, it is virtually impossible randomly to 
assign children to control groups in such settings. Additionally, due to ethical issues, parents and teachers are often unwilling to have children assigned to a control versus a treatment group. Thus, true experimental designs are extremely difficult to implement in an applied setting and research that does adhere to traditional research paradigms may result in findings that have limited applicability to practise.

Recognising the problems of conducting empirical research in schools, qualitative methodologies are becoming increasingly acceptable as a way of conducting research within applied setting (e.g., schools) (Meyers, Valentino, Meyers, Boretti, \& Brent, 1996; O'Connell, 2002; Truscott, Cosgrove, Meyers, \& Eidle-Barkman, 2000). O'Connell highlights how qualitative methodologies have been recognised as a useful means to "more thoroughly understand the complexities of human nature and the organizations (i.e., schools) and issues surrounding school change ...[and]...are inherently aligned with research in the schools because they actively involve key stakeholders and are used in efforts to create school change" (p.6). In addition, qualitative research methods enable measurement of the extent to which the programme has been accepted; a crucial component since a lack of acceptance may compromise the effectiveness of an intervention (Nastasi, Varjas, Bernstein, \& Pluymert, 1998; O'Connell, 2002; Reimers \& Wacker, 1988; Reimers, Wacker, \& Koeppl, 1987). In relation to the acceptance of the DPYPS initiative, qualitative data revealed a high level of support for the programme with both deliverers and participants perceiving that the programme was beneficial, worthwhile and achievable. Given the range and diversity of individuals interviewed, this initial support for the multi-dimensional and dynamic TiD programme is encouraging. Although education is an extremely initiative-rich environment these days, and teachers are often jaded with respect to the next great, new idea (Henderson, 2003), participants remain committed and enthusiastic about its potential for the future.

Although, qualitative methods are likely to provide the richest data for evaluating the initial acceptance and perceived effectiveness of an applied intervention programme, in order to increase the trustworthiness of the evaluation of DPYPS, quantitative 
methods were also employed. Whilst the quantitative data must be interpreted with care due to the barriers of conducting traditional research within the school setting, these data provided initial support for the qualitative picture by revealing many positive trends and statistically significant improvements in both self-perceptions and participation levels of the children having participated in the DPYPS programme.

With a longitudinal (at least 5 years), systematic and coherent level of input, DPYPS may be capable of producing more impact on a target audience. One caveat is necessary however. The initiative is multi-factorial, comprising the provision of direct specialist support, new and integrated programmes of psychomotor and psycho-behaviour work, enhanced in-service training and positive integration with other work. As such, the next steps must be based on pushing forwards all aspects of this package in an integrated fashion. Furthermore, as highlighted by a number of the interviewees, the DPYPS approach could be used as an umbrella under which parallel initiatives may be philosophically and practically structured. 


\section{CHAPTER 9 CONCLUSIONS AND FUTURE DIRECTIONS}

"To build the aptitude theories of tomorrow, we need a language for describing the processes that connect persons and situations - the processes that operate in the interface" (Snow, 1992, p.19).

\subsection{TID in Sport: An Overview}

Within Chapter One, the appeal of establishing scientific TID programmes was emphasised. It was highlighted that sport organisations, coaches and researchers dedicate tremendous effort, time and money on elite athletic performance and that the recruitment of the "right" athletes is a crucial concern when targeting scarce resources (Sport Industry Research Centre, 2003). However, limitations of current procedures for identifying talented athletes have been reported and it has become apparent that potential talent is often overlooked and scarce resources inappropriately allocated (Helsen et al., 2000). As such, research has an important role to play in informing TID practices. Therefore, the purpose of this thesis was to evaluate current processes for identifying talented athletes and to develop a theoretically driven model that coaches, scouts and others involved in sport could use to direct TID efforts.

Within Chapter Two, based on a review of relevant literature (e.g., Durand-Bush \& Salmela, 1996; Ericsson et al., 1993; Simonton, 1999), it was argued that sporting talent has traditionally been conceived as an innate construct where an individual is perceived to inherit the required determinants of talent through their genes. This concept of sporting talent is consistent with most definitions of talent or expertise in the majority of performance domains (e.g., music, education etc.). This 'innate' emphasis, combined with the tendency to look at the concept of talent through the lens of a particular school of thought (e.g., anthropometry, morphology, personality), has resulted in researchers attempting to reduce sporting talent into simplistic units of study. However, literature that contributes to our understanding of factors that influence the ability of an athlete to develop and excel within sport highlights how this traditional conception of talent is simplistic as it fails to account for the dynamic 
and multi-dimensional nature of talent (De Garay, Levine, \& Carter, 1974; Jokl, 1964, Tanner, 1964, Tittel, 1965). Irrespective of physical make-up, unless an athlete actively interacts with the environment and has the resilience to cope with the challenges and setbacks they encounter as they strive to develop, they will fail to excel (Holt \& Dunn, 2004). As such, Chapter Two emphasised the need for sporting talent to be reconceptualised to account more fully for its multi-dimensional and dynamic nature. In keeping with this principle, it was proposed that talent should be conceived as a construct that evolves as a result of active interactions between an individual and his/her environment.

In order for an individual to effectively interact with the environment and make the most of the opportunities they are afforded, early development of psychomotor and psycho-behavioural characteristics in all children was advocated. Providing opportunities for all children to develop competence (perceived and actual) across a range of psychomotor skills should provide children with the confidence to choose to participate in physical activities. Relating this to the pyramid model of sport development, such an approach would enable the base of the pyramid to be increased. Whilst several versions of the pyramid model exist, the ideology is the same: "a broad base of foundation skills participation, with increasingly higher levels of performance participated in by decreasing numbers of people" (Kirk \& Gorely, 2000, p121). Additionally, and crucial to an individual achieving their potential (within and beyond the physical setting), psycho-behavioural characteristics enable an individual to optimise his/her interaction with the environment and make the most of the developmental opportunities they experience (Freeman, 2000; Hemery, 1986). Through the development of psycho-behavioural characteristics, the number of individuals who successfully make the transfer from one stage of development to the next is also likely to be increased, resulting in more people participating at each level of performance. In other words, as a greater number of individuals will have the skills required to make the transition from one stage of development to the next, the combined psychomotor and psycho-behavioural approach should not only increase the base of the pyramid but should also broaden each step of the pyramid. This emphasis on the development of sporting talent does not discount genetic influences, 
but rather, aims to overcome the failure of traditional perspectives to recognise that sporting talent does not just require the tangibles (i.e., the physical attributes such as speed, size and strength), but also that an individual needs to actively engage with the environment. For example, Michael Phelps, who won six gold and two bronze swimming medals at the Athens Olympic, would appear to have an ideal body shape for swimming - he is six-foot-four tall, has size-14 feet, a six-foot-seven-inch wingspan, and an extra-long torso. However, he is also reported to have an incredible work ethic - swimming on average seven miles a day in practice, 365 days a year (Sokolove, 2004).

Unfortunately, Chapter Three highlighted how the majority of TI processes in sport evolve around a traditional and simplistic concept of talent, where TI is based on one-off snap shot assessments of performance characterised on a small number of variables. For example, the Talent Search model initiated by the Australian Institute of Sport (AIS) in 1993 aimed to 'pull out talented' performers based on physical qualities such as ideal speed, height and agility. This approach fails to acknowledge that talent emerges as a result of 'active dynamic' interactions between the individual, the environment and the sociocultural context and consequently leaves aside $99.5 \%$ of all individuals as they don't have the 'required' physical profile. As Gagne (2004) highlights, the Talent Search approach is "an eloquent testimony of the AIS' belief that very high natural abilities are required for athletes to develop their talent to national standards" (p.137). Unfortunately, even thought the AIS has not provided an explicit theoretical basis for the Talent Search approach, a number of National sporting organisations have looked to implement the approach (e.g., Canada, England, Malaysia, Indonesia, New Zealand, North Ireland, Philippines, Scotland, South Africa). In fact, the limitations of sporting organisations downloading the Talent Search approach in the absence of a thorough examination of its tenets was recently highlighted when Scotland implemented a pilot that aimed to evaluate the potential of the Talent Search approach for directing future TI processes within UK sport (Chapter Four). 
Having established the limitations of traditional TID processes, interviews with successful athletes (Chapter Five) again emphasised the need to re-conceptualise talent. In particular, the successful athletes reemphasised the role of the individual in actively fostering positive interactions between the athlete and the environment in order for talent to evolve. Whilst genetic influences were not discounted, the extent that the athletes drew on psycho-behavioural characteristics and a range of psychomotor skills to enable them to actively interact with the physical environment and make the most of the opportunities available was clearly apparent.

A new TiD model was proposed with Chapter Six. This model, influenced strongly by the work of Simonton (1999), Bloom (1985), Cote (1999) and Durand-Bush (2000), adheres to the principles advocated by a multi-dimensional and dynamic concept of talent, where potential evolves as a result of active and dynamic interactions between the individual and the environment. Rather than focusing on innate determinants of talent, the model focuses on equipping individuals with skills that will enable them to actively interact with the environment and optimise their capacity to achieve their potential. Therefore, the model stresses the early development of psychomotor and psycho-behavioural characteristics that facilitate functional interactions between the individual and the environment. A key feature of the proposed model is the recognition of the need for individuals to exploit the opportunities they are afforded by having (a) the motor competence (perceived and actual) to participate in physical settings, and (b) the psycho-behavioural characteristics that enable an individual to optimise these interactions. Providing children with developmental opportunities that adhere to this re-conceptualisation of talent enables development processes to become an opportunity for all individuals to strive actively towards achieving their potential.

Chapter Seven set out to provide methods and resources that would enable practitioners to adhere to the principles underpinning a multi-dimensional and dynamic TiD model. This was important because research studies are often criticised for a lack of applicability of results to practice (Chan, 1991). To facilitate a coherent approach to TiD, consideration was given to how psycho-behavioural and 
psychomotor characteristics can be progressively promoted across primary schools, secondary schools and by NGBs. Whilst the primary focus of this thesis is the promotion of psycho-behavioural characteristics that support the ability of an individual to positively interact with the environment and strive towards achieving his/her potential, the importance of promoting these skills in tandem with psychomotor skills was emphasised. The approach advocated provides a structure for an inclusive approach to physical development where all children are provided with the opportunities to develop psychomotor and psycho-behavioural characteristics. This approach is in contrast to traditional TID approaches, which advocate the early identification of the most 'talented' based on the summation of a few physical or performance variables.

In order to test the proposed TiD strategy, a programme termed 'Developing the Potential of Young People in Sport' (DPYPS) was established in partnership with sportscotland (Chapter Eight). This programme, which placed the emphasis on talent development as opposed to talent identification, employed the system and resources presented in Chapter Seven. The approach promoted the development of psychomotor skills and psycho-behavioural characteristics within all Primary School year seven children and provided an opportunity for all children attending year one and year two of the pilot secondary schools to attend an advanced psychomotor and psycho-behavioural programme. Coaches were also provided with the knowledge to promote the application of psycho-behavioural characteristics within the sport specific context. As such, this programme provided an opportunity for all children to develop the skills needed for them to successfully participate in health related physical activities or performance sport. The implementation of the DPYPS approach in two regions of Scotland resulted in considerable support from both participants and deliverers (e.g., teachers, coaches, sport coordinators), and provided initial confirmatory evidence in support of the model. 


\subsection{Current Context}

Since the commencement of this research, national sporting organisations have increasingly recognised the limitations with traditional TID approaches that only emphasise 'genetic' determinants of talent. For example, sportscotland, SPARC (New Zealand), Sport England, and Northern Ireland all recently rejected the Talent Search approach. However, despite this shift in attitude, many sport specific organisations from these same countries continue to employ one-dimensional and over-simplistic determinants of 'talented'. For instance, a recent report presented in New Zealand highlights that SPARC, the national body of sport, wishes to move away from relying on traditional TID approaches and advocates a greater emphasis on talent development (Mahon, 2004). Unfortunately, other organisations within New Zealand continue to pursue the Talent Search approach. For example, the Peter Snell Institute (PSI) aims to employ a systematic process for seeking out talented school age athletes within New Zealand that demonstrate the capacity necessary to ultimately succeed at international level. Although, PSI acknowledge that talent is a result of physical, physiological, psychological and skill attributes, PSI adopt the Talent Search approach and selection is based on children's profile on "seven standard physical education tests". ${ }^{12}$ Within Britain, UK athletics continues to employ a TI system that selects the 'talented' based on performance on a limited range of anthropometrical and physical determinants. This approach continues despite the national sporting organisation for Wales, Scotland and England rejecting the approach.

This mixed picture of current practices may reflect the practical complexities that result from a multi-dimensional and dynamic concept of talent and the absence of explicit alternative strategies. This programme of research aimed to bridge the gap

\footnotetext{
${ }^{12}$ The Peter Snell Institute (PSI) has adopted the Australian Talent Search approach which aims to identify the 'talented' based on the height, weight, arm span, vertical jump performance, seated basketball throw performance, $40 \mathrm{~m}$ sprint performance and shuttle run performance of children tested.
} 
between theory and practice by providing practitioners with a system and accompanying resources that enable them to adhere to the principles advocated by a multi-dimensional and dynamic model of TID. In contrast to the practical complexities that result from a multi-dimensional and dynamic concept of talent, the (apparent) ease of implementation of Talent Search may make it an appealing option, especially for those organisations that are in the early stages of establishing systematic TI processes. Nevertheless, despite this somewhat disjointed picture, the evidence is that progress is slowly occurring and TID policies are currently being reconsidered in accordance with a multi-dimensional and dynamic concept of talent. For example, sportscotland have recently emphasised how all future work will aim to embrace the multidimensional and dynamic concept of talent that underpins the DPYPS approach (Randak, personal communication May 13, 2005). This is in contrast to previous work that supported age group performers without considering the potential of these youngsters to develop into successful athletes at the senior level.

Whilst the shift in thinking reported by sportscotland is extremely positive, a number of challenges remain if a coherent approach to TID based on a multi-dimensional and dynamic concept of talent can be implemented successfully nationwide. The key challenges are highlighted below:

a. Ensuring that personnel within and across sporting organisations are interpreting the term 'talent' consistently. Traditional approaches to identifying 'talented' athletes that focus on age-group success to determine resource distribution may imply that many prioritise age group rather than senior success. Round table discussions with teachers, coaches and others involved in physical activity and sport promotion could be a valueable process in achieving clarification. Discussions could include defining 'talent' and identifying indicators of successful TID systems.

b. Organisations that promote health (e.g., World Health Organisation, WHO), physical activity (e.g., Health Education Board for Scotland, HEBS) and sport (e.g., sportscotland) have many areas of mutually reinforcing activity. However, a lack of interaction between these organisations has been reported 
(Kirk \& Gorely, 2000). Establishing better links between these organisations will help ensure physical objectives are better addressed and prevent duplication of efforts. Collaboration between these organisations will also help provide more efficient and coherent initiatives across schools, community sport and NGBs.

c. In order to adhere to the philosophies advocated by the current TiD approach, it is important that long-term development be consistently promoted across athlete experiences. For instance, it is recommended that sporting organisations consider the extent that current education and rewards for coaches optimally promote the development of athletes. Specifically, do the reward structures for coaches working with development athletes currently acknowledging those whose athletes successfully progress to the next stage of development or are rewards primarily based on age-group successes?

d. In a similar fashion, sporting organisations also need to consider the appropriateness of funding strategies that typically distribute support based on age-group performances rather than potential to develop.

A common factor across each of these challenges is the need for effective collaboration from a range of organisations (e.g., sportscotland, Department for Education and Skills, NGBs, etc.). This collaboration is in itself a major challenge as, at this time, the evidence is that organisations typically work in isolation even when addressing related issues (Kirk \& Gorely, 2000).

Conclusions and Future Directions 


\subsection{Future Research Directions}

It is anticipated that this programme of research may provide a practical and useful model to assist in promoting coherent TiD processes by teachers, coaches and others involved in both physical activity promotion and performance sport. However, further research is still required in some areas. In future, researchers should consider expanding on the interview study reported in chapter 5 to incorporate a comparison group. Ideally, retrospective interviews would not only be carried out with athletes that have reached world-class levels, but also with athletes who have unsuccessfully strived to reach world-class levels despite considerable investment in a sport. This research could provide an invaluable insight into factors (e.g., psycho-behavioural characteristics, physical attributes, availability of support, opportunities) that distinguish successful from less successful athletes. Corroborating interviews with significant others (e.g., parents) and coaches that had worked with the 'successful' and 'unsuccessful' athletes could also be conducted.

In addition, longitudinal research is needed to fully explore the developmental pathway of athletes and how successful and less successful athletes interact with the environment. Whilst longitudinal research is costly to undertake, it would provide valuable information to sport practitioners on key determinants of talent. In addition, interdisciplinary research is needed that not only identifies key factors that affect the development of athletes, but also how these variables interact overtime to facilitate and inhibit progress. Currently, the majority of sport-science research is onedimensional and does not consider how variables from across disciplines (e.g. physiology, psychology, biomechanics, sociology) interact to impact on behaviour. However, when trying to understand complex problems such as human behaviour and achievement the need for interdisciplinary research is apparent (Burwitz, Moore, \& Wilkinson, 1994).

In recognising psycho-behavioural characteristics as crucial to the successful development of athletes, future research needs to establish a greater understanding of how these characteristics develop. For example, there is still a lot to be learnt about 
how a psycho-behaviour such as self-awareness can be optimally developed and facilitate progress across different sport specific contexts. It is recommended that this research consider the best methods of promoting psycho-behaviours across different developmental stages, settings and age groups. This research could consider strategies, environments (e.g., home, school and sport-specific environment) and behaviours (e.g., teachers, coaches and parents) that affect the development of these characteristics. This research would provide valuable information for practitioners (e.g., coaches and sport-psychologists) when promoting psycho-behavioural development with athletes. Additionally, it is likely that many of the issues discussed in this thesis that relate to sport transfer to other performance domains (e.g., business, education, arts etc.) (Gould, 2002; Lubinski \& Benbow, 2001; Simonton, 1999). Indeed many of the psycho-behavioural characteristics that are considered necessary for talent development in sport (such as mental focus, goal-setting and selfevaluation) are beginning to receive greater attention across a range of performance domains (Jones, 2002; Loehr \& Schwatz, 2001; McPherson, 2005). In future work, researchers should explore the benefits to be gained from actively facilitating such psychological skills throughout an individual's development across different performance settings (e.g., sport, academia, music).

The establishment of a diagnostic tool to evaluate the ability of an athlete to employ psycho-behavioural characteristics to optimise their development and performance would also be of value. Such a tool could help athletes, coaches and sport psychologists identify areas psychological skills training that would facilitate future development and performance. Smith and Christensen (1995) developed the "Athletic Coping Skills Inventory" (ASCI-28) in order to assess seven psychological skills items that athletes use to manage their sports performance. The seven psychobehavioural characteristics assessed were: coping with adversity, coachability, concentration, confidence and achievement motivation, goal setting and mental preparation, peaking under pressure and freedom from worry. However, this inventory only focuses on performance and does not consider how psychobehavioural skills can be employed to optimise development. More recently, Thomas et al. (1999) designed the "Test of Performance Strategies" self-report instrument to 
monitor the use of psycho-behavioural characteristics (goal setting, imagery, activation, self-talk, emotional control, negative thinking and relaxation) in both training and competition. However, the purpose of this questionnaire was to measure the extent that athletes employ psycho-behavioural characteristics in training rather than how effectively athletes use these skills to optimise development. Therefore, these measures could be usefully refined to evaluate not only the extent that athletes employ key psycho-behaviours in training and performance, but also the effectiveness of their use. In this regard, research that explores how psychobehavioural characteristics can be optimally employed across different sport-specific contexts would be of value. For example, a 110m hurdle specialist and a rugby full back will employ imagery in very unique ways to optimise development and performance and any diagnostic tool would need to reflect such differences. Within team sports, consideration could also be given to position-specific variations.

Final thoughts associated with this programme of research are related to the importance of continued research on factors that affect the adoption of a physically active life-style. With concerns over an increasingly sedentary population, and more and more research establishing links between inactivity and health issues (e.g., heart disease, diabetes, high-blood pressure, colon cancer) (U.S. Department of Health and Human Services, 1996), it is also important that researchers continue to investigate factors that impact the uptake and adherence to physical activity. Whilst the focus of this programme of research was on performance sport, some initial support for the approach benefiting children with low levels of perceived physical competence was apparent. Therefore, continued research is needed on the potential of a combined psycho-behavioural and psychomotor programme to provide all children with the competence (perceived and actual) to participate in physical activities. If research supports the value of this approach for both the promotion of physical active lifestyles and the development of performance athletes, developmental opportunities can be provided to all and the split between the educational and the sporting community over the ethics of performance sport can begin to be addressed. In addition, whilst many researchers have hypothesized that the physical activity 
patterns established in childhood and adolescence carry over into adult patterns of physical activity (Bar-Or, 2002), future research needs to explore these claims. 


\section{REFERENCES}

Abbott, A., Collins, D., Martindale, R., \& Sowerby, K. (2002). Talent identification and development: An academic review. Edinburgh: sportscotland.

Ackland, T. R., \& Bloomfield, J. (1996). Stability of human proportions through adolescent growth. Australian Journal of Science and Medicine in Sport, 28, $57-60$.

American Academy of Paediatrics. (2000). Intensive training and sports specialization in young athletes. Paediatrics, 106, 154-157.

Armstrong, N. (1990). New directions in physical education. Champaign IL: Human Kinetics.

Australian Sports Commission. (1993). Sports search - the search is over. Canberra: Australian Sports Commission.

Australian Sports Commission. (n.d.). National talent search program - what is it? Retrieved 3rd March, 2005, from http://www.ais.org.au/talent/what.asp

Bajin, B. (1987). Talent identification program for Canadian female gymnasts. In B. Petiot, J. H. Salmela \& T. B. Hoshizaki (Eds.), World identification systems for gymnastic talent (pp. 34-44). Montreal, Canada: Sport Psyche Editions.

Baker, J. (2003). Early specialization in youth sport: a requirement for adult expertise. High Ability Studies, 14, 85-94.

Baker, J., Côté, J., \& Abernethy, B. (2003). Learning from the experts: practice activities of expert decision-makers in sport. Research Quarterly for Exercise and Sport, 74, 342-347.

Baker, J., Horton, S., Robertson-Wilson, J., \& Wall, M. (2003). Nurturing sport expertise: factors influencing the development of elite athlete. Journal of Sports Science and Medicine, 2, 1-9.

Balsevich, V., \& Progonjuk, L. (2001). New prospects of identification and development of sports talents. Russia: Russian State Academy of Physical Education, University of Surgui.

Balyi, I., \& Hamilton, A. (2000). Key to success: long-term athlete development. Sports Coach, Autumn, 30-32.

Barab, S. A., \& Duffy, T. (2000). From practice fields to communities of practice. In D. Jonassen \& S. M. Land (Eds.), Theoretical foundations of learning environments (pp. 25-56). Mahwah, NJ: Lawrence Erlbaum Associates, Inc.

Barab, S. A., \& Plucker, J. A. (2002). Smart people or smart contexts? Cognition, ability, and talent development in an age of situated approaches to knowing and learning. Educational Psychologist, 37, 165-182.

Barnsley, R. H., \& Thompson, A. H. (1988). Birthdate and success in minor hockey: the key to the NHL. Canadian Journal of Behavioural Science, 20, 167-176.

Barnsley, R. H., Thompson, A. H., \& Barnsley, P. E. (1985). Hockey success and birthdate: the relative age effect. CAHPER/ACSEPL Journal, 51(8), 23-28. 
Barnsley, R. H., Thompson, A. H., \& Legault, P. (1992). Family planning football style. International Review for the Sociology of Sport, 27, 77-88.

Bar-Or, O. (2002). Health benefits of physical activity during childhood and adolescence. President's Council on Physical Fitness and Sports Research Digest, 2(4), available online at http://www.fitness.gov/childhood.html.

Barynina, I. I., \& Vaitsekhovskii, S. M. (1992). The aftermath of early sports specialization for highly qualified swimmers. Fitness and Sports Review International, 27(4), 132-133.

Baum, S. M., Owen, S. V., \& Oreck, B. A. (1996). Talent beyond words: identification of potential talent in dance and music in elementary students. Gifted Child Quarterly, 40(2), 93-101.

Baxter-Jones, A. D. G., \& Helms, P. J. (1996). Effects of training at a young age: a review of The Training of Young Athletes (TOYA) Study. Paediatric Exercise Science, 8, 310-327.

Bernstein, N. A. (1967). The control and regulation of movements. London: Pergamon Press.

Beunen, G., Malina, R., Van't Hof, M., Simons, J., Ostyn, M., Renson, R., et al. (1981). Adolescent growth and motor performance. Child Development Abstracts and Bibliography, 62, 320.

Biddle, S., Akande, D., Armstrong, N., Ashcroft, M., Brooke, R., \& Goudas, M. (1996). The Self-Motivation Inventory modified for children: Evidence on psychometric properties and its use in physical exercise. International Journal of Sport Psychology, 27, 237-250.

Bjorklund, D. F. (2000). Children's thinking: developmental function and individual differences (3rd ed.). Belmont, CA: Wadsworth/Thomson Learning.

Blanksby, B. A., Bloomfield, J., Ponchard, M., \& Ackland, T. R. (1986). The relationship between anatomical characteristics and swimming performance in state age-group championship competitors. Journal of Swimming Research, 2(2), 30-36.

Blanksby, B. B. (1980). Measures of talent identification in competitive swimming. Sports Coach, 15(4), 13-19.

Bloom, B. S. (1985). Developing talent in young people. New York: Ballantine.

Bloomfield, J. (1995). Talent identification and profiling. In J. Bloomfield, P. A. Fricker \& K. D. Fitch (Eds.), Science and medicine in sport (2nd ed., pp. 206221). Cambridge: Blackwell Science.

Bloomfield, J., \& Blanksby, B. A. (1971). Strength flexibility and anthropometric measurements: a comparison of highly successful male university swimmers and normal university students. Australian Journal of Sports Medicine, 3, 815 .

Bloomfield, J., Blanksby, B. A., \& Ackland, T. R. (1990). Morphological and physiological growth of competitive swimmers and non-competitors through adolescence. Australian Journal of Science and Medicine in Sport, 22, 4-12. 
Bompa, T. O. (1985). Talent identification. Science Periodical on Research and Technology in Sport, February, 1-11.

Bompa, T. O. (1990). Theory and methodology of training. Dubuque, Iowa: Kendall/Hunt.

Bompa, T. O. (1994). Theory and methodology of training: the key to athletic training. Champaign, IL: Human Kinetics.

Bompa, T. O. (1999). Periodization. Theory and methodology of training (4th ed.). Champaign, IL: Human Kinetics.

Borms, J. (1994). From theory to practice: talent identification and selection - the future for British Governing Bodies. Paper presented at the BOA CAG Seminar, London.

Boucher, J., \& Halliwell, W. (1991). The Novem system: a practical solution to age grouping. CAHPER/ACSEPL, 57(1), 16-20.

Boucher, J., \& Mutimer, B. T. P. (1994). The relative age phenomenon in sport: a replication and extension with ice-hockey players. Research Quarterly for Exercise and Sport, 65, 377-381.

Bouffard, M., Watkinson, E. J., Thompson, L. P., Caugrove Dunn, J. L., \& Romanow, S. K. E. (1996). A test of the activity deficit hypothesis with children with movement difficulties. Adapted Physical Activity Quarterly, 13, 61-73.

Boyce, B. A. (1992). The effects of goal proximity on skill acquisition and retention of a shooting task in a field-based setting. Journal of Sport and Exercise Psychology, 14, 298-308.

Boyd, M. P., Weinmann, C., \& Yin, Z. (2002). The relationship of physical selfperceptions and goal orientations to intrinsic motivation for exercise. Journal of Sport Behavior, 25, 1-18.

Brewer, J., Balsom, P., \& Davis, J. (1995). Seasonal birth distribution amongst European soccer players. Sports Exercise and Injury, 1, 154-157.

Bryan, W. L., \& Harter, N. (1899). Studies on the telegraphic language: The acquisition of a hierarchy of habits. Psychological Review, 6, 345-375.

Burwitz, L., Moore, P. M., \& Wilkinson, D. M. (1994). Future directions for performance-related sports science research: an interdisciplinary approach. Journal of Sport Sciences, 12, 93-109.

Carter, J. E., \& Ackland, T. R. (1998). Sexual dimorphism in the physiques of world championship divers. Journal of Sport Sciences, 16, 317-329.

Chauveau, M. (1999, 27/28 September). The key factors to the preparation of elite athletes. Paper presented at the International Forum on Elite Sport, Sydney, Australia.

Citizens for Better Schools. (1995). Risk factors: characteristics associated with dropping out. CBS action, stay-in-school tool box. Retrieved December, 2000, from susie.stemnet.nf.ca/Users/coop9011/research/dropouts.htm 
Clark, G., \& Zimmerman, E. (1984). Inquiry about art ability and talent: a remembrance of things past. Theory into Practice, 23, 321-329.

Clough, J., McCormack, C., \& Trail, R. (1993). A mapping of participation rates in junior sports. ACHPER National Journal, 40, 4-7.

Correnti, V., \& Zauli, B. (1964). Olympionici 1960. Roma, Italy: Marves.

Côté, J. (1999). The influence of the family in the development of talent in sports. Sport Psychologist, 13, 395-417.

Côté, J., Baker, J., \& Abernethy, B. (2003). From play to practice: A developmental framework for the acquisition of expertise in team sport. In J. Starkes \& K. A. Ericsson (Eds.), Expert performance in sports: Advances in research on sport expertise (pp. 89-114). Champaign, IL: Human Kinetics.

Csikszentmihalyi, M., Rathunde, K. R., \& Whalen, S. (1997). Talented teenagers: the roots of success and failure (Vol. 1). Cambridge: Cambridge University Press.

Currie, C., Hurrelmann, K., Settertobulte, W., Smith, B., \& Todd, J. (1999). Health and health behaviour among young people: international report (No. 1). Copenhagen: World Health Organisation.

Currie, C., Roberts, C., Settertobulte, W., Morgan, A., Smith, R., Samdal, O., et al. (2004). Young people's health in context. Health behaviour in school-aged children (HBSC) study: international report from the 2001/2002 survey (No. 4). Copenhagen: World Health Organisation.

Czeschlik, T., \& Rost, D. H. (1988). Hochbegabte und irehe peers (High talented and their peers). Festschrift für Pedagogische Psychologie, 2, 1-23.

Dalton, S. E. (1992). Overuse injuries in adolescent athletes. Sports Medicine, 13, $58-70$.

Davids, K. (2000). Skill acquisition and the theory of deliberate practice: It ain't what you do it's the way that you do it! Commentary on Starkes, J. "The road to expertise: is practice the only determinant?" International Journal of Sport Psychology, 31, 461-465.

de Garay, A., Levine, L., \& Carter, J. E. (1974). Genetic and anthropological studies of Olympic athletes. New York: Academic Press.

Department for Education and Employment, \& Qualifications and Curriculum Authority. (1999). The national curriculum for England: physical education. London: Department for Education and Employment and Qualifications and Curriculum Authority.

Department of Education and Science. (1991). National curriculum. Physical education working group. London: Department of Education and Science.

Department of Health. (2001). The NHS plan: a plan for investment, a plan for reform. London: Stationery Office.

Department of National Heritage. (1995). Sport - raising the game. London: Department of National Heritage. 
Dettweiler, A., Daehne, H. O., \& Loots, J. M. (1991). Physical and physiological aspects of participants in the 1987/88 Ultraman competition. SA Journal for Research in Sport Physical Education and Recreation, 14, 23-31.

Digel, H. (2002). The context of talent identification and promotion: a comparison of Nations. New Studies in Athletics, 17, 3/4, 13-26.

Durand-Bush, N. (2000). The development and maintenance of expert athletic performance: perceptions of Olympic and World champions, their parents and coaches. Unpublished Doctoral dissertation, Doctoral dissertation, University of Ottawa., Ottawa.

Durand-Bush, N., \& Salmela, J. (2002). The development and maintenance of expert athletic performance: perceptions of world and Olympic champions. Journal of Applied Sport Psychology, 14, 154-171.

Durand-Bush, N., \& Salmela, J. H. (1996). Nurture over nature: a new twist to the development of expertise. Avante, 2(2), 87-109.

Durand-Bush, N., \& Salmela, J. H. (2001). Development of talent in sport. In R. N. Singer, H. A. Hausenblas, \& C. M. Janelle (Eds.), Handbook of sport psychology (2nd ed., pp. 269-289). New York: John Wiley.

Edwards, S. (1994). Born too late to win? Nature, 370, 186.

English Institute of Sport. (2003). Black cat in the darkness. Retrieved 10th November, 2004, from http://www.eis2win.co.uk/gen/news_blackcat171103.aspx

English Sports Council. (1998). Development of sporting talent 1997: report of findings. London: ESC.

Ericsson, K. A., \& Charness, N. (1994). Expert performance: its structure and acquisition. American Psychologist, 49, 725-747.

Ericsson, K. A., Krampe, R. T., \& Tesch-Romer, C. (1993). The role of deliberate practice in the acquisition of expert performance. Psychological Review, 100, 363-406.

Ericsson, K. A., \& Lehmann, A. C. (1996). Expert and exceptional performance: evidence of maximal adaptation to task constraints. Annual Review of Psychology, 47, 273-305.

Ferraro, T., \& Rush, S. (2000). Why athletes resist sport psychology. Athletic Insight, 2(3), Online journal at: http://www.athleticinsight.com/Vol2Iss3/Resistance.htm.

Ferreira, M. B. R. (1986). Youth sport in Brazil. In M. R. Weiss \& D. Gould (Eds.), Sport for children and youths (pp. 11-15). Champaign, IL: Human Kinetics.

Fisher, R. (1996). Gifted children and young people in physical education and sport. In N. Armstrong (Ed.), New direction in Physical Education: change and innovation (pp. 131-143). London: Cassell Education.

Fisher, R. J., \& Borms, J. (1990). The background to the selection of gifted young people in sport. Sport International, 84, 25-30. 
Flavell, J. H. I. (1987). Speculations about the nature and development of metacognition. In F. E. Weinert \& R. H. Kluwe (Eds.), Metacognition, motivation and understanding (pp. 21-29). Hillsdale, NJ: Erlbaum.

Fleishman, E. A. (1972). Structure and measurement of psychomotor abilities. In R. N. Singer (Ed.), Psychomotor domain: movement behaviour (pp. 113-117). Philadelphia: Lea \& Febiger.

Flynn, J. R. (1991). Asian Americans: achievement beyond IQ. Hillsdale, NJ: Erlbaum.

Fowler, W. (1981). Case studies of cognitive precocity: The role of exogenous and endogenous stimulation in early mental development. Journal of Applied Developmental Psychology, 2, 319-367.

Freeman, J. (2000). Teaching for talent: lessons from the research. In C.F.M. van Lieshout \& P. G. Heymans (Eds.), Developing talent across the life span (pp. 231-248). Hove, UK: Psychology Press.

Froehle, T. C., \& Fuqua, D. R. (1981). Systematic inquiry in the school context. Personnel and Guidance Journal, 59, 509-514.

Gagne, F. (2004). Transforming gifts into talents: the DMGT as a developmental theory. High Ability Studies, 15, 119-147.

Gallahue, D. L. (1982). Fundamental movement experiences for children. New York: Wiley.

Gallahue, D. L. (1996). Developmental physical education for today's children (3rd ed.). Dubuque, IA: Brown \& Benchmark.

Gallahue, D. L., \& Ozmun, J. C. (1995). Understanding motor development: Infants, children, adolescents, adults. Madison, WI: Brown \& Benchmark.

Galton, F. (1874). On men of science: their nature and nurture. Nature, 9, 344-345.

Galton, F. (1892). Hereditary genius: an enquiry into its laws and consequences (2nd ed.). London: Macmillan.

Gardner, H. (1993). Creating minds: an anatomy of creativity seen through the lives of Freud, Einstein, Picasso, Stravinsky, Eliot, Graham, and Gandhi. New York: Basic Books.

Gardner, H. (1997). Extraordinary minds: portraits of exceptional individuals and an examination of our extraordinariness. New York: Basic Books.

Geron, E. (1978). Psychological assessment of sport-giftedness. In U. Simri (Ed.), International Symposium on Psychological Assessment in Sport (pp. 216231). Netanya, Israel: Wingate Institute.

Gimbel, B. (1976). Possibilities and problems in sports talent detection research. Leistungssport, 6(3), 159-167.

Glamser, F. D., \& Marciani, L. M. (1992). The birthdate effect and college athletic participation: some comparisons. Journal of Sport Behavior, 15, 227-238.

Goldsmith, W. (2000). A multidisciplinary approach to performance: the integration of the sports sciences in smart coaching. Sports Coach, 23, 14-15. 
Gottfried, A. W., Gottfried, A. E., Bathurst, K., \& Guerin, D. W. (1994). Gifted IQ: early developmental aspects. New York: Plenum Press.

Gould, D., Dieffenbach, K., \& Moffett, A. (2002). Psychological characteristics and their development in Olympic champions. Journal of Applied Sport Psychology, 14, 172-204.

Gould, D., Eklund, R. C., \& Jackson, S. A. (1992a). 1988 U.S. Olympic wrestling excellence: I. Mental preparation, precompetitive cognition, and affect. Sport Psychologist, 6, 358-382.

Gould, D., Eklund, R. C., \& Jackson, S. A. (1992b). 1988 U.S. Olympic wrestling excellence: II. Thoughts and affect occurring during competition. Sport Psychologist, 6, 383-402.

Gould, D., Finch, L. M., \& Jackson, S. A. (1993a). Coping strategies used by national champion figure skaters. Research Quarterly for Exercise and Sport, 64, 453-468.

Gould, D., Jackson, S., \& Finch, L. (1993b). Life at the top: the experiences of U.S. national figure skaters. Sport Psychologist, 7, 354-374.

Gould, D., Jackson, S., \& Finch, L. (1993c). Sources of stress in national champion figure skaters. Journal of Sport and Exercise psychology, 15, 134-159.

Grabiner, M. D., \& McKelvain, R. (1987). Implementation of a profiling/prediction test battery in the screening of elite men gymnasts. In B. Petiot, J. H. Salmela \& T. B. Hoshizaki (Eds.), World identification systems for gymnastic talent (pp. 121-125). Montreal, Canada: Sport Psyche Editions.

Greenberg, H. M. (1999). The psychology of the winner. Retrieved 7th February, 2005, from http://www.caliperonline.com/pdfs/cs_orlando.pdf

Gustin, W. C. (1985). The development of exceptional research mathematicians. In B. S. Bloom (Ed.), Developing talent in young people (pp. 139-192). New York: Ballantine.

Hahn, A. (1990). Identification and selection of talent in Australian rowing. Excel, 6(3), 5-11.

Hany, E. A. (1996). How leisure activities correspond to the development of creative achievement: insights from a study of highly intelligent individuals. High Ability Studies, 7, 65-82.

Harre, D. (1982). Principles of sports training. Berlin: Sportverlag.

Haubenstricker, J., \& Seefeldt, V. (1986). Acquisition of motor skills during childhood. In V. Seefeldt (Ed.), Physical activity and well-being (pp. 41-102). Reston, Virginia: AAHPERD.

Havlicek, I., Komadel, L., Komarik, E., \& Simkova, N. (1982). Principles of the selection of youth talented in sport. Paper presented at the International Conference on the selection and preparation of sport talent, Bratislava, Czechoslovakia.

Haywood, K. M. (1993). Life span motor development (2nd ed.). Champaign, IL: Human Kinetics. 
Health Education Authority. (1998). Young and active? Young people and health enhancing physical activity- evidence and implications. London: Health Education Authority.

Hebbelinck, M., Ross, W. D., Carter, J. E. L., \& Borms, J. (1980). Anthropometric characteristics of female Olympic rowers. Canadian Journal of Applied Sport Sciences, 5, 255-262.

Heller, K. A., \& Viek, P. (2000). Support for university students: individual and social factors. In C.F.M. van Lieshout \& P. G. Heymans (Eds.), Developing talent across the life span (pp. 299-321). Hove, UK: Psychology Press.

Helsen, W. F., Hodges, N. J., Van Winckel, J., \& Starkes, J. L. (2000). The roles of talent, physical precocity and practice in the development of soccer expertise. Journal of Sports Sciences, 18, 727-736.

Helsen, W. F., Starkes, J. L., \& Hodges, N. J. (1998). Team sports and the theory of deliberate practice. Journal of Sport and Exercise Psychology, 20, 12-34.

Hemery, D. (1986). The pursuit of sporting excellence. London: Collins.

Henderson, D. (2003, 15th August). Ministers face the music. Times Education Supplement, p. 12.

Hill, M. R. (2002). The physical and visual characteristics of junior North American biathletes (Doctoral dissertation, University of Utah). Retrieved 20th January, 2005, from UMI ProQuest Dissertation Abstracts International

Ho, R. (1987). Talent identification in China. In B. Petiot, J. H. Salmela \& T. B. Hoshizaki (Eds.), World identification systems for gymnastic talent (pp. 1420). Montreal, Canada: Sport Psyche Editions.

Hoare, D. (1996). The Australian national talent search programme. Coaching Focus, 31, 3-4.

Hoare, D. (1998). Talent search. Sports Coach, 21(3), 32-33.

Hoare, D., \& Warr, C. R. (2000). Talent identification and women's soccer: an Australian experience. Journal of Sport Sciences, 18, 751-758.

Hodges, N. J., \& Starkes, J. L. (1996). Wrestling with the nature of expertise: a sportspecific test of Ericsson, Krampe and Tesch-Romer's (1993) theory of deliberate practice. International Journal of Sports Psychology, 27, 400-424.

Holt, N., L. (2002). A comparison of the soccer talent development systems in England and Canada. European Physical Education Review, 8, 270-285.

Holt, N. L., \& Dunn, J. G. H. (2004). Toward a grounded theory of the psychosocial competencies and environmental conditions associated with soccer success. Journal of Applied Sport Psychology, 16, 199-219.

Holyoak, K. J. (1994). Symbolic connectionism: toward third-generation theories of expertise. In K. A. Ericsson \& J. Smith (Eds.), Toward a general theory of expertise: prospects and limits (pp. 301-336). New York: Cambridge University Press.

Horne, D. (1965). The lucky country. Melbourne: Penguin. 
Horton, P. A. (2000). The 'Green' and the 'Gold': the Irish-Australians and their role in the emergence of the Australian sports culture. International Journal of the History of Sport, 17, 65-92.

Houlihan, B. (2000). Sporting excellence, schools and sports development: the politics of crowded policy spaces. European Physical Education Review, 6, 171-193.

Howe, M. J. A. (1999). Genius explained. New York: Cambridge University Press.

Howe, M. J. A., Davidson, J. W., \& Sloboda, J. A. (1996). Innate gifts and talents: reality or myth? Behavioural Brain Science, 21, 399-419.

Ievleva, L., \& Orlick, T. (1991). Mental links to enhanced healing: an exploratory study. Sport Psychologist, 5, 25-40.

Jackson, S. A., Mayocchi, L., \& Dover, J. (1998). Life after winning gold: II. Coping with change as an Olympic gold medallist. Sport Psychologist, 12, 137-155.

Jancarik, A., \& Salmela, J. H. (1987). Longitudinal changes in physical, organic and perceptual factors in Canadian male gymnasts. In B. Petiot, J. H. Salmela \& T. B. Hoshizaki (Eds.), World identification systems for gymnastic talent (pp. 151-159). Montreal, Canada: Sport Psyche Editions Montreal.

Jefferies, S. C. (1986). Youth sport in the Soviet Union. Eugene: University of Oregon.

Jess, M. (1999a). Basic movements and movement concepts: a developmental framework for a lifetime of physical education, sport and exercise. Unpublished paper.

Jess, M. (1999b). The young peoples physical activity questionnaire. Unpublished paper.

Jess, M., Collins, D., \& Burwitz, L. (1999). The role of children's movement competence as an antecedent of lifelong physical activity. Unpublished paper.

Jobling, I. F. (1987). Australian sporting heroes. In W. Vamplew (Ed.), Sport: nationalism and internationalism: A.S.S.H studies in Sports History (pp. 91118). Australia: A.S.S.H.

Jokl, E. (1964). Medical sociology and cultural anthropology of sport and physical education. Springfield, IL: Thomas.

Jones, G. (2002). Performance excellence: a personal perspective on the link between sport and business. Journal of Applied Sport Psychology, 14, 268-281.

Kalinowski, A. G. (1985). The development of Olympic swimmers. In B. S. Bloom (Ed.), Developing talent in young people (pp. 139-192). New York: Ballantine.

Keller, F. S. (1958). The phantom plateau. Journal of the Experimental Analysis of Behavior, 1, 1-13.

Kelso, J. A. S. (1995). Dynamic patterns: the self-organization of brain and behaviour. London: MIT Press. 
Kirk, D., \& Gorely, T. (2000). Challenging thinking about the relationship between school physical education and sport performance. European Physical Education Review, 6, 119-134.

Kirk, D., \& Macdonald, D. (1998). Situated learning in physical education. Journal of Teaching in Physical Education, 17, 376-387.

Kohlrausch, W. (1929). Zusammenhange von korperform und leistung. ergbnisse der anthropometrischen messungen an den athlete der Amsterdamer Olympiade. (Relationship of body composition to athletic performance. Results of an anthropometrical analysis of athletes at the Amsterdam Olympiad). Internationaler Zeitschrift fuer angewandte Physiologie, 2, 187-204.

Kozel, J. (1996). Talent identification and development in Germany. Coaching Focus, 31(Spring), 5-6.

Krane, V., Andersen, M. B., \& Strean, W. B. (1997). Issues of qualitative research methods and presentation. Journal of Sport and Exercise Psychology, 19, 213.

Kreiner-Phillips, K., \& Orlick, T. (1993). Winning after winning: The psychology of ongoing excellence. Sport Psychologist, 7, 31-48.

Kremer, P. J., \& Marchant, D. B. (2002). Reflections and considerations of providing sport psychology services with professional football players. In W. Spinks (Ed.), Science and Football IV (pp. 294-299). London: Routledge.

Kunst, G., \& Florescu, C. (1971). The main factors for performance in wrestling. Bucharest: National Sports Council.

Lidor, R., \& Lavyan, Z. (2002). A retrospective picture of early sport experiences among elite and near-elite Israeli athletes: developmental and psychological perspectives. International Journal of Sport Psychology, 33, 269-289.

Lippman, L. G., \& Rushall, B. S. (1993). The role of imagery in skill development. Paper presented at the 2nd Maccabiah-Wingate International Congress on Sport and Coaching Sciences, Netanya, Israel.

Loehr, J., \& Gullikson, T. (2001). Maintaining technique under pressure. In P. Roetert (Ed.), World-class tennis technique (pp. 131-143). Champaign, IL: Human Kinetics.

Loehr, J., \& Schwartz, T. (2001). The making of a corporate athlete. Harvard Business Review, 79, 120-128.

Logan, G. D. (1985). Skill and automaticity: relations, implications, and future directions. Canadian Journal of Psychology, 39, 367-386.

Lumpkin, A., Stoll, S. K., \& Beller, J. M. (1999). Sport ethics: applications for fair play (2nd ed.). St. Louis: McGraw-Hill.

Magdalinski, T. (2000). The reinvention of Australia for the Sydney 2000 Olympic Games. In J. A. Mangan \& J.Nauright (Eds.), Sport in Australian society: past and present (pp. 305-322). London: Frank Cass. 
Mahon, T. (2004). Linking promise to the podium. Talent identification and development (TID) in New Zealand: A report to SPARC's board from the TID taskforce. Wellington: New Zealand Academy of Sport.

Mahoney, M. J. (1989). Psychological predictors of elite and non-elite performance in Olympic weightlifting. International Journal of Sport Psychology, 20, 112.

Malina, R. M. (1997). Talent identification and selection in sport. Spotlight on youth sports, 20, 1-3.

Malina, R. M., \& Bouchard, C. (1991). Growth, maturation and physical activity. Champaign, IL: Human Kinetics.

Malina, R. M., Pena-Reyes, M. E., Eisenmann, J. C., Horta, L., Rodrigues, J., \& Miller, R. (2000). Height, mass and skeletal maturity of elite Portuguese soccer players aged 11-16 years. Journal of Sports Sciences, 18, 685-693.

Markland, D. (1999). Self-determination moderates the effects of perceived competence on intrinsic motivation in an exercise setting. Journal of Sport and Exercise Psychology, 21, 350-360.

Markland, D., \& Hardy, L. (1997). On the factorial and construct validity of the intrinsic motivation inventory: conceptual and operational concerns. Research Quarterly for Exercise and Sport, 68, 20-32.

Marsh, H. W. (1990). Self-Description Questionnaire - II - manual. Sydney: University of Sydney.

Marsh, H. W. (1996). Physical self-description questionnaire: Stability and discriminant validity. Research Quarterly for Exercise and Sport, 67, 249264.

Matsudo, V. K. R. (1996). Prediction of future athletic excellence. In O. Bar-Or (Ed.), The child and adolescent athlete (pp. 92-109). Oxford: Blackwell Scientific Publications.

May, R. M. (1974). Biological populations with non overlapping generations: Stable points, stable cycles and chaos. Science, 186, 645-647.

McCaffrey, N., \& Orlick, T. (1989). Mental factors related to excellence among top professional golfers. International Journal of Sport Psychology, 20, 256-278.

McCall, R. B., Evahn, C., \& Kratzer, L. (1992). High school underachievers. Newbury Park, CA: Sage.

McCleish, S., \& Collins, D. (2002). Talent identification and development in Scottish soccer: where did we go wrong? Unpublished undergraduate dissertation, University of Edinburgh, Edinburgh.

McDonald, D. (1984). Skating: the quickest way to become a better hockey player is to improve your skating. That means working on the basics - stopping, starting turning - everytime you get on the ice. Hockey Today, 83, 24-25.

McDonald, J., \& Orlick, T. (1994). Excellence in surgery: psychological considerations. Contemporary Thought on Performance Enhancement, 3, 1332 . 
McDonald, J., Orlick, T., \& Letts, M. (1995). Mental readiness in surgeons and its links to performance excellence in surgery. Journal of Paediatric Orthopaedics, 15, 691-697.

McNab, T. (1981). Cash in the shoe-1: it' s got to come. Former national coach Tom $\mathrm{McNab}$ puts the case for professional athletes. Sport and Leisure, 22, 36-37.

McPherson, G. E. (2005). From child to musician: skill development during the beginning stages of learning an instrument. Psychology of Music, 33, 5-35.

Meij, J. T., Riksen-Walraven, J. M. A., \& van Lieshout, C. F. M. (1995). Patterns of change and consistency in parental support as related to children's competence motivation. Paper presented at the Early Mother-Child Interaction and Attachment: Old and New Approaches, Amsterdam.

Meyer-Lindenberg, A., Ziemann, U., Hajak, G., Cohen, L., \& Berman, K. F. (2002). Transitions between dynamical states of differing stability in the human brain. Procedures of the National Academy of Science, 99, 10948-10953.

Meyers, B., Valentino, C. T., Meyers, J., Boretti, M., \& Brent, D. (1996). Implementing prereferral intervention teams as an approach to school based consultation in an urban school setting. Journal of Educational and Psychological Consultation, 7, 119-149.

Milgram, R. M., \& Hong, E. (1997). Leisure activities and career development in intellectually gifted Israeli adolescents. In B. Bain, H. Janzen, J. Paterson, L. Stewin \& A. Yu. (Eds.), Psychology and education in the 21st century (pp. 223-227). Edmonton: ICP Press.

Montpetit, R., \& Cazorla, G. (1982). La detection du talent en notation (the detection of talent in swimming). La Revue de l'Entraineur, 5, 26-37.

Moore, P., Collins, D. J., Burwitz, L., \& Jess, M. (1998). The Development of Talent Study (DOTS). London: English Sports Council.

Moran, A. P. (1996). The psychology of concentration in sport performers: a cognitive analysis. Hove, UK: Psychology Press.

Morgan, W. P. (1980). Sport personology: the credulous-skeptical argument in perspective. In W. F. Straub (Ed.), Sport psychology : an analysis of athlete behavior (2nd ed., pp. 330-339). Ithaca, New York: Mouvement Publications.

Morris, T. (2000). Psychological characteristics and talent identification in soccer. Journal of Sports Sciences, 18, 715-726.

Morrone, A. S., \& Pintrich, P. R. (1997). Achievement motivation. In G. Bear, K. Minke \& A. Thomas (Eds.), Children's needs II: psychological perspectives (pp. 387-395). Washington, DC: National Association of School Psychologists.

Muller, E., Benko, U., Raschner, C., \& Schwameder, H. (2000). Specific fitness training and testing in competitive sports. Medicine and Science in Sports and Exercise, 32, 216-220. 
Nastasi, B. K., Varjas, K., Bernstein, R., \& Pluymert, K. (1998). Mental health programming in schools and the role of the school psychologist. School Psychology Review, 27, 217-232.

Nieuwenhuis, C. F., Spamer, E. J., \& van Rossum, J. H. (2002). Prediction function for identifying talent in 14- to 15-year-old female field hockey players. High Ability Studies, 13, 21-34.

O'Connell, L. M. (2002). Qualitative collaborative action research as an approach to program evaluation. Application in a rural elementary school: Bridging the chasms (PsyD dissertation, Alfred University). Retrieved 5th May, 2005, from UMI ProQuest Dissertation Abstracts International

Okley, A. D., Booth, M. L., \& Patterson, J. W. (2001). Relationship of physical activity to fundamental movement skills among adolescents. Medicine and Science in Sports and Exercise, 33, 1899-1904.

Organisation for Economic Co-operation and Development. (1987). Administration as service: The public as client. Paris: OECD.

Orlick, T. (1989). Reflections on sportpsych consulting with individual and team sport athletes at Summer and Winter Olympic Games. Sport Psychologist, 3, 358-365.

Orlick, T. (1996). The wheel of excellence. Journal of Performance Education, 1, 318.

Orlick, T., \& Partington, J. (1988). Mental links to excellence. The Sport Psychologist, 2, 105-130.

Orlick, T. D., Hansen, H., Reed, A., \& O'Hara, T. (1979). Psychological attributes and on-ice indicators of high calibre hockey players. In J. Terauds \& H. J. Gros (Eds.), Science in skiing, skating and hockey: Proceedings of the International Congress of Sports Sciences (pp. 151-157). Del Mar, CA: Academic Publishers.

Pain, M. A., \& Harwood, C. G. (2004). Knowledge and perceptions of sport psychology within English soccer. Journal of Sports Sciences, 22, 813-826.

Partington, J., \& Orlick, T. (1987). The Sport Psychology Consultant Evaluation Form. Sport Psychologist, 1, 309-317.

Petiot, B., Salmela, J. H., \& Hoshizaki, T. B. (Eds.). (1987). World identification systems for gymnastic talent. Montreal, Canada: Sport Psyche Editions Montreal.

Pienaar, A. E., \& Spamer, E. J. (1994). A scientific approach towards the developing and identifying of rugby talent among ten and eleven year old boys in the new South Africa. Paper presented at the 1st Africa Regional Conference on Physical, Health Education, Recreation and Dance, Gabrone, Botswana.

Pienaar, A. E., \& Spamer, E. J. (1996). A scientific approach towards the identifying of rugby talent among ten and eleven year old boys. Kinesiology, 28, 48-53. 
Pienaar, A. E., \& Spamer, E. J. (1998). A longitudinal study of talented young rugby players as regards their rugby skills, physical and motor abilities and anthropometric data. Journal of Human Movement Studies, 34, 13-32.

Pine, G. J. (1981). The collaborative action research in school counseling: The integration of research and practice. Personnel and Guidance Journal, 59, 495-501.

Plomin, R. (1991). Behavioural genetics. In P. R. McHugh \& V. A. McKusick (Eds.), Genes, brain and behavior (pp. 165-180). New York: Raven Press.

Pollock, M., Pels, A. E., Foster, C., \& Holum, D. (1986). Comparison of male and female Olympic speedskating candidates. In Sport and elite performers: proceedings of the Olympic scientific congress (pp. 143-152). Champaign USA: Eugene Human Kinetics.

Raskin, E. A. (1936). Comparison of scientific and literary ability: A biographical study of eminent scientists and men of letters of the nineteenth century. Journal of Abnormal and Social Psychology, 31, 20-35.

Regnier, G., Salmela, J., \& Russell, S. J. (1993). Talent detection and development in sport. In R. N. Singer, M. Murphy \& L. K. Tennant (Eds.), Handbook on research on sport psychology (pp. 290-313). New York: Macmillan.

Regnier, G., \& Salmela, J. H. (1987). Predictors of success in Canadian male gymnasts. In B. Petiot, J. H. Salmela \& T. B. Hoshizaki (Eds.), World identification systems for gymnastic talent (pp. 143-150). Montreal, Canada: Sport Psyche Editions.

Reid, P. (2003). More than a game? The role of sports Governing Bodies in the development of sport education programmes. European Physical Education Review, 9, 309 - 317.

Reilly, T. (1990). Football. In T.Reilly, N. Secher, P. Snell \& C. Williams (Eds.), Physiology of sports (pp. 371-425). London: E. \& F.N. Spon.

Reilly, T., Williams, A. M., Nevill, A., \& Franks, A. (2000). A multidisciplinary approach to talent identification in soccer. Journal of Sports Sciences, 18, 695-702.

Reimers, T. M., \& Wacker, D. P. (1988). Parents' ratings of the acceptability of behavioral treatment recommendations made in an outpatient clinic: a preliminary analysis of the influence of treatment effectiveness. Behavioral Disorders, 14, 7-15.

Reimers, T. M., Wacker, D. P., \& Koeppl, G. (1987). Acceptability of behavioral interventions: a review of the literature. School Psychology Review, 16, 212227.

Reuschlein, P. L., \& Vogel, P. G. (1985). Motor performance and physical fitness status of regular and special education students. In J. E. Clark \& J. H. Humphrey (Eds.), Motor development, current selected research (Vol. 1, pp. 147-165). Pennington, N.J.: Princeton Book Company.

Riksen-Walraven, J. M., \& Zevalkink, J. (2000). Gifted infants: what kinds of support do they need? In C. F. M. van Lieshout \& P. G. Heymans (Eds.), 
Developing talent across the life span (pp. 203-229). Philadelphia, PA, US: Psychology Press/Taylor and Francis.

Rimm, S. (1984). The characteristics approach: identification and beyond. Gifted Child Quarterly, 23, 181-187.

Rimm, S., Davis, G. A., \& Bien, Y. (1982). Identifying creativity: a characteristics approach. Gifted Child Quarterly, 26, 165-171.

Riordan, J. (1986). The selection of top performers in East European sport. In G. Gleeson (Ed.), The growing child in competitive sport (pp. 220-240). London: Hodder \& Stoughton.

Riordan, J. (1990). A bright future shrouded in mist: sport in Eastern Europe. Journal of Sport History, 17, 69-74.

Riordan, J. (1993). Rewriting Soviet sports history. Journal of Sport History, 20, 247-258.

Rose, B. (1994). The Importance of gross motor coordination in the psycho-social lives of children. Unpublished $\mathrm{PhD}$, University of Western Australia.

Rose, B., Larkin, D., \& Berger, B. (1997). Coordination and gender influences on the perceived competence of children. Adapted Physical Activity Quarterly, 14, 210-221.

Rose, J., \& Jevne, R. F. J. (1993). Psychosocial processes associated with athletic injuries. Sport Psychologist, 7, 309-328.

Ross, J. G., Dotson, C. O., Gilbert, G. G., \& Katz, S. J. (1985). What are kids doing in physical education? Journal of Physical Education Recreation and Dance, $56,31-34$.

Rowley, S. (1992). Training of young athletes study (TOYA): TOYA and lifestyle. London: The Sports Council.

Rowley, S. (1994). The British perspective: talent identification and selection - the future for British Governing Bodies. London: British Olympic Association.

Rushall, B. S. (1989). Sport psychology: the key to sporting excellence. International Journal of Sport Psychology, 20, 165-190.

Ryan, R. M., Frederick, C. M., Lepes, D., Rubio, D., \& Sheldon, K. S. (1997). Intrinsic motivation and exercise adherence. International Journal of Sport Psychology, 28, 335-354.

Sallis, J. F. (1993). Epidemiology of physical activity and fitness in children and adolescents. Critical Reviews in Food Science and Nutrition, 33, 403-408.

Scanlan, T. K., Stein, G. L., \& Ravizza, K. (1989). An in-depth study of former elite figure skaters: II. Sources of enjoyment. Journal of Sport and Exercise Psychology, 11, 65-83.

Schmidt, R. A., \& Lee, T. D. (1999). Motor control and learning: a behavioral emphasis (3rd ed.). Champaign IL: Human Kinetics. 
Schmidt, R. A., \& Wrisberg, C. A. (2000). Motor learning and performance: a problem-based learning approach. Champaign, IL: Human Kinetics Publishers.

Schunk, D. H. (1990). Self concept and school achievement. In C. Rogers \& P. Kutnick (Eds.), The social psychology of the primary school (pp. 70-91). London: Routledge.

Seefeldt, V. (1996). The concept of readiness applied to the acquisition of motor skills. In F. L. Smoll \& R. E. Smith (Eds.), Children and youth sport: a biopsychosocial perspective (pp. 49-56). Madison: Brown \& Benchmark.

Seefeldt, V., Haubenstricker, J., \& Reuschlein, S. (1979). Why physical education in elementary school curriculum? Ontario Physical Education and Health Education Association Journal, 5, 21-31.

Seefeldt, V. D., \& Ewing, M. E. (1997). Youth sports in America: an overview. President's Council on Physical Fitness and Sports Research Digest, 2(11), $1-17$.

Sfard, A. (1998). On two metaphors for learning and the dangers of choosing just one. Educational Researcher, 27(2), 4-13.

Shakespear, P. (1980). Identification and selection of talent in rowing. Sports Coach, 15(4), 9-12.

Shephard, R. J. (1998). Aging and exercise. Retrieved 25th March, 2005, from http://sportsci.org

Silva, J. M., Shultz, B. B., Haslam, R. W., Martin, T. P., \& Murray, D. F. (1985). Discriminating characteristics of contestants at the United States Olympic Wrestling Trials. International Journal of Sport Psychology, 16, 79-102.

Simonton, D. K. (1994). Greatness: who makes history and why? New York: Guilford.

Simonton, D. K. (1999). Talent and its development: an emergenic and epigenetic model. Psychological Review, 106, 435-457.

Singer, R. N., \& Janelle, C. M. (1999). Determining sport expertise: from genes to supremes. International Journal of Sport Psychology, 30, 117-150.

Skinner, R. A., \& Piek, J. P. (2001). Psychosocial implications of poor motor coordination in children and adolescents. Human Movement Science, 20, 7394.

Slavin, R. E. (1989). PET and the pendulum: Faddism in education and how to stop it. Phi Delta Kappan, 90, 750-758.

Sloboda, J. A., \& Howe, M. J. A. (1991). Biographical precursors of musical excellence: An interview study. Psychology of Music, 19(44), 2-56.

Smith, D. J. (2003). A framework for understanding the training process leading to elite performance. Sports Medicine, 33, 1103-1126. 
Smith, R., \& Christensen, D. (1995). Psychological skills as predictors of performance and survival in professional baseball. Journal of Sport and Exercise Psychology, 17, 399-415.

Smith, R. E., Schutz, R. W., Smoll, F. L., \& Ptacek, J. T. (1995). Development and validation of a multidimensional measure of sport-specific psychological skills: the Athletic Coping Skills Inventory-28. Journal of Sport and Exercise Psychology, 17, 379-398.

Snow, R. E. (1992). Aptitude theory: yesterday, today, and tomorrow. Educational Psychologist, 27, 5-32.

Sokolove, M. (2004, August 8). Built to swim. New York Times.

Sol, J. B. M. (1987). The Bisdom/Sol aptitude test for female gymnasts. In B. Petiot, J. H. Salmela \& T. B. Hoshizaki (Eds.), World identification systems for gymnastic talent (pp. 113-117). Montreal, Canada: Sport Psyche Editions Montreal.

Sosniak, L. A. (1985). Learning to be a concert pianist. In B. S. Bloom (Ed.), Developing talent in young people (pp. 19-67). New York: Ballentine.

Sport Industry Research Centre. (2003). European sporting success: a study of the development of medal winning elites in five European countries. London: UK Sport.

Sports Council. (1993). Young people and sport: policy and frameworks for action. London: Sports Council.

Standage, M., Duda, J. L., \& Ntoumanis, N. (2003). A model of contextual motivation in Physical Education: using constructs from self-determination and achievement goal theories to predict physical activity intentions. Journal of Educational Psychology, 95, 97-110.

Starkes, J. L., \& Allard, F. (Eds.). (1993). Cognitive issues in motor expertise. Amsterdam: Elsevier.

Starkes, J. L., Deakin, J. M., Allard, F., Hodges, N. J., \& Hayes, A. (1996).

Deliberate practice in sports: what is it anyway? In K. A. Ericsson (Ed.), The road to excellence: the acquisition of expert performance in the arts, sciences, sports and games. Mahwah, N.J: Erlbaum.

Stevens, R. J. (2004). Why do educational innovations come and go? What do we know? What can we do? Teaching and Teacher Education, 20, 389-396.

Stevenson, C. L. (1990). The athletic career: Some contingencies of sport specialization. Journal of Sport Behavior, 13, 103.

Strategy Unit. (2002). Game Plan: a strategy for delivering Government's sport and physical activity objectives. London: Cabinet Office.

Talbot-Honeck, C., \& Orlick, T. (1998). The essence of excellence: mental skills of top classical musicians. The Journal of Excellence, 1(1), 66-81.

Tanner, J. M. (1964). The physique of the Olympic athlete. London: George Allen \& Unwin. 
Taylor, J. A., \& Shaw, D. F. (2002). The effects of outcome imagery on golf-putting performance. Journal of Sport Sciences, 20, 607-613.

Tebbenham, D. (1998). The nature of talent development and importance of athletic transition in UK sport. Unpublished Masters, Crewe \& Alsager Faculty, Manchester Metropolitan University, Alsager.

Tergerson, J. L., \& King, K. A. (2002). Do perceived cues, benefits, and barriers to physical activity differ between male and female adolescents? Journal of School Health, 72, 374-380.

Thelen, E., \& Smith, L. B. (1994). A dynamic systems approach to the development of cognition and action. Cambridge, MA: MIT Press.

Thomas, J. R., \& Nelson, J. K. (2001). Research methods in physical activity. Champaign, IL: Human Kinetics.

Thomas, P. R., Murphy, S. M., \& Hardy, L. (1999). Test of performances strategies: development and preliminary validation of a comprehensive measure of athletes' psychological skills. Journal of Sports Sciences, 17, 697-711.

Thompson, A. H., Barnsley, R. H., \& Stebelsky, G. (1991). Born to play ball: the relative age effect and Major League baseball. Sociology of Sport Journal, 8, 146-151.

Thomson, I. (1992). Giftedness, excellence and sport. Edinburgh: Scottish Sports Council.

Tittel, K. (1965). Zur biotypologie und funktionellen anatomic des leistungssportlers. Nova Acta Leopoldina, 30, 172.

Truscott, S. D., Cosgrove, G., Meyers, J., \& Eidle-Barkman, K. A. (2000). The acceptability of organizational consultation with prereferral intervention teams. School Psychology Quarterly, 15, 172-206.

Tyler, J. (1991). The serious business of play: a focus on recreation in the Milwaukee agenda. Milwaukee, WI: Public Policy Forum, 633 W. Wisconsin Avenue.

U.S. Department of Health and Human Services. (1996). The surgeon general's report: physical activity and health. Washington, DC: U.S. Department of Health and Human Services.

Ulrich, D. (1985). Test of Gross Motor Development. Austin, TX: Pro-Ed.

Van der Merwe, C. A. (1997). Talent Identification and development among black 12 year-old rugby players. Unpublished $\mathrm{PhD}$, Potchefstroom University, Potchefstroom, Republic of South Africa.

Van der Walt, T. S. P. (1988). Antropometriese tipering by topdeelnemers in verskillende Olimpiese sportsoorte. (Anthropometrical typecasting amongst competitors in different Olympic events.). SA Journal for Research in Sport Physical Education and Recreation, 11, 101-120.

Van Ingen Schenau, G. L., De Koning, J. J., Bakker, F. C., \& De Groot, G. (1996). Performance-influencing factors in homogeneous groups of top athletes: a cross-sectional study. Medicine and Science in Sports and Exercise, 28, 13051310. 
Van Lieshout, C. F. M., \& Heymans, P. G. (2000). Developing talent across the life span. Hove, UK: Psychology Press.

Vernacchia, R. A., McGuire, R. T., Reardon, J. P., \& Templin, D. P. (2000). Psychosocial characteristics of Olympic track and field athletes. International Journal of Sport Psychology, 31, 5-23.

Wall, A. E. (2004). The developmental skill-learning gap hypothesis: Implications for children with movement difficulties. Adapted Physical Activity Quarterly, $21,197-218$.

Wall, A. E., McClements, J., Bouffard, M., Findlay, H., \& Taylor, J. (1985). A knowledge-based approach to motor development: Implications for the physically awkward. Adapted Physical Activity Quarterly, 2, 21-42.

Wallingford, R. (1975). Long distance running. In A. W. Tayler \& F. Landry (Eds.), The scientific aspects of sport training (pp. 118-130). Springfield, IL: Charles C. Thomas.

Walters, G. D. (2002). Developmental trajectories, transitions, and nonlinear dynamical systems: a model of crime deceleration and desistance. International Journal of Offender Therapy and Comparative Criminology, 46, 30-44.

Waskiewicz, Z., \& Zajac, A. (2001). The imagery and motor skills acquisition. Biology of Sport, 18, 71-83.

Weiss, M., Bredemeier, B., \& Shewchuk, R. (1985). An intrinsic/extrinsic motivation scale for the youth setting: a confirmatory factor analysis. Journal of Sport Psychology, 7, 75-91.

Weiss, M. R. (2000). Motivating kids in physical activity. President's Council on Physical Fitness and Sports Research Digest, 3, 1-6.

Welsman, J. R., \& Armstrong, N. (2000). Longitudinal changes in submaximal oxygen uptake in 11- to 13-year olds. Journal of Sport Sciences, 18, 183-189.

Wiersma, L. D. (2000). Risks and benefits of youth sport specialization: perspectives and recommendations. Paediatric Exercise Science, 12, 13.

Williams, A. M. (2000). Perceptual skill in soccer: implications for talent identification and development. Journal of Sports Sciences, 18, 737-750.

Williams, A. M., Davids, K., \& Williams, J. G. (1999). Visual perception and action in sport. London: Routledge, Taylor \& Francis.

Williams, A. M., \& Franks, A. (1998). Talent identification in soccer. Sports Exercise and Injury, 4, 159-165.

Williams, A. M., \& Reilly, T. (2000). Talent identification and development. Journal of Sport Sciences, 18, 657-667.

Wimmers, R. H., Savelsbergh, G. J. P., Beek, P. J., \& Hopkins, B. (1998). Evidence for a phase transition in the early development of prehension. Developmental Psychobiology, 32, 235-248. 
Young, B. W., \& Salmela, J. H. (2002). Perceptions of training and deliberate practice of middle distance runners. International Journal of Sport Psychology, 33, 167-181.

Zha, Z. (1993). Programs and practices for identifying and nurturing giftedness and talent in People's Republic of China. In K. Heller, F. J. Monks \& A. H. Passow (Eds.), International handbook of research and development of giftedness and talent (pp. 809-814). Oxford: Pergamon Press.

Ziegler, A., \& Raul, T. (2000). Myth and reality: a review of empirical studies on giftedness. High Ability Studies, 11, 113-136.

Ziemainz, H., \& Gulbin, J. (2002). Talent selection, -identification and -development exemplified in the Australian Talent Search programme. New Studies in Athletics, 17 (3/4), 27-32. 


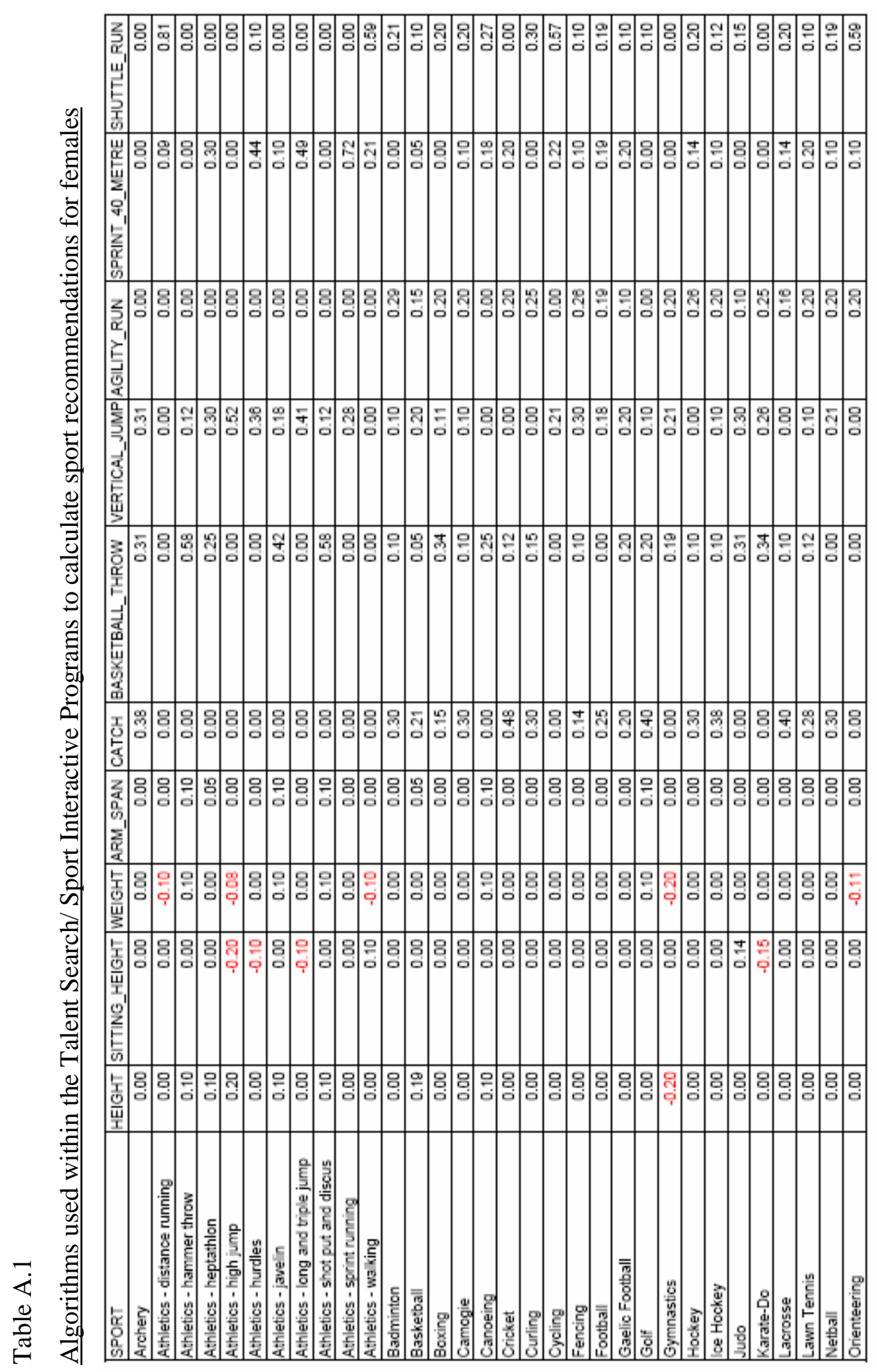




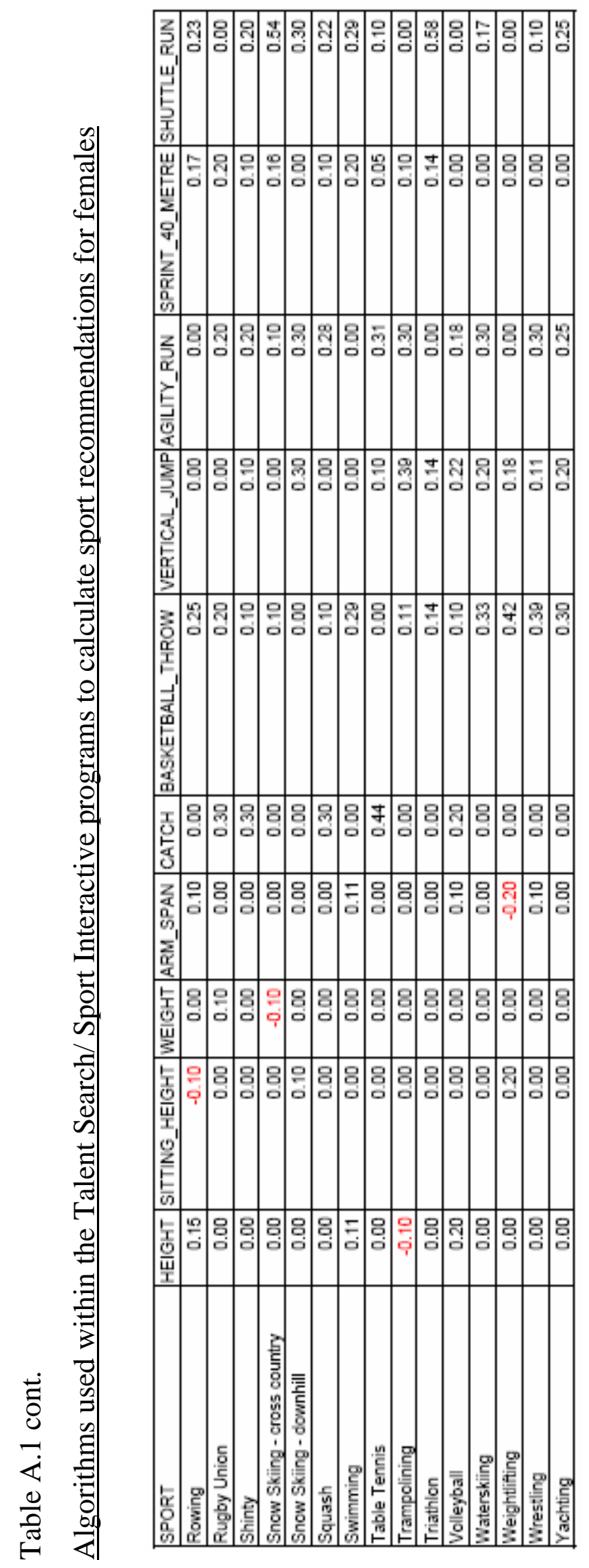




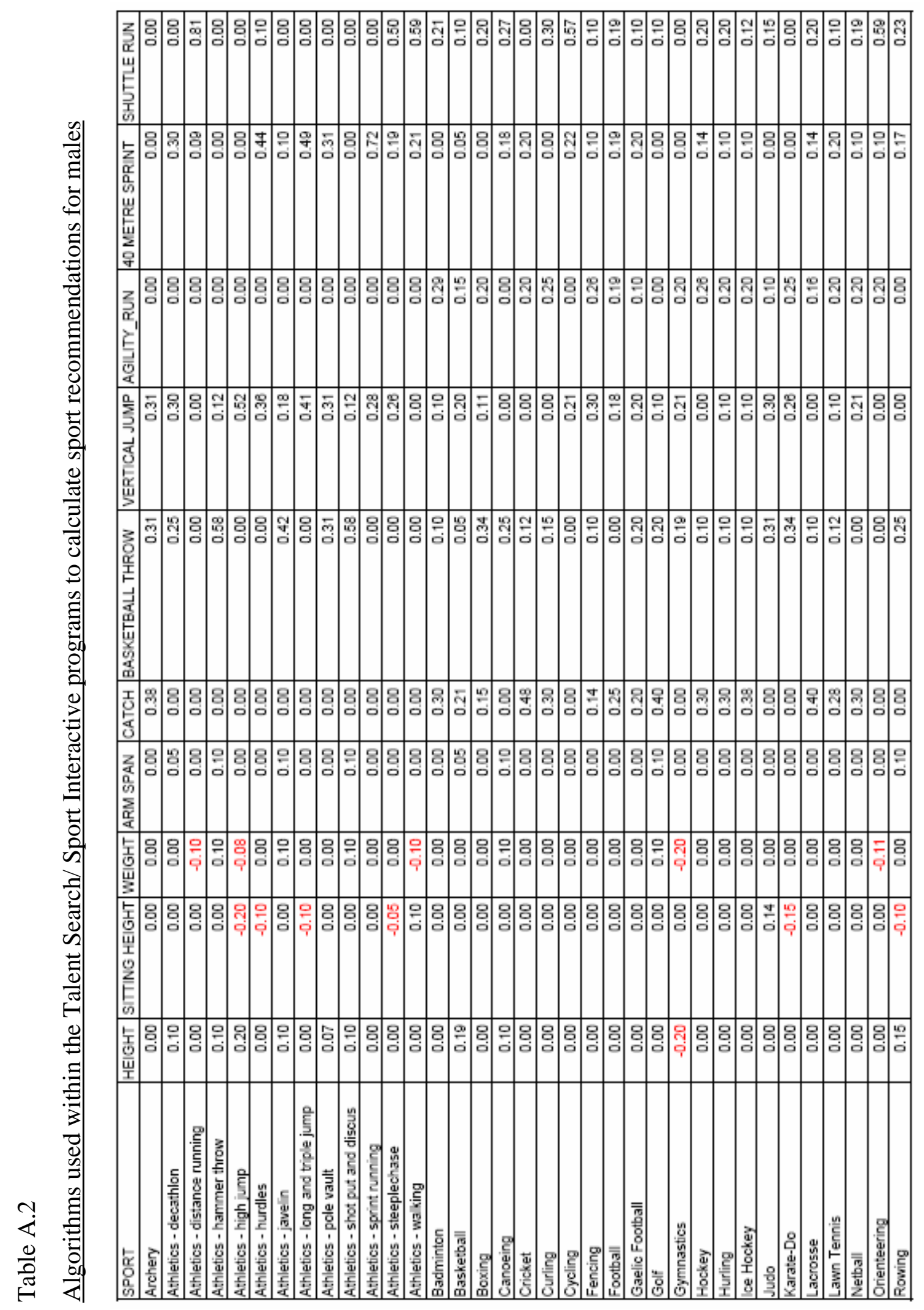




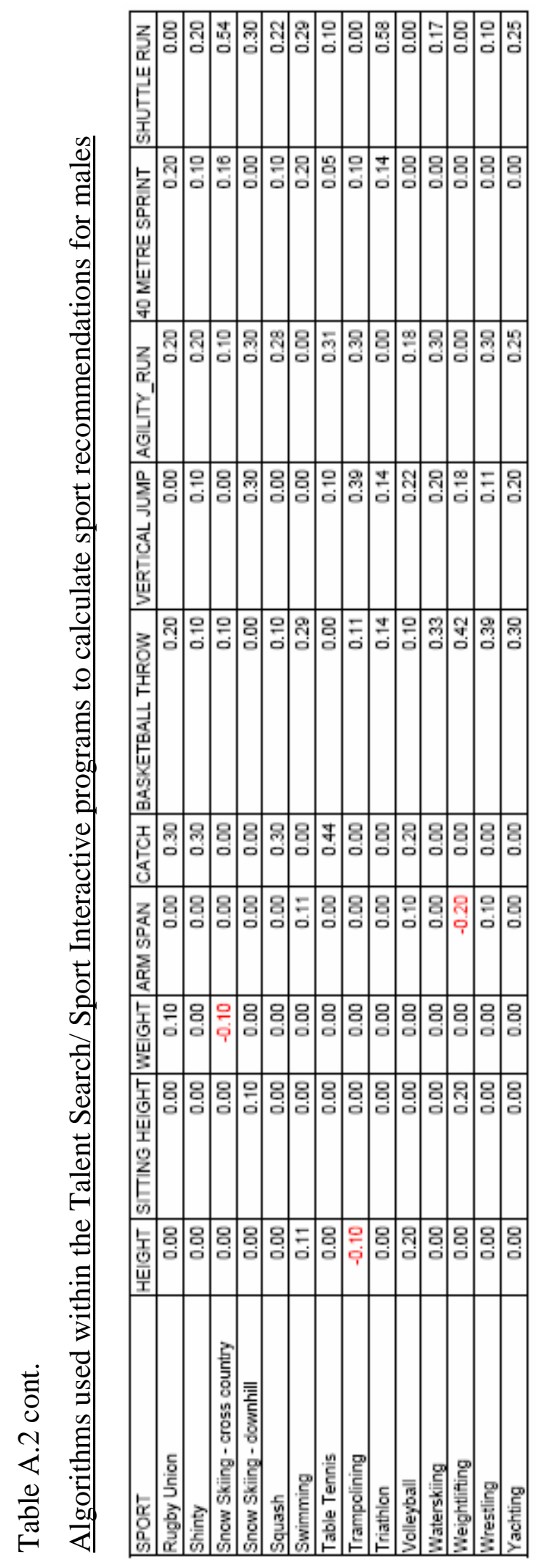


APPENDIX B

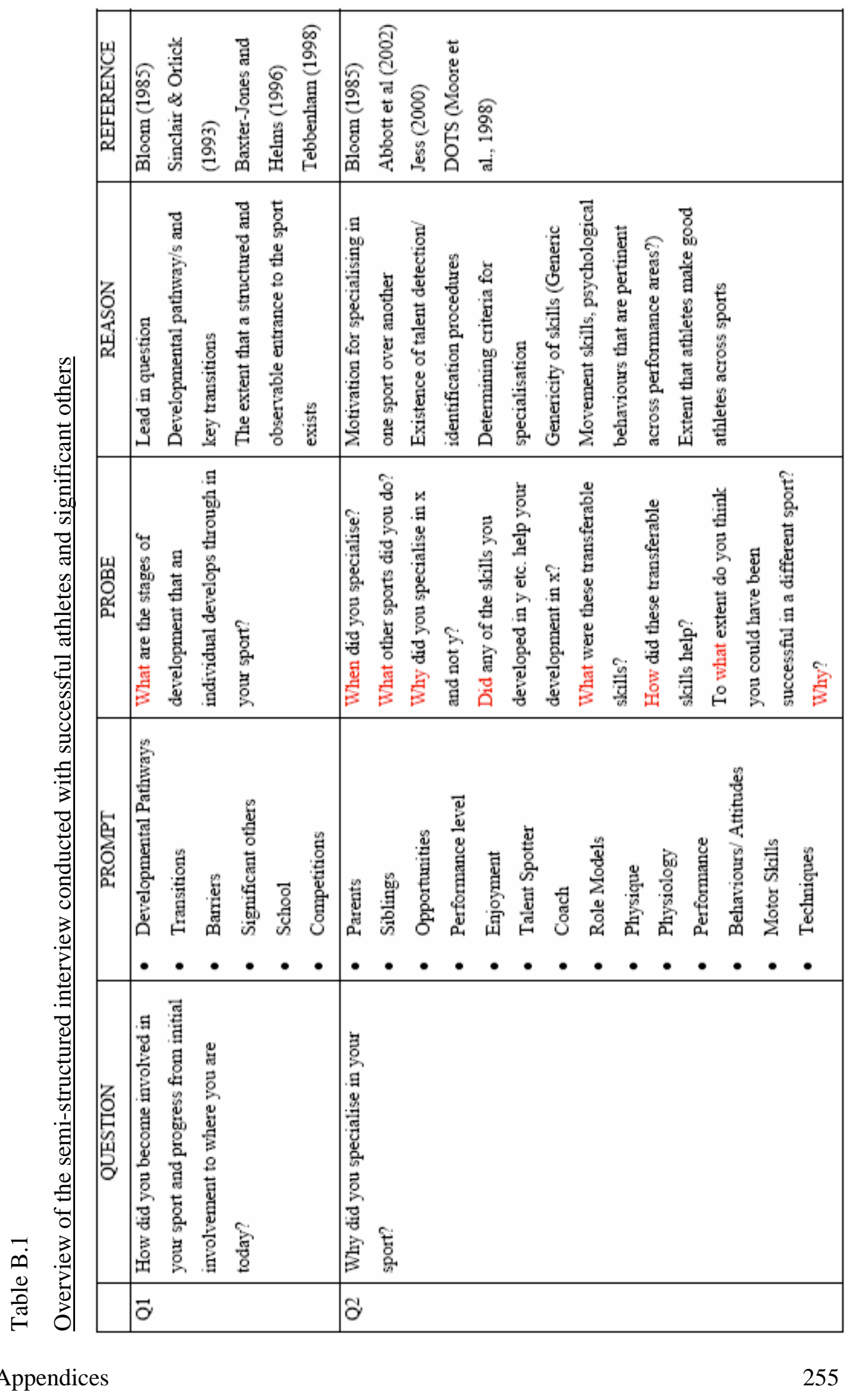




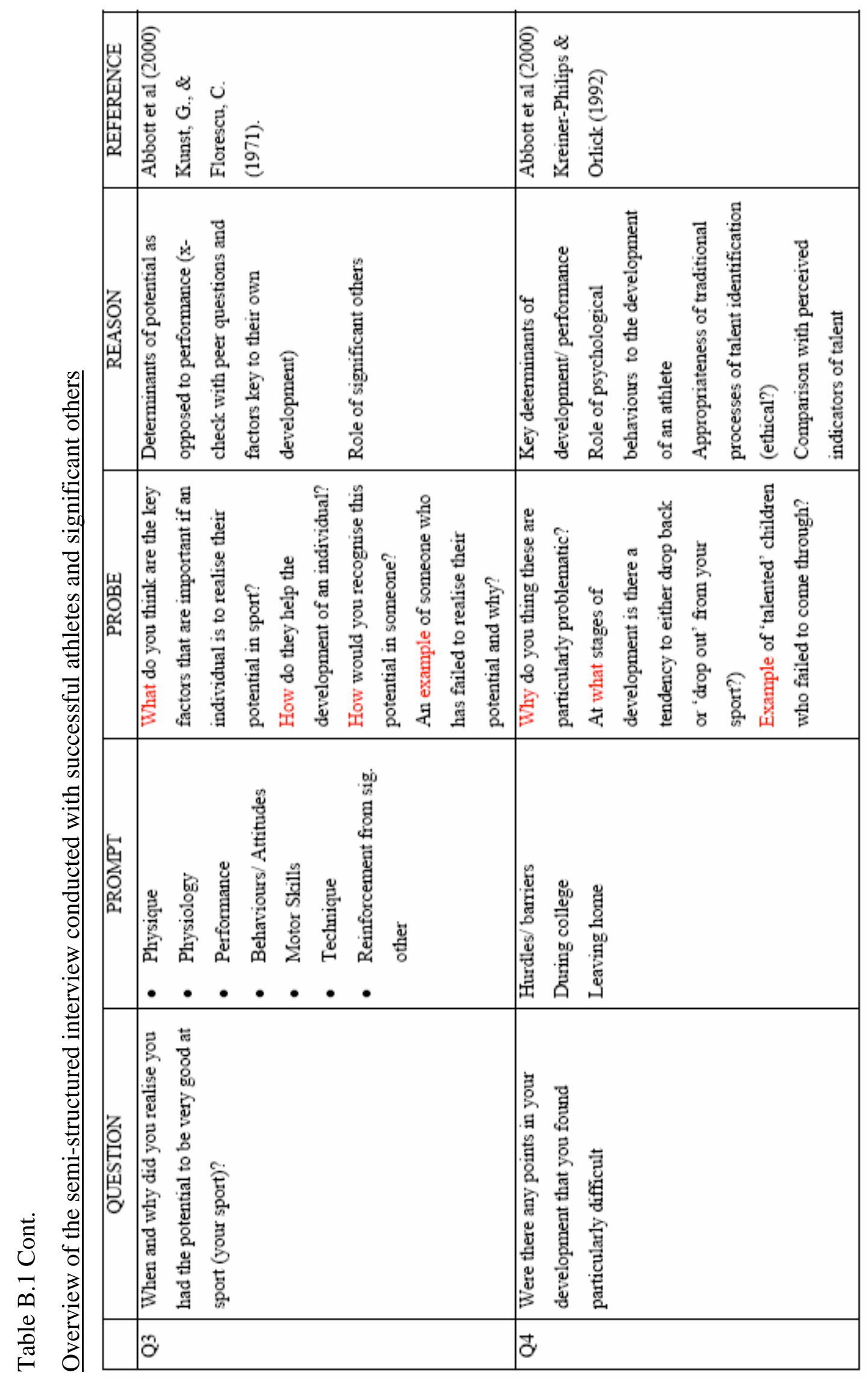




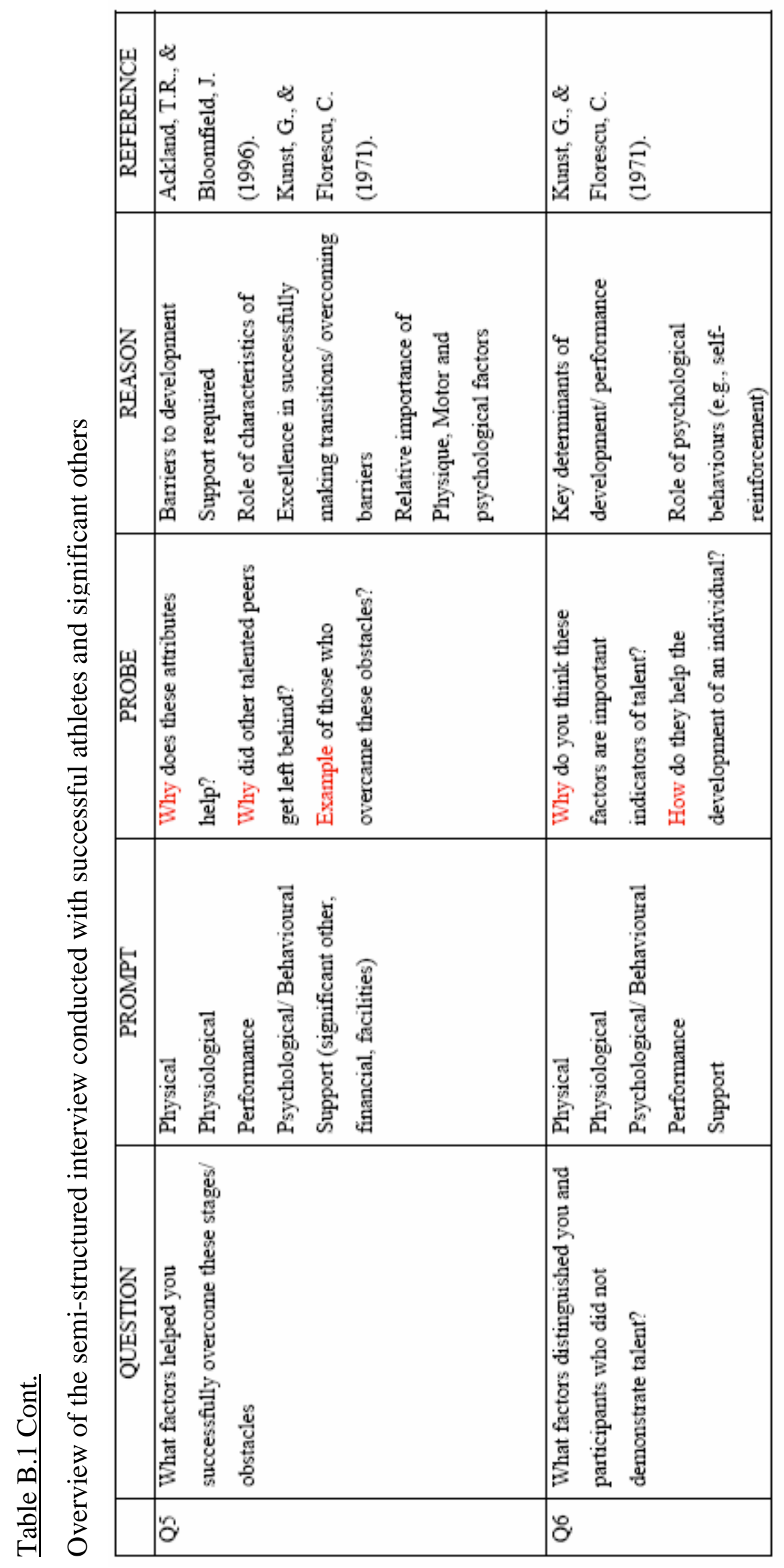

Appendices 


\section{APPENDIX C}

Psychomotor and Psycho-Behavioural Resources used within DPYPS 


\section{APPENDIX D}

\section{Philosophy of DPYPS}

a. What do you see as the underpinning philosophy of DPYPS?

b. What do you like about the philosophy?

c. What do you not like about the philosophy?

d. How do you think the philosophy fits in with your own philosophy as a Teacher?

e. Do you think the philosophy of DPYPS has wider applications than sport and physical activity? (Examples?)

f. Any other comments?

\section{Psychomotor Resources}

a. What are your feelings about the psychomotor curriculum?

- Philosophy?

- $\quad$-Basic Moves

- Cognitive elements

- Structure?

- Developmental

- Flexible

b. How useful are the resources?

- What do you like about the resources?

- What do you not like about the resources?

c. To what extent do the resources allow you to achieve you targets within physical education?

- link to 5-14 curriculum

- ability to cater for differing levels of children

d. Are the psychomotor skills something that children need to be taught?

- Why?

- Do you think that primary school is an appropriate place to teach these skills?

- To what extent were the children's needs being catered for before?

- To what extent does the programme allow children's needs to be catered for now?

- Have you seen any differences?

e. Any other comments?

Figure D.1 Overview of the interview conducted with teachers at the conclusion of the DPYPS programme 


\section{Psycho-Behavioural Resources}

a. What are your feelings about the psycho-behavioural curriculum?

- Philosophy?

- Structure?

- Developmental

- Ability to link with the physical

- Ability to link with non-physical areas

b. How useful are the resources?

- What do you like about the resources?

- What do you not like about the resources?

c. Do you feel that the psycho-behavioural curriculum can contribute towards children's development in activity and sport?

d. Do you think the resources have any non-sport applications? (Examples?).

- Have you used them elsewhere? (Examples?)

- Has this application helped the children?

e. Are the psycho-behavioural skills something that children need to be taught?

- Why?

- Do you think that primary school is an appropriate place to teach these skills?

- To what extent were the children's needs being catered for before?

- To what extent does the programme allow children's needs to be catered for now?

- Have you seen any differences?

f. Any other comments?

\section{In-service Training}

a. What are your feelings about the inservice training that you received through DPYPS?

- How has this compared with other training you've had in physical education

b. What did you find useful about the training?

c. What did you not find useful about the training?

d. What did you need more information on?

- What else would have helped? (e.g., lesson planning)

e. Any other comments?

Figure D.1 cont. Overview of the interview conducted with teachers at the conclusion of the DPYPS programme 


\section{Implementation of the programme}

a. How have you found the actual implementation of the DPYPS programme?

- psychomotor

- psycho-behavioural

- making the links between psycho-motor and psycho-behavioural

b. Have there been any barriers to implementing the programme? What have these been?

- Problems related to the programme?

- Problems not directly related to the programme

c. Do you feel that you have had adequate support? Where, if anywhere, would you have liked more support?

d. Any other comments?

\section{Outcomes}

a. What impact, if any, has the programme had on...

- the children?

- Impact on physical activity/ sport involvement (psychomotor and psychobehaviour)

- Impact on non- physical issues (psychomotor and psycho-behaviour)

- you?

- Your philosophy?

- Your method?

- Other?

- the school?

- Philosophy?

- Method?

- Other?

- Any other issues that you would have liked to have seen DPYPS target?

b. Following the conclusion of the pilot, will you continue to use the resources you've been provided with or will you revert to how you used to teach?

- Psychomotor, why? (philosophy, method)

- Psycho-behavioural, why? (philosophy, method)

c. Any other comments?

Figure D. 1 cont. Overview of the interview conducted with teachers at the conclusion of the DPYPS programme 


\section{Philosophy}

a. What is the club (DPYPS) about?

- Psychomotor

- What do you do in the sessions?

- What are the sessions trying to achieve?

- Do other programmes that you've been involved in do this?

- Psycho-behaviour

- What do you do in the sessions?

- What are the sessions trying to achieve?

- Do other programmes that you've been involved in do this?

\section{Practice}

a. Why did you become involved in the programme?

b. What do you think about the activities you do?

- Psychomotor

- Do you enjoy the activities? Why? (examples)

- Do you find the activities challenging? Why? (examples)

- Do you find what you learn is useful? Why? (examples)

c. How does the programme compare to other programmes you have done?

- What is better?

- What is not so good?

- Which do you gain from most?

\section{Application}

a. When have you used what you have learnt as a result of the programme?

- Sport applications (psychomotor \& psycho-behavioural)

- Example of what you used

- Example of how it helped

- What would you have done in this situation before?

- Non sport applications (psychomotor \& psycho-behavioural)

- Example of what you used

- Example of how it helped

- What would you have done in this situation before?

b. What did you learn in the last psychomotor session?

- How do you think you could use these skills?

c. What did you learn in the last psycho-behavioural session?

How do you think you could use these skills? (sport and non sport)

Figure D.2 Overview of the interview conducted with children at the conclusion of the DPYPS programme 


\section{Outcomes}

a. How has the programme changed you?

- Has it changed how you feel about taking part in physical activities? (school \& non school clubs)

- Has it changed how you feel about taking part in non-physical activities? (e.g., music club)

- Has it changed how you feel about yourself?

- Has it changed how you feel/think about others?

b. Are you happy to try new sports?

- Example?

- Have you always been happy/ not happy to take part in new sports?

- What would encourage you to do more physical activities?

- Are you involved in more or less physical activities now than you were before starting DPYPS? Why?

\section{Future Intentions/ Ambitions}

a. Do you want the programme to continue?

- Why?

b. If the programme continues, will you keep coming along?

- Why

- Aims?

c. In the future, do you think you will do more or less physical activities/ sports?

- Why?

- Aims?

Figure D. 2 cont. Overview of the interview conducted with children at the conclusion of the DPYPS programme 


\section{APPENDIX E}

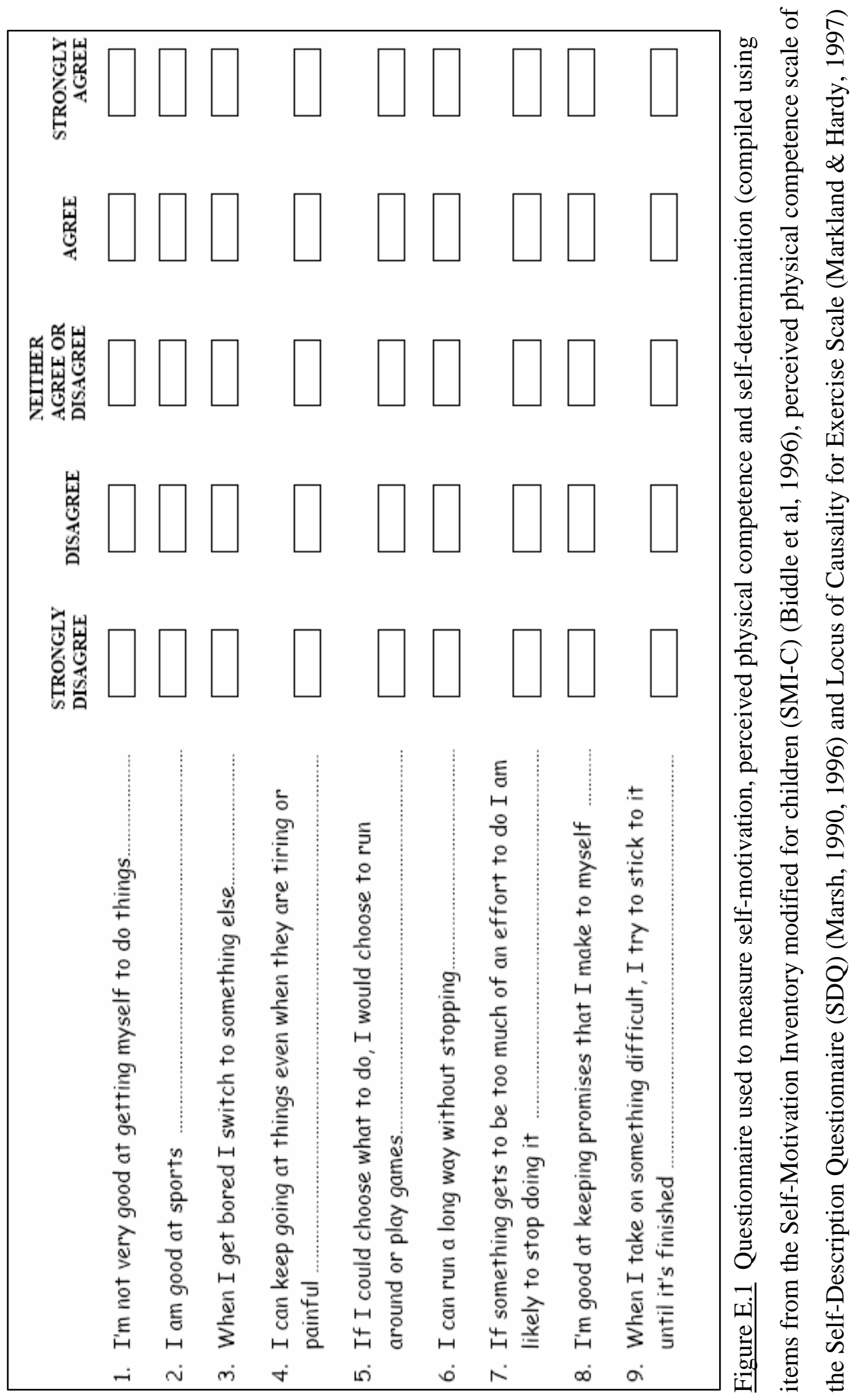




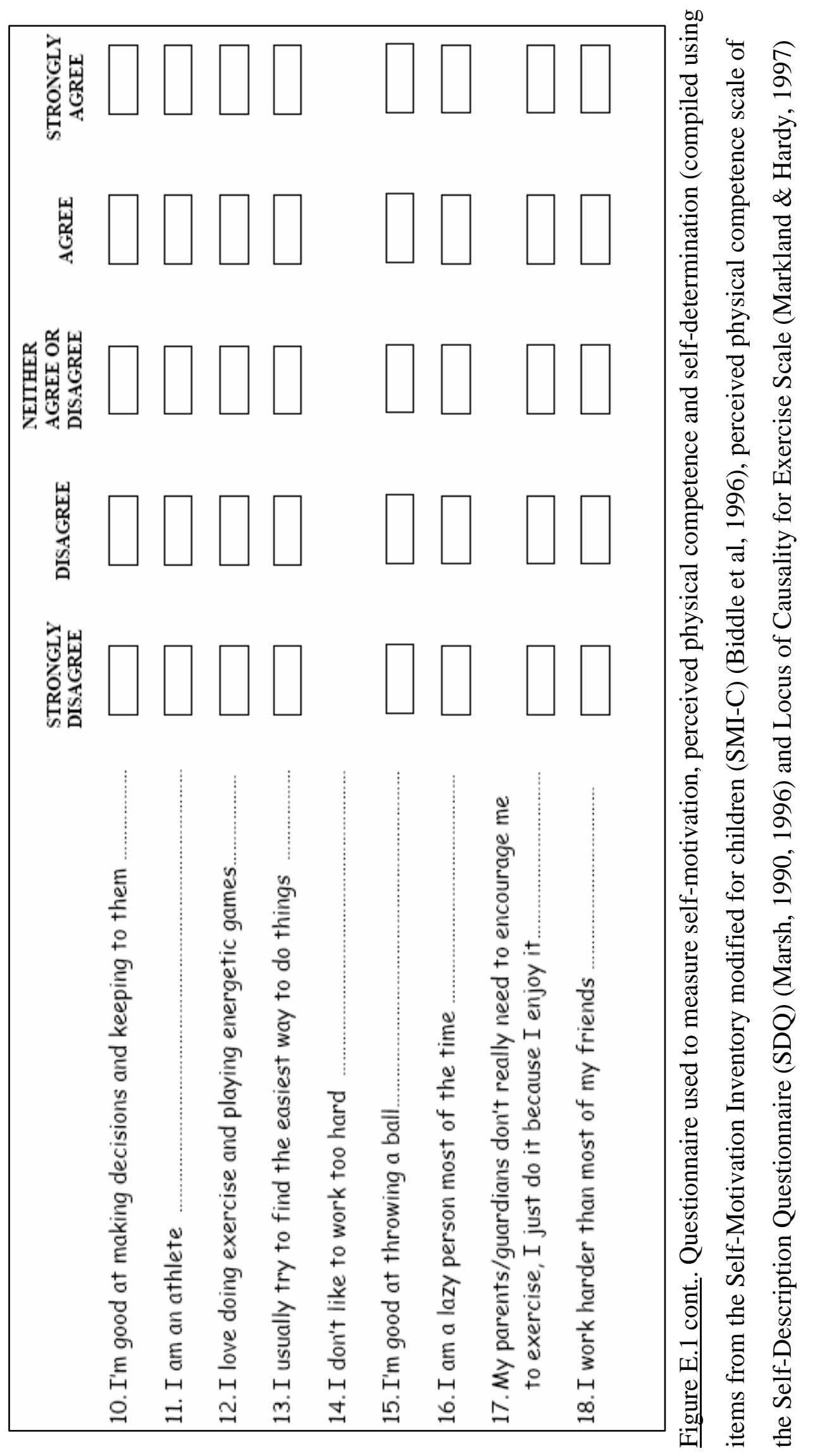




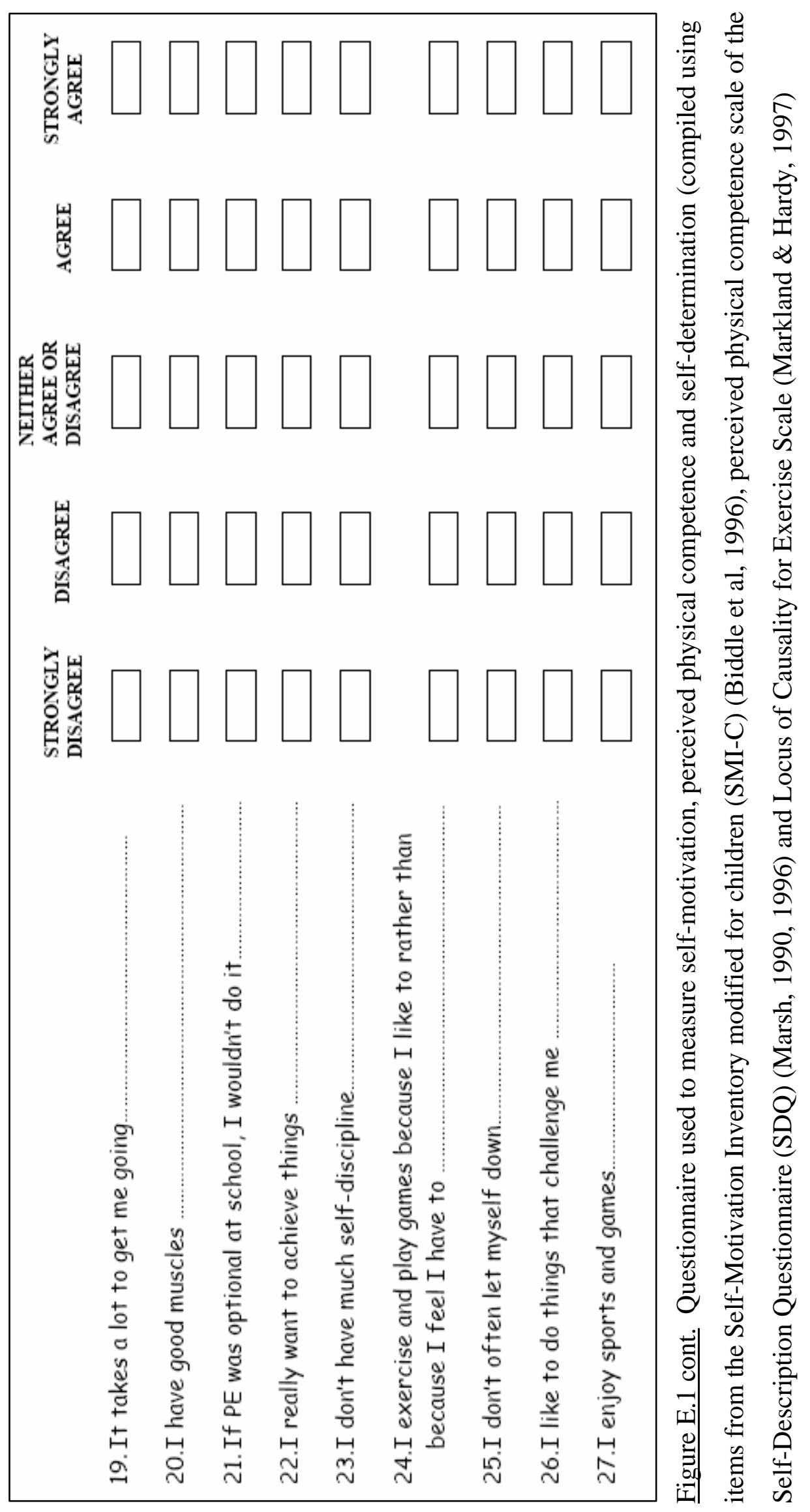




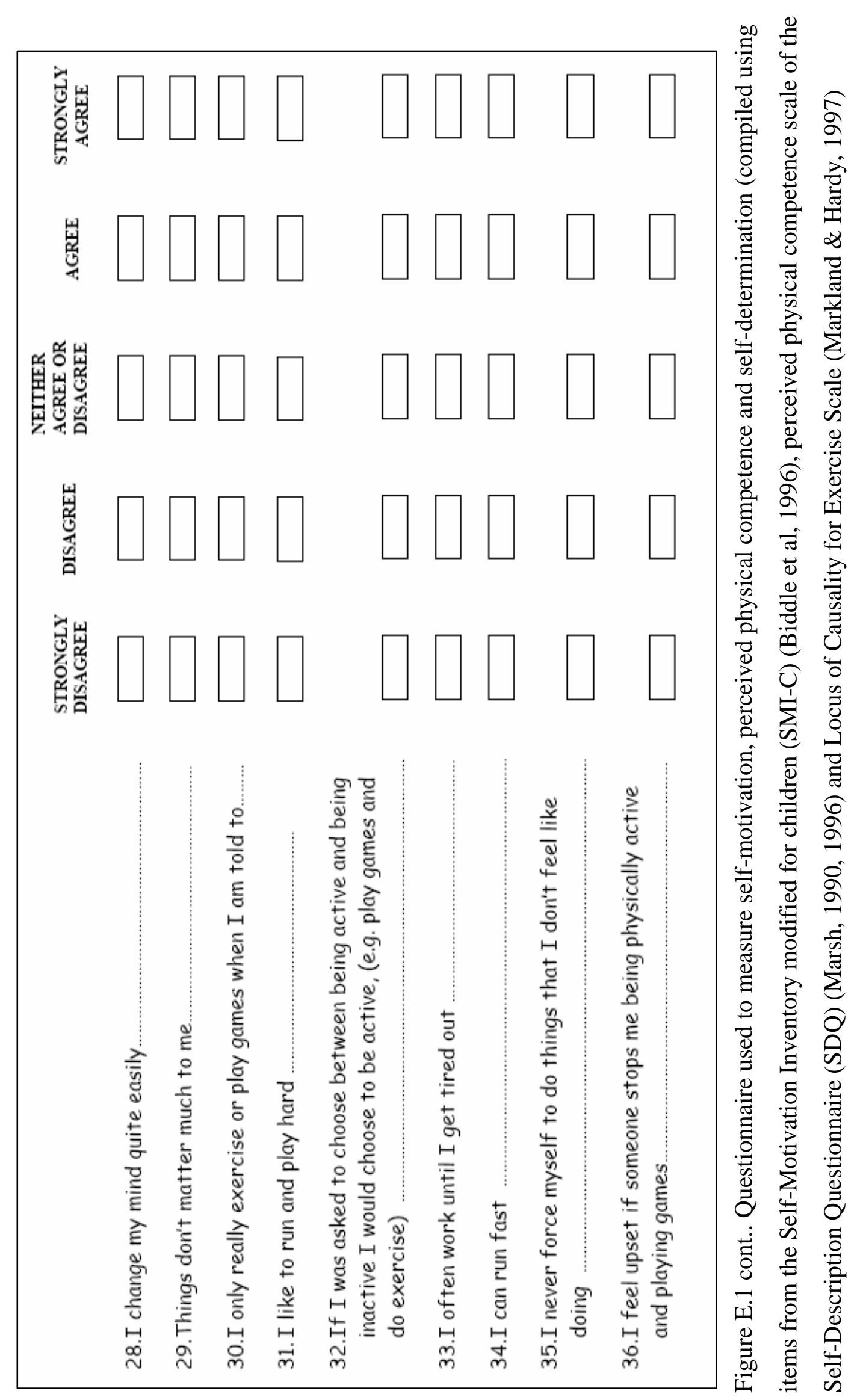




\section{CODE: \\ The University of Edinburgh \\ The Young \\ People's \\ Physical Activity \\ Questionnaire}

\section{Important:}

There are no right or wrong answers. Your responses will be kept secret to allow you to answer all questions honestly.

Your Name:

Your Date of Birth: Day

Month

Year

Your School Name:

Cumbrae Primary

Your School Year:

Primary 7

Today's date: Day 5 Month 12 Year 2002

Figure E.2 The Young Peoples Physical Activity Questionnaire (Jess, 1999b) 
Information for children

- With the help of a parent or guardian, please answer the questions on pages $1-9$.

- Pages 10-11 should be completed by your parent/guardian and returned within the next few days

\section{How to fill in the questionnaire}

1. Read each question carefully

2. Most questions can be answered by putting a tick in the box that applies to you. For example

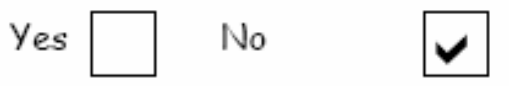

3. Sometimes you might be asked to write a number on a line.

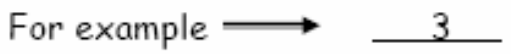

4. Sometimes you might be asked to write your answer on a line.

$$
\text { For example } \longrightarrow \text { Sport }
$$

5. Questions are written on both sides of the paper so please be careful that you do not miss any

Figure E.2 The Young Peoples Physical Activity Questionnaire (Jess, 1999b) 


\section{Section A}

A1. Are you a boy or a girl?

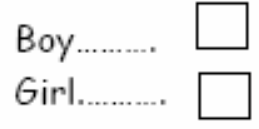

A2. Which school year are you now in?

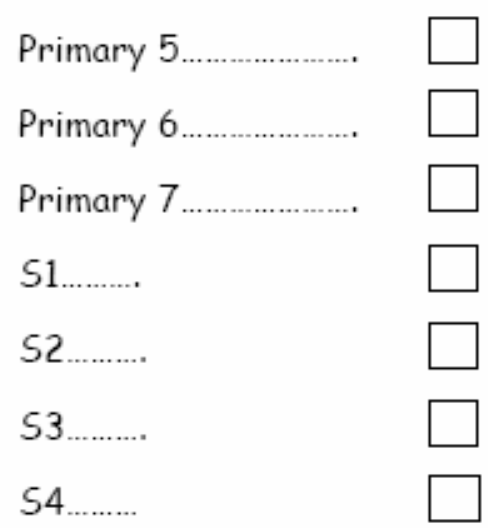

A3. How old are you now?

$\begin{array}{ll}7 \text { years old } \\ 8 & 11 \text { years old } \\ 8 \text { years old } \\ 9 \text { years old }\end{array}$

A4. In what month of the year were you born?

\begin{tabular}{|c|c|c|}
\hline January & May & September \\
\hline February & June & October \\
\hline March & July & November \\
\hline April & August & December \\
\hline
\end{tabular}

Figure E.2 cont. The Young Peoples Physical Activity Questionnaire (Jess, 1999b) 


\section{Section B - School Clubs (organised by your school)}

This section of the questionnaire is about sport and physical activity clubs/sessions that take place at your school only. Do not include non-school clubs and PE lessons that take place during your normal school days.

B1. At the moment, how many school sport or physical activity clubs do you go to at least one time per week?

No clubs

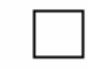

One club

Two clubs

Three clubs

More than 3

B2. What are the school sport or physical activity clubs you go to and on what $\operatorname{day}(s)$ do they take place?

Type of Sport or Physical Day(s)

Activity (e.g., Tennis) (e.g., Wednesday \& Friday)

$\begin{array}{ll}1 & \square \\ 3 & \square \\ 4 & \end{array}$

B3. Since August 2002, have you gone to a school sport or physical activity club/session that you have now stopped going to?

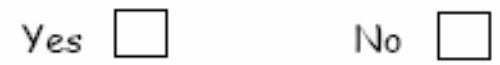

Figure E.2 cont. The Young Peoples Physical Activity Questionnaire (Jess, 1999b) 


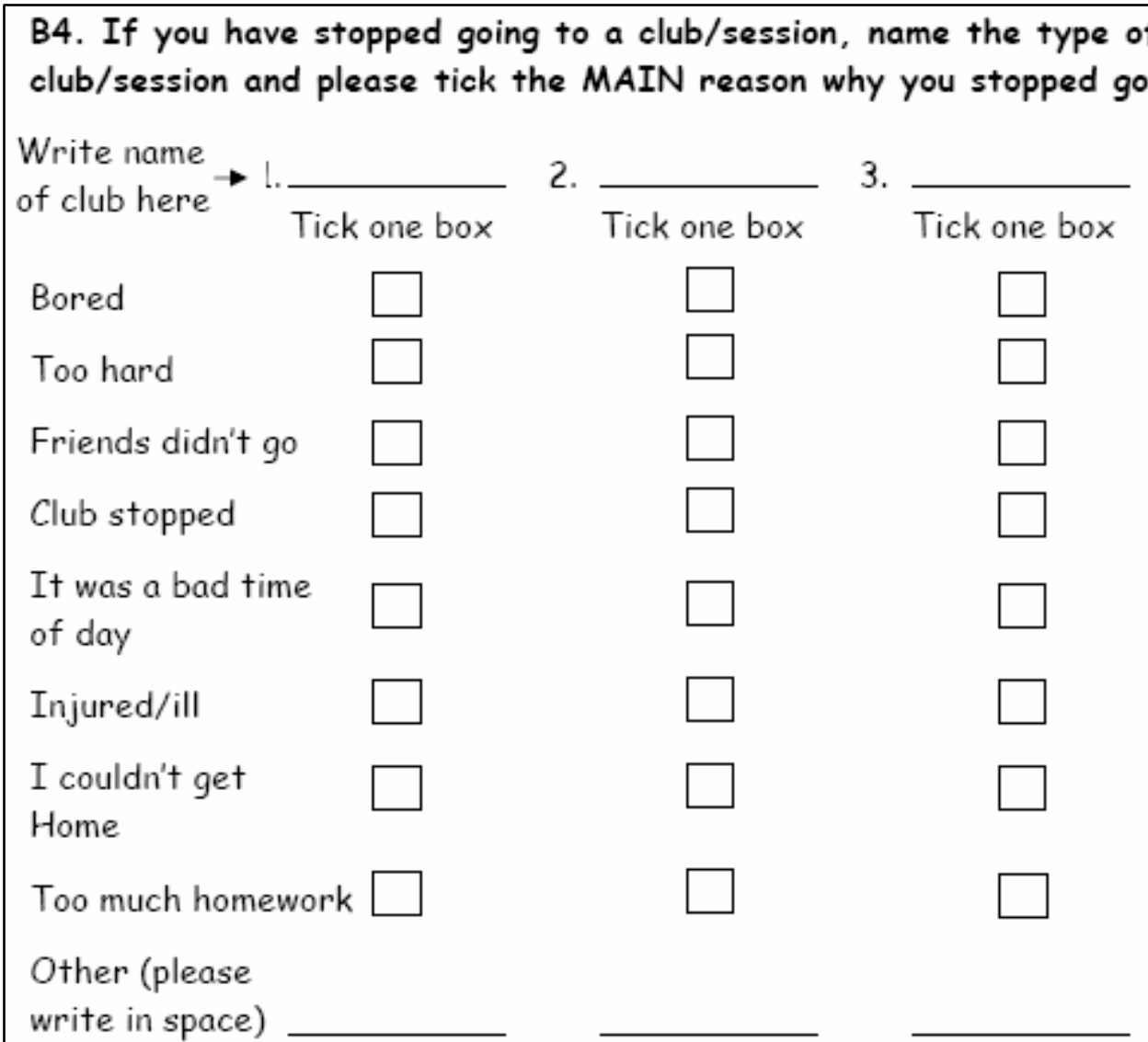

B5. At any school club, do you play in competitions against other schools yes $\square$ No $\square$

If YES, which sports/ physical activities do you play in these competitions?

1.

2.

3.

B6. Have you represented your CITY/REGION/COUNTY OR NATIONAL SCHOOLS TEAM against another CITY/REGION/COUNTY OR NATIONAL SCHOOLS TEAM?

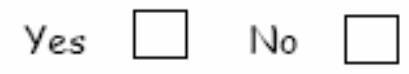

If YES, in which sport(s)/ physical activity (ies)?

1.

2.

Figure E.2 cont. The Young Peoples Physical Activity Questionnaire (Jess, 1999b) 


\section{Section C-NON-School Clubs (NOT organised by your school)}

This section of the questionnaire is about sport and physical activity clubs that are NOT run by your school.

C1. At the moment, how many sport or physical activity clubs/sessions (NOT school clubs, guides, scouts etc) do you go to at least one time per week?

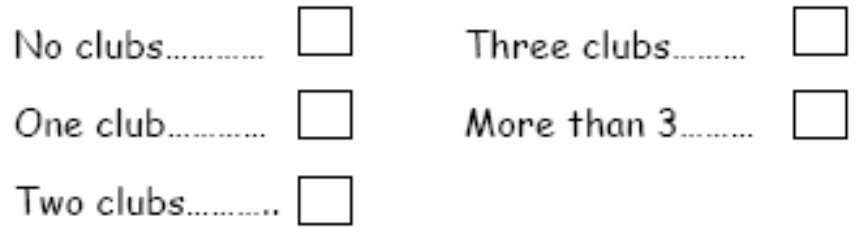

C2. What are the names of the sport or physical activities you go to (not school clubs) and on what day(s) do they take place?

Name of Sport/Physical Activity Day(s)

1.

2.

3.

C3. Who USUALLY takes you to the sports or physical activity clubs/ sessions you go to?

NAME OF SPORTS OR PHYSICAL ACTIVITIES

Write name

of club here $\rightarrow$

- 2

Tick one box

2.

3.

Parent/ Guardian

Go with Friend

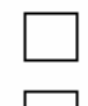

Tick one box

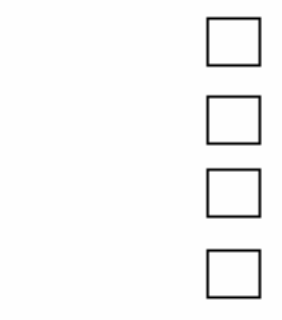

Friend's parents

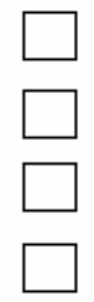

Go by self

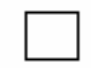

Other person

(please name)

Figure E.2 cont. The Young Peoples Physical Activity Questionnaire (Jess, 1999b) 
C4. Since August 2002, have you gone to a sport or physical activity club/session (not at school) that you then stopped going to?

$$
\text { Yes } \square \text { No } \square
$$

C5. If you have stopped going to a club/session (not at school) please name the club and tick the MAIN reason why you stopped going.

\section{NAME OF SPORTS OR PHYSICAL ACTIVITIES}

Write name

Tick one box of club here $\rightarrow 1$

2.

\section{Tick one box}

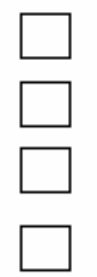

Club stopped

It was a bad time of day

Injured/ill

I couldn't get home

Too much homework

Other (please write in space)
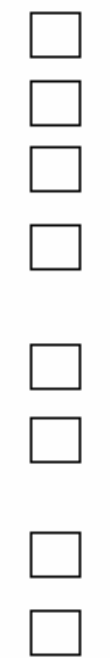
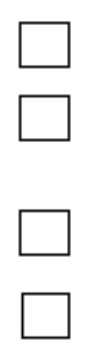

3.

Tick one box

C6. At any of your sport or physical activity clubs sessions (outside of School), do you play in competitions that are against other clubs?

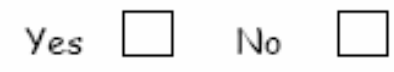

If yes, which sports/ physical activities?

1.

3.

2.

Figure E.2 cont. The Young Peoples Physical Activity Questionnaire (Jess, 1999b) 
C7. Have you represented your CITY/REGION/ COUNTY or NATIONAL TEAM against another CITY/REGION/COUNTY or NATIONAL TEAM?

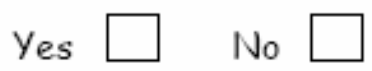

If yes, in which sports/ physical activities?

1.

2.

C8. Are you a member of any other clubs outside school where you regularly take part in sport or physical activity?

Yes No

Girls Brigade/ Boys Brigade

Guides/Scouts

Brownies/ Cubs

Church club or religious club

Youth club or religious club

Youth club where you regularly

do sport or physical activity

Other club where you regularly do sport or physical activity

(Please name).

\section{Section D}

D1. Are there any sport or physical activities that you do not do at the moment but would like to?

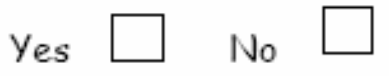

Figure E.2 cont. The Young Peoples Physical Activity Questionnaire (Jess, 1999b) 
If YES, please name the sport(s)/ physical activity(ies) that you would like to do and tick whether there is a club/session that you could go to?

Write name

of club here $\rightarrow$

1.

2.

3.

YES, there is a club

NO, there is no club

I don't know
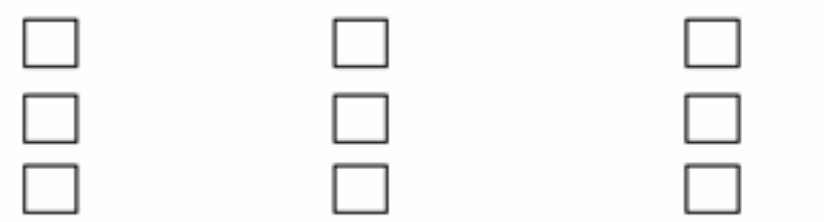

D2. If there is a club, please tick the MAIN reason why you don't go

NAME OF SPORTS OR PHYSICAL ACTIVITIES

Write name

of club here

$\rightarrow 1$.

Tick one box

2.

3.

My friends don't go

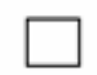

Tick one box

Tick one box

My parents/ guardians

don't want me to go
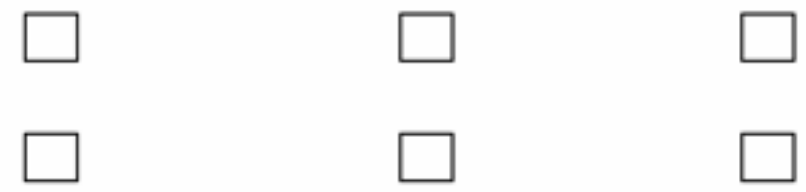

I can't get there or I

can't get home
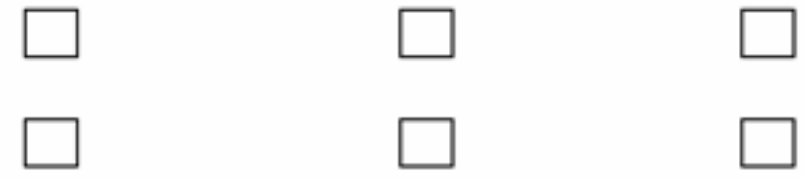

I don't think I'm

good enough

I can't make the team

It's too far away

It is at a bad time

of day

I don't like the

coach/ teacher

I do another activity at

the same time
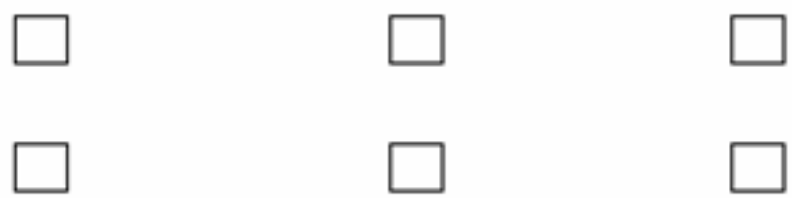

Too much homework
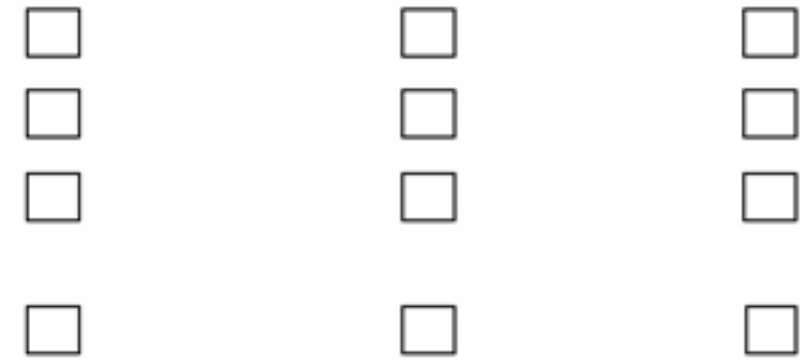

Other (please write

in space)

Figure E.2 cont. The Young Peoples Physical Activity Questionnaire (Jess, 1999b) 


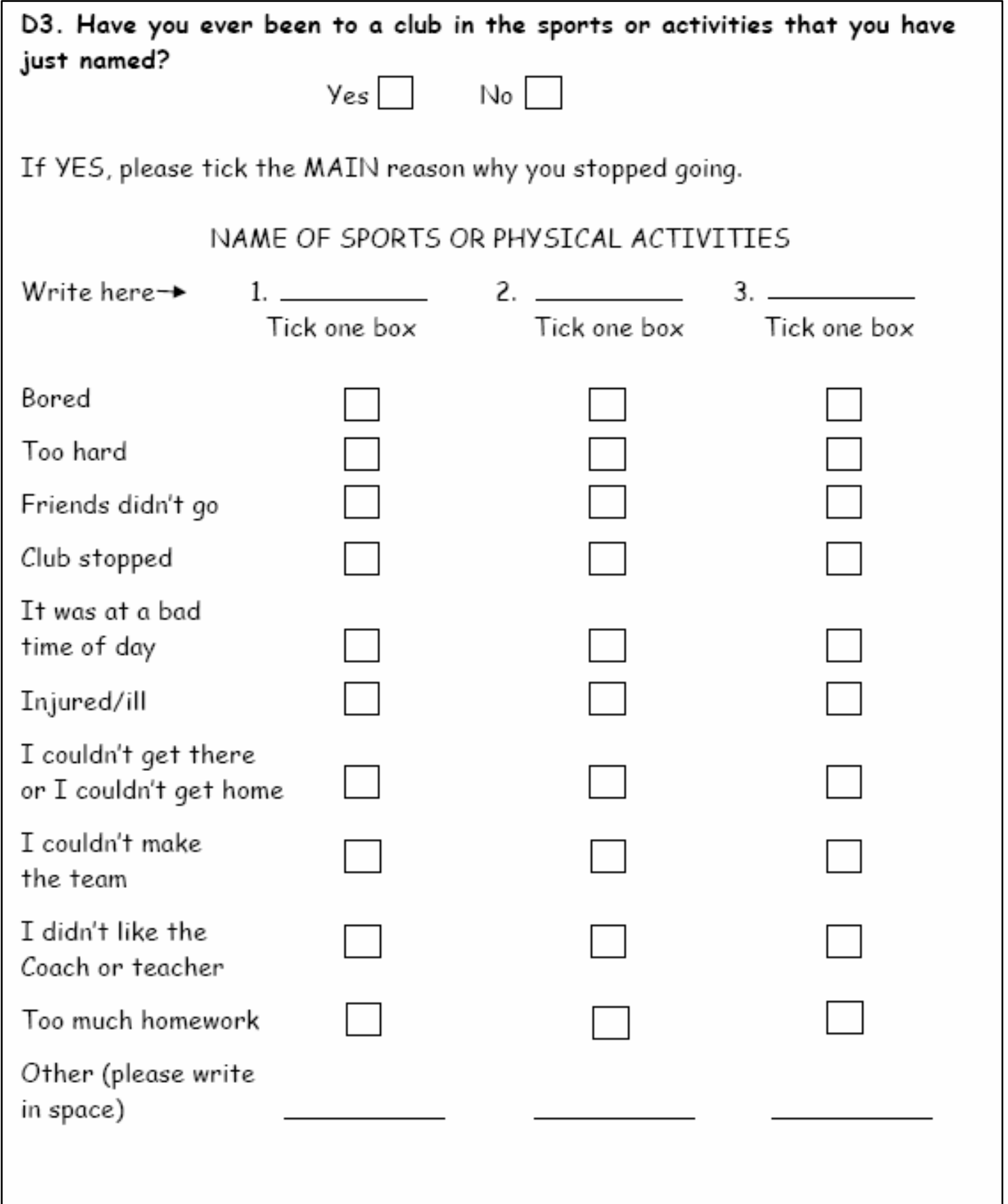

Figure E.2 cont. The Young Peoples Physical Activity Questionnaire (Jess, 1999b) 


\section{Publications}

\section{Refereed Publications}

Abbott, A., \& Collins, D. (2002). A theoretical and empirical Analysis of a 'State of the Art' talent identification model. High Ability Studies, 13, 157-178.

Abbott, A., \& Collins, D. (2004). Eliminating the dichotomy between theory and practice in talent identification and development: Considering the role of psychology. Journal of Sports Sciences, 22, 395-408.

Abbott, A., Button, C., Pepping, G-J, and Collins, D. (2005). Unnatural selection: talent identification and development in sport. Nonlinear Dynamics, Psychology, and Life Sciences, 9, 61-88.

\section{Book Chapters}

Abbott, A., \& Easson, B. (2002). The Mental Profile. In B. D. Hale \& D. Collins (Eds.), Rugby Tough (pp. 17-33). Champaign, Ill.: Human Kinetics.

\section{Published Reports}

Abbott, A., Collins, D., Martindale, R., \& Sowerby, K. (2002). Talent identification and development: An academic review. Edinburgh: sportscotland. 